\title{
Molecular mechanism of B cell antigen receptor-induced SHIP activation
}

\author{
PhD Thesis \\ in partial fulfillment of the requirements for the degree \\ “Doctor rerum naturalium (Dr. rer. nat.)" \\ in the Molecular Biology Program at the \\ Georg August University Göttingen, Faculty of Biology
}

submitted by

Birgit Manno

born in

Schwäbisch Hall, Germany 


\section{PhD Thesis Committee}

Prof. Dr. Jürgen Wienands (First referee)

Dept. of Cellular and Molecular Immunology

Georg-August University, Göttingen

Prof. Dr. Andreas Wodarz (Second referee)

Stem Cell Biology, Dept. of Anatomy and Cell Biology

Georg-August University, Göttingen

Prof. Dr. Lutz Walter

Dept. of Primate Genetics

German Primate Center

Day of PhD examination: January 12, 2012 


\section{Affidavit}

I hereby declare that I prepared the PhD thesis "Molecular mechanism of B cell antigen receptor-induced SHIP activation” on my own and with no other sources and aids than quoted.

\section{Birgit Manno}

November 29, 2011

Göttingen, Germany 


\section{Contents}

Affidavit ............................................................................................................................

Contents ............................................................................................................................. II

Acknowledgements ........................................................................................................... V

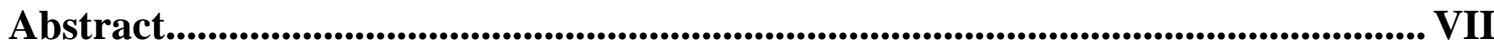

List of Figures....................................................................................................................VIII

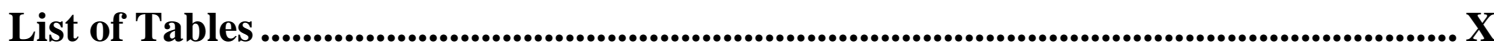

Abbreviations ....................................................................................................

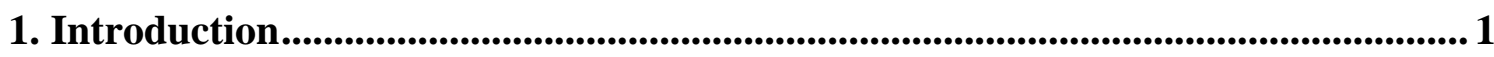

1.1 The B cell antigen receptor - crucial for B cell function........................................... 1

1.2 Early B cell activation and the role of the cytoskeleton............................................ 3

1.3 Signal transduction from the BCR .................................................................... 4

1.4 A closer look at the role of phosphoinositides ..................................................... 7

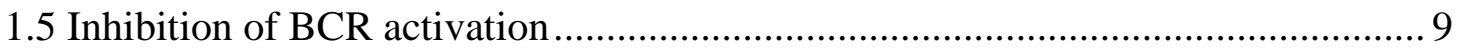

1.6 SHIP - an important regulator of phospholipid metabolism ................................... 11

1.6.1 SHIP structure ………………………………………………………..... 12

1.6.2 Regulation of SHIP activity................................................................... 13

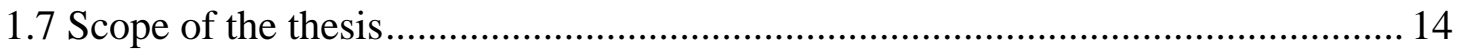

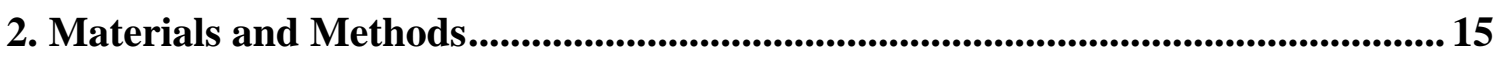

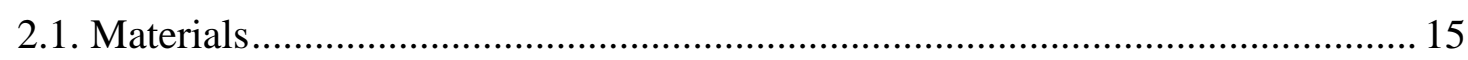

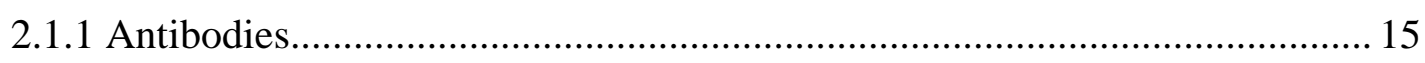

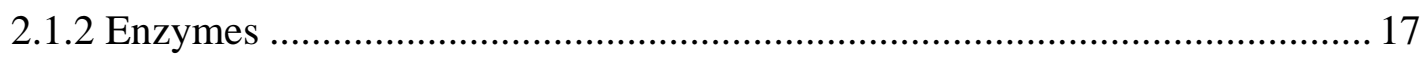

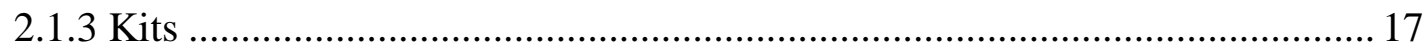

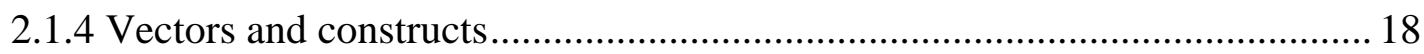

2.1.5 Oligonucleotides........................................................................................ 22

2.1.6 Recombinant peptides ........................................................................... 26

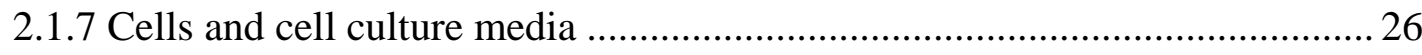

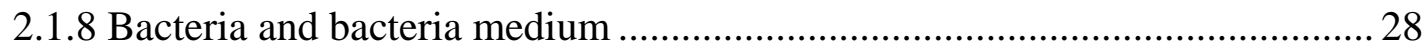




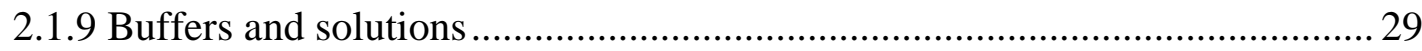

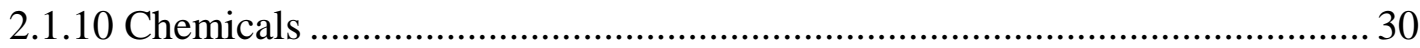

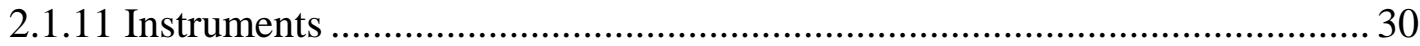

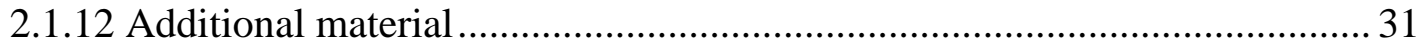

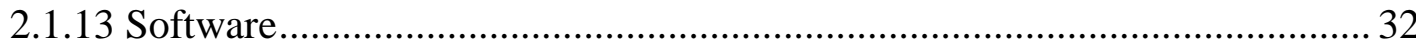

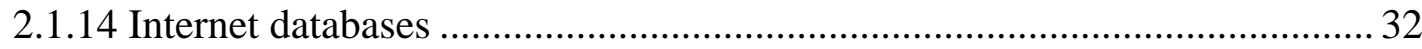

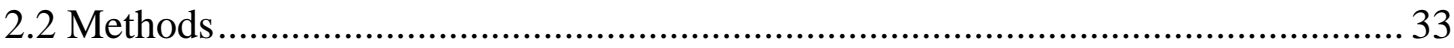

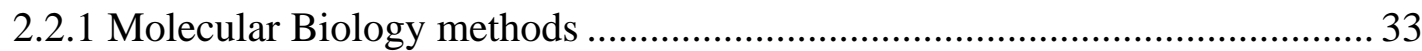

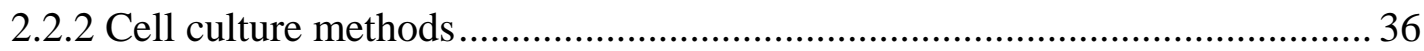

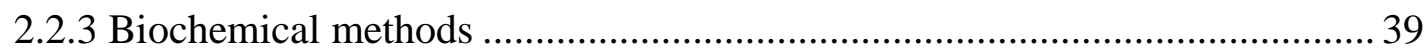

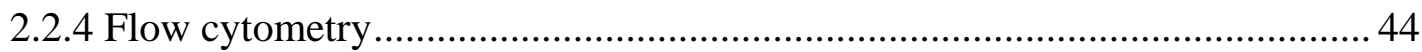

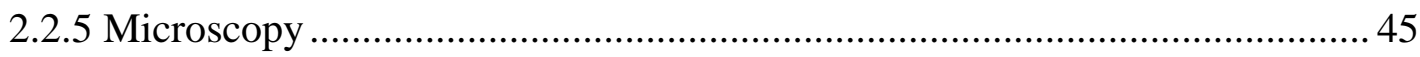

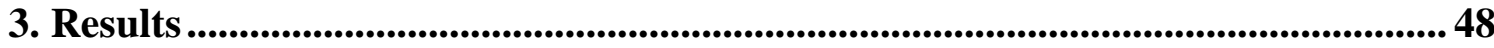

3.1 FcyRIIB-independent recruitment and activation of SHIP ….............................. 48

3.1.1 SHIP is FcyRIIB-independently recruited in primary B cells ....................... 48

3.1.2 DT40 cells are a suitable model system .................................................... 49

3.1.3 Fc $\gamma$ RIIB coactivation does not enhance BCR-induced SHIP recruitment ..... 52

3.2 Structural requirements for Fc $\gamma$ RIIB-independent SHIP activation ..................... 53

3.2.1 The SH2 domain is required for recruitment, phosphorylation and inhibition

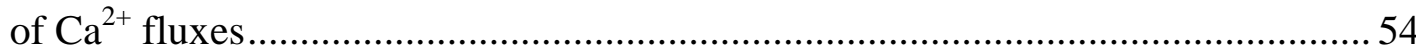

3.2.2 The NPXY motifs: Y1020 is functionally relevant ..................................... 56

3.2.3 The proline-rich regions are involved in SHIP activation............................. 58

3.2.4 The catalytic domain is not required for recruitment ..................................6 60

3.2.5 SHIP activation has additive structural requirements .................................61 61

3.2.6 SHIP recruitment in primary B cells requires the same protein domains as in DT40 62

3.3 Impact of putative effector proteins on Fc $\gamma$ RIIB-independent SHIP activation ... 64

3.3.1 SHIP interactome analysis identifies potential effector proteins from different

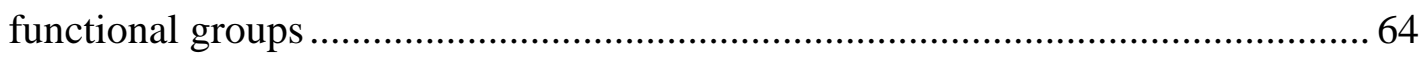

3.3.2 Lyn activity is required for SHIP phosphorylation and recruitment .............. 70

3.3.3 Components of ternary complexes contribute to Fc $\gamma$ RIIB-independent SHIP

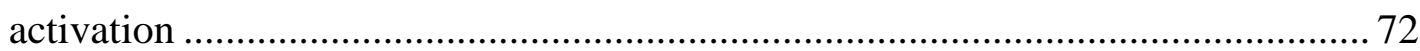

3.3.4 Regulators of the cytoskeleton play a minor role in SHIP activation ............ 79

3.3.5 SHIP colocalizes with BCR microclusters ................................................. 86 


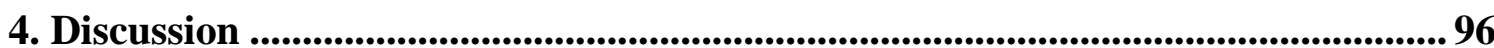

4.1 SHIP is activated independently of the FcyRIIB ............................................ 96

4.2 Molecular mechanism of Fc $\gamma$ RIIB-independent SHIP activation......................... 98

4.2.1 SHIP colocalizes with BCR microclusters .................................................. 98

4.2.2 SHIP interacts with the signaling subunits of the BCR ................................ 99

4.2.3 Stabilization of SHIP plasma membrane localization by ternary complexes

4.2.4 SHIP-HS1 interaction contributes to membrane recruitment..... 105

5. Summary and Conclusions 109

Bibliography 111

Curriculum vitae 126 


\section{Acknowledgements}

It is a pleasure to thank all those who supported me during the completion of this project.

I would like to begin with expressing my gratitude to Prof. Jürgen Wienands for giving me the exciting opportunity to join his department and work on brilliant B cells! Thank you for your advice and helpful discussions.

Furthermore, I want to thank Prof. Andreas Wodarz and Prof. Lutz Walter for support as members of my thesis committee and for helpful comments during thesis committee meetings.

I am indebted to my supervisor Dr. Michael Engelke for this interesting project, for guidance, encouragement and supervision during these years as well as for critically reading this thesis.

Thanks to all current and former members of the Department of Cellular and Molecular Immunology for good times, fruitful discussions and fun. Special thanks to Marion Lösing, who shared office and lab, ups and downs, over the years! In addition, I want to thank my former lab rotation supervisor Konstantin Neumann as well as our diploma students Xiao Li and Johannes Tucholski for contributing to the SHIP story. Thanks go also to Lars König for providing me with an established protocol for the retroviral transfection of primary cells.

I also would like to thank my talented lab rotation students Kathrin Brenker, Stefanie Riesenberg, Sarah Tjaden and Christoffer Hitzing.

I am also much obliged to Ines Heine for excellent technical assistance, Gabriele Sonntag for the isolation of primary cells as well as Ingrid Teuteberg and Rosemarie Döhne from the secretariat for organizational support.

Sincere gratitude to Dr. Facundo Batista and all the members of the Lymphocyte Interaction Laboratory for welcoming me in their group during my research visit in 
London. In particular I want to thank Tim Schnyder for teaching me how to do TIRF microscopy! I am grateful to the European Molecular Biology Organization for funding this visit with an EMBO short-term fellowship.

Furthermore I want to thank Prof. Henning Urlaub and Thomas Oellerich for cooperation on mass spectrometry analyses and Prof. Carsten Lüder for giving me the possibility to do confocal microscopy in the Department of Medical Microbiology.

I want to acknowledge the International Max Planck Research School for Molecular Biology for offering so many great possibilities to $\mathrm{PhD}$ students and for financial support in terms of bridging fund and travel grant, which allowed me to visit an exciting Keystone symposium and the Autumn School of Immunology. In particular, I would like to thank Dr. Steffen Burkhardt, Ivana Jurik and Kerstin Grüninger for support on organizational issues.

For financial support, I further would like to thank the German Research Foundation and the Medical Faculty of the University of Göttingen.

Many thanks to Karen Linnemannstöns, Martina Podleschny, Jennifer Theiss and Marion Lösing for proofreading!

During my time in Göttingen, valuable friendships arose, and I feel very fortunate having such good friends in my life.

Finally, I am very grateful to my family for their truly unconditional support and to Hannes for being at my side with an impressive inspirational attitude. 


\section{Abstract}

Regulation of B cell activation is highly important to keep the balance between immunity and self-tolerance. The SH2 domain-containing 5' inositol phosphatase (SHIP) is an inhibitor of B cell activation as it hydrolyzes the membrane phospholipid phosphatidylinositol-3,4,5-trisphosphate. It thereby depletes membrane anchors required for plasma membrane recruitment of effectors of B cell activation, more precisely of components of the $\mathrm{Ca}^{2+}$ initiation complex. This results in inhibition of $\mathrm{Ca}^{2+}$ mobilization. SHIP was discovered as an inhibitor activated by immune complexes, which are found at the end of immune responses. Immune complexes coactivate the $\mathrm{B}$ cell antigen receptor (BCR) and the low-affinity receptor for IgG, Fc $\gamma$ RIIB, which directly binds to SHIP. Later studies demonstrated FcyRIIB-independent SHIP functions as well. However, the molecular mechanism underlying this BCRautonomous activation was unknown. Here, SHIP activation in the absence of the Fc $\gamma$ RIIB was clearly demonstrated in DT40 cells. Live cell imaging of EGFP-labeled SHIP variants was done to analyze SHIP plasma membrane recruitment, which is considered to be the most essential step in its activation, providing it with access to its substrate. This showed that the process of SHIP activation has several structural requirements. Most pivotal is its $\mathrm{SH} 2$ domain. Mass spectrometry analysis in combination with biochemical analyses demonstrated binding of this domain to the signaling subunits of the BCR, Ig $\alpha$ and $\operatorname{Ig} \beta$. It will be interesting to identify the exact binding site, offering insights into how SHIP competes with Syk for binding to Ig $\alpha$ and $\operatorname{Ig} \beta$. In line with this, a more detailed study of membrane localization was performed using total internal reflection microscopy. This revealed that SHIP colocalizes with BCR microclusters, which mediate assembly of signaling-active microsignalosomes. Since protein composition of microsignalosomes is tightly regulated, SHIP recruitment into these microsignalosomes underlines the essential role of SHIP in BCR-autonomous signaling. It was furthermore shown, that membrane localization is stabilized by two ternary complexes, consisting of SHIP-Grb2-Dok-3 and SHIP-Grb2-Shc as well as by interaction of SHIP with actin cytoskeleton-associated HS1. Collectively, in this thesis, I deciphered the molecular mechanism of SHIP activation. These results further imply that the BCR complex not only initiates the BCR signaling cascade but also recruits the negative regulator SHIP. 


\section{List of Figures}

1.1 Schematic representation of the BCR..................................2

1.2 Simplified overview of BCR-mediated signaling pathway.....................6

1.3 Phosphoinositide metabolism.........................................8

1.4 Schematic representation of the structure of SHIP.......................... 12

3.1 FerRIIB-independent recruitment of SHIP to the plasma membrane in primary cells........................................................ 49

3.2 SHIP is functional in DT40 cells not expressing Fc $\gamma$ RIIB .....................50

3.3 SHIP translocates to the plasma membrane following activation of the BCR

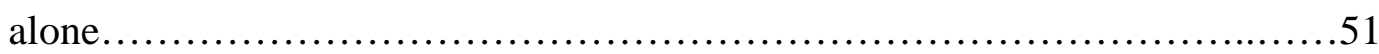

3.4 SHIP is phosphorylated after activation of the BCR alone....................52

3.5 No quantitative difference in SHIPwt-EGFP recruitment following BCR activation alone or following BCR-Fc $\gamma$ RIIB coactivation...................52

3.6 The SH2 domain is important for SHIP recruitment and function................54

3.7 Inactivation of the SH2 domain does not lead to quantitative differences between SHIP recruitment following BCR activation alone and following

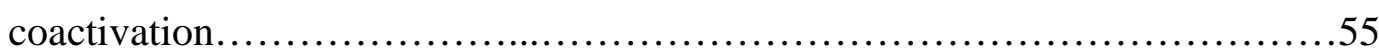

3.8 The SH2 domain is required for efficient SHIP phosphorylation..............56

3.9 Y1020 is more important for SHIP recruitment and function than Y917.......57

3.10 Schematic structure of SHIP indicating the location of proline-rich regions...........................................................58

3.11 Screen of proline-rich regions for their impact on SHIP recruitment and function.......................................................... 59

3.12 Interaction between the catalytic domain of SHIP and its substrate is not important for recruitment per se.....................................61

3.13 Consequences of the combined inactivation of several protein domains and motifs of SHIP..................................................62

3.14 SHIP recruitment in primary B cells.................................63

3.15 The SHIP interactome can be divided into different functional groups..........69 
3.16 Lyn is required for SHIP phosphorylation and contributes to SHIP

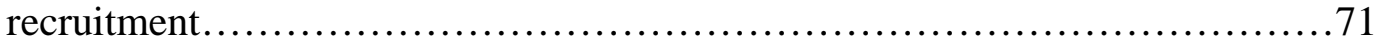

3.17 The role of Lyn in SHIP recruitment exceeds phosphorylation of SHIP........72

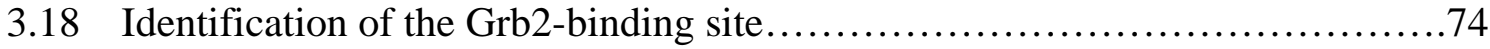

3.19 Interaction between SHIP and Grb2 is a prerequisite for Shc-Grb2 binding and for Shc-SHIP binding ...................................................

3.20 Influence of Grb2 on SHIP plasma membrane recruitment...................76

3.21 Requirements of phosphotyrosine motifs for the interaction of SHIP with Dok-3

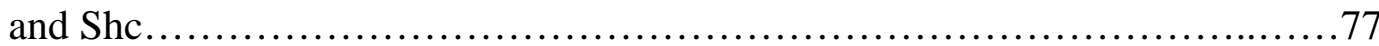

3.22 SHIP recruitment is impaired in Shc-deficient and Dok-3-deficient cells.........78

3.23 CD2AP binding to SHIP is not prevented by inactivation of single selected proline-rich regions in SHIP........................................... 80

3.24 SHIP interacts with CIN85 and CD2AP in DT40 B cells.........................81

3.25 The recruitment of SHIP carrying mutations in described CIN85 binding motifs

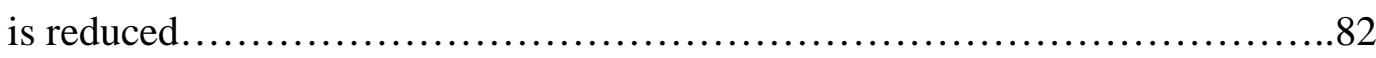

3.26 SHIP interacts with Nck2 in DT40 B cells.................................83

3.27 Binding of HS1 to SHIP is mediated by proline-rich regions encompassing R1145 and K1151.......................................................84

3.28 Lack of HS1 reduces SHIP plasma membrane recruitment...................85

3.29 Pre-recruitment of SHIP to the plasma membrane of unstimulated cells is associated with expression of HS1 and Abp1 and presumably with their interaction with SHIP.............................................86

3.30 SHIP colocalizes with antigen-containing microclusters and this depends on the SH2 domain of SHIP .88

3.31 Dok-3, Grb2 and Shc contribute to SHIP colocalization with antigen-containing microclusters

3.32 SHIP is recruited to the plasma membrane and is functional when signaling is only mediated via $\operatorname{Ig} \alpha$ or $\operatorname{Ig} \beta$. .91

3.33 The intact SH2 domain of SHIP precipitates $\operatorname{Ig} \alpha$ and $\operatorname{Ig} \beta \ldots \ldots \ldots \ldots \ldots \ldots \ldots . . \ldots 2$

3.34 Direct interaction between the SH2 domain of SHIP and $\operatorname{Ig} \alpha$ and $\operatorname{Ig} \beta \ldots \ldots \ldots \ldots . .93$

3.35 SHIP binds with its SH2 domain to phosphorylated $\operatorname{Ig} \alpha$.....................95

4.1 Proposed model of Fc $\gamma$ RIIB-independent SHIP activation ...................108 


\section{List of Tables}

2.1 Antibodies used in this study....................................15

2.2 Enzymes used in this study..................................... 17

2.3 Commercial kits used in this study.................................17

$2.4 \quad$ Vectors used in this study......................................... 18

$2.5 \quad$ Constructs used in this study..........................................19

2.6 Oligonucleotides used in this study...................................23

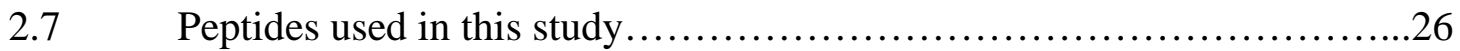

$2.8 \quad$ DT40 cell lines used in this study..................................27

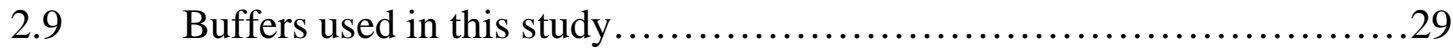

2.10 Cycling conditions for PCR ....................................... 35

$2.11 \quad$ ECL buffers......................................................43

3.1 The SHIP interactome analyzed by non-quantitative mass spectrometry...65

3.2 The SILAC-based SHIP interactome - Analysis I.......................66

3.3 The SILAC-based SHIP interactome - Analysis II.....................67 


\section{Abbreviations}

A

A, G, T, C (in the context of primer sequence)

Abp1

Ag

AP

Arp2/3

BCR

bp

BSA

Btk

CCL

CD

CD2AP

CIN85

D

DAG

Dok

DOPC

E. coli

ECL

EGFP

$\mathrm{F}$

FCS

Fc $\gamma$ RIIB

FITC

G

GFP alanine

deoxyadenosine, deoxyguanosine, thymidine, deoxycytidine

actin-binding protein 1

antigen

affinity purification

actin-related protein $2 / 3$

$B$ cell antigen receptor

base pair

bovine serum albumine

Bruton's tyrosine kinase

cleared cellular lysate

cluster of differentiation

CD2-associated protein

Cbl-interacting protein of $85 \mathrm{kDa}$

aspartic acid

diacylglycerol

downstream of kinase

1,2-dioleoyl-phosphatidylcholine

Escherichia coli

enhanced chemiluminescence

enhanced green fluorescent protein

phenylalanine

fetal calf serum

Fc $\gamma$ receptor IIB

Fluorescein Isothiocyanate

glycine

green fluorescent protein 


\begin{tabular}{|c|c|}
\hline Grb2 & growth factor receptor-bound protein 2 \\
\hline GST & glutathione S-transferase \\
\hline h & hour \\
\hline HA & hemagglutinin \\
\hline HRP & horseradish peroxidase \\
\hline HS1 & hematopoietic cell-specific Lyn substrate 1 \\
\hline Ig & immunoglobulin \\
\hline $\operatorname{Ins}(1,4,5) \mathrm{P}_{3}$ & inositol-1,4,5-trisphophate \\
\hline IP & immunoprecipitation \\
\hline ITAM & immunoreceptor tyrosine-based activation motif \\
\hline ITIM & immunoreceptor tyrosine-based inhibitory motifs \\
\hline $\mathrm{K}$ & lysine \\
\hline $\mathrm{Kb}$ & kilo bases \\
\hline $\mathrm{kDa}$ & kilo Dalton \\
\hline LB & lysogeny broth \\
\hline LDS & lithium dodecyl sulfate sample loading buffer \\
\hline LPS & lipopolysaccharide \\
\hline Lyn & Lck/Yes-related novel protein tyrosine kinase \\
\hline MAPK & mitogen-activated protein kinases \\
\hline MFI & mean fluorescence intensity \\
\hline $\mathrm{N}$ & asparagine \\
\hline Nck2 & noncatalytic region of tyrosine kinase 2 \\
\hline NFAT & nuclear factor of activated T cells \\
\hline $\mathrm{NF}-\kappa \mathrm{B}$ & as nuclear factor- $\kappa \mathrm{B}$ \\
\hline $\mathrm{P}$ & proline \\
\hline PAGE & polyacrylamide gel electrophoresis \\
\hline PBS & phosphate-buffered saline \\
\hline PH domain & pleckstrin homology domain \\
\hline PI3K & phosphoinositide 3-kinase \\
\hline PirB & paired immunoglobulin-like receptor B \\
\hline PKC- $\beta$ & protein kinase $C-\beta$ \\
\hline PLC- $\gamma 2$ & phospholipase C- $\gamma 2$ \\
\hline PTB domain & phosphotyrosine-binding domain \\
\hline PtdIns & phosphatidylinositol \\
\hline
\end{tabular}




\begin{tabular}{|c|c|}
\hline PtdIns $(3,4,5) \mathrm{P}_{3}$ & phosphatidylinositol-3,4,5-trisphosphate \\
\hline $\operatorname{PtdIns}(4,5) \mathrm{P}_{2}$ & phosphatidylinositol-4,5-bisphosphate \\
\hline PTEN & phosphatase and tensin homolog \\
\hline $\mathrm{R}$ & arginine \\
\hline Ras & Rat sarcoma \\
\hline RasGRP & Ras guanyl-releasing protein \\
\hline RPE & R-phycoerythrin \\
\hline RRI & relative recruitment index \\
\hline SD & standard deviation \\
\hline SDS & sodium dodecyl sulfate \\
\hline SEM & standard error of the mean \\
\hline SH2 domain & Src homology 2 domain \\
\hline SH3 domain & Src homology 3 domain \\
\hline Shc & Src homology and collagen protein \\
\hline SHIP & SH2 domain-containing 5' inositol phosphatase \\
\hline SHP1 & SH2-domain-containing protein tyrosine phosphatase 1 \\
\hline SILAC & stable isotope labeling with amino acids in cell culture \\
\hline SLP-65 & SH2 domain-containing leukocyte adaptor protein of $65 \mathrm{kDa}$ \\
\hline SOCE & store-operated calcium entry \\
\hline Sos & son of sevenless \\
\hline Syk & spleen tyrosine kinase \\
\hline $\mathrm{T}$ & threonine \\
\hline TAE & tris-acetate-EDTA \\
\hline TIRFM & total internal reflection fluorescence microscopy \\
\hline wt & wild-type \\
\hline $\mathrm{Y}$ & tyrosine \\
\hline
\end{tabular}




\section{Introduction}

The immune system is an amazing achievement of evolution, providing us with immunity. Immunitas, the Latin origin, described a special protection from fiscal, military and judicial powers that was granted to certain individuals. Likewise, the immune system protects us from pathogens like bacteria, viruses, fungi and parasites. It can be divided into two parts, which do not function separately but support each other (Iwasaki \& Medzhitov, 2004). On the one hand, there is the innate immune system, which provides an immediate but unspecific reaction to pathogens. On the other hand, there is the adaptive immune system, which is highly specific, constantly adjusts to new challenges and mediates immunological memory. As complex as it may be, its purpose is remarkably simple- to recognize, remove and remember specific pathogens. The effector cells of the adaptive immune system are the $\mathrm{B}$ cells and the $\mathrm{T}$ cells, both derived from a common lymphoid progenitor. While $\mathrm{T}$ cells are mainly responsible for the cell-mediated adaptive immune response, the primary function of $\mathrm{B}$ cells is to produce antibodies specific for a certain antigen. How an organism can react to the extremely large number of potential foreign antigens in its surrounding, while at the same time tolerating self-antigens, was explained by the clonal selection theory of Burnett and Talmage (Burnet, 1959; Talmage, 1959). Every B cell produces one type of antibody with a unique specificity. These antibodies first occur only in membranebound forms. After encounter with a particular antigen, clones of the respective lymphocyte are selected and expanded. The differentiated effector cells are specific for the same antigen as the parental cells, but undergo affinity maturation, a process of variation and selection, to increase their affinity for the particular antigen.

\subsection{The $B$ cell antigen receptor - crucial for $B$ cell function}

The membrane-bound form of an antibody, or immunoglobulin (Ig), is part of the B cell antigen receptor (BCR, Figure 1.1), which is of paramount importance for B cells. The virtually unlimited B cell repertoire is explained by the composition of the 
immunoglobulin. It consists of two identical heavy chains, which are connected to each other and to two identical light chains by disulfide bridges. The heavy chains are encoded by $V_{H}, D_{H}, J_{H}$ and $C_{H}$ gene segments while the light chains, which can be of type $\kappa$ or $\lambda$, are encoded by $V_{L}, J_{L}$ and $C_{L}$ gene segments. The combination of the respective gene segments generates high antibody diversity. The $\mathrm{C}_{\mathrm{H}}$ segment furthermore determines whether the isotype of the resulting Ig will be $\operatorname{IgM}, \operatorname{IgD}, \operatorname{IgG}$, IgE or IgA. Cell surface expression requires binding of the Ig to the invariant Ig $\alpha$ and $\operatorname{Ig} \beta$ chains, leading to generation of a complete BCR (Hombach et al., 1988; Venkitaraman et al., 1991). One disulfide bridge-linked heterodimer of $\operatorname{Ig} \alpha$ and $\operatorname{Ig} \beta$ is noncovalently associated with each membrane-bound Ig. Since the membrane-bound Ig only has a very short cytoplasmic domain, $\operatorname{Ig} \alpha$ and $\operatorname{Ig} \beta$ are needed to transmit signals into the cell (Sanchez et al., 1993). They each contain an immunoreceptor tyrosinebased activation motif (ITAM) in their cytoplasmic part having the consensus sequence $\mathrm{YXX}(\mathrm{I} / \mathrm{L}) \mathrm{X}_{6-8} \mathrm{YXX}(\mathrm{I} / \mathrm{L})$, where $\mathrm{X}$ is any amino acid. ITAMs are widely used in the immune system to transmit signals that positively regulate B cell activation (Humphrey et al., 2005).

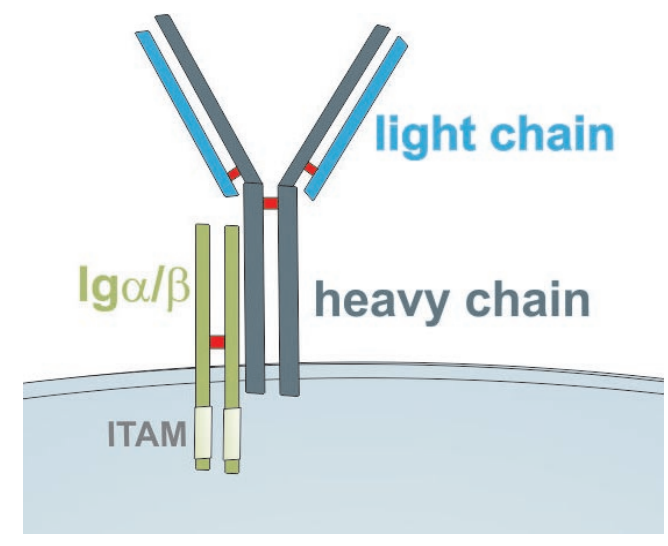

Figure 1.1: Schematic representation of the BCR. Membrane-bound Ig, consisting of heavy and light chains, is associated with the signaling subunits $\operatorname{Ig} \alpha$ and $\operatorname{Ig} \beta$. Interchain disulfide bridges are shown in red. The number of disulfide bridges between the heavy chains varies between one and two, depending on the Ig isotype.

Signals transmitted by the BCR regulate B cell fate (Niiro \& Clark, 2002) and are necessary for B cell survival (Lam et al., 1997). Furthermore, the BCR mediates antigen internalization, processing and presentation to $\mathrm{T}$ cells, clearly demonstrating its crucial role in the adaptive immune system. 


\subsection{Early B cell activation and the role of the cytoskeleton}

Progresses made in live-cell imaging techniques have only recently allowed detailed studies on how the BCR perceives binding of an antigen to its extracellular domain and what the very early events in BCR signaling are. These studies revealed that the structure of the plasma membrane and the coordinated action of the cytoskeleton are of particular importance for membrane heterogeneity and the regulation of membrane dynamics (Batista et al., 2001; Gupta et al., 2006; Sohn et al., 2006).

The current view of the plasma membrane is that it contains dynamic compartments which allow free lateral diffusion of membrane lipids and proteins within confined compartments while making long-range lateral diffusion of larger oligomers more difficult as this requires "hopping" from one compartment to the other. This is explained by the picket-fence model in which compartmentalization is caused by the membrane-associated actin cytoskeleton (the fence) and the actin-anchored transmembrane proteins (the pickets) (Kusumi et al., 2005). Assumed that antigen binding induces BCR oligomerization, this might lead to trapping of BCR molecules in one compartment as their hopping into other compartments is hindered.

Because BCR signaling is not initiated by soluble monovalent ligands, the traditional view is that BCR activation requires a crosslinking ligand that brings two BCRs close enough for reciprocal phosphorylation by associated kinases. Other models of activation exist as well (reviewed in Engels et al., 2008). For instance, one model postulates the antigen-induced disruption of preformed BCR oligomers to explain the fact that a virtually unlimited number of antigens can lead to efficient cross-phosphorylation of ITAMs by associated kinases (Schamel \& Reth, 2000).

Whether B cells in vivo are rather activated by soluble antigen or by membrane-bound antigen like e. g. on antigen-presenting cells, is still under debate (Harwood \& Batista, 2008). In either case, the recognition of antigen is followed by significant cytoskeletal reorganization. First, antigen-containing BCR microclusters are formed independently of signaling (Depoil et al., 2008) in highly ordered subdomains of the plasma membrane called lipid rafts or glycolipid-enriched microdomains. These are fluctuating assemblies of proteins, cholesterol and sphingolipids that form dynamic platforms for BCR signaling and are influenced by the actin cytoskeleton (Gupta et al., 2006). Some signaling proteins like e. g. the Src-family kinase Lck/Yes-related novel protein tyrosine kinase (Lyn) are constitutively enriched in lipid rafts (Field et al., 1997). They influence signal transduction by the specific inclusion or exclusion of signaling proteins. Formation of microclusters is followed by the recruitment of proteins important for 
BCR downstream signaling (Weber et al., 2008) and actin-dependent B cell spreading, during which the cell extends lamellipodia to maximize the number of antigens encountered (Fleire et al., 2006). The extent of spreading depends on antigen affinity and density. In the subsequent contraction phase antigen is concentrated in a central cluster, corresponding to the central supramolecular activation cluster of the immunological synapse (Batista et al., 2001), where it will be internalized. This highly regulated process underlines the importance of protein localization for successful B cell activation.

\subsection{Signal transduction from the BCR}

BCR ligation by antigen can have as different consequences as proliferation, differentiation, anergy, or apoptosis. This is influenced by affinity and avidity of the antigen and depends furthermore on the immunological context, i. e. differential expression of co-receptors, which can either modify BCR signaling directly or indirectly via activation of additional pathways. Moreover, the differentiation stage of a B cell also affects signal transduction (Marshall et al., 2000; Niiro \& Clark, 2002).

One recurring process in signal transduction cascades is protein phosphorylation, which is counterbalanced by phosphatase-mediated dephosphorylation (Wienands et al., 1996). Following engagement of the BCR with its cognate antigen, $\operatorname{Ig} \alpha$ and $\operatorname{Ig} \beta$ become phosphorylated on tyrosine residues within their ITAMs (Gold et al., 1991). Ig $\alpha$ is additionally phosphorylated on a tyrosine residue located outside the ITAM, the nonITAM Y204 (Engels et al., 2001). The traditional view was that ITAM phosphorylation is carried out by the Src-family protein tyrosine kinase Lyn (Tamir \& Cambier, 1998) and that then the doubly phosphorylated ITAM serves as a docking site for the tandem Src homology 2 (SH2) domains of the spleen tyrosine kinase (Syk) (Wienands et al., 1995) (Figure 1.2). More recent findings have found that also Syk itself can phosphorylate ITAMs, thereby creating its own binding sites. This implies a positive product feedback, meaning that Syk is an allosteric enzyme that is stabilized in an open, active conformation after binding to phosphorylated ITAMs (Rolli et al., 2002). Subsequently, Syk is autophosphorylated and phosphorylates several proteins involved in BCR signaling. The most proximal Syk substrate is the SH2 domain-containing leukocyte adaptor protein of $65 \mathrm{kDa}$ (SLP-65) (Wienands et al., 1998), which is also called B-cell linker protein (Fu et al., 1998) or B cell adaptor containing SH2 domain (Goitsuka et al., 1998). There is good evidence that BCR expression induces the 
assembly of a preformed transducer complex consisting at least of SLP-65, Syk and, as recently published, also of the Cbl-interacting protein of $85 \mathrm{kDa}$ (CIN85) (Wienands et al., 1996; Zhang et al., 1998; Oellerich et al., 2011). SLP-65 binds to the non-ITAM Y204, which is one possible way of translocation into the vicinity of Syk (Engels et al., 2001). Phosphorylated SLP-65 mediates the assembly of the $\mathrm{Ca}^{2+}$-initiation complex consisting of SLP-65, Bruton's tyrosine kinase (Btk) and phospholipase C- $\gamma 2$ (PLC- $\gamma 2$ ). In the context of this complex, Btk is phosphorylated and thereby activated by Syk and Lyn (Kurosaki \& Kurosaki, 1997) and can in turn phosphorylate and activate PLC- $\gamma 2$. Activation of the $\mathrm{Ca}^{2+}$-initiation complex requires its translocation to the plasma membrane. On the one hand, this is caused by SLP-65, which can stabilize membrane association with its $\mathrm{N}$-terminus and which can direct the $\mathrm{Ca}^{2+}$-initiation complex into specific membrane compartments like lipid rafts via its SH2 domain (Simons \& Toomre, 2000; Kohler et al., 2005; Abudula et al., 2007). On the other hand, Btk and PLC $-\gamma 2$ contribute to membrane localization by binding with their pleckstrin homology (PH) domains to phosphorylated membrane lipids like phosphatidylinositol-3,4,5trisphosphate (PtdIns(3,4,5) $\mathrm{P}_{3}$ ) (Salim et al., 1996; Falasca et al., 1998).

Activated PLC- $\gamma 2$ hydrolyzes phosphatidylinositol-4,5-bisphosphate (PtdIns $\left.(4,5) \mathrm{P}_{2}\right)$ to yield the second messengers diacylglycerol (DAG), which stays at the plasma membrane, and soluble inositol-1,4,5-trisphophate $\left(\operatorname{Ins}(1,4,5) \mathrm{P}_{3}\right)$ (Takata \& Kurosaki, 1996; Hashimoto et al., 2000). Ins(1,4,5) $\mathrm{P}_{3}$ binds to $\operatorname{Ins}(1,4,5) \mathrm{P}_{3}$ receptor channels in the membrane of the endoplasmatic reticulum, induces their opening and the release of $\mathrm{Ca}^{2+}$ into the cytosol. The resulting transient increase in cytosolic $\mathrm{Ca}^{2+}$ concentration is supported by the entry of $\mathrm{Ca}^{2+}$ from the extracellular space. The latter process is called store-operated calcium entry (SOCE) and involves stromal interaction molecules. SOCE happens if intracellular stores are completely depleted and explains why minor changes in PLC- $\gamma 2$ activation can cause large differences in $\mathrm{Ca}^{2+}$ signaling (Scharenberg et al., 2007). 


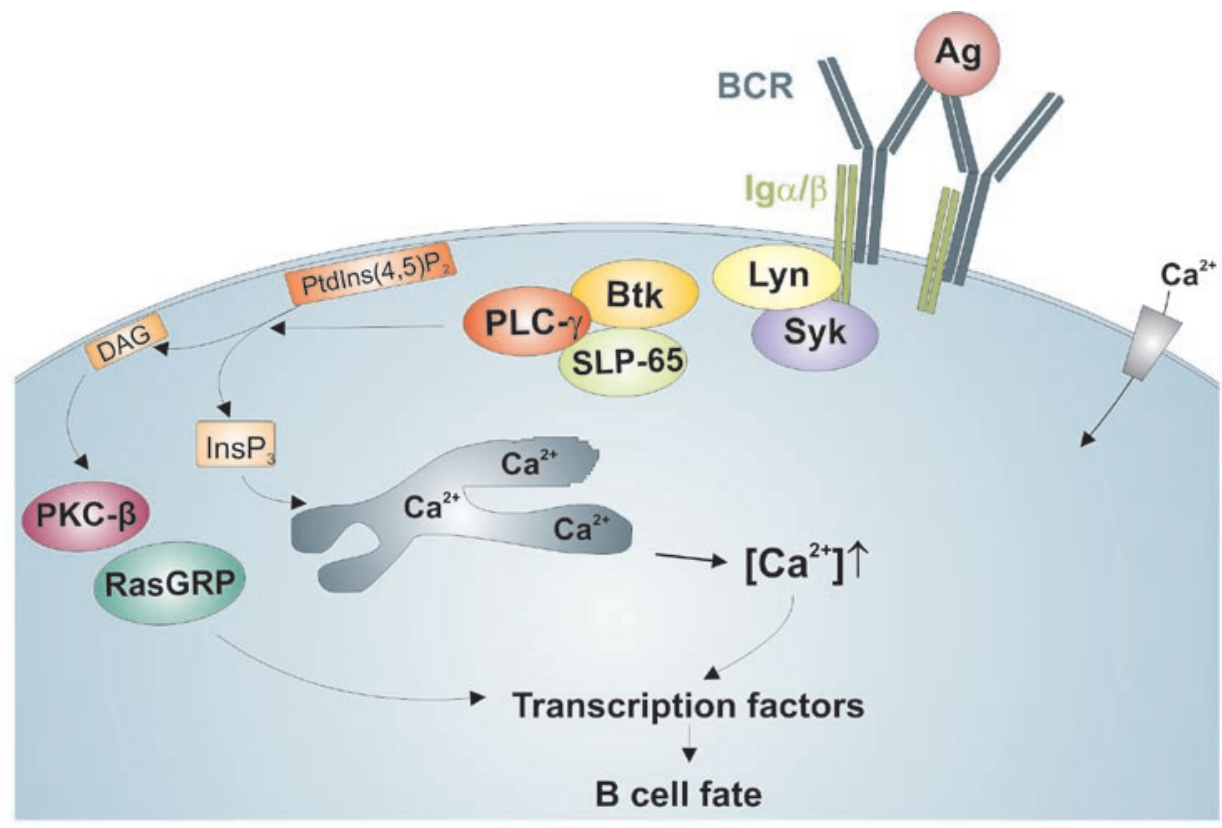

Figure 1.2: Simplified overview of BCR-mediated signaling pathway. Following binding of antigen (Ag) to the BCR, Lyn phosphorylates ITAMs of Ig $\alpha$ and $\operatorname{Ig} \beta$. Subsequently, Syk is recruited to the doubly phosphorylated ITAMs. This results in activation of key molecules of signal transduction, SLP-65 and Btk. SLP-65 mediates assembly of the $\mathrm{Ca}^{2+}$ initiation complex consisting of SLP-65, Btk and PLC- $\gamma 2$. PLC- $\gamma 2$ is activated by Btk and produces the second messengers DAG and $\operatorname{InsP}_{3}$. InsP $\mathrm{P}_{3}$ mediates $\mathrm{Ca}^{2+}$ release from the endoplasmatic reticulum, followed by influx of extracellular $\mathrm{Ca}^{2+}$. Depending on the $\mathrm{Ca}^{2+}$ profile, differential activation of transcription factors takes place, determining B cell fate. DAG recruits PKC- $\beta$ and RasGRP, ultimately also leading to activation of transcription factors.

Several aspects determine how the universally used second messenger $\mathrm{Ca}^{2+}$ influences B cell fate. On the one hand, short-term functions like B cell motility and formation of the immunological synapse can be influenced. On the other hand, $\mathrm{Ca}^{2+}$ also affects longterm functions, which involve a change in gene transcription. Well-studied transcription factors in $B$ cells are the family of nuclear factor of activated $T$ cells (NFAT) transcription factors, which requires rather prolonged elevation of $\mathrm{Ca}^{2+}$ levels or oscillations to become activated (Dolmetsch et al., 1997), as well as nuclear factor- $\kappa B$ $(\mathrm{NF}-\kappa \mathrm{B})$ and JUN N-terminal kinase and its substrate activating transcription factor 2. The latter are rather activated by transient increases in $\mathrm{Ca}^{2+}$-concentration (Dolmetsch et al., 1997; Antony et al., 2004). Full activation of NF- $\kappa B$ requires both PLC- $\gamma 2$ products. DAG recruits protein kinase C- $\beta$ (PKC- $\beta$ ) to the plasma membrane and $\operatorname{Ins}(1,4,5) \mathrm{P}_{3}$ mediated $\mathrm{Ca}^{2+}$ release allows binding of $\mathrm{Ca}^{2+}$ to $\mathrm{PKC}-\beta$ to fully activate it. Activated PKC- $\beta$ jolts the canonical pathway so that NF- $\kappa \mathrm{B}$ is released from inhibition, translocates to the nucleus, and initiates target gene transcription (Hayden \& Ghosh, 
2008). NFAT proteins are inactive as long as they are heavily phosphorylated. Dephosphorylation by the calmodulin-dependent serine/threonine phosphatase calcineurin allows nuclear localization. Activation of calcineurin in turn requires $\mathrm{Ca}^{2+}$, which provides another link between $\mathrm{Ca}^{2+}$ concentration and gene expression (Hogan et al., 2003). Besides the activation of PKC- $\beta$, DAG also recruits Rat sarcoma (Ras) guanyl-releasing protein (RasGRP), which results in activation of Ras and mitogenactivated protein kinases (MAPKs), ultimately leading to cell proliferation (Zhang \& Liu, 2002).

As explained below in more detail, phosphoinositides at the inner leaflet of the plasma membrane are also involved in BCR signaling. The phosphoinositide 3-kinase (PI3K) generates essential phosphoinositides and is therefore another important mediator of BCR activation. Phosphoinositides can constitute membrane anchors for PLC- $\gamma 2$, Btk and the serine-threonine kinase Akt. Pro-survival functions of Akt are demonstrated by its ability to phosphorylate and inhibit the pro-apoptotic proteins caspase 9 (Cardone et al., 1998) and Bcl-2-associated death promoter (Datta et al., 1997) and to activate the survival factor NF-kB (Kane et al., 1999).

\subsection{A closer look at the role of phosphoinositides}

Taking a more thorough look at BCR signaling processes reveals additional essential players apart from the protein molecules. These are the membrane phosphoinositides, which are phospholipids derived from phosphatidylinositol (PtdIns) by differential and reversible phosphorylation at the inositol hydroxyl groups (Figure 1.3). As they have a specific subcellular distribution (Di Paolo \& De Camilli, 2006), the enrichment of specific phosphoinositides defines organelle identity. The resulting phosphoinositides can be substrates for enzymes or act as membrane anchors for BCR effector proteins. By relating differential phosphorylation to recruitment of signaling proteins into distinct subcellular locations at membranes, phosphoinositides participate in signaling in a similar way as tyrosine-phosphorylated proteins that recruit proteins with the appropriate recognition domains. The phosphorylation status is regulated by phosphoinositide kinases and phosphatases. 


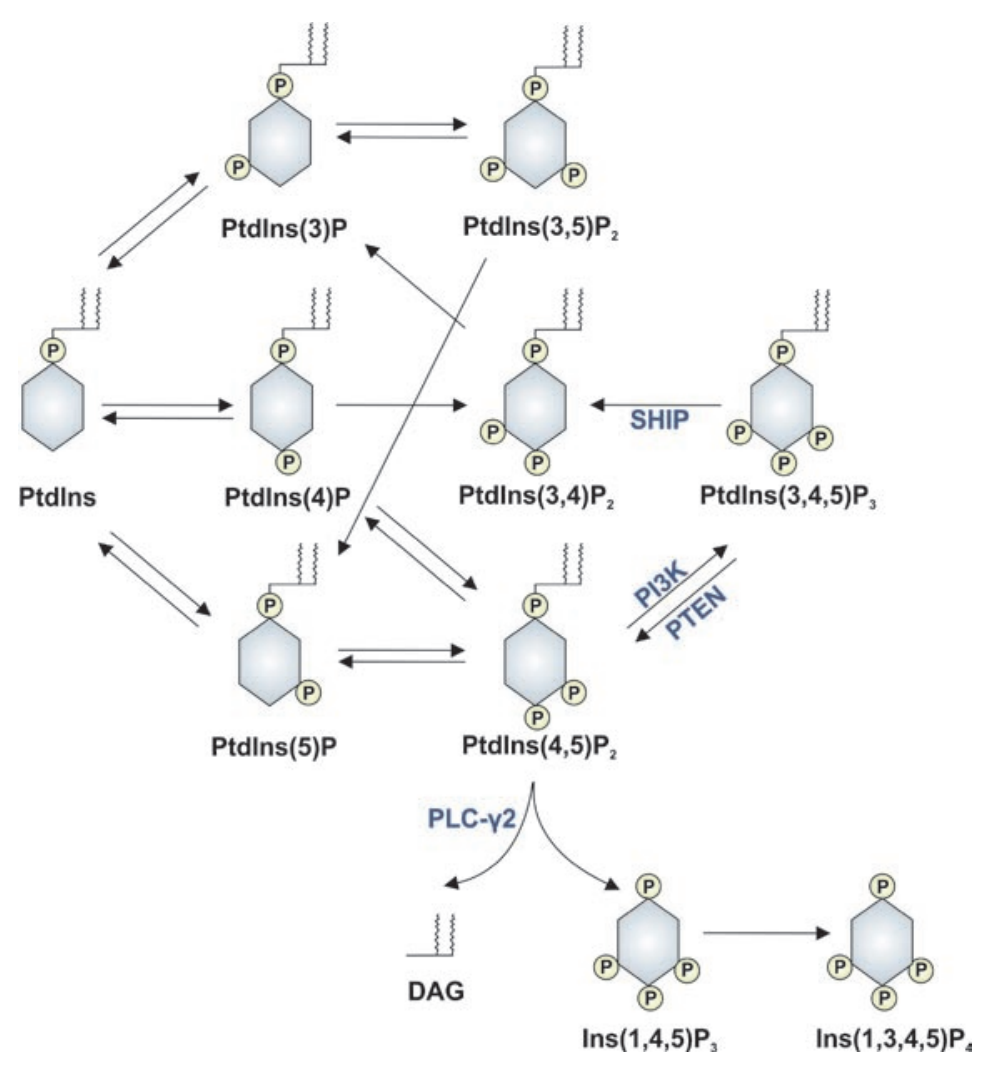

Figure 1.3: Phosphoinositide metabolism. Phosphorylation of phosphatidylinositol (PtdIns) at different positions of the inositol ring yields different phosphoinositides, e.g. phosphatidylinositol-3,4,5trisphosphate $\left(\operatorname{PtdIns}(3,4,5) \mathrm{P}_{3}\right)$. Numbers in brackets refer to positions of the inositol ring being phosphorylated (P). SH2 domain-containing 5' inositol phosphatase (SHIP), phosphatase and tensin homolog (PTEN), phosphoinositide 3-kinase (PI3K) and phospholipase C- $\gamma 2$ (PLC- $\gamma 2$ ) are enzymes with significant impact on phosphoinositide signaling downstream of the BCR.

Several classes of PI3K phosphorylate the 3' position of the inositol ring to produce phosphatidylinositol-3-phosphate (PtdIns(3)P), PtdIns(3,4) $\mathrm{P}_{2}$ or phosphatidylinositol3,4,5-trisphosphate (PtdIns $\left.(3,4,5) \mathrm{P}_{3}\right)$. In $\mathrm{B}$ cells, class I PI3K is the most important PI3K type and the only one that generates PtdIns(3,4,5) $\mathrm{P}_{3}$. PI3K is a heterodimeric protein consisting of the catalytic subunit p110 and the regulatory subunit p85. Its activation can be mediated by CD19, which is a B cell co-receptor that, following BCR activation, becomes tyrosine phosphorylated and provides a binding site for the SH2 domains of p85 (Tuveson et al., 1993). This process is supported by the B cell adaptor for PI3K, which contributes to bridging BCR activation and PI3K signaling by being a substrate for Syk and Btk on the one hand, and providing a membrane anchor for PI3K on the other hand (Okada et al., 2000). Some PtdIns, like PtdIns(3)P, are present in unstimulated cells as well, while PtdIns(3,4) $\mathrm{P}_{2}$ or PtdIns(3,4,5) $\mathrm{P}_{3}$ are only found at relevant levels after cellular activation and are considered to be second messengers 
(Gold \& Aebersold, 1994). Important effectors of PtdIns(3,4,5) $\mathrm{P}_{3}$ are $\mathrm{PH}$-domain containing proteins like Btk (Salim et al., 1996) and the actin regulatory protein Wiskott-Aldrich syndrome protein-family verprolin-homologous protein (Oikawa et al., 2004). PLC- $\gamma 2$ is among the effectors of PtdIns(3,4,5) $\mathrm{P}_{2}$ (Falasca et al., 1998) while Akt can bind to PtdIns(3,4) $\mathrm{P}_{2}$ as well as PtdIns(3,4,5) $\mathrm{P}_{3}$ (Franke, 2008). PH domains are protein domains of approximately 120 amino acids that can, by interacting with PtdIns, specifically mediate recruitment of their host protein to certain membrane compartments. Interconnectivity of the PLC $-\gamma 2$ and PI3K pathways is demonstrated by the fact that the PI3K provides membrane anchors that are required for recruitment and activation of proteins important for PLC- $\gamma 2$ activation (Falasca et al., 1998).

The importance of $\mathrm{PH}$ domains and their lipid counterparts is demonstrated by the consequences of disturbed interaction. They can range from X-linked agammaglobulinaemia in case of mutations within the PH domain of Btk (Lindvall et al., 2005) to cancer that can be observed if the $\mathrm{PH}$ domain of the pro-survival protein Akt permanently associates with the plasma membrane (Carpten et al., 2007).

Considering the fundamental role of PtdIns in intracellular signaling, it is obvious that their turnover is regulated. Two phosphatases are of particular importance to inhibit PtdIns signaling or to adjust its specificity. These are the phosphatase and tensin homolog (PTEN), which directly reverts PI3K action (Maehama \& Dixon, 1998), and the SH2 domain-containing 5' inositol phosphatase (SHIP), which dephosphorylates the 5' position of specific phosphatidylinositols.

\subsection{Inhibition of BCR activation}

BCR activation triggers powerful pathways as explained above and must therefore be tightly regulated (Scharenberg et al., 2007). The importance of many kinases and adaptors involved in regulation is demonstrated by the sometimes fatal consequences of their targeted disruption which may lead to a block in maturation or to inappropriate and overshooting immune responses. Fine-tuning of $\mathrm{Ca}^{2+}$ concentration can be achieved by regulating $\mathrm{Ca}^{2+}$ transporters and channels. Lyn-mediated phosphorylation of Ins $(1,4,5) \mathrm{P}_{3}$ receptor channels e. g. increases the affinity for $\operatorname{Ins}(1,4,5) \mathrm{P}_{3}$ (Cui et al., 2004). Very essential in the context of down-modulating BCR responses and determining the cellular activation threshold are inhibitory co-receptors expressed on the surface of B cells. A common theme of inhibitory co-receptors is that they contain 
one or several immunoreceptor tyrosine-based inhibitory motifs (ITIMs) (Daeron et al., 1995) in their cytoplasmic domains. The restricted consensus amino acid sequence is (V/I)XYXX(L/V), where X denotes any amino acid, while a broader definition also includes the consensus sequence (I/V/L/S)XYXX(I/V/L/S) (Sinclair, 2000). The small hydrophobic amino acid at position -2 influences the binding specificity. While phosphorylated ITAMs recruit effectors of activation, phosphorylated ITIMs can serve as docking sites for effectors of inhibition, i. e. mainly phosphatases. Inhibition at the level of protein effectors is mediated by the SH2-domain-containing protein tyrosine phosphatase 1 (SHP1) (Maeda et al., 1998), whereas inhibition at the level of phospholipids is carried out by SHIP and PTEN with the latter not being recruited to ITIMs. ITIM-containing co-receptors include CD22, CD72, paired immunoglobulinlike receptor B (PirB) and the low-affinity receptor for IgG, Fc $\gamma$ RIIB. CD22 is a coreceptor that binds to sialic-acid-bearing ligands. Such ligands are very common and CD22 is therefore generally inhibitory (Sgroi et al., 1993). Its inhibitory potential is due to the fact that its ITIM can recruit SHP1 (Doody et al., 1995), which subsequently dephosphorylates and inactivates effectors of BCR signaling like Ig $\alpha$, Ig $\beta$, Syk, Btk and SLP-65 leading to down-regulation of PLC- $\gamma 2$ activation (Maeda et al., 1999; Adachi et al., 2001). CD72 (Adachi et al., 2001) and PirB (Maeda et al., 1999) also recruit SHP1. Some proportion of CD22 and CD72 interacts constitutively with the BCR and inhibits BCR signaling by SHP1 recruitment as soon as the BCR is activated. This suggests that they set a general threshold for BCR signaling (reviewed in Adachi et al., 2001). PirB also seems to be involved in the maintenance of immune homeostasis and mediates a more general and constitutive inhibition as it can bind to MHC-I on the same cell surface (Masuda et al., 2007).

Fc $\gamma$ RIIB, on the other hand is only phosphorylated after co-activation with the BCR (Nimmerjahn \& Ravetch, 2008) although FcyRIIB-autonomous signaling might have a role in the negative selection of B cells in germinal centers (Pearse et al., 1999). Coactivation occurs by binding to immune complexes, which are composed of antigen that is already bound by soluble IgG. In this case, the antigen binds to the BCR and the constant part of IgG binds to the Fc $\gamma$ RIIB, thereby co-crosslinking both receptors and bringing FcrRIIB into the vicinity of BCR-associated Lyn for subsequent phosphorylation. In contrast to the above mentioned co-receptors, inhibition of BCR signaling following coactivation of the Fc $\gamma$ RIIB is mediated by SHIP (Ono et al., 1997). SHIP hydrolyzes PtdIns(3,4,5) $\mathrm{P}_{3}$ and thereby depletes membrane anchors for $\mathrm{PH}$ domain-containing effectors of $\mathrm{B}$ cell activation. This results in inhibition of BCR- 
induced $\mathrm{Ca}^{2+}$ mobilization (Ono et al., 1996) and decreased Akt activity (Jacob et al., 1999). The presence of immune complexes, which is required for BCR-Fc $\gamma$ RIIB coactivation, implies that further antibody production is not required. Cells recognizing antigen in the context of immune complexes should therefore not become activated.

In summary, the two inhibitory proteins SHP1 and SHIP intervene at two different levels of B cell activation. The tyrosine phosphatase SHP1 is a negative regulator because it directly opposes the action of protein tyrosine kinases that initiate and transduce B cell activation. The inositol phosphatase SHIP targets PI3K action and prevents the localization of activating effector proteins to the plasma membrane where signal initiation takes place.

\subsection{SHIP - an important regulator of phospholipid metabolism}

The phosphatase SHIP is an essential component of negative regulation of $\mathrm{B}$ cell activation. It was originally discovered as a $145 \mathrm{kDa}$ protein co-purified with the adaptor proteins growth factor receptor-bound protein 2 (Grb2) and the Src homology and collagen protein (Shc) following growth factor stimulation or stimulation with interleukin-3 (Liu et al., 1994; Damen et al., 1996). It hydrolyses PtdIns(3,4,5) $\mathrm{P}_{3}$ to generate PtdIns(3,4) $\mathrm{P}_{2}$ and can, at least in vitro, also dephosphorylate soluble inositol1,3,4,5-tetrakisphosphate $\left(\operatorname{Ins}(1,3,4,5) \mathrm{P}_{4}\right)$ at the 5' position (Damen et al., 1996). Two homologues of SHIP exist. SHIP1, often just referred to as SHIP, is the subject of this study. It is expressed in hematopoietic cells and adult testis (Liu et al., 1998). The expression level in B lymphocytes is comparable between different developmental stages. The other homologue SHIP2 (Pesesse et al., 1997) exhibits about $38 \%$ amino acid identity to SHIP1, is more ubiquitously expressed and can only use PtdIns $(3,4,5) \mathrm{P}_{3}$ as a substrate. This indicates a non-redundant function. Indeed, SHIP2 was shown to be a negative regulator of insulin signaling (Clement et al., 2001).

The importance of SHIP is seen in SHIP-deficient mice which have a reduced life span due to myeloid cell infiltration into the lungs (Helgason et al., 1998). Myeloid cells and their precursors are more sensitive to growth factor stimulation (Helgason et al., 1998) and less sensitive to pro-apoptotic signals (Liu et al., 1999) owing to constitutive Akt activation. While the number of precursor and immature B cells is reduced, SHIPdeficient B cells have more mature B cells and higher serum Ig levels (Helgason et al., 
2000). Moreover, SHIP antagonizes PI3K activity and thereby generally attenuates activation, proliferation and survival. SHIP was therefore suggested to be tumorsuppressive (Sattler et al., 1999).

\subsubsection{SHIP structure}

SHIP contains several protein domains (Figure 1.4). The catalytic domain conferring inositol phosphatase activity is located in the middle of the protein and was shown not to be sufficient for inhibitory signaling (Aman et al., 2000). C-terminal of the catalytic domain is a PtdIns(3,4) $\mathrm{P}_{2}$-binding C2 domain (Ong et al., 2007). The N-terminal SH2 domain binds to phosphorylated ITIMs from e. g. Fc $\gamma$ RIIB (Nakamura et al., 2000) and to ITAMs in the cytoplasmic domains of FceRI, CD3 and the T cell receptor chain $\zeta$ in vitro (Osborne et al., 1996). It was also reported to bind to phosphorylated Shc (Liu et al., 1997a) in negative signaling conditions, although other studies showed that interaction with Shc does not require the SH2 domain of SHIP (Lamkin et al., 1997). Baran and colleagues observed binding of the SH2 domain of SHIP to Lyn in a monocytic cell line (Baran et al., 2003) while Liu and colleagues reported interaction of the SH2 domain with the tyrosine phosphatase SHP2 following stimulation with interleukin-3 (Liu et al., 1997b).

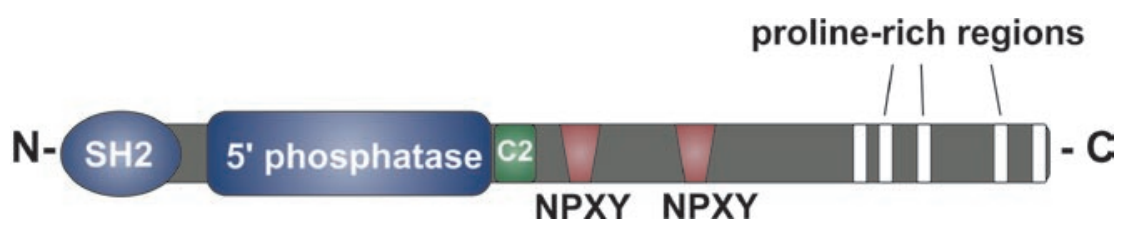

Figure 1.4: Schematic representation of the structure of SHIP. Apart from the N-terminal SH2 domain and the catalytic 5' phosphatase domain, SHIP possesses a C2 domain for allosteric regulation, two NPXY motifs and several proline-rich regions, that are found throughout the protein but are concentrated in the C-terminal region.

The SHIP sequence further encompasses two NPXY phosphotyrosine motifs, located around Y917 and Y1020. They mediate inducible interaction with proteins containing phosphotyrosine-binding domains (PTBs) such as Shc (Lioubin et al., 1996) and proteins of the downstream of kinase (Dok) family like Dok-1 (Tamir et al., 2000) and Dok-3 (Lemay et al., 2000). Moreover, SHIP has several proline-rich regions with conserved PXXP motifs, where X is any amino acid (Mayer \& Eck, 1995). More 
precisely, two types of consensus sequences are often observed. In most cases, an arginine residue is found three residues $\mathrm{N}$-terminal or two residues $\mathrm{C}$-terminal of the PXXP motif. Considering the frequency of hydrophobic residues within proline-rich regions, Mayer and Eck suggested the consensus sequences to be $\mathrm{RX} * \mathrm{PX} * \mathrm{P}$ and *PX*PXR with * being proline, valine, leucine or another hydrophobic amino acid (Mayer \& Eck, 1995). In addition, non-canonical proline-rich regions lacking the PXXP motif occur. Proline-rich regions interact with Src homology 3 (SH3) domains, which are domains of about 60 residues found in many signaling molecules. One not yet precisely defined proline-rich region in the C-terminus of SHIP is suggested to mediate binding to the C-terminal SH3 domain of the adaptor Grb2 (Damen et al., 1996). It was furthermore demonstrated that the C-terminus, where most proline-rich regions are located, is necessary for inhibition of $\mathrm{Ca}^{2+}$ mobilization (Damen et al., 2001). Even though the responsible protein domain is not known yet, SHIP localization to the cytoskeleton was shown in macrophages (Cox et al., 2001) and thrombocytes (Giuriato et al., 1997).

\subsubsection{Regulation of SHIP activity}

As described above, SHIP dephosphorylates the 5' position of the inositol ring. Damen and colleagues showed that SHIP only recognizes substrates that are phosphorylated at the 3' position, demonstrating that SHIP acts on PI3K products (Damen et al., 1996). The catalytic activity per se is not regulated by phosphorylation of the NPXY motifs (Phee et al., 2000). The factor that has the largest influence on SHIP's ability to inhibit signaling seems to be its translocation to the plasma membrane where the phospholipid substrate is located (Aman et al., 2000; Phee et al., 2000). Once SHIP is localized to the plasma membrane and starts to produce $\operatorname{PtdIns}(3,4) \mathrm{P}_{2}$, it seems to be allosterically activated by PtdIns(3,4) $\mathrm{P}_{2}$ binding to a phospholipid-binding C2 domain of SHIP (Ong et al., 2007). All initial experiments concerning SHIP activation and function were performed in negative signaling conditions i. e. coactivation of the BCR and the Fc $\gamma$ RIIB, simulating immune complexes. However, Okada and colleagues showed that also BCR activation alone resulted in increased $\mathrm{Ca}^{2+}$ mobilization in SHIP-deficient cells, implying a regulatory role of SHIP in autonomous BCR signaling (Okada et al., 1998). This was corroborated by studies indicating that B cells from SHIP-deficient mice had increased levels of PtdIns(3,4,5) $\mathrm{P}_{3}$ upon BCR activation compared to B cells from wild-type mice (Brauweiler et al., 2000) and that consequently association of Btk 
with the plasma membrane was elevated in the absence of SHIP (Bolland et al., 1998). Another hint for a role of SHIP not only in inhibitory but also in activating signaling came from studies showing enhanced proliferation of B cells from SHIP-deficient mice after BCR activation (Helgason et al., 2000). In spite of these studies implying a role for SHIP in FcrRIIB-independent BCR signaling, the underlying molecular mechanism remains to be identified. In negative signaling conditions, the SH2 domain of SHIP binds to phosphorylated ITIMs of the FcyRIIB as described above. This supports its relocation to the plasma membrane and access to its phospholipid substrate. A potential membrane-localized binding partner of the SH2 domain in positive signaling conditions is, however, not known yet. In addition, an evaluation of the individual impact of other interaction domains of SHIP on its activation is still missing. Elucidation of the molecular mechanism of SHIP activation will contribute to a better understanding of the inhibition of autonomous BCR signaling as well as the balance of inhibition and would be of use for therapeutic approaches that already today target SHIP using specific activators (Ong et al., 2007).

\subsection{Scope of the thesis}

One essential negative regulator of B cell activation is the inositol phosphatase SHIP, which depletes membrane anchors for activating enzymes of the BCR signaling cascade. Apart from its activation as a consequence of BCR-Fc $\gamma$ RIIB coactivation by immune complexes, a role of SHIP in autonomous BCR signaling was demonstrated by studies showing that SHIP is also activated in the absence of the Fc $\gamma$ RIIB. However, despite the important role of SHIP, it is still unknown how SHIP is activated in such situations. The goal of this thesis therefore was to identify the underlying molecular mechanism of this process. How is BCR signaling attenuated in the absence of Fc $\gamma$ RIIB involvement? How is SHIP recruited to the plasma membrane in order to gain access to its substrate? What are the structural requirements for this process? To answer these questions, the suitability of the chicken B cell line DT40 as a model system to study SHIP activation was tested. With such a tool at hand, the goal of this study was to discover the requirements for the FcyRIIB-independent activation of SHIP. Therefore, the prerequisites regarding SHIP itself and the requirements for interaction partners were analyzed. 


\section{Materials and Methods}

\subsection{Materials}

\subsubsection{Antibodies}

Antibodies used in this study are listed in table 2.1. Primary antibodies for western blot were used at a dilution of 1:1000-1:3000. Secondary antibodies conjugated to horseradish peroxidase (HRP) were used at a dilution of 1:10 000. Antibodies for flow cytometry were used as indicated. Stimulating antibodies were used as explained in 2.2.3.1.

Table 2.1: Antibodies used in this study. FC (flow cytometry), IP (immunoprecipitation), WB (western blot), S (stimulation).

\begin{tabular}{l|l|l}
\hline Antibody & Application & Supplier/ Reference \\
\hline Rabbit-anti-human actin & WB & Sigma \\
Rabbit-anti-human CD2AP & WB & Santa Cruz Biotechnology \\
Rabbit-anti-human CIN85 & WB & Sigma \\
Rabbit-anti-chicken Dok-3 & WB & (Lösing, 2007) \\
mouse-anti-GFP (clones 7.1 and 13.1) & IP, WB & Roche Diagnostics \\
anti-Grb2 (clone 3F2) & WB & Upstate \\
Mouse-anti-GST (clone GST-2) & WB & Sigma \\
Rat-anti-HA (clone 3F10) & IP, WB & Roche Diagnostics \\
Rabbit-anti-chicken HS1 & WB & Dr. A. Hennemann \\
Goat-anti-mouse IgG-HRP & WB & Thermo Scientific
\end{tabular}




\begin{tabular}{|c|c|c|}
\hline Antibody & Application & Supplier/ Reference \\
\hline Goat-anti-mouse IgG1-HRP & WB & Southern Biotech \\
\hline Goat-anti-mouse IgG2b-HRP & WB & Southern Biotech \\
\hline Goat-anti-rabbit IgG-HRP & WB & Thermo Scientific \\
\hline Goat-anti-rat IgG-HRP & WB & Thermo Scientific \\
\hline Mouse-anti-human Nck2 (clone 8.8) & WB & Santa Cruz Biotechnology \\
\hline Mouse-anti-phosphotyrosine (clone 4G10) & WB & Upstate Biotechnology \\
\hline Rabbit-anti-human Shc & IP, WB & BD Biosciences \\
\hline Mouse-anti-mouse SHIP1 (clone P1C1) & WB & Santa Cruz Biotechnology \\
\hline Rabbit-anti-human Syk (clone N-19) & WB & Santa Cruz Biotechnology \\
\hline anti-human CD8 RPE (clone DK25) & FC $(1: 100)$ & Dako A/S \\
\hline Mouse-anti-CD32 (clone AT10) & $\mathrm{FC}(1 \mu \mathrm{g} / \mathrm{ml})$ & (Greenman et al., 1991) \\
\hline anti-mouse IgG-FITC & FC $(1: 100)$ & Southern Biotech \\
\hline anti-mouse IgM Cy5 & FC $(1: 200)$ & Southern Biotech \\
\hline Mouse-anti-human CD8 (clone MEM-87) & S & ImmunoTools \\
\hline $\mathrm{F}\left(\mathrm{ab}^{\prime}\right)_{2}$ goat anti-mouse IgG+IgM & $\mathrm{S}$ & Jackson Immunoresearch \\
\hline $\begin{array}{l}\text { Mouse-anti-chicken IgM } \\
\text { (clone M4, IgM) }\end{array}$ & S & Southern Biotech \\
\hline $\begin{array}{l}\text { Mouse-anti-chicken IgM } \\
\text { (clone M1, IgG2b) }\end{array}$ & S & (Chen et al., 1982) \\
\hline Rabbit-anti-mouse IgM & S & Jackson Immunoresearch \\
\hline $\mathrm{F}\left(\mathrm{ab}^{\prime}\right)_{2}$ anti-human IgM+IgG & S & Jackson Immunoresearch \\
\hline $\mathrm{F}\left(\mathrm{ab} \mathrm{b}^{\prime}\right)_{2}$ goat-anti-mouse IgM & $\mathrm{S}$ & Jackson Immunoresearch \\
\hline
\end{tabular}




\subsubsection{Enzymes}

The enzymes used in this study are listed in table 2.2. They were used with the buffers supplied.

Table 2.2: Enzymes used in this study.

\begin{tabular}{l|l}
\hline Enyzme & Supplier \\
\hline Calf Intestine Phosphatase & New England Biolabs \\
Pfu DNA Polymerase & Promega \\
Phusion DNA Polymerase & Finnzymes \\
Restriction endonucleases & New England Biolabs \\
T4 DNA Ligase & New England Biolabs \\
\hline
\end{tabular}

\subsubsection{Kits}

The kits used for the indicated applications are listed in table 2.3. They were used according to the manufacturer's protocol with the buffers supplied.

Table 2.3: Commercial kits used in this study.

\begin{tabular}{|c|c|c|}
\hline Kit & Application & Supplier \\
\hline Innu PREP Plasmid Mini Kit & plasmid DNA purification & analytic jena \\
\hline Invisorb Spin Plasmid Mini Two & plasmid DNA purification & invitek \\
\hline MACS B cell isolation kit & Isolation of mouse B cells & Miltenyi Biotec \\
\hline$\mu$ MACS GFP Tagged Protein & Isolation of green & Miltenyi Biotec \\
\hline $\begin{array}{l}\text { Isolation Kit (used in combination } \\
\text { with MACS Separation Columns, } \\
\text { Multi Stand, } \mu \text { MACS Separator) }\end{array}$ & $\begin{array}{l}\text { fluorescent protein (GFP)- } \\
\text { tagged proteins from } \\
\text { cellular lysates }\end{array}$ & \\
\hline NucleoSpin Extract II & $\begin{array}{l}\text { PCR Clean-Up, } \\
\text { gel extraction }\end{array}$ & Macherey-Nagel \\
\hline $\begin{array}{l}\text { Pure Yield Plasmid Midiprep } \\
\text { System }\end{array}$ & plasmid DNA purification & Promega \\
\hline
\end{tabular}




\subsubsection{Vectors and constructs}

Several constructs were generated in this study and some already existing constructs were used for production of fusion proteins in Escherichia coli or for transfection of cells. The basic vectors, to which the others go back, are listed in table 2.4. The constructs that were used in this study are listed in table 2.5.

Table 2.4: Vectors used in this study. p (resistance to puromycin), bleo (resistance to bleomycin), blast (resistance to blasticidin).

\begin{tabular}{|c|c|c|}
\hline Vector & Application & Reference \\
\hline pABESIIp & Expression vector used for electroporation & Dr. N. Engels \\
\hline pCDNA3p & Expression vector used for electroporation & Invitrogen, Dr. G. Ygit \\
\hline pEGFP-N1 & $\begin{array}{l}\text { Cloning vector, expression of EGFP-tagged } \\
\text { proteins in mammalian cells, used for } \\
\text { retroviral transfection }\end{array}$ & $\begin{array}{l}\text { BD Biosciences } \\
\text { Clontech }\end{array}$ \\
\hline pGEX-4T-1 & $\begin{array}{l}\text { GST fusion vector (N-terminal GST), bacterial } \\
\text { expression vector }\end{array}$ & $\begin{array}{l}\text { Amersham } \\
\text { Biosciences }\end{array}$ \\
\hline pLNCX2 & $\begin{array}{l}\text { mammalian expression vector used for } \\
\text { retroviral transfection }\end{array}$ & $\begin{array}{l}\text { BD Biosciences } \\
\text { Clontech }\end{array}$ \\
\hline pMSCVp & $\begin{array}{l}\text { Cloning vector, mammalian expression vector } \\
\text { used for retroviral transfection }\end{array}$ & $\begin{array}{l}\text { BD Biosciences } \\
\text { Clontech }\end{array}$ \\
\hline pMSCV-bleo & $\begin{array}{l}\text { mammalian expression vector used for } \\
\text { retroviral transfection of cells containing } \\
\text { already resistance to puromycin }\end{array}$ & $\begin{array}{l}\text { BD Biosciences } \\
\text { Clontech, } \\
\text { Dr. M. Engelke }\end{array}$ \\
\hline $\begin{array}{l}\text { pMSCV- } \\
\text { blast }\end{array}$ & $\begin{array}{l}\text { mammalian expression vector used for } \\
\text { retroviral transfection containing already } \\
\text { resistance to puromycin }\end{array}$ & $\begin{array}{l}\text { BD Biosciences } \\
\text { Clontech, Dr. B. Stork }\end{array}$ \\
\hline $\begin{array}{l}\text { pHCMV- } \\
\text { VSV-G }\end{array}$ & Pseudotyping of retroviruses & M. Jücker \\
\hline
\end{tabular}


Table 2.5: Constructs used in this study. p (resistance to puromycin), bleo (resistance to bleomycin), neo (resistance to neomycin), L (enzyme used for linearization).

*either wild-type (wt) SHIP or SHIP carrying mutations or combinations of mutations in proline-rich regions, NPXY motifs and the Src homology 2 (SH2) domain.

\begin{tabular}{|c|c|c|}
\hline Construct & $\begin{array}{l}\text { Description of protein } \\
\text { encoded }\end{array}$ & Cloning strategy/ Reference \\
\hline $\begin{array}{l}\text { pABESIIpCD8Ig } \alpha \\
\text {-HA (L: ScaI) }\end{array}$ & $\begin{array}{l}\text { Human CD8 fused to the } \\
\text { intracellular, ITAM-carrying, } \\
\text { part of mouse Ig } \alpha \text {, C-terminal } \\
\text { HA-tag }\end{array}$ & $\begin{array}{l}\text { CD8Ig } \alpha \text { was amplified from } \\
\text { pMSCVbleoCD8Ig } \alpha \text { using the } \\
\text { primers pMSCV-for and Ig } \alpha- \\
\text { HA rev and cloned into } \\
\text { pABESIIp via BglII-BamHI/ } \\
\text { Xho-SalI }\end{array}$ \\
\hline $\begin{array}{l}\text { pABESIIpCD8Ig } \beta- \\
\text { HA (L: ScaI) }\end{array}$ & $\begin{array}{l}\text { Human CD8 fused to the } \\
\text { intracellular, ITAM-carrying, } \\
\text { part of mouse Ig } \beta \text {, C-terminal } \\
\text { HA-tag }\end{array}$ & $\begin{array}{l}\text { CD8Ig } \beta \text { was amplified from } \\
\text { pMSCVbleoCD8 } \operatorname{Ig} \beta \text { using the } \\
\text { primers pMSCV-for and } \operatorname{Ig} \beta- \\
\text { HA rev and cloned into } \\
\text { pABESIIp via BglII-BamHI/ } \\
\text { Xho-SalI }\end{array}$ \\
\hline $\begin{array}{l}\text { pABESIIpSHIPwt- } \\
\text { EGFP (L: PvuI) }\end{array}$ & $\begin{array}{l}\text { Mouse SHIPwt with C-terminal } \\
\text { EGFP-tag }\end{array}$ & $\begin{array}{l}\text { SHIPwt-EGFP was mobilized } \\
\text { from pMSCVbleoSHIPwt- } \\
\text { EGFP using EcoRI and cloned } \\
\text { into pABESIIp via EcoRI }\end{array}$ \\
\hline $\begin{array}{l}\text { pABESIIpSHIP } \\
\text { R34Gwt-EGFP } \\
\text { (L: PvuI) }\end{array}$ & $\begin{array}{l}\text { Mouse SHIP with inactivated } \\
\text { SH2 domain, C-terminal } \\
\text { EGFP-tag }\end{array}$ & $\begin{array}{l}\text { SHIPR34G-EGFP was } \\
\text { mobilized from } \\
\text { pMSCVbleoSHIPR34G-EGFP } \\
\text { using EcoRI and cloned into } \\
\text { pABESIIp via EcoRI }\end{array}$ \\
\hline $\begin{array}{l}\text { pCDNApCD8Ig } \alpha \\
\text { (L: BglII) }\end{array}$ & $\begin{array}{l}\text { Human CD8 fused to the } \\
\text { intracellular, ITAM-carrying, } \\
\text { part of mouse Ig } \alpha\end{array}$ & $\begin{array}{l}\text { CD8Ig } \alpha \text { was mobilized from } \\
\text { pMSCVbleoCD8Ig } \alpha \text { using } \\
\text { BglII/NotI and cloned into } \\
\text { pCDNAp via BamHI/NotI }\end{array}$ \\
\hline $\begin{array}{l}\text { pcDNApCD8Ig } \beta \\
\text { (L: BglII) }\end{array}$ & $\begin{array}{l}\text { Human CD8 fused to the } \\
\text { intracellular, ITAM-carrying, } \\
\text { part of mouse } \operatorname{Ig} \beta\end{array}$ & $\begin{array}{l}\mathrm{CD} 8 \operatorname{Ig} \beta \text { was mobilized from } \\
\text { pMSCVbleoCD8Ig } \beta \text { using } \\
\text { BglII/NotI and cloned into } \\
\text { pCDNAp via BamHI/NotI }\end{array}$ \\
\hline
\end{tabular}




\begin{tabular}{|c|c|c|}
\hline Construct & $\begin{array}{l}\text { Description of protein } \\
\text { encoded }\end{array}$ & Cloning strategy/ Reference \\
\hline $\begin{array}{l}\text { pGEX-4T1- } \\
\text { CD2AP[SH3 }]_{3}\end{array}$ & $\begin{array}{l}\text { All three SH3 domains of } \\
\text { human CD2AP, N-terminal } \\
\text { GST-tag }\end{array}$ & V. Bremes \\
\hline $\begin{array}{l}\text { pGEX-4T1-Grb2 } \\
\text { [cSH3] }\end{array}$ & $\begin{array}{l}\text { C-terminal SH3 domain of } \\
\text { mouse Grb2, N-terminal GST- } \\
\text { tag }\end{array}$ & Dr. A. Grabbe \\
\hline $\begin{array}{l}\text { pGEX-4T1-HS1 } \\
\text { [SH3] }\end{array}$ & $\begin{array}{l}\text { SH3 domain of chicken HS1, } \\
\text { N-terminal GST-tag }\end{array}$ & Dr. A. Hennemann \\
\hline $\begin{array}{l}\text { pGEX-4T1-SHIP } \\
\text { [SH2] }\end{array}$ & $\begin{array}{l}\text { SH2 domain of mouse SHIP1 } \\
\text { with N-terminal GST-tag }\end{array}$ & $\begin{array}{l}\text { The SH2 domain was amplified } \\
\text { from pSHIPwt-EGFP using the } \\
\text { primers SHIPSH2XhoI-rev and } \\
\text { SHIPSH2EcoRI-for and the } \\
\text { product was cloned via } \\
\text { XhoI/EcoRI into pGEX-4T1 }\end{array}$ \\
\hline $\begin{array}{l}\text { pGEX-4T1-SHIP } \\
\text { [SH2R34G] }\end{array}$ & $\begin{array}{l}\text { Inactivated SH2 domain of } \\
\text { mouse SHIP1 with N-terminal } \\
\text { GST-tag }\end{array}$ & $\begin{array}{l}\text { SH2 R34G was amplified from } \\
\text { pSHIPR34G-GFP using the } \\
\text { primers SHIPSH2XhoI-rev and } \\
\text { SHIPSH2EcoRI-for and the } \\
\text { product was cloned via } \\
\text { XhoI/EcoRI into pGEX-4T1 }\end{array}$ \\
\hline $\begin{array}{l}\text { pGEX-4T1- } \\
\text { SLP-65 [SH2] }\end{array}$ & $\begin{array}{l}\text { SH2 domain of human SLP-65 } \\
\text { with N-terminal GST-tag }\end{array}$ & Insa Weigel, Dr. A. Grabbe \\
\hline $\begin{array}{l}\text { pGEX-4T1-Syk } \\
{[\mathrm{SH} 2]_{2}}\end{array}$ & $\begin{array}{l}\text { Tandem SH2 domain of human } \\
\text { Syk, N-terminal GST-tag }\end{array}$ & (Wienands et al., 1995) \\
\hline $\begin{array}{l}\text { pLNCXneo } \\
\text { SHIPwt }\end{array}$ & Mouse SHIP1 & Dr. K. Neumann \\
\hline $\begin{array}{l}\text { pMSCVbleoCD8 } \\
\operatorname{Ig} \alpha\end{array}$ & $\begin{array}{l}\text { Human CD8 fused to the } \\
\text { intracellular, ITAM-carrying, } \\
\text { part of mouse Ig } \alpha\end{array}$ & Dr. M. Engelke \\
\hline $\begin{array}{l}\text { pMSCVbleoCD8 } \\
\operatorname{Ig} \beta\end{array}$ & $\begin{array}{l}\text { Human CD8 fused to the } \\
\text { intracellular, ITAM-carrying, } \\
\text { part of mouse } \operatorname{Ig} \beta\end{array}$ & Dr. M. Engelke \\
\hline
\end{tabular}




\begin{tabular}{|c|c|c|}
\hline Construct & $\begin{array}{l}\text { Description of protein } \\
\text { encoded }\end{array}$ & Cloning strategy/ Reference \\
\hline $\begin{array}{l}\text { pMSCVbleo } \\
\text { Fc } \gamma \text { RIIB } 1\end{array}$ & human wt Fe $\gamma$ RIIB1 & Dr. M. Engelke \\
\hline $\begin{array}{l}\text { pMSCVbleoSHIP } \\
\text { wt-EGFP }\end{array}$ & $\begin{array}{l}\text { Mouse SHIPwt with C-terminal } \\
\text { EGFP-tag }\end{array}$ & $(\mathrm{Li}, 2008)$ \\
\hline $\begin{array}{l}\text { pMSCVbleoSHIP } \\
\text { R34G-EGFP }\end{array}$ & $\begin{array}{l}\text { Mouse SHIP with inactivated } \\
\text { SH2 domain (Rameh et al., } \\
\text { 1995; Liu et al., 1997a), C- } \\
\text { terminally EGFP-tagged }\end{array}$ & $\begin{array}{l}\text { SHIPR34G was mobilized from } \\
\text { pSHIPR34G-EGFP and cloned } \\
\text { into pMSCVbleo via BglII/NotI }\end{array}$ \\
\hline $\begin{array}{l}\text { pMSCVp } \\
\text { Fc } \gamma \text { RIIB1-HA }\end{array}$ & $\begin{array}{l}\text { human wt Fc } \gamma \text { RIIB1 with C- } \\
\text { terminal HA-tag }\end{array}$ & $\begin{array}{l}\text { Fc } \gamma \text { RIIB was amplified from } \\
\text { pMSCVbleoFc } \gamma \text { RIIB using the } \\
\text { primers pMSCV-for and Fc } \gamma \text { R- } \\
\text { HA-rev and cloned into } \\
\text { pMSCVp via BglII/NotI }\end{array}$ \\
\hline $\begin{array}{l}\text { pMSCVpSHIPwt- } \\
\text { EGFP }\end{array}$ & $\begin{array}{l}\text { Mouse SHIP1 with C-terminal } \\
\text { EGFP-tag }\end{array}$ & $(\mathrm{Li}, 2008)$ \\
\hline $\begin{array}{l}\text { pMSCVpSHIP } \\
\text { D676G-EGFP }\end{array}$ & $\begin{array}{l}\text { Mouse SHIP1 with inactivated } \\
\text { phosphatase domain (Damen et } \\
\text { al., 2001) }\end{array}$ & $(\mathrm{Li}, 2008)$ \\
\hline $\begin{array}{l}\text { pMSCVpSHIP } \\
\text { Y917F-EGFP, } \\
\text { pMSCVPSHIP } \\
\text { Y1020F-EGFP, } \\
\text { pMSCVpSHIP } \\
\text { Y917F/Y1020F- } \\
\text { EGFP }\end{array}$ & $\begin{array}{l}\text { Mouse SHIP1 carrying the } \\
\text { indicated mutations in NPXY } \\
\text { motifs, C-terminally EGFP- } \\
\text { tagged }\end{array}$ & $(\mathrm{Li}, 2008)$ \\
\hline $\begin{array}{l}\text { pMSCVpSHIP- } \\
\text { EGFP * }\end{array}$ & $\begin{array}{l}\text { Mouse SHIP1* with C-terminal } \\
\text { EGFP-tag }\end{array}$ & $\begin{array}{l}\text { SHIP-EGFP was mobilized } \\
\text { from pSHIP-EGFP* using } \\
\text { BglII/NotI/AseI and cloned into } \\
\text { pMSCVp via BglII/NotI }\end{array}$ \\
\hline
\end{tabular}




\begin{tabular}{|c|c|c|}
\hline Construct & $\begin{array}{l}\text { Description of protein } \\
\text { encoded }\end{array}$ & Cloning strategy/ Reference \\
\hline $\begin{array}{l}\text { pMSCVpSHIP } \\
{[\text { SH2]-EGFP }}\end{array}$ & $\begin{array}{l}\text { SH2 domain of SHIP with C- } \\
\text { terminal EGFP-tag }\end{array}$ & $\begin{array}{l}\text { The SH2 domain was amplified } \\
\text { from pSHIPwt-EGFP using the } \\
\text { primers pEGFP-for and } \\
\text { SHIPAge-rev and cloned into p- } \\
\text { EGFP-N1 via BglII/AgeI. From } \\
\text { there, SH2-EGFP was } \\
\text { mobilized and used to replace } \\
\text { SHIPwt in pMSCVpSHIPwt- } \\
\text { EGFP via BglII/NotI }\end{array}$ \\
\hline pSHIPwt-EGFP & $\begin{array}{l}\text { Mouse SHIP1 with C-terminal } \\
\text { EGFP-tag }\end{array}$ & $(\mathrm{Li}, 2008)$ \\
\hline pSHIPR34G-GFP & $\begin{array}{l}\text { Mouse SHIP with inactivated } \\
\text { SH2 domain, C-terminally } \\
\text { tagged with EGFP }\end{array}$ & $(\mathrm{Li}, 2008)$ \\
\hline pSHIP-EGFP* & Mouse SHIP1* & $\begin{array}{l}\text { pSHIP-EGFP was subjected to } \\
\text { mutagenesis using the } \\
\text { appropriate mutagenesis } \\
\text { primers. In case of overlap } \\
\text { extension PCR, the product of } \\
\text { the second round of PCR was } \\
\text { used to replace SHIPwt in } \\
\text { pSHIP-EGFP via BglII/AgeI }\end{array}$ \\
\hline
\end{tabular}

\subsubsection{Oligonucleotides}

All oligonucleotides used in this study were synthesized by MWG Operon. They are listed in table 2.6. To verify mutagenesis, DNA constructs were sequenced by MWG Operon or Seqlab. 
Table 2.6: Oligonucleotides used in this study. $M_{\text {proline }}$ (mutagenesis of proline-rich region).

\begin{tabular}{|c|c|c|}
\hline Primer name & Sequence $\left(5^{\prime} \rightarrow 3^{\prime}\right)$ & Application \\
\hline CD8-for & CTGGACTTCGCCTGTGATATCTAC & $\begin{array}{l}\text { cloning, } \\
\text { sequencing }\end{array}$ \\
\hline pEGFPN1-for & GTCGTAACAACTCCGCCC & $\begin{array}{l}\text { cloning, } \\
\text { sequencing }\end{array}$ \\
\hline pEGFPN1-rev & GTCCAGCTCGACCAGGATG & $\begin{array}{l}\text { cloning, } \\
\text { sequencing }\end{array}$ \\
\hline FcgR-HA-rev & $\begin{array}{l}\text { TAATGCGGCCGCTTAAGCGTAGTCTGGGA } \\
\text { CGTCGTATGGGTAAATACGGTTCTGGTCA } \\
\text { TCAGGCT }\end{array}$ & $\begin{array}{l}\text { generation of } \\
\text { HA-tagged } \\
\text { Fc } \gamma \text { RIIB }\end{array}$ \\
\hline Ig $\alpha$-HA-rev & $\begin{array}{l}\text { TAATCTCGAGTTAAGCGTAGTCTGGGACG } \\
\text { TCGTATGGGTACTTTTCCAGCTGGGCATCT } \\
\text { CC }\end{array}$ & $\begin{array}{l}\text { generation of } \\
\text { HA-tagged } \\
\text { chimera }\end{array}$ \\
\hline Igb-HA-rev & $\begin{array}{l}\text { TAATCTCGAGTTAAGCGTAGTCTGGGACG } \\
\text { TCGTATGGGTATTCCTGGCCTGGATGCTCT } \\
\text { CC }\end{array}$ & $\begin{array}{l}\text { generation of } \\
\text { HA-tagged } \\
\text { chimera }\end{array}$ \\
\hline pMSCV-for & CCCTTGAACCTCCTCGTTCGACC & $\begin{array}{l}\text { cloning, } \\
\text { sequencing }\end{array}$ \\
\hline pMSCV-rev & GAGACGTGCTACTTCCATTTGTC & sequencing \\
\hline SHIP HindIII 5 & ССТTCССTAAGCTTGTGCCC & $\begin{array}{l}\text { introduction of } \\
\text { HindIII site }\end{array}$ \\
\hline SHIP HindIII 3' & GGGCACAAGCTTAGGGAAGG & $\begin{array}{l}\text { introduction of } \\
\text { HindIII site }\end{array}$ \\
\hline SHIPR34G 5’ & TTCCTTGTGGGTGCCAGCGAGT & $\begin{array}{l}\text { inactivation of } \\
\text { the } \mathrm{SH} 2 \\
\text { domain }\end{array}$ \\
\hline SHIPR34G 3’ & ССTTCCСTAAGCTTGTGCCC & $\begin{array}{l}\text { inactivation of } \\
\text { the } \mathrm{SH} 2 \\
\text { domain }\end{array}$ \\
\hline
\end{tabular}




\begin{tabular}{|c|c|c|}
\hline Primer name & Sequence $\left(5^{\prime} \rightarrow 3^{\prime}\right)$ & Application \\
\hline $\begin{array}{l}\text { mSHIP-R132A- } \\
\text { for }\end{array}$ & GAGCTGCCTCCCGCAAACATTCC & $\mathrm{M}_{\text {proline }}$ \\
\hline $\begin{array}{l}\text { mSHIP-R132A- } \\
\text { rev }\end{array}$ & CATAGGAATGTTTGCGGGAGGCAG & $\mathrm{M}_{\text {proline }}$ \\
\hline $\begin{array}{l}\text { mSHIP-R250A- } \\
\text { for }\end{array}$ & CCAGGCCTTGCCCCACGAC & $\mathrm{M}_{\text {proline }}$ \\
\hline $\begin{array}{l}\text { mSHIP-R250A- } \\
\text { rev }\end{array}$ & GGTCGTGGGGCAAGGCCT & $\mathrm{M}_{\text {proline }}$ \\
\hline SHIPY917F-for & $\begin{array}{l}\text { GATGATCAATCCAAACTTCATTGGTATGG } \\
\text { GGCCTT }\end{array}$ & $\begin{array}{l}\text { mutagenesis of } \\
\text { NPXY motif }\end{array}$ \\
\hline SHIPY917F-rev & $\begin{array}{l}\text { AAGGCCCCATACCAATGAAGTTTGGATTG } \\
\text { ATCATC }\end{array}$ & $\begin{array}{l}\text { mutagenesis of } \\
\text { NPXY motif }\end{array}$ \\
\hline $\begin{array}{l}\text { mSHIP-K974A- } \\
\text { for }\end{array}$ & CTCTGTCGCCAGCGAAGTTTTCATC & $\mathrm{M}_{\text {proline }}$ \\
\hline $\begin{array}{l}\text { mSHIP-K974A- } \\
\text { rev }\end{array}$ & TGAAAACTTCGCTGGCGACAGAGG & $\mathrm{M}_{\text {proline }}$ \\
\hline $\begin{array}{l}\text { SHIP-K974A/ } \\
\text { K975A-for }\end{array}$ & CGCCAGCGGCGTTTTCATCTTC & $\mathrm{M}_{\text {proline }}$ \\
\hline $\begin{array}{l}\text { SHIP-K974A/ } \\
\text { K975A-rev }\end{array}$ & AGATGAAAACGCCGCTGGCG & $\mathrm{M}_{\text {proline }}$ \\
\hline SHIPY1020F-for & $\begin{array}{l}\text { GAAGGAACTCACGGATCCAAACAGTGGG } \\
\text { TTCTCAAA }\end{array}$ & $\begin{array}{l}\text { mutagenesis of } \\
\text { NPXY motif }\end{array}$ \\
\hline $\begin{array}{l}\text { SHIPY1020F- } \\
\text { rev }\end{array}$ & $\begin{array}{l}\text { TTTGAGCCACCACTGTTTGGATCCGTGAG } \\
\text { TTCCTTC }\end{array}$ & $\begin{array}{l}\text { mutagenesis of } \\
\text { NPXY motif }\end{array}$ \\
\hline $\begin{array}{l}\text { SHIP-R1033A- } \\
\text { for }\end{array}$ & AAGCTTGTGCCCGCGAAAGAGCAG & $\mathrm{M}_{\text {proline }}$ \\
\hline $\begin{array}{l}\text { SHIP-R1033A- } \\
\text { rev }\end{array}$ & CTGCTCTTTCGCGGGCACAAGC & $\mathrm{M}_{\text {proline }}$ \\
\hline
\end{tabular}




\begin{tabular}{|c|c|c|}
\hline Primer name & Sequence $\left(5^{\prime} \rightarrow 3^{\prime}\right)$ & Application \\
\hline $\begin{array}{l}\text { SHIP-R1033A/ } \\
\text { K1034A-for }\end{array}$ & TTGTGCCCGCGGCAGAGCAGGAG & $\mathrm{M}_{\text {proline }}$ \\
\hline $\begin{array}{l}\text { SHIP-R1033A/ } \\
\text { K1034A-rev }\end{array}$ & CTCCTGCTCTGCCGCGGGCACAA & $\mathrm{M}_{\text {proline }}$ \\
\hline $\begin{array}{l}\text { SHIP-R1043A- } \\
\text { for }\end{array}$ & CAAGATGCTGGCGAAGGAGCC & $\mathrm{M}_{\text {proline }}$ \\
\hline $\begin{array}{l}\text { SHIP-R1043A- } \\
\text { rev }\end{array}$ & GCTCCTTCGCCAGCATCTTGG & $\mathrm{M}_{\text {proline }}$ \\
\hline $\begin{array}{l}\text { SHIP-K1044A- } \\
\text { for }\end{array}$ & ATGCTGCGGGCGGAGCCCC & $\mathrm{M}_{\text {proline }}$ \\
\hline $\begin{array}{l}\text { SHIP-K1044A- } \\
\text { rev }\end{array}$ & GGGGGCTCCGCCCGCAGCA & $\mathrm{M}_{\text {proline }}$ \\
\hline $\begin{array}{l}\text { SHIPK1128A- } \\
\text { for }\end{array}$ & GGCCTGTCGCGCCTTCCAGGTCA & $\mathrm{M}_{\text {proline }}$ \\
\hline $\begin{array}{l}\text { SHIPRK1128A- } \\
\text { rev }\end{array}$ & CCTGGAAGGCAAGACAGGCCTCT & $M_{\text {proline }}$ \\
\hline $\begin{array}{l}\text { mSHIP-R1145A- } \\
\text { for }\end{array}$ & CCAGCTCCAGCGCCACCCCTG & $M_{\text {proline }}$ \\
\hline $\begin{array}{l}\text { mSHIP-R1145A- } \\
\text { rev }\end{array}$ & CAGGGGTGGCGCTGGAGCTGG & $M_{\text {proline }}$ \\
\hline $\begin{array}{l}\text { mSHIP-K1151A } \\
\text {-for }\end{array}$ & CCTGCCAGTCGCGAGTCCTGC & $M_{\text {proline }}$ \\
\hline $\begin{array}{l}\text { mSHIP-K1151A } \\
\text {-rev }\end{array}$ & AGCAGGACTCGCGACTGGCAG & $M_{\text {proline }}$ \\
\hline $\begin{array}{l}\text { SHIPSH2 } \\
\text { EcoRI-for }\end{array}$ & $\begin{array}{l}\text { TAATGAATTCATGCCTGCCATGGTCCCTG } \\
\text { G }\end{array}$ & $\begin{array}{l}\text { amplification of } \\
\text { SH2 domain }\end{array}$ \\
\hline $\begin{array}{l}\text { SHIPSH2 Xho- } \\
\text { rev (I) }\end{array}$ & ATTACTCGAGCAGGTGGGTCACCAGCC & $\begin{array}{l}\text { amplification of } \\
\text { shorter SH2 } \\
\text { domain }\end{array}$ \\
\hline
\end{tabular}




\begin{tabular}{l|l|l}
\hline \multicolumn{1}{c|}{ Primer name } & Sequence (5') $\mathbf{3}$ ') & Application \\
\hline $\begin{array}{l}\text { SHIPSH2 Xho- } \\
\text { rev (II) }\end{array}$ & $\begin{array}{l}\text { TAATCTCGAGTGACATGACACTTTCTACA } \\
\text { GTGTCCTCCT }\end{array}$ & $\begin{array}{l}\text { amplification of } \\
\text { longer SH2 } \\
\text { domain }\end{array}$ \\
SP6 & CATTTAGGTGACACTATAG & sequencing \\
T7 & TAATACGACTCACTATAGGG & sequencing \\
\hline
\end{tabular}

\subsubsection{Recombinant peptides}

The biotinylated peptides used in this study encompass parts of the cytoplasmic domain of murine Ig $\alpha$. They are listed in table 2.7 and were purchased from Eurogentec (kindly provided by Dr. N. Engels) or Thermo Scientific.

Table 2.7: Peptides used in this study.

\begin{tabular}{l|l|l}
\hline Name & Sequence & Supplier \\
\hline$\alpha 1-$ & Biotin-CSM ENLYEGLNLDDCSMYEDISR-OH & Eurogentec \\
$\alpha 1 \mathrm{pY}_{\mathrm{N}}$ & Biotin-CSM ENLpYEGLNLDDCSMYEDISR-OH & Eurogentec \\
$\alpha 1 \mathrm{pY}_{\mathrm{C}}$ & Biotin-ENLYEGLNLDDCSMpYEDISR-COOH & Thermo Scientific \\
$\alpha 1 \mathrm{pY}_{\mathrm{N}, \mathrm{C}}$ & Biotin-CSM ENLpYEGLNLDDCSMpYEDISR-OH & Eurogentec \\
$\alpha 2-$ & Biotin-CSM YEDISRGLQGTYQDVGN-OH & Eurogentec \\
$\alpha 2 \mathrm{pY}_{204}$ & Biotin-CSM YEDISRGLQGTpYQDVGN-OH & Eurogentec \\
$\alpha 2 \mathrm{pY}_{\mathrm{C}, 204}$ & Biotin-CSM pYEDISRGLQGTpYQDVGN-OH & Eurogentec \\
\hline
\end{tabular}

\subsubsection{Cells and cell culture media}

\subsubsection{DT40}

The immature DT40 chicken B cell line is a widely used model system for the study of B cell receptor signaling. It is derived from a bursal lymphoma induced by an avian leukosis virus (Baba \& Humphries, 1984). Because of its high random DNA integration 
ratio, it can be genetically manipulated and this feature was also exploited in this study. DT40 express IgM on the cell surface and can be stimulated with antibodies directed against IgM. They were cultured in RPMI 1640 + GlutaMAX (Gibco) supplemented with $10 \%$ fetal calf serum (FCS), $1 \%$ chicken serum, $1 \mathrm{mM}$ L-glutamine, $50 \mu \mathrm{M} \beta$ mercaptoethanol and $1 \%$ penicillin/streptomycin. Several DT40 strains lacking expression of a specific protein were used in this study. They are listed in table 2.8.

Table 2.8: DT40 cell lines used in this study.

\begin{tabular}{l|l}
\hline DT40 background & Reference \\
\hline$a b p 1^{-/-}$ & (Hennemann, 2010) \\
$d o k-3^{-/-}$ & (Stork et al., 2007) \\
$g r b 2^{-/-}$ & (Hashimoto et al., 1998) \\
$h s 1^{-/-}$ & Dr. M. Engelke \\
$l y n^{-/-}$ & (Takata et al., 1994) \\
$n c k^{-/-}$ & (Tucholski, 2010) \\
shc & (Hashimoto et al., 1998) \\
$s h i p^{-/-}$ & (Ono et al., 1997) \\
ship-/ FcyRIIB & (Li, 2008) \\
syk & (Takata et al., 1994) \\
\hline
\end{tabular}

\subsubsection{Ramos}

Ramos B cells originate from a Burkitt's lymphoma. They express IgM on their surface and are mature human B cells. Ramos cells were cultured in RPMI 1640 + GlutaMAX (Gibco) supplemented with $10 \%$ FCS, $2 \mathrm{mM}$ pyruvate (Biochrom AG), $50 \mu \mathrm{M} \beta$ mercaptoethanol and $1 \%$ penicillin/streptomycin.

\subsubsection{Plat E}

The Platinum retroviral packaging cell line, Plat E, is based on the $293 \mathrm{~T}$ cell line. The moloney murine leukemia virus (MMLV)-based packaging genes gag, pol and env are stably integrated in the Plat E genome and Plat E cells can produce retroviruses after 
transient transfection. The Plat E system is an ecotropic packaging system, i.e. genes can be delivered to dividing murine cells only. The retroviral particles can be pseudotyped by co-transfecting a plasmid encoding the envelope glycoprotein of the vesicular stromatitis virus (VSV-G). This alternative envelope protein also allows infection of non-murine cells. The Plat E system allows stable integration of genetic information and long-term expression. Plat E cells were cultured in DMEM (Gibco), 10 \% FCS and 1\% penicillin/streptomycin and regularly treated with $2 \mu \mathrm{g} / \mathrm{ml}$ puromycine and $10 \mu \mathrm{g} / \mathrm{ml}$ blasticidin to select for cells expressing the packaging genes.

\subsubsection{Primary cells}

Primary mouse B cells were cultured in medium called R10, which was RPMI $1640+$ GlutaMAX (Gibco) supplemented with 10 \% FCS, 1mM L-glutamine, $2 \mathrm{mM}$ pyruvate (Biochrom AG), $50 \mu \mathrm{M} \beta$-mercaptoethanol and 1\% penicillin/streptomycin.

During retroviral transduction of primary cells, D10 medium was needed which was composed of DMEM+GlutaMAX (Gibco) supplemented with 10 \% FCS, 1 mM Lglutamine, 2 mM pyruvate (Biochrom AG) and $1 \%$ penicillin/streptomycin.

\subsubsection{Bacteria and bacteria medium}

In this study, Escherichia coli (E. coli) strains were used for the amplification of plasmid DNA and for the production of recombinant GST-fusion proteins.

Chemically competent E. coli TOP10F' (Invitrogen) were used for the production of plasmid DNA. They had the following genotype: F'[lacIq, Tn10(TetR)]mcrA $\Delta$ (mrr-

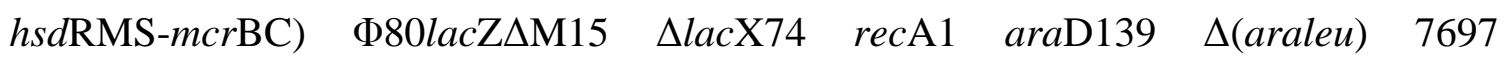
galUgalKrpsL (StrR) endA1 nupG.

For the production of recombinant proteins, expression competent BL21 cells (Invitrogen) were used. Their genotype is $F^{-}$ompThsd $S_{B}\left(r_{B}^{-} m_{B}^{-}\right)$gal dcm (DE3). DE3 is a $\lambda$ prophage which carries the IPTG-inducible T7 RNA polymerase gene.

E. coli was grown in either lysogeny broth (LB) medium (10 g tryptone peptone, $5 \mathrm{~g}$ yeast extract, $5 \mathrm{~g} \mathrm{NaCl}$, ad $1 \mathrm{l} \mathrm{H}_{2} 0$ ) or 2YT medium (16 g tryptone peptone, $15 \mathrm{~g}$ yeast extract, $5 \mathrm{~g} \mathrm{NaCl}$, ad $1 \mathrm{l} \mathrm{H}_{2} 0$ ). For production of agar plates, $2 \%$ agar-agar was added to the LB medium. It was autoclaved at $120^{\circ} \mathrm{C}$ for $30 \mathrm{~min}$ and after cooling to $60^{\circ} \mathrm{C}$, antibiotics were added (100 $\mu \mathrm{g} / \mathrm{ml}$ ampicillin or $50 \mu \mathrm{g} / \mathrm{ml}$ kanamycin). 


\subsubsection{Buffers and solutions}

All buffers were set up with double-distilled water purified by the purification system arium G11. Buffers and solutions used throughout the study are listed in table 2.9. Phosphate-buffered saline (PBS) was autoclaved at $120^{\circ} \mathrm{C}$ for $30 \mathrm{~min}$.

Table 2.9: Buffers used in this study.

\begin{tabular}{|c|c|}
\hline Buffer & Composition \\
\hline $\begin{array}{l}\text { Bacteria lysis } \\
\text { buffer }\end{array}$ & $\begin{array}{l}50 \mathrm{mM} \text { Tris/HCl (pH 7.4), } 150 \mathrm{mM} \mathrm{NaCl}, 5 \mathrm{mM} \text { DTT, } 1 \text { x } \\
\text { protease inhibitor cocktail (Sigma), }\end{array}$ \\
\hline Blotting buffer & $\begin{array}{l}39 \mathrm{mM} \text { glycine, } 48 \mathrm{mM} \text { Tris, } 0.0375 \% \text { SDS, } 0.01 \% \mathrm{NaN}_{3} \text {, } \\
20 \% \mathrm{MeOH}\end{array}$ \\
\hline $\begin{array}{l}\text { Coomassie } \\
\text { destaining solution }\end{array}$ & $30 \%$ methanol, $5 \%$ glacial acetic acid, $65 \% \mathrm{H}_{2} \mathrm{O}$ \\
\hline $\begin{array}{l}\text { Coomassie } \\
\text { solution (reusable) }\end{array}$ & $\begin{array}{l}2.5 \text { g Coomassie brilliant Blue R-250 (Serva), } 450 \mathrm{ml} \text { methanol, } \\
100 \mu \mathrm{l} \text { acetic acid, ad } 1 \mathrm{l} \mathrm{H}_{2} \mathrm{O}\end{array}$ \\
\hline $\begin{array}{l}\text { DNA loading } \\
\text { buffer }(6 \mathrm{x})\end{array}$ & $\begin{array}{l}10 \text { mM Tris (pH 7.6), } 60 \text { mM EDTA ( } \mathrm{pH} \mathrm{8.0),60 \%} \mathrm{glycerin} \\
0,03 \% \text { bromophenol blue }\end{array}$ \\
\hline $\begin{array}{l}\text { Erythrocyte lysis } \\
\text { buffer }\end{array}$ & $\begin{array}{l}\text { nine volumes of } 0.16 \mathrm{M} \quad \mathrm{NH}_{4} \mathrm{Cl} \text { and one volume of } \\
0.17 \mathrm{mM} \text { Tris/ } \mathrm{HCl}(\mathrm{pH} 7.6) \text { were mixed directly before usage and } \\
\text { sterile filtrated }\end{array}$ \\
\hline $\begin{array}{l}\text { Krebs-Ringer } \\
\text { solution }\end{array}$ & $\begin{array}{l}140 \mathrm{mM} \mathrm{NaCl}, 4 \mathrm{mM} \mathrm{KCl}, 1 \mathrm{mM} \mathrm{MgCl}_{2}, 10 \mathrm{mM} \text { D-glucose, } \\
10 \mathrm{mM} \text { HEPES (pH 7.4, sterile filtrated) }\end{array}$ \\
\hline $\begin{array}{l}\text { Laemmli sample } \\
\text { buffer }(4 \mathrm{x})\end{array}$ & $\begin{array}{l}250 \text { mM Tris/HCl (pH 6.8), } 8 \% \text { SDS, } 35 \% \text { glycerol, } 0.02 \% \\
\text { bromophenol blue, } 0.3 \text { M DTT (Laemmli, 1970) }\end{array}$ \\
\hline $\begin{array}{l}\text { Lauryl maltoside } \\
\text { cell lysis buffer }\end{array}$ & $\begin{array}{l}20 \mathrm{mM} \text { Tris/HCl (pH 7.5), } 150 \mathrm{mM} \mathrm{NaCl}, 0.5 \mathrm{mM} \text { EDTA, } \\
10 \mathrm{mM} \mathrm{NaF}, 10 \mu \mathrm{M} \mathrm{MoO}_{4}, 1 \mathrm{mMNa}_{3} \mathrm{VO}_{4}, 1 \text { x protease inhibitor } \\
\text { cocktail (Sigma), } 1 \text { \% lauryl maltoside (Sigma) }\end{array}$ \\
\hline $\begin{array}{l}\text { NP40 cell lysis } \\
\text { buffer }\end{array}$ & $\begin{array}{l}20 \mathrm{mM} \text { Tris/HCl (pH 7.5), } 150 \mathrm{mM} \mathrm{NaCl}, 0.5 \mathrm{mM} \text { EDTA, } \\
10 \mathrm{mM} \mathrm{NaF}, 10 \mu \mathrm{M} \mathrm{MoO}_{4}, 1 \mathrm{mM} \mathrm{Na}_{3} \mathrm{VO}, 1 \text { x protease inhibitor } \\
\text { cocktail (Sigma), } 1 \text { \% IGEPAL CA-630 (Sigma) }\end{array}$ \\
\hline PBS $(1 \mathrm{x})$ & $\begin{array}{l}137 \mathrm{mM} \mathrm{NaCl}, 2.7 \mathrm{mM} \mathrm{KCl}, 4.3 \mathrm{mM} \mathrm{Na} \mathrm{HPO}_{4} \times 12 \mathrm{H}_{2} 0,1.4 \mathrm{mM} \\
\mathrm{KH}_{2} \mathrm{PO}_{4}(\mathrm{pH} \mathrm{6.6)}\end{array}$ \\
\hline
\end{tabular}




\begin{tabular}{|c|c|}
\hline Buffer & Composition \\
\hline PBS-T (1 x) & $\begin{array}{l}137 \mathrm{mM} \mathrm{NaCl}, 2.7 \mathrm{mM} \mathrm{KCl}, 4.3 \mathrm{mM} \mathrm{Na} \mathrm{HPO}_{4} \mathrm{x} 12 \mathrm{H}_{2} 0,1.4 \mathrm{mM} \\
\mathrm{KH}_{2} \mathrm{PO}_{4} \text { (pH 6.6), } 0.1 \% \text { Tween } 20 \text { (Roth) }\end{array}$ \\
\hline $\begin{array}{l}\text { Pervanadate } \\
\text { solution }\end{array}$ & $\begin{array}{l}50 \mu \mathrm{l} 50 \mathrm{mM} \mathrm{PerVO}_{4} \text { and } 15 \mu \mathrm{l} 30 \% \mathrm{H}_{2} \mathrm{O}_{2} \text { were incubated for } 5 \\
\text { min at RT. } 520 \mu \mathrm{H}_{2} \mathrm{O} \text { was added and the solution was used 1:50. }\end{array}$ \\
\hline $\begin{array}{l}\text { SDS PAGE } \\
\text { running buffer }\end{array}$ & 25 mM Tris; 192 mM glycine; 0.1 \% SDS \\
\hline TAE $(1 \mathrm{x})$ & 40mM Tris, 20mM glacial acetic acid and 1mM EDTA \\
\hline TBS $(1 \mathrm{x})$ & 20 mM Tris, 137 mM NaCl (pH 7.6) \\
\hline TBS-T (1 x) & 20 mM Tris, 137 mM NaCl (pH 7.6), 0.1 \% Tween 20 (Roth) \\
\hline TFB I & $\begin{array}{l}50 \mathrm{mM} \mathrm{MnCl}_{2} \cdot 4 \mathrm{H}_{2} \mathrm{O}, 100 \mathrm{mM} \mathrm{KCl}, 10 \mathrm{mM} \mathrm{CaCl}_{2} \cdot 2 \mathrm{H}_{2} \mathrm{O} \text {, } \\
30 \mathrm{mM} \mathrm{KOAc} \mathrm{(pH} \mathrm{6.0),} 15 \% \text { (v/v) glycerol, adjust to } \mathrm{pH} 6.1 \text { with } \\
\text { HOAC }\end{array}$ \\
\hline TFB II & $\begin{array}{l}75 \mathrm{mM} \mathrm{CaCl}_{2} \cdot 2 \mathrm{H}_{2} \mathrm{O}, 10 \mathrm{mM} \mathrm{KCl}, 10 \mathrm{mM} \text { MOPS, } 15 \% \text { (v/v) } \\
\text { glycerol, adjust to pH } 7.0 \text { with } \mathrm{KOH}\end{array}$ \\
\hline
\end{tabular}

\subsubsection{Chemicals}

All chemicals, if not mentioned otherwise, were purchased from Roth, Merck, Sigma, Invitrogen and Gerbu.

\subsubsection{Instruments}

autoMACS cell separation station (Miltenyi Biotec)

Analytical balance MC1 (Sartorius)

Bacteria incubator Heraeus Kelvitron ${ }^{\circledR} \mathrm{t}$

Biophotometer (eppendorf)

Cell culture incubator HeraCell 150 (Heraeus)

Cell culture safety cabinet Herasafe (Heraeus)

Centrifuge Multifuge 3 S-R (Heraeus)

Centrifuge RC 3B Plus (Sorvall)

Centrifuge RC 2G Plus (Sorvall)

Centrifuge mini spin (eppendorf) 
Centrifuge 5417R (eppendorf)

ChemoCam Imager (Intas)

Confocal Laser scanning microscope TCS SP2 (Leica)

Cytometer LSRII (Becton Dickinson)

Cytometer FACS Calibur (Becton Dickinson)

Electrophoresis Power Supply (Amersham Biosciences)

Freezer HERAfreeze (Heraeus)

Freezer Platilab 340 (Angelantoni)

Gel Electrophoresis system (peqlab)

Gel Imager (Intas)

Gene Pulser Electroporator (Bio-Rad)

Heater FCS2 Controller (Bioptechs)

Ice machine (Ziegra Eismaschinen)

Inverted microscope Telaval 31 (Zeiss)

Magnetic stirrer IKA REO (IKAMAG)

Mastercycler epgradient (eppendorf)

MC1 LC1200 S scales (Sartorius)

Mini-PROTEAN Tetra Electrophoresis System (Bio-Rad)

Olympus TIRFM system (Treanor et al., 2010)

pH meter (inoLab)

Platform shaker Duomax 1030 (Heidolph)

Platform shaker 3005 (GFL)

Rotator SB3 (Stuart)

Shaking Incubator Infors (Unitron)

TE77 semidry western blot transfer unit (GE Healthcare)

Thermomixer comfort (eppendorf)

Ultrasonic device Sonoplus (Bandelin)

Vortex-Genie 2 (Scientific Industries)

Water bath (GFL)

Water purification system arium G11 (Sartorius)

\subsubsection{Additional material}

Blotting Paper (Sartorius Stedim)

Electroporation cuvette (peqlab) 
FCS2 closed chamber system (Bioptechs)

Filtropur filters (Sarstedt)

Hybond ECL (Amersham Biosciences)

Immersion oil (Merck)

Lab-Tek chambered borosilicate coverglass system (Nunc)

Microscope paper (neoLab)

MultiFlex Round Tips (Sorenson BioScience Inc.)

Neubauer improved counting chamber (Brand)

Pipettes and electronic pipet filler from eppendorf

Poly-D-lysine-coated glass bottom culture dishes (MatTek)

Tissue culture equipment (pipettes, tubes, culture dishes) (Greiner, Nunc)

\subsubsection{Software}

Cell Quest Pro Software (Becton Dickinson)

CorelDraw X5 (Corel Corporation)

FACS Diva Software (Becton Dickinson)

FlowJo (TriStar)

Image J

Imaris (Bitplane Scientific Software)

Intas Chemostar

Leica Confocal Software

MS Office (Microsoft)

Photoshop

Prism 5 (GraphPad Software)

Xcellence software (Olympus)

\subsubsection{Internet databases}

http://www.ncbi.nlm.nih.gov

http://www.ensembl.org

http://cbm.bio.uniroma2.it/SH3-Hunter (Ferraro et al., 2007)

http://scansite.mit.edu/motifscan_seq.phtml

http://elm.eu.org (eukaryotic linear motif resource)

http://multalin.toulouse.inra.fr/multalin (Corpet, 1988) 


\subsection{Methods}

\subsubsection{Molecular Biology methods}

If not indicated otherwise, standard procedures were carried out as described in the manufacturer's protocol or in "Molecular Cloning: A Laboratory Manual” (Sambrook \& Russell, 2000).

\subsubsection{Restriction digestion of DNA}

Plasmid DNA or PCR products were subjected to site-specific restriction digestion in order to obtain DNA fragments containing the desired sequence. Restriction digestion was carried out according to manufacturer's instructions.

\subsubsection{Electrophoretic separation of DNA fragments}

Plasmid DNA subjected to restriction digestion or PCR products were separated electrophoretically on agarose gels. 0.7-2 \% (w/v) agarose was melted in Tris-acetateEDTA (TAE) buffer and ethidium bromide (Roth) was added to a concentration of 0.5 $\mu \mathrm{g} / \mathrm{ml}$. Agarose gels were casted and DNA samples, mixed with DNA loading buffer (New England Biolabs), were loaded, separated at 5V/cm electrodal distance and visualized using UV light.

\subsubsection{DNA extraction from agarose gels}

Excised DNA was extracted from agarose gels using the NucleoSpin Extract II.

\subsubsection{Ligation of DNA fragments}

DNA inserts and vector backbones that have been digested with suitable restriction enzymes were ligated using T4 DNA ligase. If only one enzyme was used for cloning, vector backbones were incubated with calf intestine phosphatase for $1 \mathrm{~h}$ at $37^{\circ} \mathrm{C}$, followed by a purification step. Calf intestine phosphatase removes 5 ' phosphate groups from DNA and thus prevents vector self-ligation.

\subsubsection{Generation of chemically competent $E$. coli}

$150 \mathrm{ml}$ LB medium were inoculated with an overnight culture of E. coli. They were grown until an $\mathrm{OD}_{600}$ of approximately 0.5 and then cooled on ice for $10 \mathrm{~min}$. They were centrifuged at $1000 \mathrm{~g}$ and $4{ }^{\circ} \mathrm{C}$ for $10 \mathrm{~min}$ and the pellet was resuspended in $30 \mathrm{ml}$ 
cold sterile TFB I. This was followed by another incubation step of $10 \mathrm{~min}$ on ice, centrifugation and resuspension in $6 \mathrm{ml}$ cold sterile TFB II. Aliquots were frozen in liquid nitrogen.

\subsubsection{Transformation of bacteria and selection}

For plasmid DNA amplification, the plasmid or the ligation reaction was used to transform competent bacteria, here E. coli TOP10F'. For protein expression by bacteria (2.2.3.8), the same transformation protocol was applied, only that E. coli BL21 was used. Competent bacteria were thawed on ice. For retransformation of already existing plasmids, approximately $0.3 \mu \mathrm{g}$ plasmid DNA was added. If a ligation was to be transformed, the complete ligation reaction was added. After mixing with a pipet tip, the bacteria were incubated with the DNA on ice for $30 \mathrm{~min}$. Heat- shock was performed at $42{ }^{\circ} \mathrm{C}$ for $45 \mathrm{~s}$, followed by incubation on ice for 2 min and recovery with warm LB medium at $37^{\circ} \mathrm{C}$ for $30 \mathrm{~min}$. The bacteria were streaked on LB agar plates containing antibiotic for selection and cultured overnight at $37^{\circ} \mathrm{C}$. All vectors used throughout this study contained a gene conferring resistance to ampicillin, except for pEGFP-based vectors, which conferred resistance to kanamycin.

\subsubsection{Plasmid isolation from bacteria}

To isolate plasmid DNA from bacteria, $4 \mathrm{ml} \mathrm{LB}$ medium containing the appropriate antibiotic for selection (100 $\mu \mathrm{g} / \mathrm{ml}$ ampicillin or $50 \mu \mathrm{g} / \mathrm{ml}$ kanamycin) were inoculated with a colony of $E$. coli containing the plasmid. They were grown overnight at $37^{\circ} \mathrm{C}$ with constant agitation. Kits listed in table 2.3 were used to isolate plasmid DNA from the overnight culture according to the manufacturers' instructions.

\subsubsection{Long-term storage of bacteria}

E. coli can be stored in glycerol stocks at $-80^{\circ} \mathrm{C}$ for several years. Glycerol stocks were prepared by adding $150 \mu \mathrm{l} 86 \%$ glycerol to $850 \mu \mathrm{l}$ of a logarithmic-phase E. coli culture in a cyrotube vial. They were mixed by inverting them, frozen in liquid nitrogen and stored at $-80^{\circ} \mathrm{C}$. For recovery, parts of the stocks were scratched with a pipette tip and cultured in LB medium containing the appropriate antibiotic. 


\subsubsection{Phenol-chloroform extraction and DNA precipitation}

To purify linearized DNA, equal volumes of the linearization reaction and phenol:chloroform:isoamyl alcohol were mixed. After centrifugation at full speed for 5 min, a phase separation could be observed and DNA could be recovered from the aqueous phase. To concentrate DNA, $1 / 10$ volume $5 \mathrm{M} \mathrm{NaCl}$ and 2.5 volumes of ice-cold $70 \%$ ethanol were incubated with the DNA sample for $10 \mathrm{~min}$ at $-80^{\circ} \mathrm{C}$. The precipitated DNA was centrifuged at full speed and $4{ }^{\circ} \mathrm{C}$ for $15 \mathrm{~min}$, the DNA pellet was allowed to dry and resuspended in $\mathrm{H}_{2} 0$.

\subsubsection{Polymerase chain reaction (PCR)}

Polymerase chain reaction allows the specific amplification of DNA sequences in vitro (Saiki et al., 1985). In this study, PCR was used to generate DNA sequences containing desired restriction sites or to add sequences encoding for the hemagglutinin (HA) tag to genes of choice. Another application of PCR was to insert mutations into existing sequences.

Common considerations for primer design were taken into account, like e.g. a base composition of 50-60\% $(\mathrm{G}+\mathrm{C})$, if possible, no primer self-complementarity and primer lengths between 17-28 bp wherever possible. The primers used in this study are listed in table xyz. PCRs were either performed with Phusion polymerase or with Pfu polymerase according to the manufacturer's protocol. The cycling conditions for both polymerases are listed in table 2.10 .

Table 2.10: Cycling conditions for PCR. Cycle steps 2-4 were repeated about 30 times. $*$ The annealing temperature was chosen to be $3-5{ }^{\circ} \mathrm{C}$ below the lowest primer melting temperature.

\begin{tabular}{l|l|l}
\hline Cyle step & PCR with Phusion polymerase & PCR with Pfu polymerase \\
\hline 1. Initial denaturation & $98{ }^{\circ} \mathrm{C}, 30 \mathrm{~s}$ & $95^{\circ} \mathrm{C}, 1 \mathrm{~min}$ \\
2. Denaturation & $98{ }^{\circ} \mathrm{C}, 10 \mathrm{~s}$ & $95^{\circ} \mathrm{C}, 30 \mathrm{~s}$ \\
3. Annealing & $*, 30 \mathrm{~s}$ & $*, 30 \mathrm{sec}$ \\
4. Extension & $72{ }^{\circ} \mathrm{C}, 20 \mathrm{~s} / \mathrm{kb}$ & $72{ }^{\circ} \mathrm{C}, 2 \mathrm{~min} / \mathrm{kb}$ \\
5. Final extension & $72{ }^{\circ} \mathrm{C}, 2$-fold extension time & $72{ }^{\circ} \mathrm{C}$, \\
\end{tabular}


The melting temperature was either chosen as indicated by the supplier or- in the case of mutagenesis primers-calculated using the following formula:

$T_{m}=81.5+0.41 \%$ GC-675/N-\% mismatch $\quad$ N: primer length

\subsubsection{Mutagenesis}

In this study, several mutageneses were performed to generate constructs encoding for proteins with amino acid exchanges. Two different strategies were pursued, depending on vector size and the specific cloning conditions.

For smaller vectors, mutagenesis was performed by allowing Pfu polymerase to synthesize the complete vector based on two mutagenesis primers containing the desired base pair exchanges. Pfu polymerase exhibits $3{ }^{\prime} \rightarrow 5^{\prime}$ proofreading activity. Therefore whole vectors can be synthesized with high fidelity. The primers are complementary to opposite strands of the vector and the newly synthesized vector will contain staggered nicks. Treatment with Dpn I endonuclease will digest the dam methylated parental DNA. The remaining mutation-containing DNA was transformed into competent bacteria which were capable of repairing the nicks.

Another often used strategy was overlap extension PCR. This strategy consists of two consecutive PCRs. In the first round, two PCRs were performed using one of two complementary mutagenesis primers and an outer primer, respectively. This first round generated two DNA fragments with overlapping ends. These two fragments were used as template DNA in the second round of PCR that was performed with the outer primers only.

\subsubsection{Cell culture methods}

\subsubsection{General aspects}

Cell culture work was carried out under sterile conditions in a laminar flow hood. FCS and CS were generally heated to $56^{\circ} \mathrm{C}$ for $30 \mathrm{~min}$ to inactivate the complement system. Cells were cultured in the above mentioned media (see 2.1.7) at $37^{\circ} \mathrm{C}$ and $5 \% \mathrm{CO}_{2}$ in a humidified incubator. DT40 cells were usually passaged daily 1:3-1:5. Ramos cells were passaged every other day 1:3-1:4. Plat-E cells are adherent cells that were passaged every other day 1:5 by detaching them from the plates using $0.05 \%$ trypsinEDTA (Invitrogen). If not indicated otherwise, centrifugation steps were carried out at 
$300 \mathrm{~g}$ and $4{ }^{\circ} \mathrm{C}$ for $4 \mathrm{~min}$. Cells were counted using a Neubauer improved counting chamber. To distinguish between living and dead cells, the cell suspension was mixed with an equal volume of $0.4 \%$ trypan blue in PBS before counting

Frozen cell stocks were prepared by resuspending cells in freezing medium (10\% DMSO, $90 \%$ FCS) at a density of about approximately $5 \cdot 10^{6} / \mathrm{ml}$. Cells were cooled at a rate of approximately $1{ }^{\circ} \mathrm{C} / \mathrm{min}$ and stored at $-140{ }^{\circ} \mathrm{C}$. For thawing, cells were warmed in a $37^{\circ} \mathrm{C}$ water bath, quickly transferred into pre-warmed medium, centrifuged and resuspended in fresh medium.

\subsubsection{Stable transfection by electroporation}

Cells to be transfected were grown at a relatively high density of about $1.5 \cdot 10^{6} \mathrm{cells} / \mathrm{ml}$. For electroporation, $10^{7}$ cells were washed twice with cold PBS, resuspended in $700 \mu \mathrm{l}$ PBS and transferred to a chilled electroporation cuvette. 10-20 $\mu \mathrm{g}$ of linearized and purified endotoxin-free DNA was added and the cells were incubated on ice for $20 \mathrm{~min}$. Cells were then electroporated at a voltage of $260 \mathrm{~V}$ and a capacitance of $960 \mu \mathrm{F}$, incubated on ice for $15 \mathrm{~min}$ and resuspended in $20 \mathrm{ml}$ medium. Selection was started 24-36 h after electroporation. To obtain single clones, cells were seeded into 96 well plates with $200 \mu \mathrm{l} /$ well. For DT40, clones could be expected to become visible after 1-2 weeks. They were picked and transferred to larger volumes in order to screen for successful transfection.

\subsubsection{Stable transfection by retroviral transduction}

Retroviral transduction required the production of retroviruses by a packaging cell line. Here, Plat E cells grown to a confluency of 60-70 \% were transiently transfected using TransIT (Mirus) according to the manufacturer's instructions. Before transfection, Plat E medium was exchanged for target cell medium. For Plat E cells grown in $4 \mathrm{ml}$ medium on $6 \mathrm{~cm}$ culture dishes, $2.5 \mu \mathrm{g}$ of target DNA was used for transfection. TransIT was used at a ratio of $3 \mu \mathrm{l}$ TransIT per $\mu$ g of DNA. If Plat E cells had to be pseudotyped, $1.8 \mu \mathrm{g}$ of target DNA and $0.7 \mu \mathrm{g}$ pVSV-G were used. $48 \mathrm{~h}$ after transfection, the virus-containing supernatant was centrifuged to prevent contamination of the target cells with Plat E cells. $3 \mathrm{ml}$ supernatant was used to resuspend $1.5 \cdot 10^{6}$ target cells which were then transferred to a culture dish containing $1.5 \mathrm{ml}$ target cell medium and $3 \mu \mathrm{g} / \mathrm{ml}$ sterile polybrene (Hexadimethrine bromide, Sigma). Polybrene is a positively charged molecule that neutralizes surface charges and facilitates virus 
binding to the receptor. The retrovirus was allowed to infect the cells for $24 \mathrm{~h}$. Then the cells were centrifuged and resuspended in fresh medium. The recovery phase after infection varied depending on the antibiotic used for selection. Selection with $1 \mu \mathrm{g} / \mathrm{ml}$ puromycin (InvivoGen) or 40-50 $\mathrm{g} / \mathrm{ml}$ bleomycin (Calbiochem) was started 24-36 h after the end of infection. Blasticidin (InvivoGen) was added at a concentration of $50 \mu \mathrm{g} / \mathrm{ml}$ already after $12 \mathrm{~h}$.

As long as cultures contained free retrovirus, i.e. during the whole infection period of the target cells, respective cell culture work fell into the safety category S2. Therefore culture dishes, pipettes and waste had to be decontaminated and disposed of accordingly.

\subsubsection{Retroviral transduction of primary cells}

For retroviral transduction of primary cells, Plat E cells cultured in D10 medium in 6 cm dishes were transfected with the appropriate plasmids as described above (see table 2.4). $24 \mathrm{~h}$ after transfection, $1.5 \mathrm{ml}$ pre-warmed D10 medium was added to every $6 \mathrm{~cm}$ culture dish and Plat-E cells were cultured for another $24 \mathrm{~h}$ at $32{ }^{\circ} \mathrm{C}$ which increases virus production. The virus-containing supernatant was harvested $48 \mathrm{~h}$ after transfection and filtrated through a $0.45 \mu \mathrm{m}$ filter to avoid contaminating Plat E cells. It was then concentrated by centrifugation in two $2 \mathrm{ml}$ tubes at $20000 \mathrm{~g}$ and $4{ }^{\circ} \mathrm{C}$ for $90 \mathrm{~min}$ and discarding the upper $1.25 \mathrm{ml}$. The invisible pellet was resuspended in the remaining supernatant and both tubes were pooled again. The concentrated virus-containing supernatant was used to infect $2 \cdot 10^{6}$ primary B cells. They had been stimulated with $10 \mu \mathrm{g} / \mathrm{ml}$ lipopolysaccharide (LPS) from E. coli serotype 055:B5 (Sigma) for $36 \mathrm{~h}$ and were resuspended in $500 \mu \mathrm{l}$ pre-warmed R10 medium for the infection reaction. $4 \mu \mathrm{g} / \mathrm{ml}$ polybrene and $10 \mu \mathrm{g} / \mathrm{ml}$ LPS were added to the reaction which was subsequently centrifuged at $400 \mathrm{~g}$ and $33{ }^{\circ} \mathrm{C}$ for $3.5 \mathrm{~h}$ to facilitate infection. The supernatant was discarded and pellets were resuspended in $2 \mathrm{ml}$ pre-warmed R10 supplemented with 10 $\mu \mathrm{g} / \mathrm{ml}$ LPS. Cells were analyzed 24-48 h later.

\subsubsection{Preparation of B cells from mouse spleen}

The spleen of a C57BL/6N mouse was isolated in a laminar flow hood, put into R10 medium and homogenized with the help of a $70 \mu \mathrm{m}$ filter that was rinsed with R10 afterwards to collect all cells. Cells were pelleted by centrifugation at $300 \mathrm{~g}$ and $4{ }^{\circ} \mathrm{C}$ for $8 \mathrm{~min}$. They were washed with cold PBS and resuspended in $1 \mathrm{ml}$ erythrocyte lysis 
buffer. After $2 \mathrm{~min}$ at room temperature the reaction was stopped by the addition of 14 ml R10 medium. Cell were centrifuged again, resuspended in $10 \mathrm{ml} \mathrm{R} 10$ medium and B cells were isolated using a MACS sort kit, which depleted non B cells that bind to antiCD43, anti-CD4 or anti-Ter119, together with the autoMACS cell separation station. For subsequent retroviral infection the B cells were cultured in R10 medium supplemented with $10 \mu \mathrm{g} / \mathrm{ml}$ LPS.

\subsubsection{Stable isotope labeling with amino acids in cell culture (SILAC)}

SILAC is a convenient method to incorporate labels into proteins that are going to be analyzed quantitatively by mass spectrometry-based proteomics (Ong et al., 2002). During cell culture preceding the experiment, the cells were cultured in medium containing either a "heavy" or a "light" version of the amino acids arginine and lysine. Cell behavior was not influenced by the labeled amino acids because there was almost no chemical difference between the isotopes. However, the metabolic labeling lead to a mass shift of the resulting peptides, which could be detected by mass spectrometry. When both samples were combined and analyzed together, the peptides having different isotope compositions could still be distinguished by mass spectrometry and the ratio of the peak intensities reflects the relative abundance of the peptides in the two original samples. SILAC medium was prepared by supplementing RPMI 1640 lacking arginine and lysine (Pierce) with $10 \%$ dialyzed FCS (Invitrogen), $1 \mathrm{mM}$ pyruvate, $1 \%$ penicillin/streptomycin and either the "heavy" amino acids $0.275 \mathrm{mM}^{13} \mathrm{C}_{6},{ }^{15} \mathrm{~N}_{2}$ lysine (lysine+8) and $0.115 \mathrm{mM}^{13} \mathrm{C}_{6},{ }^{15} \mathrm{~N}_{4}$ arginine (arginine +10) (Cambridge Isotopes Laboratories Inc.), the "medium heavy" amino acids ${ }^{2} \mathrm{D}_{4},{ }^{12} \mathrm{C}_{6},{ }^{14} \mathrm{~N}_{2}$ lysine (lysine +4) and ${ }^{13} \mathrm{C}_{6},{ }^{14} \mathrm{~N}_{4}$ arginine (arginine +6 ) or with the "light" amino acids, i. e. non-labeled lysine and arginine (Sigma). SILAC was done for several days to ensure incorporation of labeled amino acids into all newly synthesized proteins.

\subsubsection{Biochemical methods}

\subsubsection{Stimulation of cells}

If stimulation-dependent events were to be analyzed, cells needed to be stimulated before cell lysis. They were first starved in serum-free RPMI at $37^{\circ} \mathrm{C}$ for 20 min with gentle shaking. After starvation, cells were either stimulated or left unstimulated. For BCR stimulation of DT40, cells were stimulated with $2 \mu \mathrm{g} / \mathrm{ml}$ mouse anti-chicken IgM 
for indicated times at $37^{\circ} \mathrm{C}$. Stimulation of cells via CD8-containing chimeras was done by incubating the cells with 3-6 $\mu \mathrm{g} / \mathrm{ml}$ anti-CD8 for 1-3 min. For coactivation of Fc $\gamma$ RIIB and BCR on DT40, $6 \mu \mathrm{g} / \mathrm{ml}$ rabbit anti-mouse IgM was added, directly followed by $2 \mu \mathrm{g} / \mathrm{ml}$ mouse anti-chicken IgM (M4) for $3 \mathrm{~min}$. If coactivation was to be compared to BCR activation alone, the control stimulation was done by adding $4 \mu \mathrm{g} / \mathrm{ml}$ $\mathrm{F}(\mathrm{ab})_{2}$ goat anti-mouse IgM, directly followed by $2 \mu \mathrm{g} / \mathrm{ml}$ mouse anti-chicken IgM (M4) for 3 min. If general protein phosphorylation was of interest, cells were starved for $10 \mathrm{~min}$ and then incubated for another $10 \mathrm{~min}$ after addition of the phosphatase inhibitor pervanadate (1:50). After stimulation cells were quickly centrifuged and kept on ice to stop activation.

\subsubsection{Immunoprecipitation}

To study protein-protein interactions or to purify a specific protein from a sample for further analysis, immunoprecipitation (IP) was performed. $2-3 \cdot 10^{7}$ cells were washed with PBS, resuspended in 700-1000 $\mu \mathrm{l}$ serum-free RPMI, starved at $37^{\circ} \mathrm{C}$ for $20 \mathrm{~min}$ with gentle shaking and stimulated as described above (see 2.2.3.1). If stimulationdependent processes were not of interest, starvation and stimulation were omitted. Cells were lysed in freshly prepared cold lysis buffer containing the nonionic detergents IGEPAL CA-630 (NP40) or lauryl maltoside which is especially useful to solubilize membrane proteins. Lysis was performed at $4{ }^{\circ} \mathrm{C}$ for $1 \mathrm{~h}$ with constant agitation. Lysates were cleared by centrifugation at full speed and $4{ }^{\circ} \mathrm{C}$ for $15 \mathrm{~min}$ and the supernatant was transferred to a new cold tube. A small amount of the cleared cellular lysate (CCL) was kept as a control for expression levels and to compare the amount of lysed cells. The remaining CCL was subjected to IP with the antibody of choice. Working concentrations were $0.7 \mu \mathrm{g} / \mathrm{ml}$ for anti-GFP IP, $0.2 \mu \mathrm{g} / \mathrm{ml}$ for anti-HA IP and $1 \mu \mathrm{g} / \mathrm{ml}$ for anti-Shc IP. IP was performed over night at $4{ }^{\circ} \mathrm{C}$ with constant agitation. This was followed by the addition of $20 \mu$ protein A/G-agarose (Santa Cruz Biotechnology, $50 \%$ slurry) to precipitate the antibody used for IP and everything that has bound to it. Three washing steps with cold lysis buffer ( $250 \mathrm{~g}, 4{ }^{\circ} \mathrm{C}, 4 \mathrm{~min}$ ) were done to break nonspecific interactions. The agarose with the precipitated proteins was then boiled with reducing $2 \times$ Laemmli sample buffer at $95{ }^{\circ} \mathrm{C}$ for $3 \mathrm{~min}$ to elute the proteins from the agarose before loading on a sodium dodecyl sulfate (SDS) gel. 


\subsubsection{Affinity purification with GST fusion proteins}

Affinity purification (AP) allows the study of protein interactions based on a specific protein domain. It was essentially carried out similar to an IP (see 2.2.3.2), except for using a specific protein domain coupled to sepharose for precipitation. The preparation of the precipitating protein domains involved their recombinant expression in bacteria and their purification and coupling to a resin (see 2.2.3.8). The protein domains used were fused to glutathione-S-transferase (GST) which makes subsequent coupling to glutathione sepharose possible. For AP, $15 \mu$ g protein coupled to glutathione sepharose (GE Healthcare) was added to every sample and incubated overnight. Washing and elution were performed in the same manner as described for the IP.

\subsubsection{Affinity purification with biotinylated peptides}

For AP with biotinylated peptides (see table 2.7), cells were lysed as described above (see 2.2.3.2) and CCLs were incubated with $1.5 \mu \mathrm{M}$ biotinylated peptide for $1 \mathrm{~h}$ at $4{ }^{\circ} \mathrm{C}$ with constant agitation. $25 \mu \mathrm{l}$ streptavidin sepharose (GE Healthcare)/sample were added and samples were incubated for $45 \mathrm{~min}$ at $4{ }^{\circ} \mathrm{C}$ with constant agitation. The samples were washed and eluted as described in 2.2.3.2.

\subsubsection{Purification of EGFP-labeled proteins for subsequent mass spectrometry analysis}

In this study, SHIP-deficient cells reconstituted with plasmids encoding for either SHIPwt-EGFP or EGFP were grown in SILAC medium (see 2.2.2.6), stimulated as described above (see 2.2.3.1) and lysed in $0.75 \%$ NP40-lysis buffer. They were then purified using the $\mu$ MACS GFP Tagged Protein Isolation Kit, which makes use of magnetic anti-GFP beads. Proteins were eluted with $95^{\circ} \mathrm{C}$ warm NuPAGE LDS Sample Buffer supplemented with NuPAGE reducing agent (Invitrogen). The eluates were pooled at a 1:1 ratio. Subsequent gel electrophoresis, in-gel digestion with trypsin and mass spectrometry analysis were performed in cooperation with Prof. Dr. Henning Urlaub (Max Planck Institute for Biophysical Chemistry Göttingen, Bioanalytical Mass Spectrometry Group) and Thomas Oellerich as described in (Oellerich et al., 2009). Two purifications were also performed without previous SILAC. In these cases, two samples, i.e. SHIP-EGFP versus EGFP, were prepared, treated separately at all times, and compared with each other. 


\subsubsection{SDS PAGE and western blot}

SDS polyacrylamide gel electrophoresis (PAGE) allows the separation of proteins according to their size (Weber \& Osborn, 1969). Glass plates for casting the gels were assembled according to the manufacturer's instructions. First, the components for a resolving gel of the desired acrylamide concentration (Sambrook \& Russell, 2000) were mixed and poured between the glass plates. Overlay with isopropanol flattens the gel surface and prevents oxygen from diffusing into the gel. After gel polymerization, the overlay was washed away and the stacking gel solution (Sambrook \& Russell, 2000) was poured on top of the polymerized resolving gel. A comb was inserted between the glass plates. After polymerization of the stacking gel, the gel was put into the electrophoresis apparatus and the inner and outer chamber were filled with SDS PAGE running buffer. Denatured protein samples that have been heated for $3 \mathrm{~min}$ at $95{ }^{\circ} \mathrm{C}$ were loaded into the wells and electrophoresis was started at a current of $10 \mathrm{~mA} / \mathrm{gel}$. Once the dye front had migrated into the resolving gel, the current was increased to $20 \mathrm{~mA} / \mathrm{gel}$. By using markers of known molecular weight, in this case Prestained Protein Marker (New England Biolabs) or Page Ruler Plus Prestained protein Ladder (Thermo Scientific), the size of the proteins could be determined. After electrophoresis, the proteins were either stained with Coomassie (see table 2.10) or transferred to a nitrocellulose membrane by semi-dry western blot (Towbin et al., 1989). Gel, nitrocellulose membrane and absorbent blotting paper were equilibrated in blotting buffer for a minute. Gel and nitrocellulose membrane were then sandwiched between blotting paper avoiding air bubbles and placed into a transfer unit where transfer of proteins from the gel to the membrane was done at $16 \mathrm{~V}$ and $140 \mathrm{~mA}$ for $50-75 \mathrm{~min}$. To avoid unspecific background binding of antibodies to the membrane, the membrane was blocked with $5 \%$ bovine serum albumin (BSA) in TBS-T for $1-3 \mathrm{~h}$ at $4{ }^{\circ} \mathrm{C}$ with constant agitation. Primary antibodies according to table 1 were diluted in TBS-T with $1 \% \mathrm{BSA}, 0.01 \% \mathrm{NaN}_{3}$ and incubation was done overnight at $4{ }^{\circ} \mathrm{C}$ with constant agitation. After three washing steps with TBS-T, the membrane was incubated with HRP-conjugated secondary antibody, diluted in TBS-T, for $50 \mathrm{~min}$ and then washed again three times with TBS-T. The membrane was developed using a homemade enhanced chemiluminescence (ECL) system (see table 2.11) which exploits the fact that HRP catalyzes the reaction of an ECL substrate into a product that will be oxidized by $\mathrm{H}_{2} \mathrm{O}_{2}$ into a light-emitting end product. Emanating chemiluminescence was detected using the ChemoCam Imager and transformed into a digital image. If the membrane was to be incubated with another primary antibody derived from another species than 
the first antibody, the HRP on the membrane was inactivated by incubation with 1\% $\mathrm{NaN}_{3}$ in TBS-T for at least $1 \mathrm{~h}$, followed by extensive washing.

Table 2.11: ECL buffers.

\begin{tabular}{l|l|l}
\hline Component & Composition & $\begin{array}{l}\text { Amount needed } \\
\text { for ECL reaction }\end{array}$ \\
\hline Solution A & $\begin{array}{l}200 \mathrm{ml} 0.1 \mathrm{M} \text { Tris/HCl (pH 8.6), 50 mg } \\
\text { Luminol sodium salt (Sigma); stored at } 4{ }^{\circ} \mathrm{C}\end{array}$ & $4 \mathrm{ml}$ \\
Solution B & $\begin{array}{l}11 \mathrm{mg} \text { para-hydroxycoumarin acid (Sigma), } \\
10 \mathrm{ml} \text { DMSO; stored in the dark }\end{array}$ & $0.4 \mathrm{ml}$ \\
$\mathrm{H}_{2} \mathrm{O}_{2}(35 \%)$ & $1.2 \mu \mathrm{l}$ \\
\hline
\end{tabular}

\subsubsection{Far western blot}

In far western blot, the membrane is probed with a non-antibody protein (Edmondson \& Dent, 2001). Here, samples for far western blot were prepared by immunoprecipitation (see 2.2.3.2), separated electrophoretically and transferred on nitrocellulose membrane. All following incubation and washing steps were performed at $4{ }^{\circ} \mathrm{C}$. The membrane was blocked with $4 \%$ milk powder (Roth) in PBS-T overnight with constant agitation. The membrane was washed three times with PBS-T and then probed with $50 \mu \mathrm{g}$ of a GSTtagged protein domain diluted in PBS-T for $1.5 \mathrm{~h}$. After three washing steps the membrane was immunoblotted with an anti-GST antibody (1:3000, in PBS-T) for $1.5 \mathrm{~h}$, washed again three times, incubated with a secondary HRP-conjugated antibody for 50 min, washed and developed as described above (see 2.2.3.6).

\subsubsection{Protein Expression and Purification}

Protein domains used for APs were recombinantly expressed in E. coli BL21 making use of the lac operon of E. coli for gene regulation (Zubay, 1973). For ease of purification, the protein domains were expressed as GST fusion proteins. $100 \mathrm{ml} \mathrm{LB}$ medium was inoculated with $4 \mathrm{ml}$ of overnight culture containing E. coli BL21 carrying a plasmid encoding the fusion protein of choice. At an $\mathrm{OD}_{600}$ of 0.5 to 0.8 the lacoperon was induced by the addition of $0.1 \mathrm{mM}$ isopropyl $\beta$-D-1-thiogalactopyranoside (IPTG). The culture was grown with constant agitation for several hours. The optimal induction time, which resulted in highest yield, had been determined beforehand for 
every newly designed fusion protein and was approximately 4-5 h. Except for bacteria producing GST-SHIP[SH2], which were grown at $25{ }^{\circ} \mathrm{C}$ to prevent the protein being contained in inclusion bodies, all cultures were grown at $37^{\circ} \mathrm{C}$. After the induction time, bacteria were centrifuged at $5000 \mathrm{~g}$ and $4{ }^{\circ} \mathrm{C}$ for $20 \mathrm{~min}$, lysed in $20 \mathrm{ml}$ bacteria lysis buffer and sonicated on ice 3 times for 30 s with 55 \% intensity. Triton-X100 was added to a final concentration of $1 \%$ and the lysate was incubated for $10 \mathrm{~min}$ on ice. Cell debris was pelleted by centrifugation for $45 \mathrm{~min}$ at $5000 \mathrm{~g}$ and at $4{ }^{\circ} \mathrm{C}$. The cleared lysate was transferred to a fresh tube and incubated rotating at $4{ }^{\circ} \mathrm{C}$ overnight with $200 \mu \mathrm{l}$ glutathione-sepharose (50\% slurry, GE Healthcare). It was washed three times with lysis buffer (500 g, $4{ }^{\circ} \mathrm{C}, 4 \mathrm{~min}$ ) and reconstituted with lysis buffer to $50 \%$ slurry. If fusion proteins were to be used for far western blot analysis (see 2.2.3.7), they had to eluted from the sepharose beads. This was done by adding $150 \mu$ l elution buffer (50 mM Tris/ $\mathrm{HCl}$ (pH 8.0), $10 \mathrm{mM}$ reduced glutathione), incubating for $15 \mathrm{~min}$ at $4{ }^{\circ} \mathrm{C}$ with constant agitation, pelleting the beads and collecting the supernatant. This elution step was repeated once and the supernatants were pooled.

\subsubsection{Determining protein concentration}

Protein concentration was determined by running the samples on a SDS gel together with samples containing known concentrations of BSA. The proteins were visualized by placing the gel into a Coomassie solution for $1 \mathrm{~h}$ on a shaker at room temperature. Coomassie binds only to proteins and nonspecifically bound Coomassie can be washed away with tab water or Coomassie destaining solution.

\subsubsection{Flow cytometry}

\subsubsection{Measurement of intracellular $\mathrm{Ca}^{2+}$ concentrations}

The mobilization of $\mathrm{Ca}^{2+}$ from the endoplasmatic reticulum was used as a readout throughout this study. Here, Indo-1, a ratiometric fluorescent indicator dye for calcium concentrations was used (Grynkiewicz et al., 1985). When excited with an ultraviolet laser, Indo-1 emits light at about $475 \mathrm{~nm}$ when not bound to $\mathrm{Ca}^{2+}$. Binding of $\mathrm{Ca}^{2+}$ shifts the emission to about $400 \mathrm{~nm}$. The change in emission observed after activation of the cell can be observed by flow cytometry. Because ratio analysis is possible, this method is very robust towards uneven loading of the cells with the dye, photobleaching and leakage. For $\mathrm{Ca}^{2+}$ monitoring it is important that the cells to be analyzed were cultured 
at a similar density. $1.5 \cdot 10^{6}$ DT40 cells were resuspended in pre-warmed $700 \mu$ RPMI containing 5 \% FCS and loaded with $1 \mu \mathrm{M}$ Indo-1 AM (Molecular Probes) and $0.015 \%$ Pluronic F127 (Molecular Probes) at $30{ }^{\circ} \mathrm{C}$ for 25 min with gentle shaking. Using the acetoxymethylester (AM) version of Indo-1 prevents the dye from leaving the cell again because the AM will be cleaved by intracellular esterases. The suspension was then diluted by the addition of $700 \mu$ pre-warmed RPMI containing $10 \%$ FCS and incubated for $10 \mathrm{~min}$ at $37^{\circ} \mathrm{C}$. The cells were washed once with Krebs Ringer solution containing $1 \mathrm{mM} \mathrm{CaCl}_{2}$ and resuspended in the same solution. They were kept at $26^{\circ} \mathrm{C}$ until measurement. To activate the cells and provoke changes in intracellular $\mathrm{Ca}^{2+}$ concentrations, cells were stimulated with $2 \mu \mathrm{g} / \mathrm{ml}$ M4. Coactivation of BCR and Fc $\gamma$ RIIB was done by adding $6 \mu \mathrm{g} / \mathrm{ml}$ rabbit anti-mouse IgM, followed by the addition of $2 \mu \mathrm{g} / \mathrm{ml} \mathrm{M} 4$ as soon as the base line was recorded. In the respective control experiment, the intact anti-mouse antibody was replaced by $4 \mu \mathrm{g} / \mathrm{ml}\left(\mathrm{Fab}^{\prime}\right)_{2}$ goat antimouse IgM. The change in the ratio of fluorescence intensities that could be observed after stimulation was recorded on an LSRII cytometer (Becton Dickinson). Data were analyzed using FlowJo. Generally, if cells expressing EGFP-labeled proteins were to be analyzed, only the EGFP-positive population was included in the analysis.

\subsubsection{Analysis of expression levels by flow cytometry}

To analyze expression of cell surface molecules, flow cytometry was performed. In this study, expression of BCR, Fc $\gamma$ RIIB and CD8 chimeras was of interest. Approximately $1 \cdot 10^{6}$ cells were harvested, washed with cold PBS and incubated with the primary antibodies at concentrations indicated in table 2.1 for 30 min in the dark on ice. They were washed once with cold PBS and, if necessary, incubated with a fluorophoreconjugated secondary antibody for $20 \mathrm{~min}$ in the dark on ice, followed by washing with cold PBS. Measurements were carried out using either an LSRII cytometer (Becton Dickinson) or a FACS Calibur (Becton Dickinson). Data were analyzed using FlowJo.

\subsubsection{Microscopy}

\subsubsection{Recruitment assay}

To study the subcellular localization of fluorophore-labeled proteins, confocal microcopy was carried out. Cells were harvested, washed once with Krebs-Ringer solution containing $1 \mathrm{mM} \mathrm{CaCl}$, resuspended in $200 \mu \mathrm{l}$ Krebs-Ringer solution 
containing $1 \mathrm{mM} \mathrm{CaCl}_{2}$ and seeded on chambered cover glasses at a concentration of $0.3 \cdot 10^{6}$ cells/well. To investigate the localization of primary cells expressing fluorophore-labeled proteins, they were seeded on poly-D-lysine coated glass-bottom culture dishes. Cells were allowed to settle on the glass before analysis at a Leica TCS SP2 confocal laser scanning microscope which is based on the Leica DM IRB inverted microscope. A HCX PL APO 63x1.32 oil objective was used for analysis. Cells were stimulated by the addition of antibody at concentrations described in 2.2.3.1, in a volume of $40 \mu$ l. Images were taken using Leica confocal software before and at defined times after stimulation at a focus level corresponding to the widest cell diameter. Every line was scanned eight times. This kind of analysis involves several drawbacks. First, EGFP bleached slightly during the course of the measurement. Second, the expression level of fluorophore-labeled proteins varied in transfected cells. And third, minor differences between different setups were difficult to detect in an unbiased way with the naked eye. Therefore, images were subjected to analysis with ImageJ and a relative recruitment index (RRI) was calculated. The RRI was calculated as:

$$
R R I=\frac{(\text { MFI at plasma membrane/ MFI in cytosol })_{\text {stimulated cells }}}{(\text { MFI at plasma membrane/ MFI in cytosol })_{\text {unstimulated cells }}}
$$

MFI: mean fluorescence intensity

RRI calculation was done with background-subtracted images. Statistical significance was determined using Student's t-test.

\subsubsection{Generation of planar lipid bilayers}

Planar lipid bilayers containing anti-chicken IgM (clone M1) as surrogate antigen were prepared in FCS2 chambers as described (Carrasco et al., 2004). Biotinylated 1,2dioleoyl-phosphatidylcholine (DOPC) was diluted in unlabeled DOPC (Avanti Polar Lipids, Inc.) 1:500-1:1000. The lipids were dropped on the microaqueduct slide of an FCS2 chamber, which was subsequently assembled and blocked with blocking buffer (PBS supplemented with $0.5 \%$ FCS, $2 \mathrm{mM} \mathrm{Mg}^{2+}, 0.5 \mathrm{mM} \mathrm{Ca}^{2+}, 1 \mathrm{~g} / \mathrm{l} \mathrm{D}$-glucose) for 45 min. Lipid bilayers were incubated with Alexa Fluor 633-conjugated strepatividin (Invitrogen) in blocking buffer for $5 \mathrm{~min}$. Following washing, streptavidin coupled to biotinylated lipids was loaded with mono-biotinylated anti-chicken IgM for 5 min. After 
washing of excess antibody, loaded bilayers were heated to $37^{\circ} \mathrm{C}$ and directly used for imaging.

\subsubsection{Total internal reflection microscopy (TIRFM)}

In order to reach higher effective magnification, total internal reflection fluorescence microscopy (TIRFM (Schneckenburger, 2005)) was used to study plasma membrane localization of SHIP. TIRFM makes use of an evanescent wave, which enters the specimen at very close proximity to the glass coverslip (up to $200 \mathrm{~nm}$ penetration depth). This allows for high-resolution analysis of plasma membrane regions because of an improved signal-to-noise ratio. Two-color acquisition enabled visualization of fluorescently-labeled anti-chicken IgM molecules, which directly show the distribution of the BCR, as well as of fluorophore-labeled SHIP molecules at the same time. Imaging was done using lipid bilayers (see 2.2.5.2). DT40 cells were harvested, resuspended in blocking buffer at a density of approximately $10^{7}$ cells $/ \mathrm{ml}$ and injected into a FCS2 chamber warmed to $37^{\circ} \mathrm{C}$. TIRFM was performed using an Olympus TIRFM system as described (Treanor et al., 2010). Images were recorded using xcellence software (Olympus) and analyzed using Imaris (Bitplane). Images were cropped to single cells and background subtracted using a filter width of $1 \mu \mathrm{m}$. Based on the fluorescence intensities of the anti-chicken IgM antibodies and the fluorescentlylabeled SHIP, the original as well as a thresholded Mander's coefficient were calculated using the Imaris colocalization module (Manders et al., 1993). Statistical significance was determined using Student's t-test. In this study, the thresholded Mander's A coefficient was used to compare data. It is calculated as follows:

Thresholded Mander's $A=\sum S_{A i} S_{B c o l o c} / \sum S_{A i}$

$\mathrm{S}_{\mathrm{Ai}}=$ channel A (SHIP-EGFP) intensity

$\mathrm{S}_{\mathrm{Bcoloc}}=1$ if $\mathrm{S}_{\mathrm{Bi}}>$ thresholded $\mathrm{B}$, otherwise $\mathrm{S}_{\mathrm{Bcoloc}}=0$

$\mathrm{S}_{\mathrm{Bi}}=$ channel B (antibody-bound BCR) intensity

Generation of lipid bilayers as well as TIRFM were done in cooperation with Tim Schnyder and Facundo Batista (Lymphocyte Interaction Laboratory, Cancer Research UK, London, UK). 


\section{Results}

\subsection{FcyRIIB-independent recruitment and activation of SHIP}

The inositol phosphatase SHIP contributes substantially to the negative regulation of B cells. Immune complexes coactivate both the BCR and the FcyRIIB. This results in SHIP recruitment to the Fc $\gamma$ RIIB and SHIP activation. Several studies have indicated though, that SHIP is also activated following BCR engagement alone. However, the molecular mechanism of SHIP activation in the absence of Fc $\gamma$ RIIB activation is still unknown. The goal of this study was to verify this independency and to identify the underlying mechanism. Therefore, FcyRIIB-independent SHIP activation was analyzed in primary cells as well as in the model system used throughout this study, the chicken B cell line DT40.

\subsubsection{SHIP is FcyRIIB-independently recruited in primary B cells}

SHIP recruitment to the plasma membrane is a prerequisite for its catalytic function because its substrate PtdIns $(3,4,5) \mathrm{P}_{3}$ is part of the inner leaflet of the plasma membrane. Therefore, the analysis of SHIP localization by confocal microscopy is a valuable readout for SHIP activation. In order to analyze the process of recruitment in primary B cells, LPS-stimulated B cells isolated from mouse spleen were transiently transfected with plasmids encoding SHIPwt-EGFP. For stimulation of mouse B cells, a F(ab’) fragment of an anti-BCR antibody was used to prevent coactivation of the FcyRIIB, which is expressed on primary mouse B cells. Translocation of SHIP from the cytosol to the plasma membrane could be observed after stimulation (Figure 3.1). 


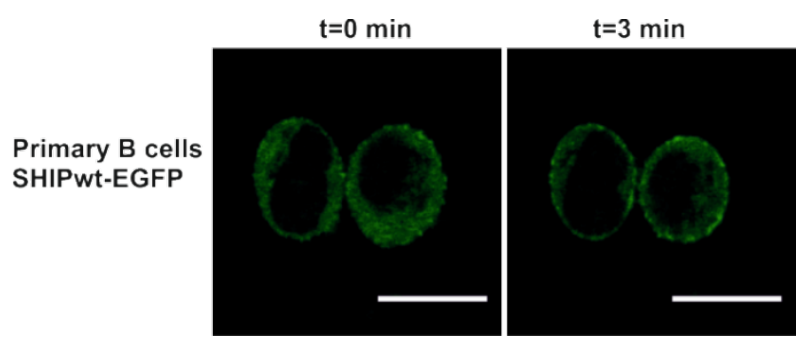

Figure 3.1: FcyRIIB-independent recruitment of SHIP to the plasma membrane in primary cells. LPS-stimulated primary B cells from C57BL/6 were transfected with plasmids encoding SHIPwt-EGFP. Cells were allowed to settle on glass coverslips and analyzed by confocal microscopy before (0 min) and after activation by the addition of $\mathrm{F}(\mathrm{ab})_{2}$ goat anti-mouse IgG+IgM (3 min). Images are representative for 15 cells. Scale bars $=5 \mu \mathrm{m}$.

\subsubsection{DT40 cells are a suitable model system}

DT40 cells do not express endogenous FcrRIIB, which was described to be the only identified Fc $\gamma$ receptor expressed on B cells (reviewed in Davis et al., 2005; Nimmerjahn \& Ravetch, 2008). They therefore provide an ideal model system to study BCR-autonomous SHIP activation. To investigate the subcellular localization of SHIP, a construct encoding for an EGFP-fusion protein was used (kindly provided by X. Li). In order to test whether the EGFP-tag had any influence, SHIP-deficient DT40 cells reconstituted with plasmids encoding SHIPwt or SHIPwt-EGFP were loaded with the $\mathrm{Ca}^{2+}$ indicator Indo-1 and analyzed by flow cytometry. Untagged SHIP and SHIP-EGFP were equally capable to regulate $\mathrm{Ca}^{2+}$ mobilization (Figure $3.2 \mathrm{~A}$ ), indicating that the tag did not influence SHIP function. Next, SHIP-deficient DT40 cells were reconstituted with plasmids encoding EGFP alone and compared to cells expressing SHIP-EGFP. The presence of SHIP lead to strongly decreased $\mathrm{Ca}^{2+}$-mobilization following BCR engagement as compared to cells expressing only EGFP (Figure 3.2 B), confirming findings by Okada and colleagues (Okada et al., 1998). 
A

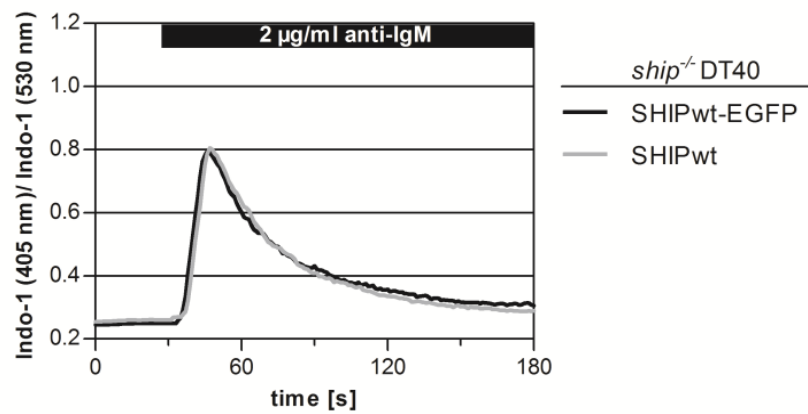

B

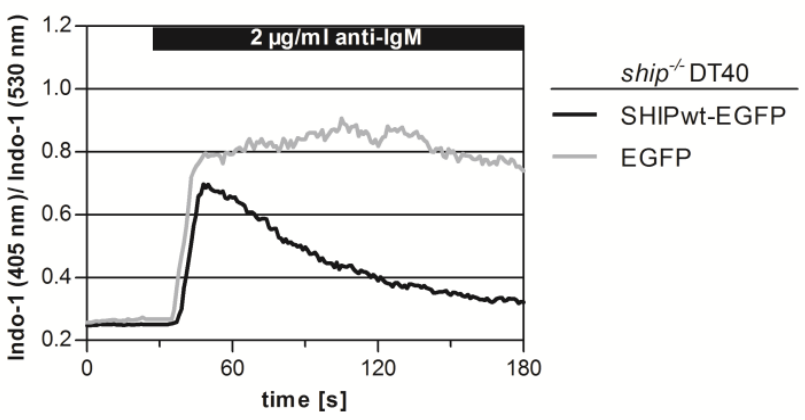

Figure 3.2: SHIP is functional in DT40 cells not expressing FcyRIIB. (A) SHIP-deficient DT40 cells were transfected with plasmids encoding SHIPwt-EGFP or untagged SHIPwt. Subsequently, cells were loaded with the $\mathrm{Ca}^{2+}$ indicator dye Indo-1. $\mathrm{Ca}^{2+}$ mobilization following stimulation with $2 \mu \mathrm{g} / \mathrm{ml}$ mouse anti-chicken IgM, which engages the BCR, was analyzed. The depicted graph is representative for 3 independent measurements. (B) SHIP-deficient DT40 cells were transfected with plasmids encoding SHIPwt-EGFP or EGFP and analyzed as described in (A). The graph shows a representative result of at least ten independent measurements.

The above described cells expressing EGFP-labeled SHIPwt were analyzed by confocal microscopy to study the BCR-induced plasma membrane recruitment of SHIP. In unstimulated cells, SHIP was mainly located in the cytoplasm (Figure 3.3, left side). Following stimulation with a BCR-engaging antibody, a significant fraction of cytosolic SHIP translocated to the plasma membrane (Figure 3.3, right side), further corroborating the fact that DT40 cells are a suitable model to study the process of BCRinduced recruitment. 


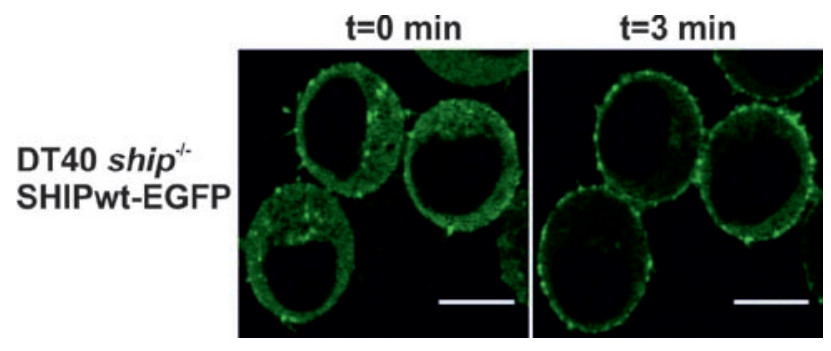

Figure 3.3: SHIP translocates to the plasma membrane following activation of the BCR alone. SHIP-deficient DT40 cells were transfected with plasmids encoding SHIPwt-EGFP. Cells were allowed to settle on glass coverslips and analyzed by confocal microscopy before $(0 \mathrm{~min})$ and after activation by the addition of mouse anti-chicken IgM antibody ( $3 \mathrm{~min}$ ). Images are representative for at least 50 cells. Scale bars $=5 \mu \mathrm{m}$.

Furthermore, it was possible to demonstrate phosphorylation of SHIP after engagement of the BCR alone. In order to compare this to phosphorylation induced by coactivation of the BCR and the FcyRIIB, a plasmid encoding this co-receptor had been introduced into SHIP-deficient DT40 cells by electroporation. One clone was chosen (cells kindly provided by $\mathrm{X}$. Li) and transfected with a plasmid encoding SHIPwt-EGFP. After activation of either the BCR alone or after BCR-FcyRIIB coactivation, anti-GFP immunoprecipitation (IP) was done to enrich SHIP in lysates and its phosphorylation was analyzed. Inducible SHIP phosphorylation after BCR activation was clearly visible (Figure 3.4, lane 2) and increased more after coactivation (Figure 3.4, lane 3). The coactivation protocol has been established before (Neumann, 2008). 


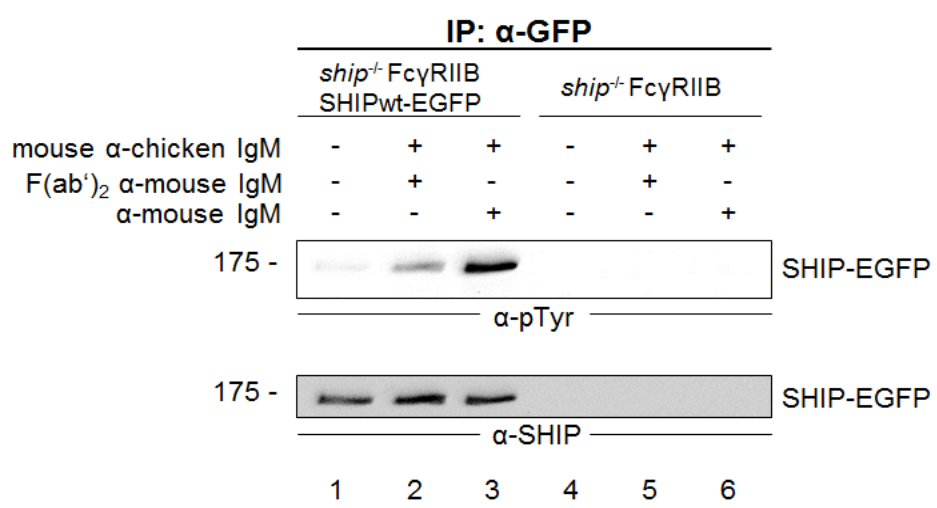

Figure 3.4: SHIP is phosphorylated after activation of the BCR alone. SHIP-deficient DT40 cells stably expressing Fc $\gamma$ RIIB after electroporation were transfected with plasmids encoding SHIPwt-EGFP (lanes 1-3) or left untransfected (lanes 4-6). They were either left unstimulated (lanes 1, 4), stimulated for 3 min with mouse anti-chicken IgM (M4) and F(ab’) $)_{2}$ anti-mouse IgM to engage only the BCR (lanes 2, 5) or with M4 and the intact anti-mouse IgM to activate both receptors (lanes 3,6). Cells were lysed and lysates were subjected to immunoprecipitation (IP) with anti-GFP antibody. After SDS-PAGE and western blot, phosphorylation of SHIP was analyzed by immunoblotting with anti-phosphotyrosine antibody ( $\alpha$-pTyr, upper panel). Pull-down efficiency had been assessed before by immunoblotting with anti-SHIP antibody (lower panel). Protein sizes are indicated in kDa. Data shown is representative for three independent experiments.

\subsubsection{FcyRIIB coactivation does not enhance BCR-induced SHIP recruitment}

After having proven that SHIP was recruited to the plasma membrane in positive signaling conditions, the next question addressed was whether BCR activation and BCR-Fc $\gamma$ RIIB coactivation resulted in different efficiencies of SHIP recruitment. The above described DT40 cells expressing Fc $\gamma$ RIIB and SHIPwt-EGFP (see 3.1.2) made it possible to compare the recruitment following BCR activation alone and following coactivation. Interestingly, no differences in plasma membrane localization of SHIP could be observed (Figure $3.5 \mathrm{~A}$ ). To facilitate quantification of the images and their comparison, the relative recruitment indices (RRI, explained in 2.2.5.1) were calculated and revealed indeed no significant difference between the RRIs in both stimulation conditions (Figure 3.5 B). As a control, SHIP-deficient DT40 cells expressing EGFP were stimulated via their BCR. EGFP should not be recruited and this was indeed the case as the RRI was approximately 1 . 
A

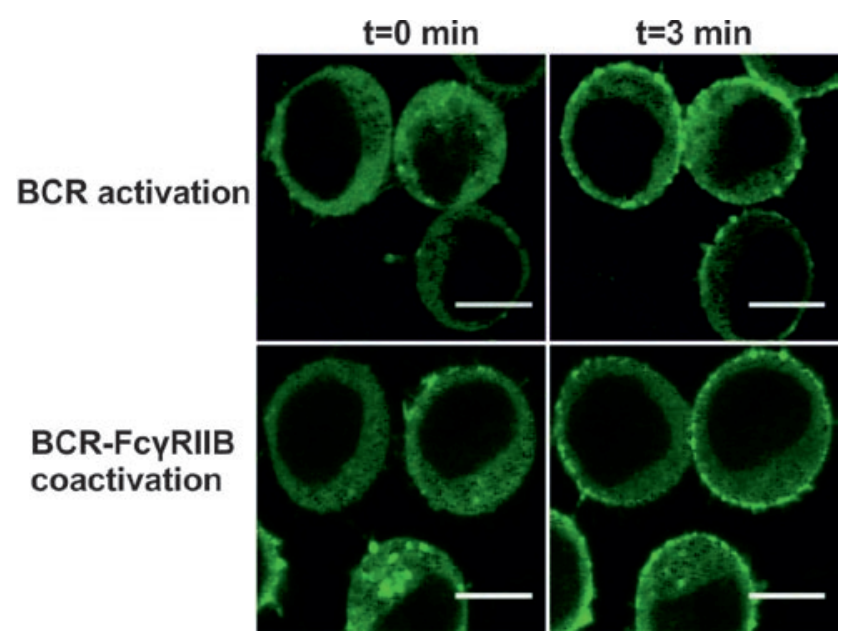

B

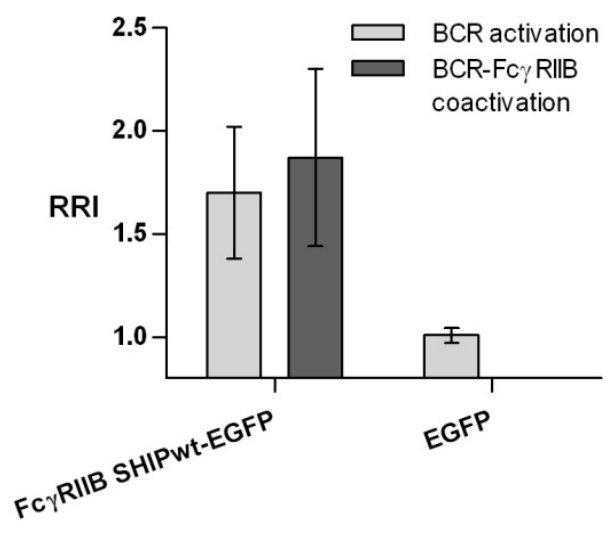

Figure 3.5: No quantitative difference in SHIPwt-EGFP recruitment following BCR activation alone or following BCR-FcyRIIB coactivation. (A) SHIP-deficient DT40 cells expressing the coreceptor Fc $\gamma$ RIIB were stably reconstituted with plasmids encoding SHIPwt-EGFP. They were allowed to settle on coverslips and analyzed by confocal microscopy. Images were acquired before and 3 min after stimulation with either mouse anti IgM and $\mathrm{F}(\mathrm{ab})_{2}$ anti-mouse IgM to engage only the BCR or with mouse anti-IgM and the intact anti-mouse IgM to activate both receptors. (B) Quantification of plasma membrane recruitment shown in (A). For comparison, SHIP-deficient DT40 cells expressing EGFP, stimulated via their BCR, were included in this diagram. Calculation of the relative recruitment index (RRI) is explained in 2.2.5.1. Briefly, the ratio of fluorescence intensity at the plasma membrane to fluorescence intensity in the cytosol in stimulated cells was divided by the same ratio of the very same cell before stimulation. Bars represent means from $n=40$ cells (+/- SD). Scale bars $=5 \mu \mathrm{m}$.

In summary, these experiments show that DT40 cells provide a valuable model system to study the activation of SHIP in the absence of Fc $\gamma$ RIIB. Moreover, after stimulation of the BCR alone, SHIP is recruited to the plasma membrane of DT40 cells to a comparable extent as after coactivation of the BCR and the Fc $\gamma$ RIIB.

\subsection{Structural requirements for FcyRIIB-independent SHIP activation}

The experiments presented above showed that SHIP is recruited to the plasma membrane and can inhibit the mobilization of $\mathrm{Ca}^{2+}$ in the absence of the Fc $\gamma$ RIIB. This led to the question how recruitment of SHIP is mediated in this case. The intent of the following part of this study was to answer this question using an approach based on the structural requirements of SHIP for this process. 


\subsubsection{The SH2 domain is required for recruitment, phosphorylation and inhibition of $\mathrm{Ca}^{2+}$ fluxes}

It was obvious to address the role of the SH2 domain in FcyRIIB-independent signaling as this is the domain mediating SHIP recruitment in the well-described process of BCRFc $\gamma$ RIIB-coactivation. In that case, the SH2 domain binds to the phosphorylated ITIM of the FcyRIIB. Experimentally, the SH2 domain can be inactivated by the amino acid exchange R34G (Liu et al., 1997a). The impact of the SH2 domain in positive signaling conditions was investigated by comparing cells expressing SHIPwt-EGFP or SHIPR34G-EGFP. Plasma membrane recruitment of SHIPR34G-EGFP was significantly reduced by about $65 \%$ but still detectable and higher than recruitment of EGFP alone (Figure 3.6 A, B). The effect on plasma membrane recruitment by inactivation of the $\mathrm{SH} 2$ domain was reflected by an impaired inhibition of $\mathrm{Ca}^{2+}$ mobilization which was, however, better than by EGFP alone, indicating that other domains must be important in this context, too (Figure 3.6 C).

A

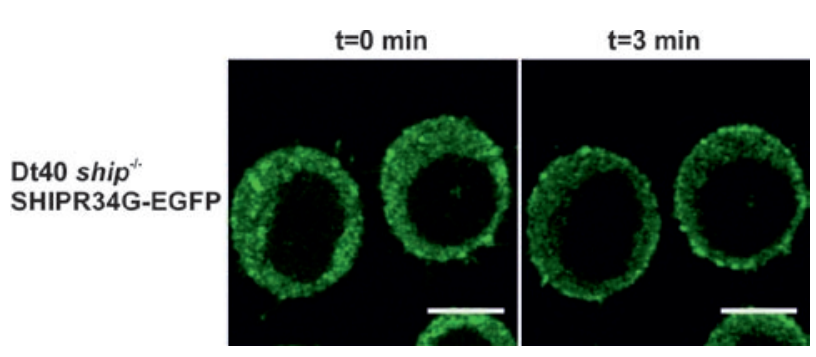

C

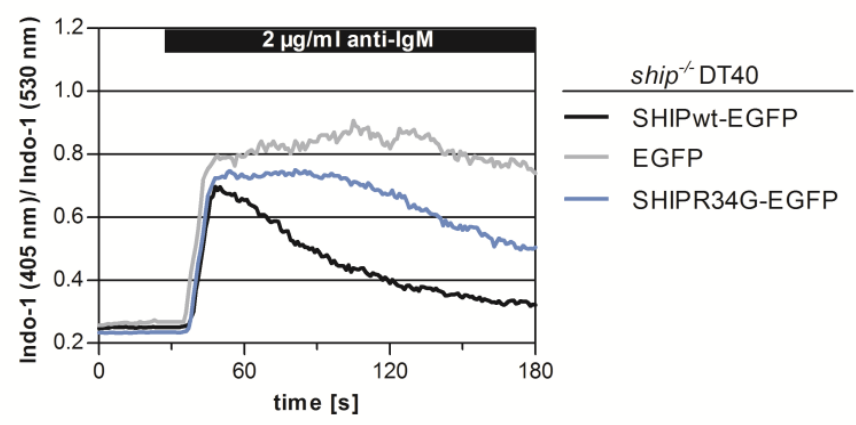

B

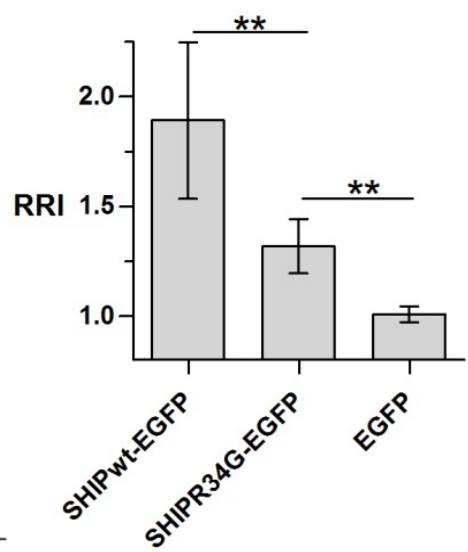

Figure 3.6: The SH2 domain is important for SHIP recruitment and function. (A) SHIP-deficient DT40 cells expressing SHIPR34G-EGFP after retroviral gene transfer were allowed to settle on glass coverslips. Images of SHIP localization were acquired before and 3 min after stimulation with antichicken IgM antibody. Scale bars $=5 \mu \mathrm{m}$. (B) Images were analyzed and RRIs were calculated as explained in figure legend 3.5. SHIPwt-EGFP and EGFP only were included for comparison. Bars represent means from $n=20$ cells ( $+/-S D)$. RRI, relative recruitment index. Student's $t$ test: ${ }^{* *} p<0.0001$. (C) Cells described in (A, B) were loaded with Indo-1 and the $\mathrm{Ca}^{2+}$ flux following stimulation with antichicken IgM antibody was analyzed. The graph shown is representative for at least 10 experiments. 
The effect of inactivating the SH2 domain was also analyzed in SHIP-deficient DT40 cells expressing Fc $\gamma$ RIIB that have been transfected with plasmids encoding SHIPR34G-EGFP. No significant difference in recruitment was observed following BCR activation alone and following BCR-Fc $\gamma$ RIIB coactivation (Figure 3.7). Recruitment was reduced compared to that of SHIPwt (Figure 3.5) but still detectable. This confirms experiments performed before that showed that the SH2 domain contributes to recruitment in positive signaling conditions. It further demonstrates that binding of the SH2 domain to the Fc $\gamma$ RIIB in negative signaling conditions has a similar effect on recruitment as has binding to the still unknown interaction partner in BCRautonomous signaling. However, DT40 cells normally do not express the FcyRIIB. In addition, it should be noted, that unless otherwise indicated, cells in this study were only activated using anti-BCR antibodies.

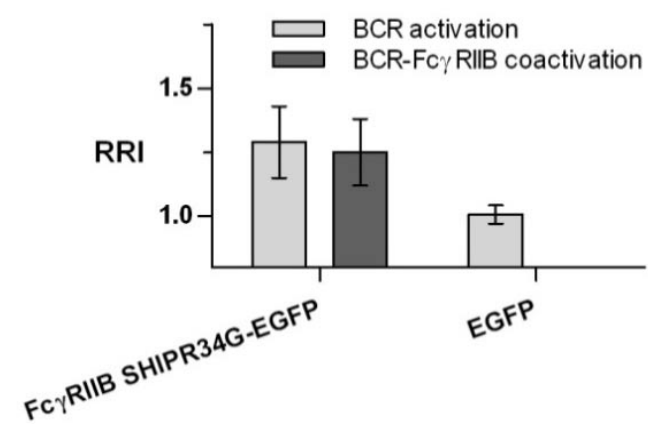

Figure 3.7: Inactivation of the SH2 domain does not lead to quantitative differences between SHIP recruitment following BCR activation alone and following coactivation. SHIP-deficient cells expressing the co-receptor Fc $\gamma$ RIIB were reconstituted with plasmids encoding SHIPR34G-EGFP and analyzed as described in figure legend 3.5. Bars represent means from $n=40$ cells (+/- SD). For comparison, SHIP-deficient DT40 cells expressing EGFP, stimulated via their BCR, were included in this diagram. RRI, relative recruitment index.

SHIP activation involves phosphorylation of its two NPXY motifs. In COS cells, SHIP was shown to be phosphorylated by membrane-localized Lyn (Phee et al., 2000). Reduced membrane recruitment of SHIPR34G led to the question whether inactivation of the SH2 domain results in impaired tyrosine phosphorylation. Indeed, almost no phosphorylation of SHIPR34G-EGFP could be observed (Figure 3.8, lanes 5, 6). 


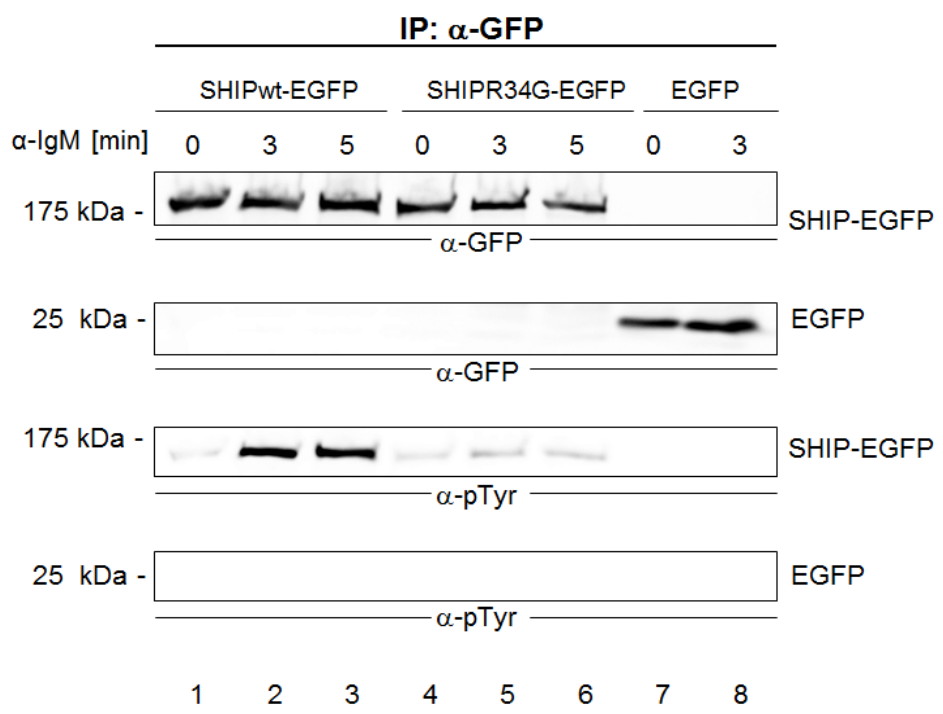

Figure 3.8: The SH2 domain is required for efficient SHIP phosphorylation. SHIP-deficient DT40 cells transfected with plasmids encoding SHIPwt-EGFP (lanes 1-3), SHIPR34G-EGFP (lanes 4-6) or EGFP (lanes 7-8) were starved in serum-free medium and left unstimulated (0) or were stimulated via their BCR for the indicated times. Cells were lysed and SHIP-EGFP was immunoprecipitated (IP) with anti-GFP antibody. Immunoprecipitates were analyzed by immunoblotting with anti-phosphotyrosine antibody ( $\alpha$-pTyr). The abundance of SHIP had been verified by anti-GFP immunoblotting. Protein sizes are indicated in $\mathrm{kDa}$. Data shown is representative for three independent experiments.

The experiments above demonstrate that the SH2 domain significantly contributes to BCR-induced recruitment of SHIP, its tyrosine phosphorylation as well as to the ability of SHIP to inhibit the mobilization of $\mathrm{Ca}^{2+}$.

\subsubsection{The NPXY motifs: Y1020 is functionally relevant}

The two NPXY motifs at Y917 and Y1020 are the main tyrosine phosphorylation sites in SHIP. Because a recurring theme in signal transduction cascades is the phosphorylation and dephosphorylation of proteins, their contribution to SHIP function was analyzed. SHIP-deficient cells were reconstituted with plasmids encoding for SHIPwt-EGFP, SHIPY917F-EGFP, SHIPY1020F-EGFP, SHIPY917F/Y1010F-EGFP (hereafter named SHIPYYFF-EGFP) or EGFP only. Confocal microscopy was carried out to investigate plasma membrane recruitment of these SHIP variants. The single mutation of Y917 had no significant effect when compared to SHIPwt (Figure 3.9 A, B). SHIPY1020F-EGFP, on the other hand, was significantly less recruited. The translocation of SHIPYYFF-EGFP to the plasma membrane was reduced by about $45 \%$ (Figure $3.9 \mathrm{~A}, \mathrm{~B}$ ). On the level of $\mathrm{Ca}^{2+}$ regulation, inactivation of both NPXY motifs 
resulted in significantly higher $\mathrm{Ca}^{2+}$ fluxes compared to SHIPwt-EGFP (Figure 3.9 C). This effect could be clearly ascribed to the second NPXY motif, Y1020, as mutation of this single motif resulted in a $\mathrm{Ca}^{2+}$ flux comparable to the situation when both NPXY motifs were mutated. Inactivating the more N-terminal NPXY motif Y917 did not change $\mathrm{Ca}^{2+}$ fluxes compared to cells expressing SHIPwt-EGFP.

A

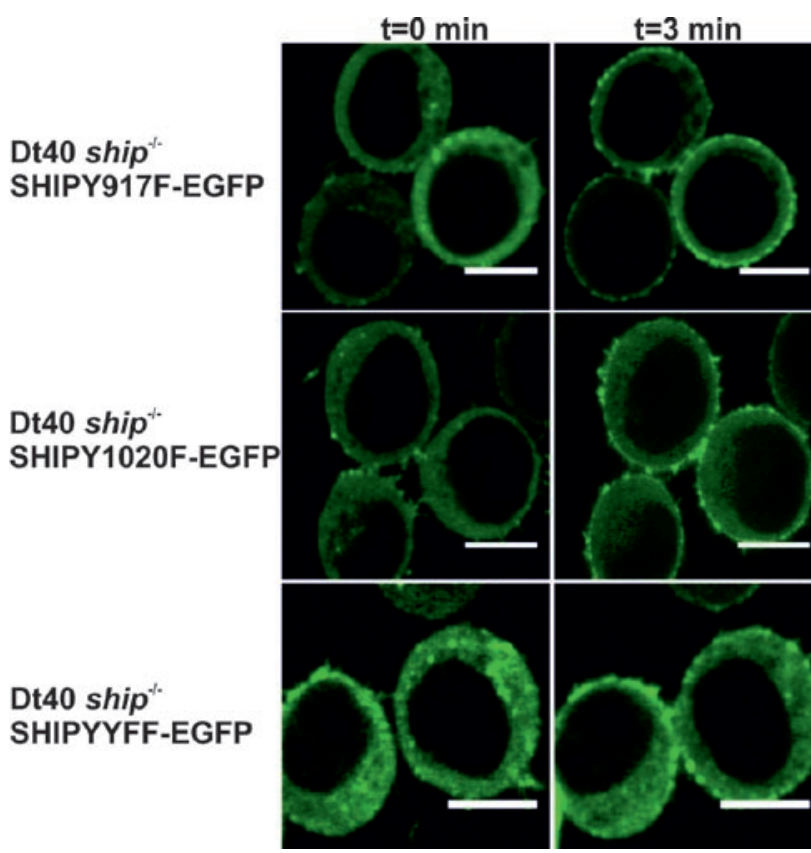

B

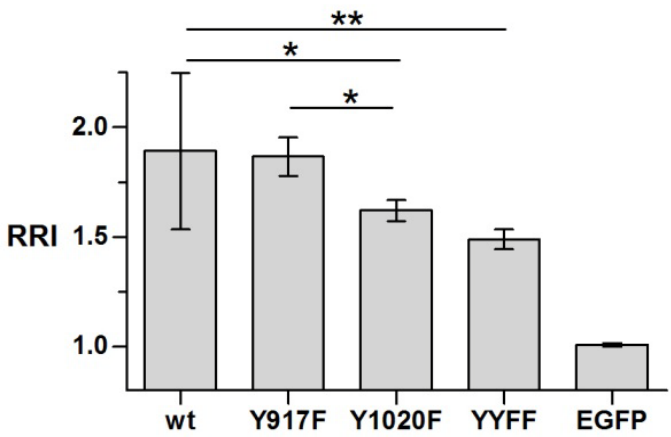

C

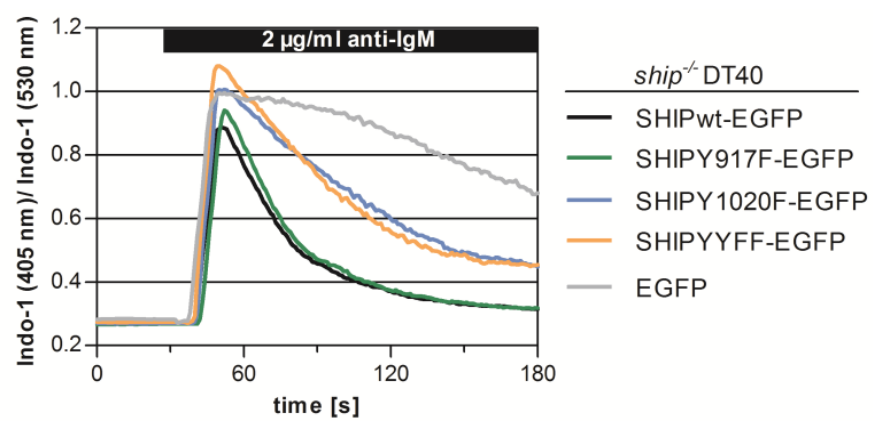

Figure 3.9: Y1020 is more important for SHIP recruitment and function than Y917. (A) SHIPdeficient cells were reconstituted with plasmids encoding SHIPY917F, SHIPY1020F or SHIPYYFF. The cells were analyzed by confocal microscopy before and $3 \mathrm{~min}$ min after stimulation with anti-chicken IgM antibody. Scale bars $=5 \mu \mathrm{m}$. (B) Images were analyzed and RRIs were calculated as explained in figure legend 3.5. SHIPwt-EGFP and EGFP only were included for comparison. Bars represent means from $n=20$ cells $\left(+/-\right.$ SD). RRI, relative recruitment index. Student's t test: ${ }^{*} p<0.05 ;{ }^{* *} p<0.0001$. (C) Cells described in (A, B) were loaded with the $\mathrm{Ca}^{2+}$ indicator Indo-1 and $\mathrm{Ca}^{2+}$ fluxes following BCR engagement were analyzed by flow cytometry. The graph shown is representative for four experiments. 
In summary, the more C-terminal NPXY motif, Y1020, contributes to SHIP plasma membrane recruitment and inhibition of $\mathrm{Ca}^{2+}$ mobilization, while inactivation of Y917 has no observable effect.

\subsubsection{The proline-rich regions are involved in SHIP activation}

SHIP has eight proline-rich regions, which were identified using the bioinformatics resource ELM. The motifs are distributed over the whole protein, but are concentrated in the C-terminus (Figure 3.10). Their function and binding partners are not known so far.

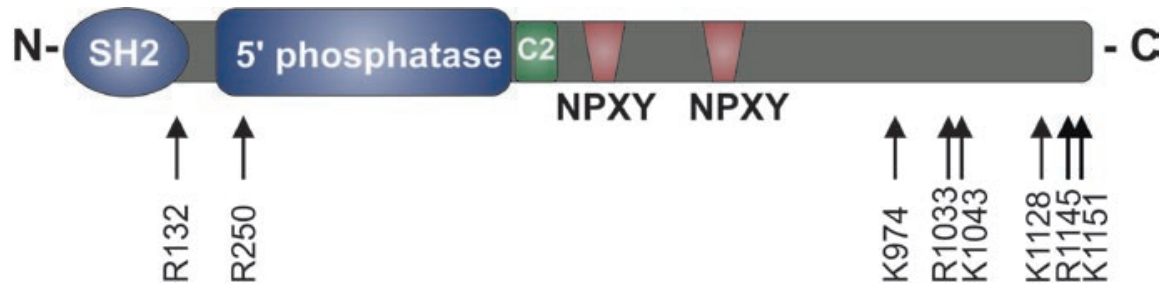

Figure 3.10: Schematic structure of SHIP indicating the location of proline-rich regions. Analyzed proline-rich regions are indicated by arrows and residues subjected to amino acid exchange are designated.

I performed mutageneses to inactivate the identified proline-rich regions and used the resulting constructs to transfect SHIP-deficient DT40 cells. Comparable EGFP expression levels were confirmed by flow cytometry (data not shown). These cells were then used to screen for defects in plasma membrane recruitment and in the inhibition of $\mathrm{Ca}^{2+}$ fluxes following BCR engagement. The most striking reduction in SHIP recruitment was observed after inactivation of the motif around T1139-R1145 and the motif encompassing P1146-K1151, which resulted in RRIs of 1.3, compared to an RRI of 1.9 for SHIPwt (Figure 3.11 A, B). Amino acid exchanges of R132A, K974A, R1033A and K1043A lead to slightly reduced recruitment, while R250A and K1128A had no significant effect (Figure 3.11 B).

It was then tested how these differences in plasma membrane recruitment translated into inhibition of $\mathrm{Ca}^{2+}$ mobilization. SHIP variants carrying the amino acid exchanges R250A, K974A, R1033A, K1043A, K1128A and R1145A reduced $\mathrm{Ca}^{2+}$ mobilization similar to SHIPwt (data not shown). Consistent with the reduced plasma membrane 
translocation, SHIPK1151A exhibited a weaker potential for signal inhibition indicating its importance for SHIP function (Figure 3.11 C). Moreover, SHIPR132A was also less efficient in inhibiting BCR-induced $\mathrm{Ca}^{2+}$ mobilization.

Some of the proline-rich regions analyzed comprised two consecutive critical residues. Therefore, double mutations were introduced in order to ensure inactivation of these proline-rich regions. However, double mutations did not change SHIP performance in the parameters analyzed here (data not shown).

A

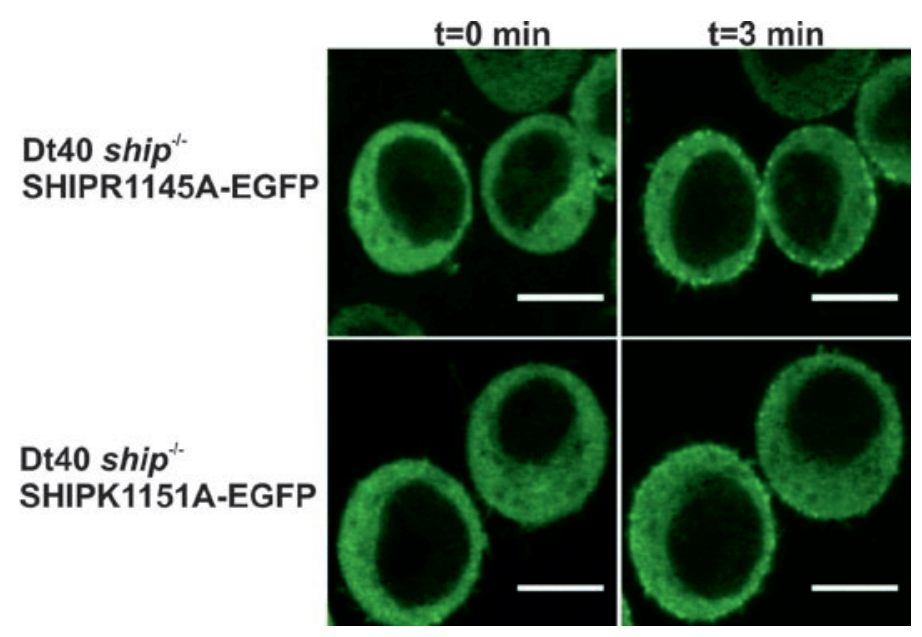

B

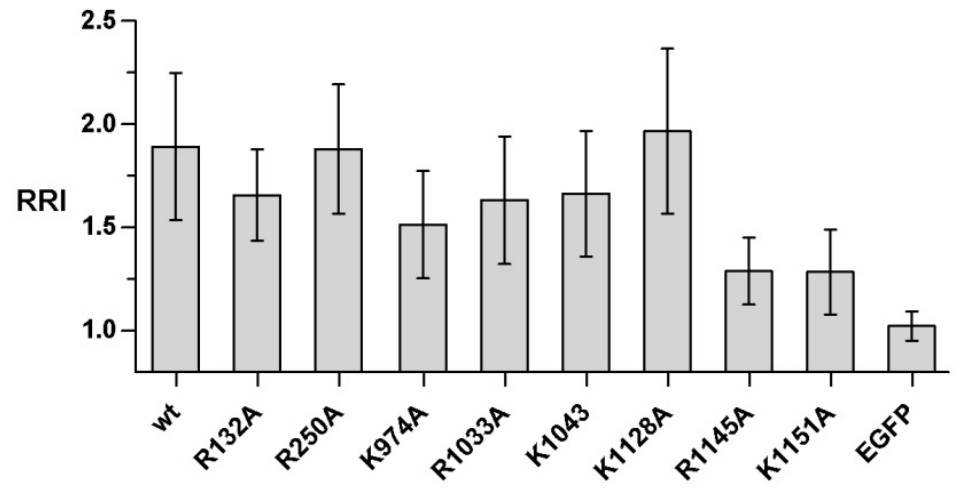

C

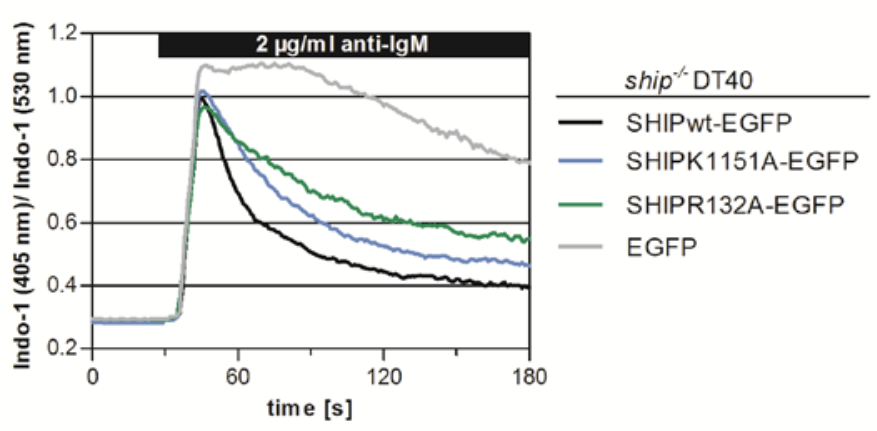

Figure 3.11: Screen of proline-rich regions for their impact on SHIP recruitment and function. For legend, see next page. 
Figure 3.11 (previous page): Screen of proline-rich regions for their impact on SHIP recruitment and function. (A) SHIP-deficient DT40 cells were transfected with plasmids encoding SHIPR1145AEGFP or SHIPK1151A-EGFP. The cells were analyzed by confocal microscopy before and 3 min after stimulation with anti-chicken IgM antibody. Scale bars $=5 \mu \mathrm{m}$. (B) SHIP-deficient DT40 cells were transfected with plasmids encoding EGFP-labeled wild-type SHIP or SHIP carrying the indicated mutations in proline-rich regions or EGFP alone. The cells were analyzed by confocal microscopy and RRIs were calculated as described for figure 3.5. Bars represent means from $n=20$ cells ( $+/-$ SD). RRI, relative recruitment index. (C) SHIP-deficient DT40 cells were transfected with plasmids encoding EGFP-labeled wild-type SHIP or SHIP carrying the indicated mutations in proline-rich regions or EGFP alone. They were loaded with the $\mathrm{Ca}^{2+}$ indicator Indo- 1 and $\mathrm{Ca}^{2+}$ fluxes following $\mathrm{BCR}$ engagement were analyzed by flow cytometry. Data shown is representative for three independent experiments.

Comparing plasma membrane recruitment of SHIP variants and their signal inhibition, K1151 seems to be the proline-rich region most essential for SHIP function. Interestingly, there is no clear correlation between plasma membrane recruitment and SHIP function as even strongly reduced recruitment of the SHIPR1145A variant does not translate into impaired inhibition of $\mathrm{Ca}^{2+}$ mobilization.

\subsubsection{The catalytic domain is not required for recruitment}

Theoretically, interaction between the catalytic domain of SHIP and its substrate PtdIns $(3,4,5) \mathrm{P}_{3}$ might contribute to plasma membrane recruitment. To assess this possibility, a catalytically inactive SHIP variant, SHIPD676G (Damen et al., 2001), was investigated. SHIP-deficient DT40 cells transfected with plasmids encoding SHIPwtEGFP, SHIPD676G-EGFP or EGFP alone were analyzed by confocal microscopy. The RRI of catalytically inactive SHIP was not decreased, but rather slightly elevated, showing that membrane recruitment does not depend on this interaction (Figure $3.12 \mathrm{~A}$ ). The BCR-induced $\mathrm{Ca}^{2+}$ flux revealed that catalytically inactive SHIPD676G was not able to efficiently inhibit the mobilization of $\mathrm{Ca}^{2+}$ (Figure $3.12 \mathrm{~B}$ ). However, a minor inhibition was still detectable, which was not the case if SHIP-deficient cells were transfected with plasmids encoding EGFP only. 
A

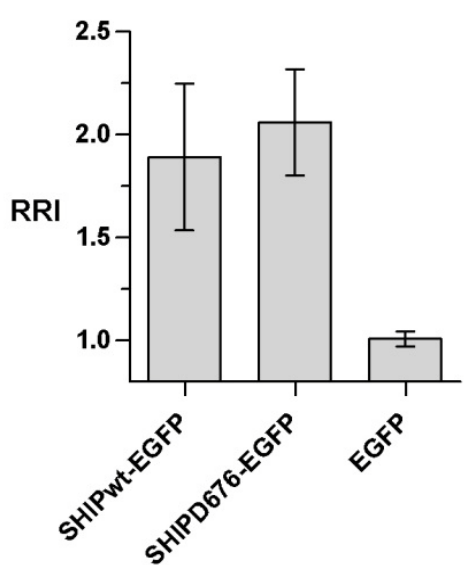

B

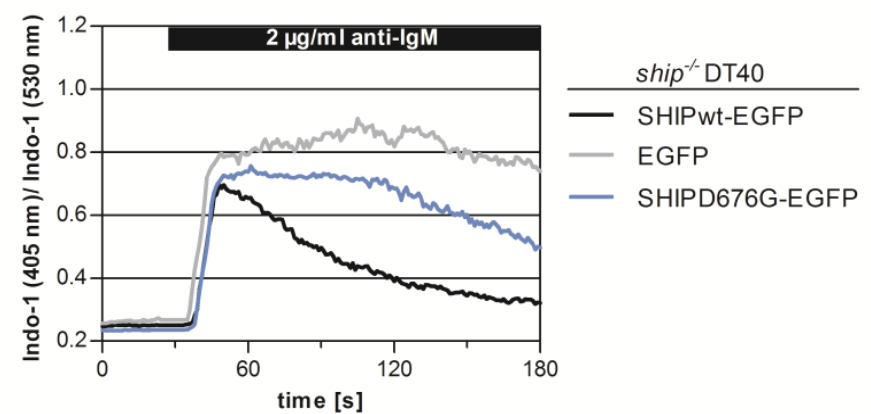

Figure 3.12: Interaction between the catalytic domain of SHIP and its substrate is not important for recruitment per se. (A) SHIP-deficient DT40 cells were transfected with plasmids encoding SHIPwtEGFP, SHIPD676G-EGFP or EGFP alone. They were allowed to settle on glass coverslips and images of SHIP localization were acquired before and 3 min after stimulation with anti-chicken IgM antibody. The images were analyzed and RRIs were calculated as described for figure 3.5. Bars represent means from $\mathrm{n}=20$ cells (+/- SD). RRI, relative recruitment index. (B) Cells described in (A) were loaded with Indo-1 and the $\mathrm{Ca}^{2+}$ flux following stimulation with anti-chicken IgM antibody was analyzed. The graph shown is representative for four experiments.

\subsubsection{SHIP activation has additive structural requirements}

The experiments described above showed the importance of the SH2 domain and the NPXY motifs for SHIP plasma membrane recruitment and function. Screening the proline-rich regions revealed that the region P1146-K1151 had the strongest impact in terms of recruitment and function. To analyze whether the defects observed for single mutations were additive, I generated SHIP constructs carrying combinations of mutations and used them to transfect SHIP-deficient cells. These cells were used for confocal microscopy analysis and $\mathrm{Ca}^{2+}$ flux analysis. Inactivation of the NPXY motifs in addition to the SH2 domain did not additionally impair recruitment of SHIPR34GEGFP (Figure $3.13 \mathrm{~A}$ ). Combining this double mutation with the amino acid exchange K1151A resulted in a mutant with strongly reduced plasma membrane recruitment, which almost reached levels of the negative control, the EGFP-expressing cells. Reduced recruitment of these variants was not due to a delayed response as the ratio of SHIP at the plasma membrane did not increase $10 \mathrm{~min}$ after stimulation (data not shown). This was slightly different when inhibition of $\mathrm{Ca}^{2+}$ mobilization was analyzed (Figure $3.13 \mathrm{~B}$ ). Here, the combined inactivation of the SH2 domain and the NPXY 
motifs clearly had additive effects and SHIP was not able to mediate inhibition of $\mathrm{Ca}^{2+}$ mobilization any more. The additional inactivation of the proline-rich region around K1151 had no extra effect. To exclude the possibility that differences might be ascribed to varying expression levels of BCR, surface expression of the BCR was examined as well and found to be comparable (data not shown).

A

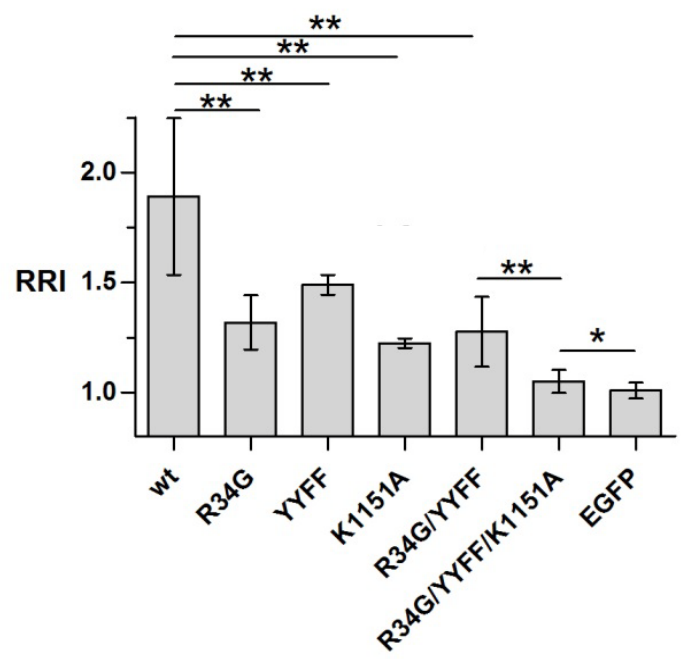

B

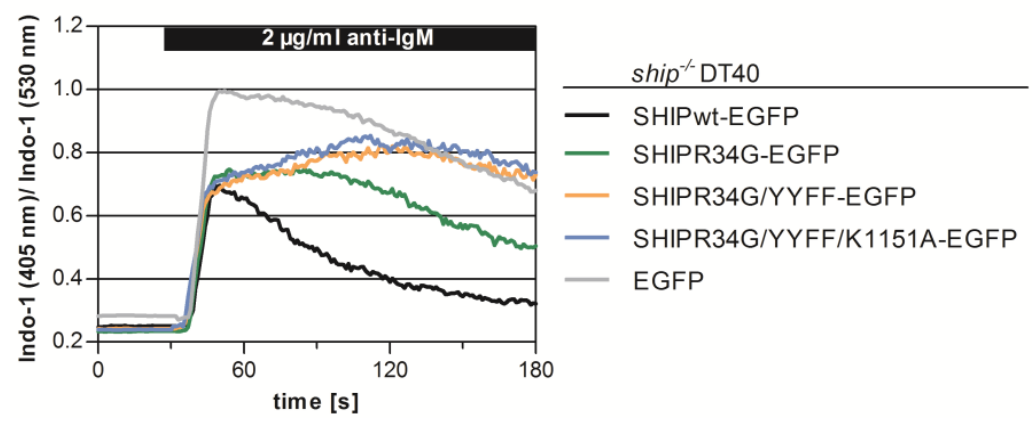

Figure 3.13: Consequences of the combined inactivation of several protein domains and motifs of SHIP. (A) SHIP-deficient DT40 cells expressing EGFP-labeled SHIPwt, SHIPR34G/YYFF, SHIPR34G/YYFF/K1151A or only EGFP after retroviral gene transfer were analyzed by confocal microscopy and RRIs were calculated as described in figure legend 3.5. Previous results obtained from SHIP carrying single mutations were included for ease of comparison. Student's $t$ test: ${ }^{*} \mathrm{p}<0.05$; ${ }^{* *} \mathrm{p}<0.0001$. (B) Cells described in (A) were used to analyze $\mathrm{Ca}^{2+}$ flux following BCR engagement by flow cytometry.

\subsubsection{SHIP recruitment in primary $B$ cells requires the same protein domains as in DT40}

To further test the impact of the SHIP SH2 domain, the NPXY motifs and the SH3 domain-binding motif at position K1151, primary mouse B cells were infected with 
retroviruses carrying plasmids encoding SHIPwt-EGFP, SHIPR34G-EGFP and EGFPtagged SHIP combining the three most relevant mutations, i.e. SHIPR34G/YYFF/K1151A. Confocal microscopy analysis revealed that inactivation of the SH2 domain clearly reduced translocation to the plasma membrane (Figure 3.14). No significant difference in recruitment could be observed between the triple mutant, which was hardly recruited in DT40 cells, and the negative control, EGFP only.

I hereby showed that the requirements for SHIP recruitment in primary B cells are similar to those in DT40 cells. These experiments underline the contribution of the SH2 domain for this process.

A

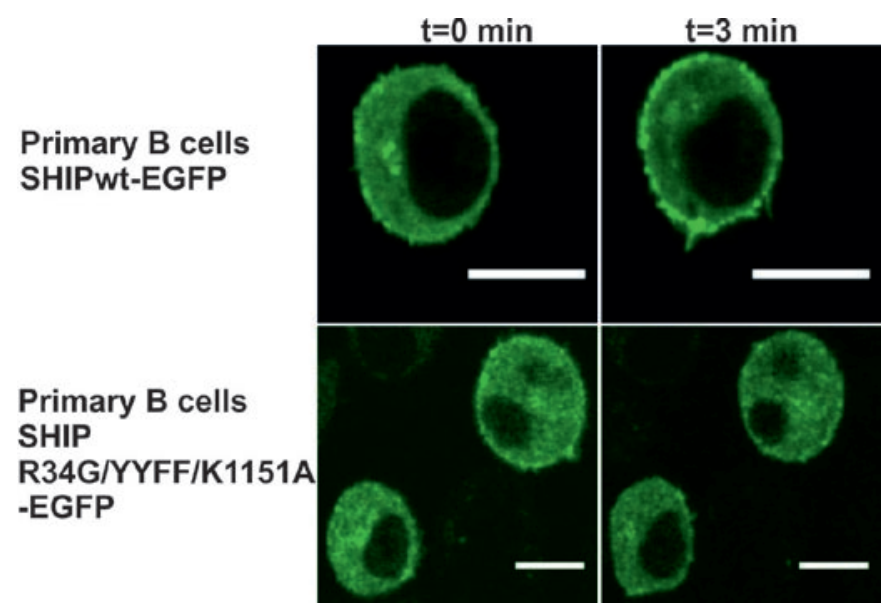

B

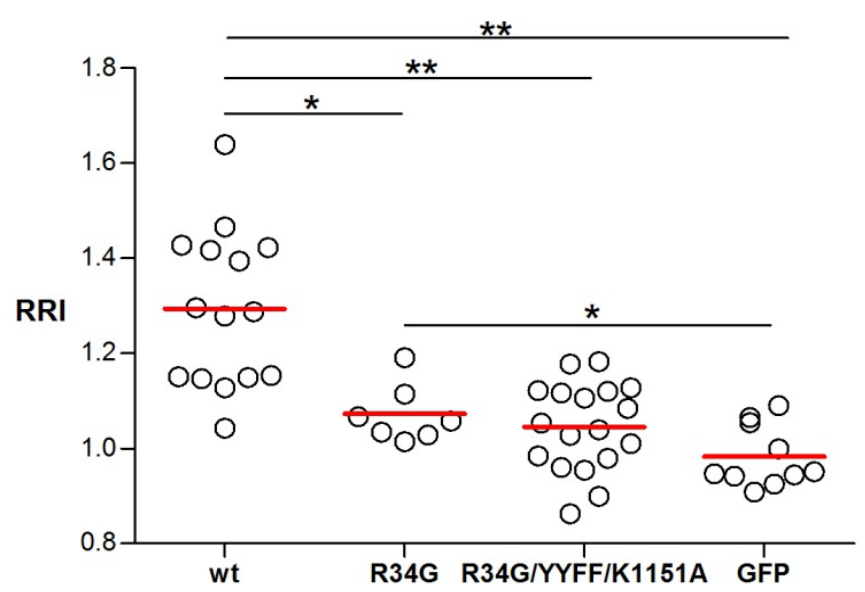

Figure 3.14: SHIP recruitment in primary B cells. (A) B cells were isolated from C57BL/6 spleen and cultured in the presence of LPS. They were infected with retroviruses containing plasmids encoding SHIPwt-EGFP or SHIPR34G/YYFF/K1151A. (continued on next page) 
(legend to Figure 3.14 continued) 30-45 h after infection, cells were seeded on poly-D-Lysine-coated glass coverslips and analyzed by confocal microscopy. Images were acquired before and 3 min after stimulation of the BCR with F(ab’) 2 goat anti-mouse IgG+IgM. (B) Relative recruitment indices (RRIs) were assessed as explained in figure legend 3.5. Cells expressing SHIPR34G-EGFP or EGFP alone were additionally included. Each point is one cell. Mean is given in red. Student's t test: ${ }^{*} \mathrm{p}<0.05$; ${ }^{* *} \mathrm{p}<0.0001$

\subsection{Impact of putative effector proteins on FcyRIIB- independent SHIP activation}

\subsubsection{SHIP interactome analysis identifies potential effector proteins from different functional groups}

The experiments described above underlined the relevance of protein interaction motifs and hence protein-protein interactions for SHIP function. Some interaction partners of SHIP have been described in different cell types and under different stimulation conditions. However, whether all these interactions also occurred in B cells after BCR engagement was uncertain. In addition, the interaction partner of the SH2 domain still remained undefined. Moreover, the known interaction partners could not explain a potential link of SHIP to the cytoskeleton, which was very likely to exist, regarding findings that SHIP recruitment is severely impaired after treatment of cells with Latrunculin B, an inhibitor of actin polymerization (Tucholski, 2010). To approach these questions and discover so far unknown interaction partners, the SHIP interactome was analyzed by mass spectrometry in cooperation with T. Oellerich, Dept. of Cellular and Molecular Immunology, Göttingen, and Prof. Dr. H. Urlaub, Bioanalytical Mass Spectrometry Group, Max Planck Institute for Biophysical Chemistry as described in (Oellerich et al., 2009). Two different experimental setups were used to identify the molecular SHIP network in B cells. Besides conventional non-quantitative mass spectrometry with high sensitivity, a quantitative approach was carried out to obtain high accuracy. For both approaches, an anti-GFP purification was performed from DT40 cells either expressing SHIPwt-EGFP or EGFP as a control.

The non-quantitative approach identified several interaction partners that were discovered only in samples derived from BCR-stimulated SHIPwt-EGFP-expressing cells (Table 3.1). Known interaction partners like Grb2, Shc and Dok-3 were found, as well as the kinase Lyn, which phosphorylates SHIP. Newly identified interaction partners for SHIP in B cells were, amongst others, CIN85 and CD2-associated protein 
(CD2AP). Noteworthy is also the presence of proteins that are connected to the cytoskeleton, e. g. actin-depolymerizing factor, noncatalytic region of tyrosine kinase 2 (Nck2) and actin-related protein 2/3 (Arp2/3) complex subunits. The interactome further included SHP1 and SHP2, which negatively regulate signaling by dephosphorylating several receptors, including the BCR.

Table 3.1: The SHIP interactome analyzed by non-quantitative mass spectrometry.

\begin{tabular}{lll}
\hline Protein & gi number & $\begin{array}{l}\text { number of unique } \\
\text { sequenced peptides }\end{array}$ \\
\hline similar to SHIP isoform 2 & gi|118094806 & 92 \\
CD2AP & gi|53133308 & 61 \\
\hline CIN85 & gi|71895227 & 50 \\
Dok-3 & gi|134085745 & 43 \\
Grb2 & gi|124110120 & 36 \\
similar to inositol polyphosphate 5- & gi|118089291 & 18 \\
phosphatase & gi|118097875 & 11 \\
similar to Grb2-related adaptor protein & gi|45383528 & 10 \\
actin-related protein 3 & gi|71895197 & 9 \\
Nck2 & gi|45382569 & 8 \\
actin-related protein 2 & gi|71894879 & 6 \\
SHP1 or SHP2 & gi|2665844 & 6 \\
\hline Shc & gi|118405176 & 5 \\
actin-related protein 2/3 complex subunit 1A & gi|57530388 & 4 \\
\hline Lyn & gi|53128989 & 4 \\
ADF (Actin-Depolymerizing Factor) protein & gi|71896007 & 4 \\
actin-related protein 2/3 complex subunit 5 & gi|45383293 & 3 \\
ARF tumor suppressor & gi|118116781 & 2 \\
\hline C-type lectin & gi|118103201 & 2 \\
\hline similar to p64 isoform of N-Shc & (1) & \\
\hline
\end{tabular}

SHIP-deficient DT40 cells expressing SHIPwt-EGFP or EGFP alone after retroviral gene transfer were stimulated via their BCR for $3 \mathrm{~min}$, lysed and SHIP-EGFP was immunoprecipitated with anti-GFP antibodies. Immunoprecipitated proteins were further processed and subjected to mass spectrometry analysis by T. Oellerich in cooperation with Prof. Dr. H. Urlaub, Bioanalytical Mass Spectrometry Group, Max Planck Institute for Biophysical Chemistry. Shown are proteins of which at least 2 peptides were identified and which only appeared in samples derived from SHIPwt-EGFP-expressing cells but not in the negative control.

This traditional non-quantitative mass spectrometry analysis provides a sensitive method to identify interaction partners. The drawback is that false-positive proteins 
might be identified as potential interaction partners. Therefore two additional SILACbased mass spectrometry analyses were performed. The quantitative approach behind allows better discrimination of non-specifically bound proteins and makes the method more accurate. SHIP-deficient DT40 cells expressing SHIPwt-EGFP after retroviral gene transfer were cultivated in medium substituted with heavy or medium heavy versions of arginine and lysine. Unstimulated and stimulated cells were compared. EGFP-expressing cells grown in light medium were used as control. This more stringent SILAC-based mass spectrometry approach confirmed most of the binding partners identified in the previous analysis (Tables 3.2 and 3.3). Grb2 and Dok-3, already established binding partners, were identified again. The two homologous proteins, CIN85 and CD2AP were once more part of the interactome in stimulated as well as in unstimulated cells, suggesting a constitutive binding. Cytoskeleton-associated proteins were identified in these analyses as well as the Ig $\mu$ chain $C$ region, which is part of the BCR. The identified major vault protein is probably a nuclear-cytoplasmic transport protein that might transport the phosphatase PTEN into the nucleus (Chung et al., 2005).

Table 3.2: The SILAC-based SHIP interactome - Analysis I

\begin{tabular}{ll} 
Protein & IPI Number $\begin{array}{l}\text { Ratio H/L } \\
\text { normalized }\end{array}$ \\
\hline
\end{tabular}

in unstimulated DT40 B cells

\begin{tabular}{|c|c|c|}
\hline similar to SHIP isoform 1 & IPI00813578 & 60.888 \\
\hline F-actin-capping protein subunit alpha-1 & IPI00821716 & 31.5 \\
\hline $\begin{array}{l}\text { SH3 domain-containing kinase-binding protein } 1 \\
\text { (CIN-85) }\end{array}$ & IPI00822393 & 31.236 \\
\hline $\begin{array}{l}\text { SH3 domain-containing kinase-binding protein } 1 \\
\text { (CIN-85) }\end{array}$ & IPI00601097 & 26.483 \\
\hline Isoform 1 of F-actin-capping protein subunit beta & IPI00591422 & 24.658 \\
\hline $\begin{array}{l}\text { similar to SH2 domain containing SOCS box protein } \\
\text { SOCS7 }\end{array}$ & IPI00577183 & 21.005 \\
\hline Dok-3 & IPI00845156 & 19.753 \\
\hline F-actin-capping protein subunit alpha-1/ alpha-2 & IPI00582081 & 19.023 \\
\hline Major vault protein & IPI00597028 & 14.305 \\
\hline similar to mitogen-activated protein kinase kinase 4 & IPI00594829 & 11.122 \\
\hline
\end{tabular}


in stimulated DT40 B cells

$\begin{array}{lll}\text { similar to SHIP isoform } 1 & \text { IPI00813578 } & 31.772 \\ \text { Grb2 } & \text { IPI00576615 } & 21.935 \\ \text { Major vault protein } & \text { IPI00597028 } & 19.894 \\ \text { Dok-3 } & \text { IPI00845156 } & 14.892 \\ \text { CD2AP } & \text { IPI00583892 } & 13.552 \\ \text { F-actin-capping protein subunit alpha-1 } & \text { IPI00821716 } & 12.598 \\ \text { Isoform 1 of F-actin-capping protein subunit beta } & \text { IPI00591422 } & 12.087 \\ \text { CIN85 } & \text { IPI00601097 } & 9.4794 \\ \text { F-actin-capping protein subunit alpha-1/ alpha-2 } & \text { IPI00582081 } & 9.4339\end{array}$

SHIP-deficient DT40 cells expressing SHIPwt-EGFP or EGFP alone after retroviral gene transfer were cultivated in medium substituted with heavy or light versions of arginine and lysine, respectively, stimulated via their BCR for 3 min or left unstimulated, lysed and SHIP-EGFP was immunoprecipitated with anti-GFP antibodies. Eluates from unstimulated SHIPwt-EGFP-expressing cells and unstimulated EGFP-expressing cells were pooled. Likewise, eluates from stimulated SHIPwt-EGFP-expressing cells and stimulated EGFP-expressing cells were pooled. Samples were further processed and subjected to mass spectrometry analysis by T. Oellerich in cooperation with Prof. Dr. H. Urlaub, Bioanalytical Mass Spectrometry Group, Max Planck Institute for Biophysical Chemistry. The proteins listed showed an at least four-fold enrichment of heavy vs. light (H/L) peptides.

Table 3.3: The SILAC-based SHIP interactome - Analysis II Protein IPI Number normalized

\section{in unstimulated DT40 B cells}

\begin{tabular}{lll}
\hline similar to glutathione synthetase & IPI00586349 & 98.548 \\
similar to Dedicator of cytokinesis protein 9 (Dock9) & IPI00584044 & 40.399 \\
similar to KDEL (Lys-Asp-Glu-Leu) containing 1 & IPI00591799 & 39.108 \\
Butyrylcholinesterase & IPI00577492 & 26.965 \\
similar to SHIP isoform 1 & IPI00813578 & 22.232 \\
Isoform 1 of F-actin-capping protein subunit beta & IPI00591422 & 15.632 \\
SH3 domain-containing kinase-binding protein 1 CD2AP & IPI00583892 & 9.0433 \\
F-actin-capping protein subunit alpha-1 & IPI00821716 & 8.4124 \\
\hline
\end{tabular}




\section{in stimulated DT40 B cells}

\begin{tabular}{|c|c|c|}
\hline Butyrylcholinesterase & IPI00577492 & 95.503 \\
\hline similar to SHIP isoform 1 & IPI00813578 & 84.475 \\
\hline similar to Dedicator of cytokinesis protein 9 (Dock9) & IPI00584044 & 74.183 \\
\hline Grb2 & IPI00576615 & 48.004 \\
\hline similar to Immunoglobin superfamily, member 21 & IPI00602319 & 47.637 \\
\hline F-actin-capping protein subunit alpha-2 & IPI00582081 & 43.355 \\
\hline CD2AP & IPI00583892 & 35.585 \\
\hline Isoform 1 of F-actin-capping protein subunit beta & IPI00591422 & 33.219 \\
\hline CIN85 & IPI00601097 & 21.143 \\
\hline F-actin-capping protein subunit alpha-1 & IPI00821716 & 20.194 \\
\hline Dok-3 & IPI00845156 & 18.029 \\
\hline Major vault protein & IPI00597028 & 14.121 \\
\hline Heat shock protein HSP 90-alpha & IPI00596586 & 7.4425 \\
\hline TNF receptor-associated protein 1 & IPI00584168 & 7.0811 \\
\hline \multicolumn{3}{|l|}{ guanine nucleotide-binding protein $\mathrm{G}(\mathrm{I}) / \mathrm{G}(\mathrm{S}) / \mathrm{G}(\mathrm{T})$} \\
\hline subunit beta-1 & IPI00596111 & 6.4472 \\
\hline similar to MGC69420 protein & IPI00586861 & 5.8026 \\
\hline Myosin-Ig & IPI00593783 & 5.7451 \\
\hline \multicolumn{3}{|l|}{ similar to Actin, alpha 2, smooth muscle, aorta isoform } \\
\hline $1 / 2$ & IPI00576059 & 5.5393 \\
\hline Actin, cytoplasmic 1 & IPI00655503 & 5.4891 \\
\hline \multicolumn{3}{|l|}{ similar to DNA segment, Chr 10, Wayne State University } \\
\hline 52, expressed & IPI00571823 & 4.9181 \\
\hline similar to guanine nucleotide binding protein alpha 13 & IPI00814447 & 4.8085 \\
\hline ATP-dependent RNA helicase DDX1 & IPI00585086 & 4.7916 \\
\hline homeobox prox 1 & IPI00681275 & 4.562 \\
\hline coronin-1C & IPI00818498 & 4.3746 \\
\hline Ig mu chain $\mathrm{C}$ region & IPI00591488 & 4.2254 \\
\hline
\end{tabular}

SHIP-deficient DT40 cells expressing SHIPwt-EGFP or EGFP alone after retroviral gene transfer were cultivated in medium substituted with medium heavy or light versions of arginine and lysine, respectively, stimulated via their BCR for $3 \mathrm{~min}$ or left unstimulated, lysed and SHIP-EGFP was immunoprecipitated with anti-GFP antibodies. They were further processed and analyzed as explained in the legend of table 3.2. 
In summary, the mass spectrometry approaches revealed SHIP binding to proteins from different functional groups. Besides adaptors and signaling regulators, several proteins were identified that are associated with the cytoskeleton or that are known regulators of the cytoskeleton (Figure 3.15).

Previous experiments in this study had underlined the importance of the NPXY motifs, the SH2 domain and several proline-rich regions for SHIP recruitment and function (see 3.2). Identification of the proteins interacting with these domains will contribute to a better understanding of the mechanism of SHIP activation. The interactome contained Shc and Dok-3, which are known interaction partners of the SHIP NPXY motifs. It furthermore comprised several potential SH3 domain-containing interaction partners of proline-rich regions of SHIP such as Grb2, CD2AP, CIN85 and Nck2. These adaptor proteins are mainly involved in regulation of the actin cytoskeleton or are activated downstream of the BCR which makes them interesting candidates for SHIP interaction. In addition, their localization is interesting since they are, just like SHIP, recruited from the cytosol to the plasma membrane in response to BCR stimulation (Stork et al., 2004). Recruitment of Nck2 as well as of CD2AP and CIN85 was demonstrated after the beginning of this study by our laboratory (Tucholski, 2010; Oellerich et al., 2011). In addition, the tyrosine kinase Lyn was part of the identified SHIP interactome. Experiments described above had already demonstrated the importance of tyrosine phosphorylation for SHIP activation (see 3.2.2). As a consequence of the interactome analysis, the following part of this study investigates the role of Lyn, Grb2, Shc and Dok-3 in SHIP activation, as well as the impact of potential binding partners of SHIP proline-rich regions.

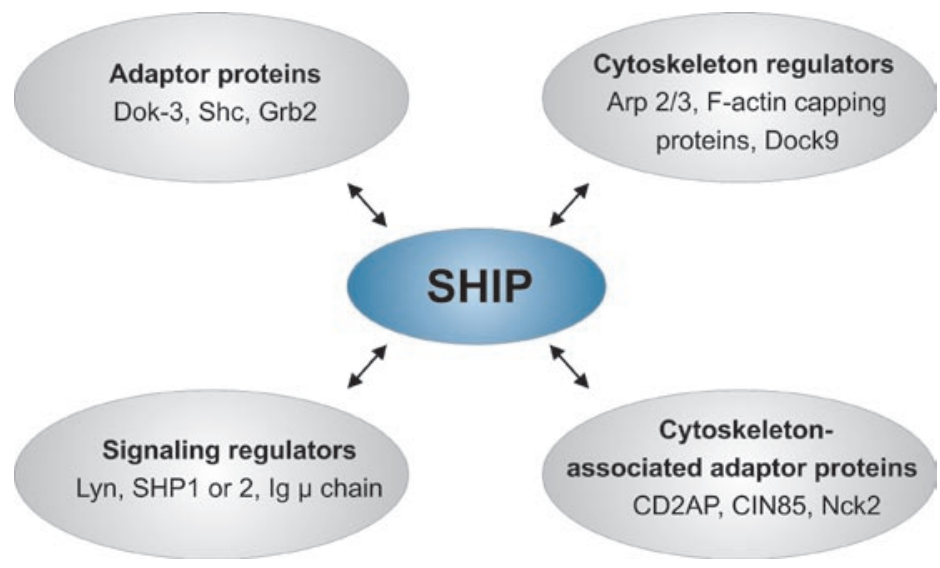

Figure 3.15: The SHIP interactome can be divided into different functional groups. Classification of selected proteins found in the mass spectrometry analyses described above. 


\subsubsection{Lyn activity is required for SHIP phosphorylation and recruitment}

Lyn was identified in the interactome analysis described above. This very central Src family kinase was described to be a SHIP binding partner in a monocytic cell line (Baran et al., 2003) and to phosphorylate SHIP in COS-7 cells (Phee et al., 2000). Furthermore, the contribution of SHIP tyrosine phosphorylation to recruitment and inhibition of $\mathrm{Ca}^{2+}$ mobilization was demonstrated in this study (see 3.2.2). To investigate whether Lyn could also phosphorylate SHIP in DT40 cells and whether Syk was able to contribute to SHIP phosphorylation, DT40 wt cells as well as Lyn-deficient and Syk-deficient DT40 cells expressing SHIPwt-EGFP were subjected to anti-GFP IP. SHIP phosphorylation was analyzed before as well as $3 \mathrm{~min}$ and $7 \mathrm{~min}$ after BCR engagement. The Lyn- and Syk-deficient DT40 cells used here expressed endogenous SHIP in addition to SHIP-EGFP. Therefore, the adequate control for this assay were DT40 wt cells reconstituted with SHIP-EGFP as they also expressed endogenous SHIP. On wild-type background, SHIP phosphorylation first increased and was found to be decreased again after 7 min (Figure 3.16 A, lanes 7-9). This was comparable to SHIP phosphorylation in Syk-deficient cells (Figure 3.16 A, lanes 4-6). In the absence of Lyn, however, no phosphorylation could be detected (Figure 3.16 A, lanes 1-3).

To determine the impact of the two tyrosine kinases Lyn and Syk on SHIP recruitment to the plasma membrane, these cells were used to analyze the RRIs. If one kinase was missing, recruitment to the plasma membrane was strongly reduced (Figure 3.16 B). In addition, a delayed response was observed in Lyn-deficient cells with almost no recruitment 3 min after stimulation. 10 min after stimulation the RRI reached similar levels as in Syk-deficient cells. 
A

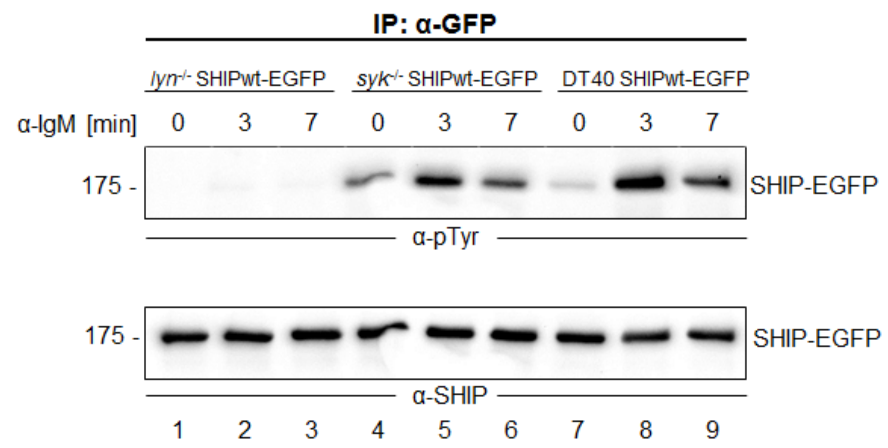

B

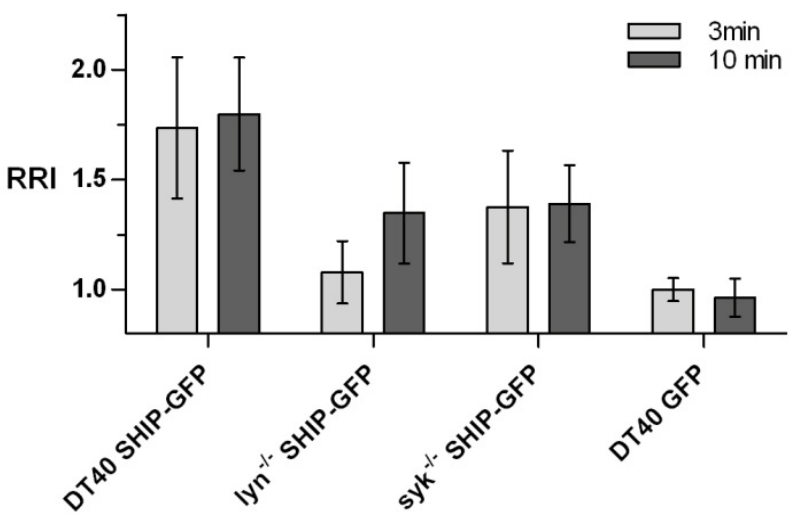

Figure 3.16: Lyn is required for SHIP phosphorylation and contributes to SHIP recruitment. (A) Lyn-deficient (lanes 1-3), Syk-deficient (lanes 4-6) and wild-type (lanes 7-9) DT40 cells were transfected with plasmids encoding SHIPwt-EGFP. They were starved in serum-free medium and left unstimulated (0) or were stimulated via their BCR for the indicated times. Cells were lysed and SHIPEGFP was immunoprecipitated (IP) with anti-GFP antibody. Immunoprecipitates were analyzed by immunoblotting with anti-phosphotyrosine antibody ( $\alpha$-pTyr, upper panel). The abundance of SHIP had been verified by probing the membrane with anti-SHIP antibody (lower panel). Protein sizes are indicated in $\mathrm{kDa}$. Data shown is representative for three independent experiments. (B) Cells described in (A) were allowed to settle on glass coverslips and analyzed by confocal microscopy. Images were acquired before as well as $3 \mathrm{~min}$ and $10 \mathrm{~min}$ following stimulation with anti-chicken IgM antibody and analyzed to obtain the RRIs as explained in figure legend 3.5. Bars represent means from $n=20$ cells (+/- SD). For comparison, EGFP-expressing DT40 cells stimulated via their BCR were included in this diagram. RRI, relative recruitment index.

The experiments showed that SHIP is not phosphorylated in the absence of Lyn. As Lyn is a key kinase is in the BCR signaling cascade, it was unclear whether phosphorylation of the two main phosphotyrosine motifs of SHIP was the only effect of Lyn in the SHIP activation process. To clarify this, SHIP recruitment in Lyn-deficient DT40 cells expressing SHIPwt-EGFP was compared to recruitment in DT40 cells expressing SHIPwt-EGFP and SHIPYYFF-EGFP after retroviral gene transfer. If Lyn was only required for SHIP phosphorylation, SHIPYYFF-EGFP should mimic Lyn deficiency 
and recruitment should be comparable at any time point which is why measurements after three minutes were chosen. Analysis of the recruitment revealed though, that SHIPYYFF-EGFP on a wild-type background was still significantly better recruited to the plasma membrane than SHIPwt-EGFP on a Lyn-deficient background (Figure 3.17). This suggests that Lyn has functions beyond SHIP phosphorylation, further proving its crucial role in SHIP plasma membrane recruitment.

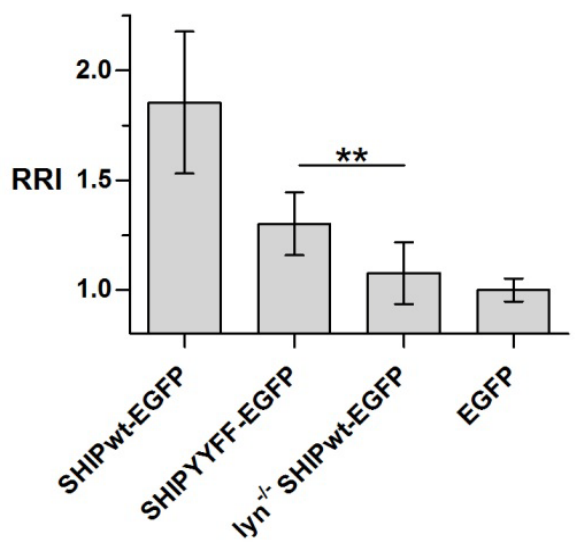

Figure 3.17: The role of Lyn in SHIP recruitment exceeds phosphorylation of SHIP. DT40 cells expressing SHIPwt-EGFP, SHIPYYFF-EGFP and EGFP alone as well as Lyn-deficient DT40 cells expressing SHIPwt-EGFP after retroviral gene transfer were analyzed by confocal microscopy. Images were acquired before as well as 3 min following stimulation with anti-chicken IgM antibody and analyzed to obtain the RRIs as described in figure legend 3.5. Bars represent means from $n=20$ cells (+/- SD). RRI, relative recruitment index. Student's t test: $* * \mathrm{p}<0.0001$.

\subsubsection{Components of ternary complexes contribute to FcyRIIB- independent SHIP activation}

The SHIP interactome includes the adaptor proteins Grb2, Shc and Dok-3 (see 3.3.1). It has been shown that these proteins form the ternary complexes SHIP-Grb2-Shc (Harmer \& DeFranco, 1999) and, after BCR-FcyRIIB coactivation, SHIP-Grb2-Dok-3 (Neumann et al., 2011). Moreover, Shc and Dok-3 bind to the NPXY motifs of SHIP, and at least Y1020 is required for full SHIP activation (see 3.2.2). Components of the ternary complexes are thus promising candidates in the search for effectors of SHIP activation. The role of Grb2, Shc and Dok-3 in SHIP activation was therefore analyzed in more detail below. 


\subsubsection{Grb2 interacts with the proline-rich region around $\mathrm{K} 1151$ and is required for SHIP recruitment}

Grb2 is a known interaction partner of SHIP and was also identified in the interactome presented above. It binds with its C-terminal SH3 domain to a proline-rich region in the C-terminus of SHIP (Damen et al., 1996). However, the exact binding site has not been identified yet. Experiments described above revealed an important role of the prolinerich region encompassing K1151 (see 3.2.3), which is therefore a promising candidate for the Grb2 binding site. To analyze the consequences of a disturbed SHIP-Grb2 interaction, the definite identification of that binding site was important. Therefore, lysates of SHIP-deficient DT40 cells expressing SHIP with mutations in proline-rich regions were subjected to affinity purification using GST-Grb2[cSH3] (kindly provided by Dr. A. Grabbe). Binding of the C-terminal SH3 domain of Grb2 to SHIPK1151A was indeed strongly reduced while all other tested SHIP variants were precipitated in comparable amounts to SHIPwt-EGFP (Figure 3.18 A, lane 9). Therefore the prolinerich region encompassing the amino acids P1146-K1151 could be identified as the Grb2-binding site. This was confirmed by anti-GFP IP from SHIP-deficient cells expressing SHIPwt-EGFP or SHIPK1151A-EGFP after retroviral gene transfer. Here, Grb2 was only co-precipitated with SHIPwt-EGFP (Figure 3.18 B, lanes 1, 2), but not with SHIPK1151A-EGFP (Figure 3.18 B, lanes 3, 4). 
A

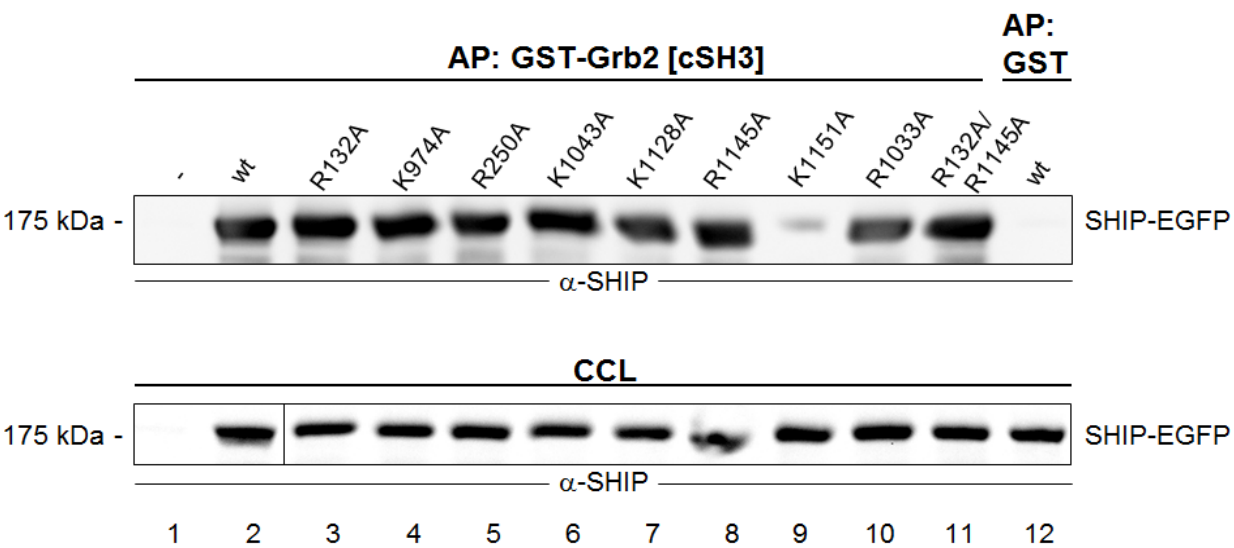

B

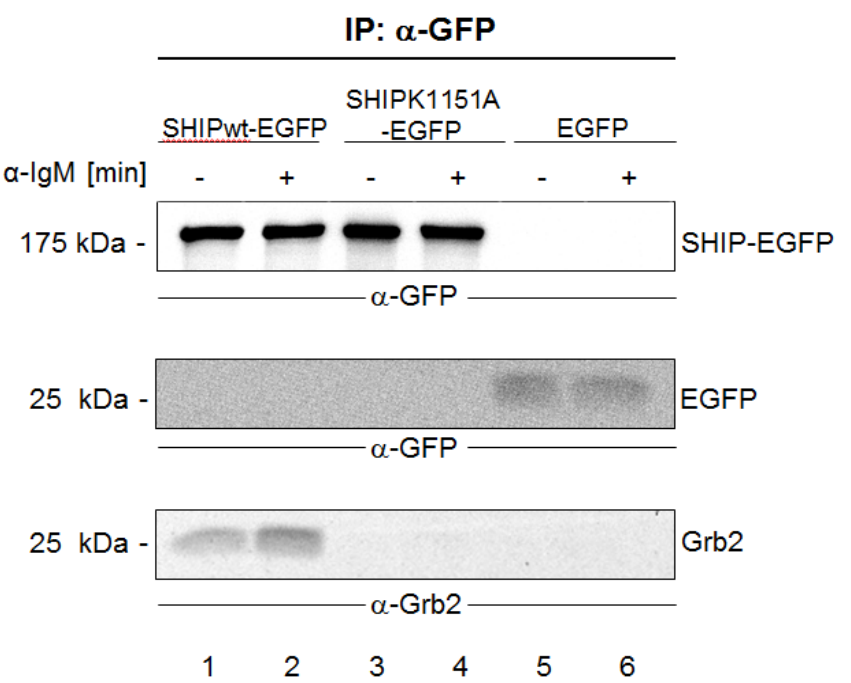

Figure 3.18: Identification of the Grb2-binding site. (A) Cleared cellular lysates (CCLs) prepared from SHIP-deficient DT40 transfectants expressing EGFP-labeled SHIP carrying the indicated mutations were lysed and lysates were subjected to affinity purification (AP) with either GST-Grb2[cSH3] (lanes 1-11) or GST (lane 12). The isolated proteins were analyzed by immunoblotting with anti-SHIP antibody ( $\alpha$-SHIP, upper panel). The indicated numbers refer to the position of amino acid exchanges that inactivated proline-rich regions. Equivalent SHIP expression was shown by immunoblotting the CCLs with antiSHIP antibody (lower panel). Protein sizes are indicated in kDa. Data represent the results of two independent experiments. (B) CCLs prepared from unstimulated (-) or BCR-stimulated (+) SHIPdeficient DT40 transfectants expressing SHIPwt-EGFP (lanes 1, 2), SHIPK1151A-EGFP (lanes 3, 4) or EGFP (lanes 5, 6) were subjected to immunoprecipitation (IP) with anti-GFP antibody. Purified proteins were analyzed by immunoblotting with antibodies against GFP (upper and middle panel) and Grb2 (lower panel). Protein sizes are indicated in $\mathrm{kDa}$. Data represent the results of two independent experiments.

Harmer and DeFranco demonstrated the requirement of Grb2 for the interaction between Shc and SHIP in the context of the ternary complex (Harmer \& DeFranco, 1999). The expression of Grb2 was necessary for the interaction between Shc and SHIP 
and the Grb2 binding sites of Shc were required for its association with SHIP. However, it was not clear, whether binding of SHIP to Grb2 was necessary for the formation of this complex. This was tested using the SHIPK1151A variant. SHIP-deficient DT40 cells expressing EGFP-labeled SHIPwt or SHIPK1151A after retroviral gene transfer as well as Grb2- and Shc-deficient DT40 cells expressing SHIPwt-EGFP after retroviral gene transfer were subjected to anti-Shc IP. Immunoblotting with anti-GFP antibody showed that a Grb2-binding-deficient SHIP variant could not be co-precipitated with Shc (Figure 3.19, lane 4), suggesting that the interaction between Shc and SHIP alone is not stable enough to keep these two proteins together. It can also be concluded that the interaction between Shc and Grb2 alone is not stable enough as a faint band representing Grb2 could only be precipitated if the cells contained SHIP that was capable to bind Grb2 (Figure 3.19, lane 2).

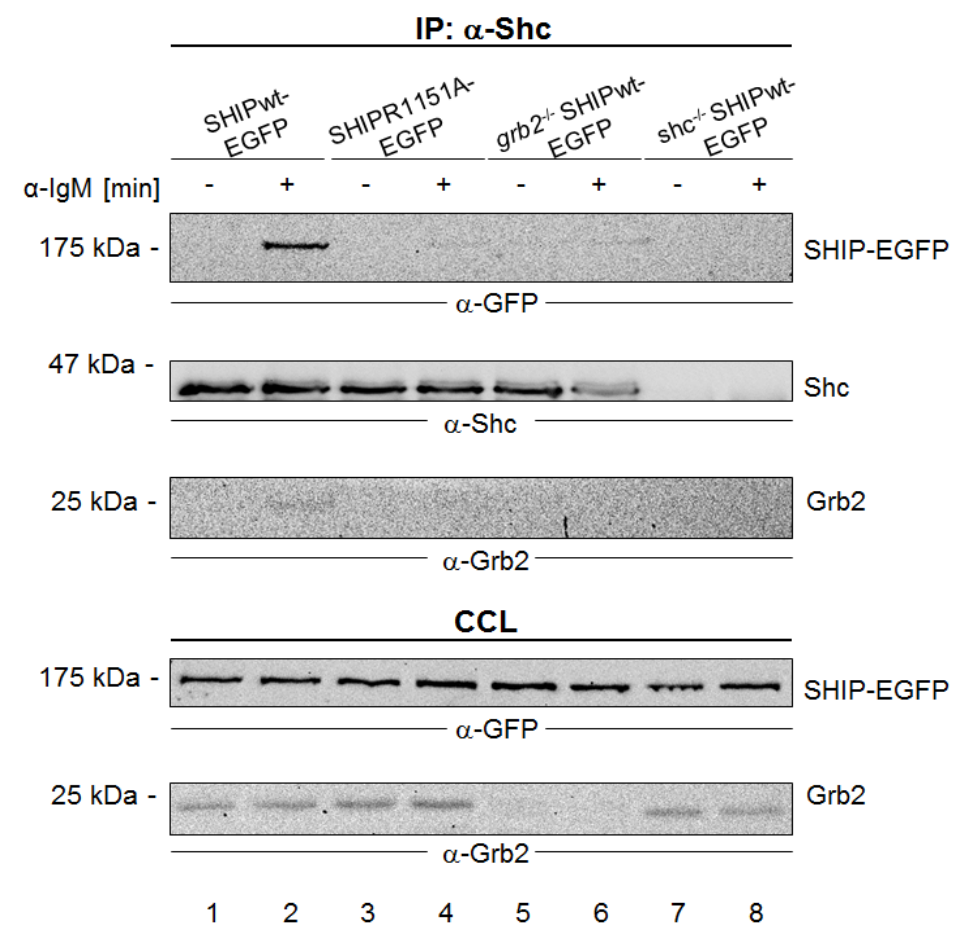

Figure 3.19: Interaction between SHIP and Grb2 is a prerequisite for Shc-Grb2 binding and for Shc-SHIP binding. Lysates of SHIP-deficient DT40 cells expressing EGFP-labeled SHIPwt (lanes 1, 2) or SHIPK1151A (lanes 3, 4) after retroviral gene transfer as well as of Grb2-deficient (lanes 5, 6) and Shc-deficient (lanes 7, 8) DT40 cells expressing SHIPwt-EGFP after retroviral gene transfer were subjected to immunoprecipitation (IP) with anti-Shc antibodies. The precipitates were analyzed by immunoblotting with anti-Shc antibody to control for equal pull-down efficiency and with anti-GFP antibody and anti-Grb2 antibody. CCLs were immunoblotted with anti-GFP and anti-Grb2 antibodies to confirm the presence of these proteins in the cells. Protein sizes are indicated in kDa. 
To see whether Grb2 is involved in the recruitment of SHIP, Grb2-deficient DT40 cells expressing EGFP-labeled SHIPwt and SHIPYYFF after retroviral gene transfer were analyzed by confocal microscopy. The recruitment of wild-type SHIP was decreased in the absence of Grb2 (Figure 3.20). Recruitment of SHIPYYFF-EGFP was not decreased in Grb2-deficient cells compared to recruitment of SHIPwt-EGFP, probably because SHIPYYFF-EGFP cannot efficiently participate in ternary complexes anyway since binding to Shc or Dok-3 is not possible.

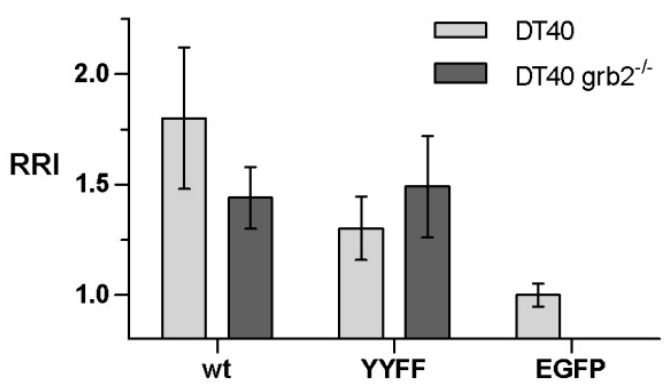

Figure 3.20: Influence of Grb2 on SHIP plasma membrane recruitment. Wild-type and Grb2deficient DT40 cells were transfected with plasmids encoding EGFP-labeled SHIPwt and SHIPYYFF. EGFP-expressing DT40 cells were used as a control. The relative recruitment index (RRI) of SHIP in these cells was analyzed as described in figure legend 3.5. Bars represent means from $n=20$ cells (+/- SD).

These experiments demonstrated the requirement of the SHIP-Grb2 interaction for assembly of the ternary complex SHIP-Grb2-Shc. Moreover, Grb2 contributes to SHIPwt recruitment to the plasma membrane.

\subsubsection{Dok-3 and Shc are required for SHIP recruitment}

The interactome analysis confirmed the known interaction of SHIP with the adaptor proteins Dok-3 and Shc. Besides the ternary complex of SHIP-Grb2-Shc, a similar complex consisting of SHIP-Grb2-Dok-3 has been detected after BCR-FcyRIIB coactivation (Neumann, 2008). One question of interest was the requirement of NPXY sites in SHIP for the formation of this complex under positive signaling conditions. The requirement of Y1020 for SHIP activation has been shown before (see 3.2.2). To answer this question, SHIP, either wild-type or carrying mutations in one or both NPXY motifs, was immunoprecipitated from unstimulated and BCR-stimulated DT40 cells. 
A
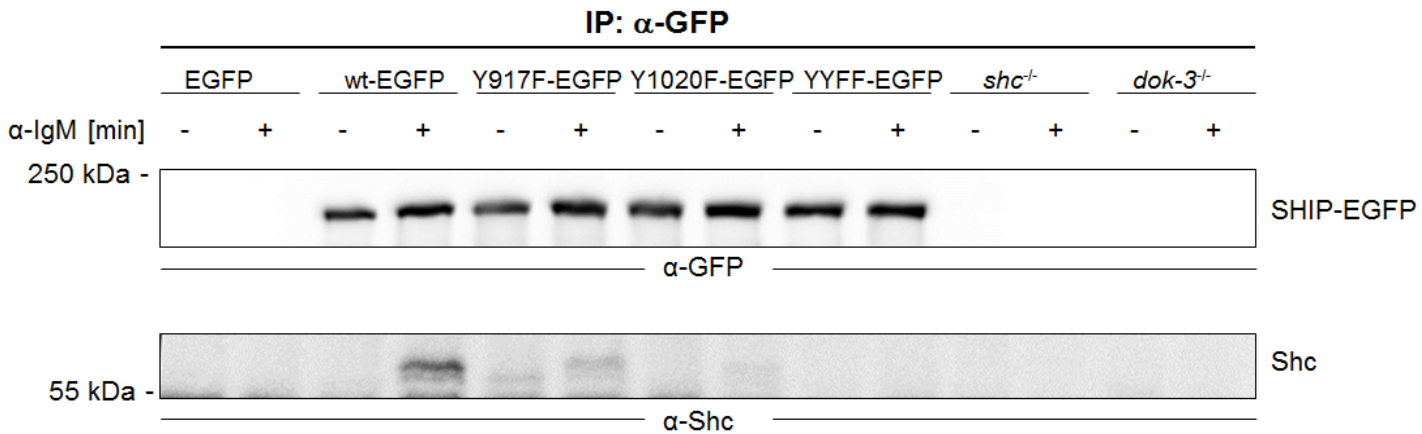

CCL

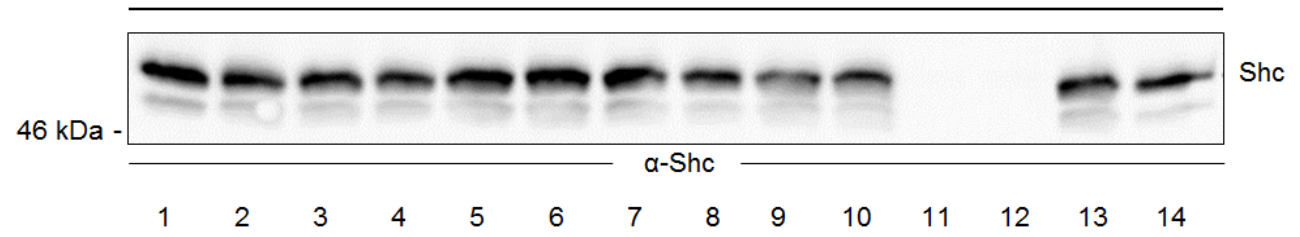

B
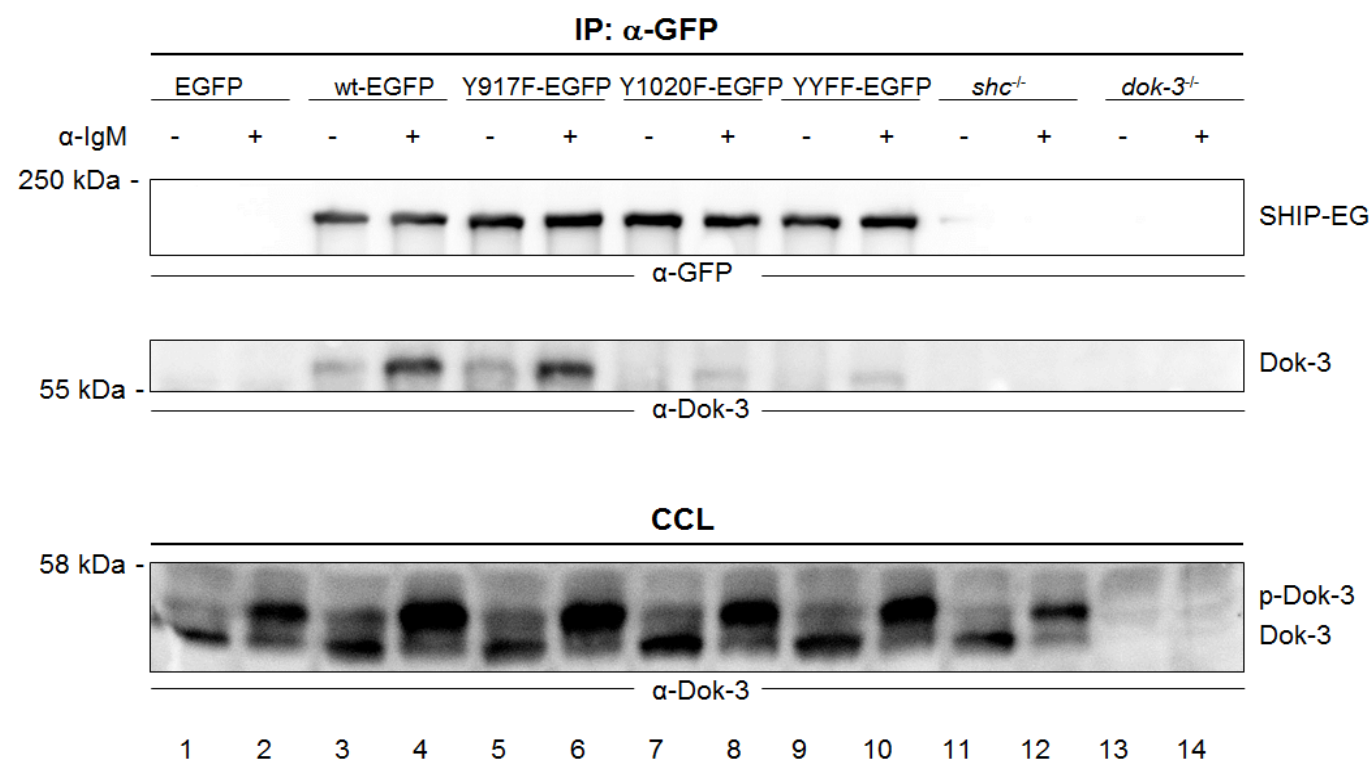

Figure 3.21: Requirements of phosphotyrosine motifs for the interaction of SHIP with Dok-3 and Shc. SHIP-deficient DT40 cells expressing EGFP (lanes 1, 2) or EGFP-labeled SHIPwt (lanes 3, 4), SHIPY917F (lanes 5, 6), SHIPY1020F (lanes 7, 8) or SHIPYYFF (lanes 9, 10) as well as Shc-deficient (lanes 11, 12) and Dok-3-deficient (lanes 13, 14) DT40 cells were left unstimulated or stimulated for 3 min via their BCR. They were lysed and the lysates (CCLs) were subjected to immunoprecipitation (IP) with anti-GFP antibodies. Immunoprecipitates were analyzed by immunoblotting with anti-GFP antibody (upper panels) to test pull-down efficiency and with either anti-Shc antibody (A, middle panel) or antiDok-3 antibody (B, middle panel). CCLs were analyzed with antibodies against Shc or Dok-3 (lower panels) to show the presence of the proteins in the cells.

Probing the immunoblots with anti-Shc (Figure 3.21 A) or anti-Dok-3 (Figure 3.21 B) antibodies showed that Y1020 of SHIP was absolutely critical for the interaction of 
SHIP with Shc (Figure 3.21 A, lane 8) and Dok-3 (Figure 3.21 B, lane 8) following stimulation of the BCR only. Y917 was negligible for interaction with Dok-3 as inactivating this NPXY motif did not impair co-IP efficiency of SHIP and Dok-3 (Figure 3.21 B, lane 6). Interaction with Shc, however, was much reduced, as only a faint band could be observed after immunoblotting with anti-Shc antibody (Figure 3.21 A, lane 6). Consequently, no co-IP was observed between SHIPYYFF-EGFP and Dok-3 or Shc (Figure $3.21 \mathrm{~A}$ and B, lanes 10).

To assess the influence of the two adaptors Shc and Dok-3 on BCR-induced SHIP translocation to the plasma membrane, confocal microscopy analysis was carried out. Different SHIP variants were introduced into either DT40 wt or DT40 cells lacking expression of Dok-3 or Shc. The analysis revealed that both Dok-3 and Shc contributed to SHIP recruitment as the RRI of SHIPwt was reduced if one of the adaptors was missing (Figure 3.22). Recruitment of SHIPYYFF on dok-3-/- or $s h c^{-/-}$background was not more impaired than that of SHIPwt even though inactivation of both NPXY motifs prevents interaction of SHIP with both proteins. To find out whether complexes containing Dok-3 or Shc are more relevant for SHIP recruitment, SHIPR34G-EGFP was analyzed, where recruiting effects of the SH2 domain are eliminated (see 3.2.1). In the absence of Shc, SHIPR34G-EGFP recruitment was very slightly reduced, whereas recruitment in Dok-3-deficient cells was comparable to wild-type background.

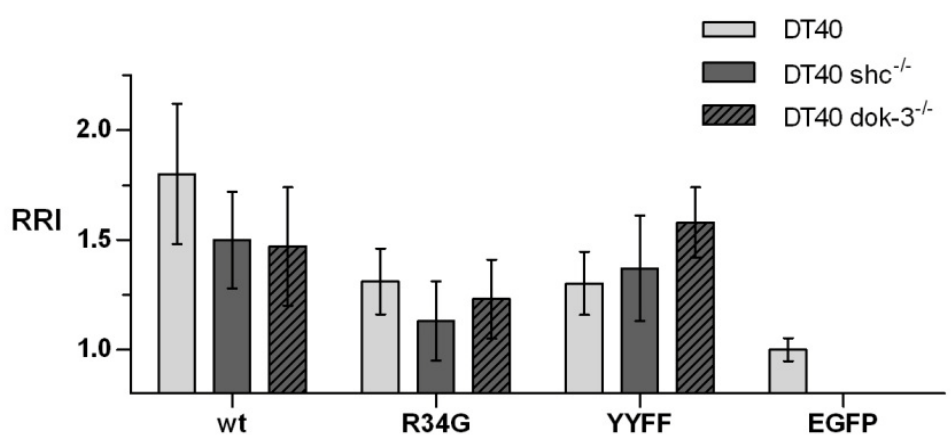

Figure 3.22: SHIP recruitment is impaired in Shc-deficient and Dok-3-deficient cells. DT40 wt, Shcdeficient and Dok-3-deficient DT40 cells were transfected with plasmids encoding EGFP-labeled SHIPwt, SHIPR34G, SHIPYYFF or EGFP alone. SHIP localization was analyzed by confocal microscopy before and 3 min after BCR activation. RRI of SHIP in these cells was analyzed as described in figure legend 3.5. Bars represent means from $n=20$ cells (+/- SD). RRI, relative recruitment index.

The experiments presented above show that binding of Grb2 to its newly identified binding site as well as interaction of Dok-3 and Shc with the NPXY motifs is essential 
for stable formation of the ternary complexes. In addition, the existence of the ternary complex SHIP-Grb2-Dok-3 in positive signaling conditions was confirmed. Finally, all three adaptors contribute to recruitment of SHIPwt.

\subsubsection{Regulators of the cytoskeleton play a minor role in SHIP activation}

Experiments in our laboratory had shown that inhibition of actin polymerization by treatment of cells with Latrunculin B impaired SHIP recruitment to the plasma membrane. This suggests a role of the actin cytoskeleton in SHIP recruitment, which is in line with studies showing association of SHIP with the cytoskeleton in macrophages and thrombocytes (Giuriato et al., 1997; Cox et al., 2001). The nature of this potential link to the cytoskeleton is, however, unknown. As the interactome analysis carried out within this study identified proteins associated with the cytoskeleton, it was obvious to investigate their contribution to SHIP activation.

\subsubsection{CIN85 and CD2AP interact with SHIP but are negligible for its activation}

CIN85 and CD2AP are two paralogous adaptors that control the assembly of multiprotein complexes involved in receptor signaling by functioning as scaffolding proteins. In addition, they are involved in actin remodeling (Kirsch et al., 1999; Gaidos et al., 2007). In this study, both proteins were identified as SHIP interaction partners by interactome analysis in DT40 cells (see 3.3.1). The interaction was already detected in unstimulated cells, suggesting that the interaction of SHIP with CD2AP and CIN85 takes place between proline-rich regions of SHIP and the SH3 domains of CIN85 and CD2AP. To identify the proline-rich regions involved in interaction with the SH3 domains of CD2AP, affinity purification was done from cells expressing SHIP variants defective in single proline-rich regions using GST fusion proteins of the CD2AP SH3 domains (kindly provided by V. Bremes). A very weak reduction in CD2AP binding was observed whenever the proline-rich region encompassing R1145 was inactivated, i. e. in SHIPR1145A, SHIPR132A/R1145A and SHIPR132A/R1145A/K974A (Figure 3.23, lanes $8,12,13)$. 


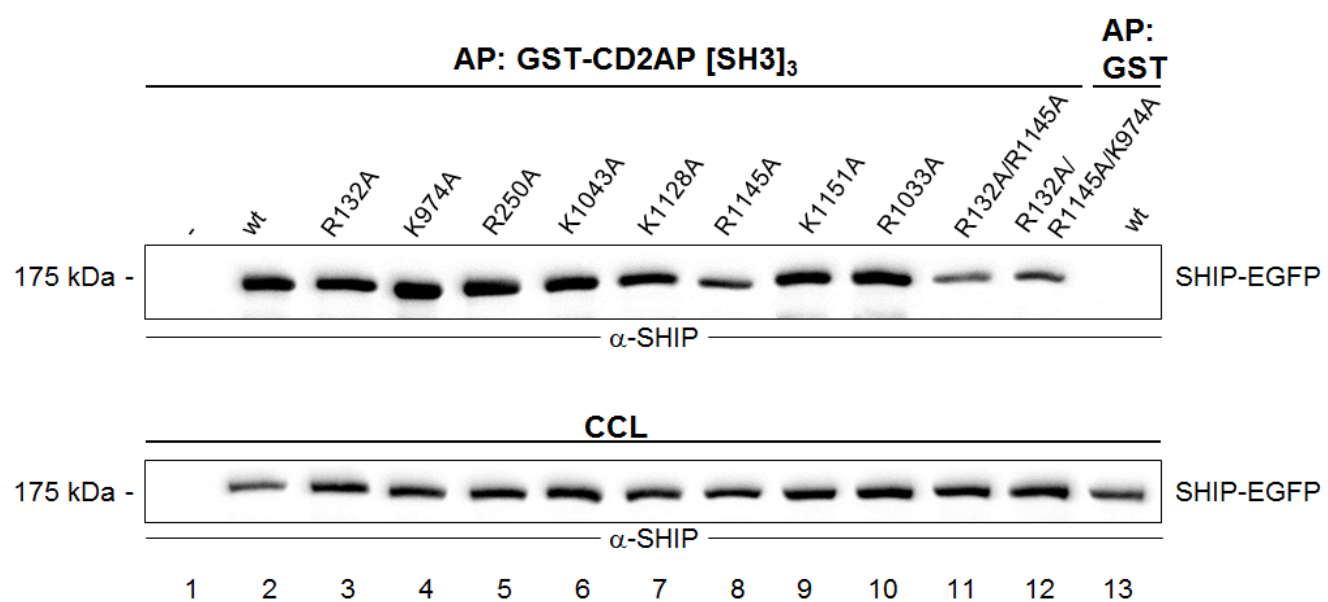

Figure 3.23: CD2AP binding to SHIP is not prevented by inactivation of single selected proline-rich regions in SHIP. Cleared cellular lysates (CCLs) were prepared from SHIP-deficient DT40 transfectants expressing EGFP-labeled SHIP carrying the indicated mutations after retroviral gene transfer. CCLs were subjected to affinity purification (AP) with either GST-CD2AP [SH3] $]_{3}$ (lanes 1-12) or GST (lane 13). The precipitated proteins were analyzed by immunoblotting with an anti-SHIP antibody (upper panel). Equivalent SHIP expression was shown by immunoblotting the CCLs with an anti-SHIP antibody (lower panel). The indicated numbers refer to the position of amino acid exchanges that inactivated proline-rich regions. Protein sizes are indicated in $\mathrm{kDa}$.

As CD2AP has three SH3 domains, SHIP binding might be mediated by more than one proline-rich region. Kowanetz and colleagues identified two proline-rich regions of human SHIP that were both necessary for binding to CIN85 in HEK cells (Kowanetz et al., 2004). I mutated the corresponding residues, R1033 and R1145, to inactivate the proline-rich regions and investigated binding to CIN85 and CD2AP. Since the two paralogs are highly similar, it can initially be considered that they have the same binding sites in SHIP. Amino acid exchange of R1145A was already shown to lead to reduced recruitment (see Figure 3.11 A). Unstimulated and stimulated SHIP-deficient DT40 transfectants expressing EGFP-labeled SHIPwt, SHIPR1145A or SHIPR1033A/R1145A were subjected to anti-GFP IP. Immunoprecipitates were analyzed for the presence of CIN85 and CD2AP. Binding of SHIPwt to both proteins could be confirmed in the DT40 system (Figure 3.24 A and B, lanes 1, 2). Amino acid exchange R1145A reduced binding of SHIP to either CIN85 (Figure 3.24 A, lanes 3, 4) or CD2AP (Figure 3.24 B, lanes 3, 4). Inactivation of both described binding motifs, however, lead to more efficient co-IP (Figure 3.24 A and B, lanes 5, 6). 
A
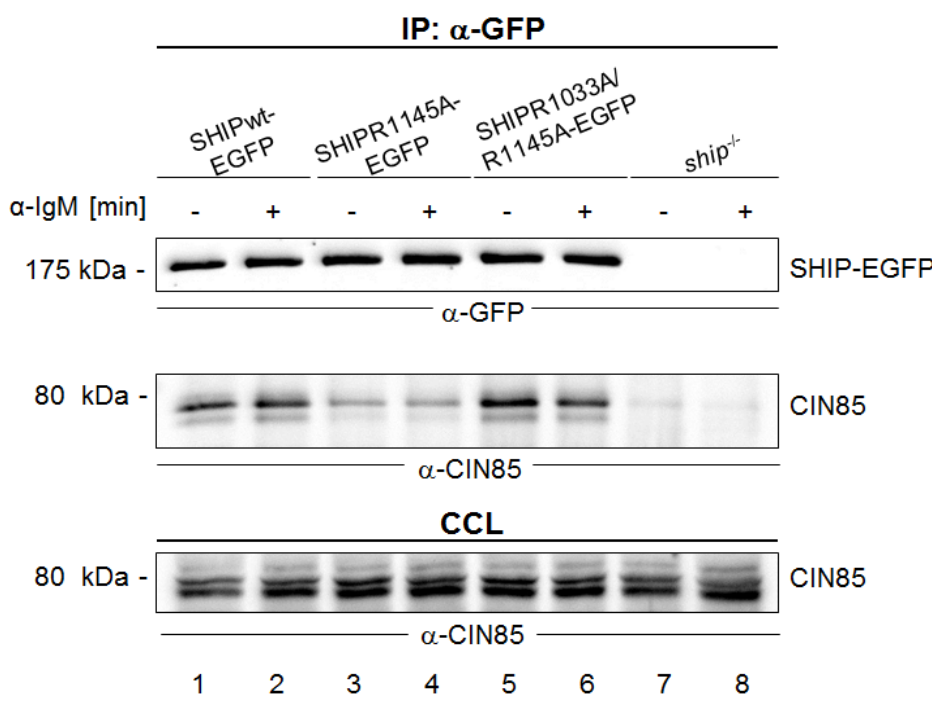

B

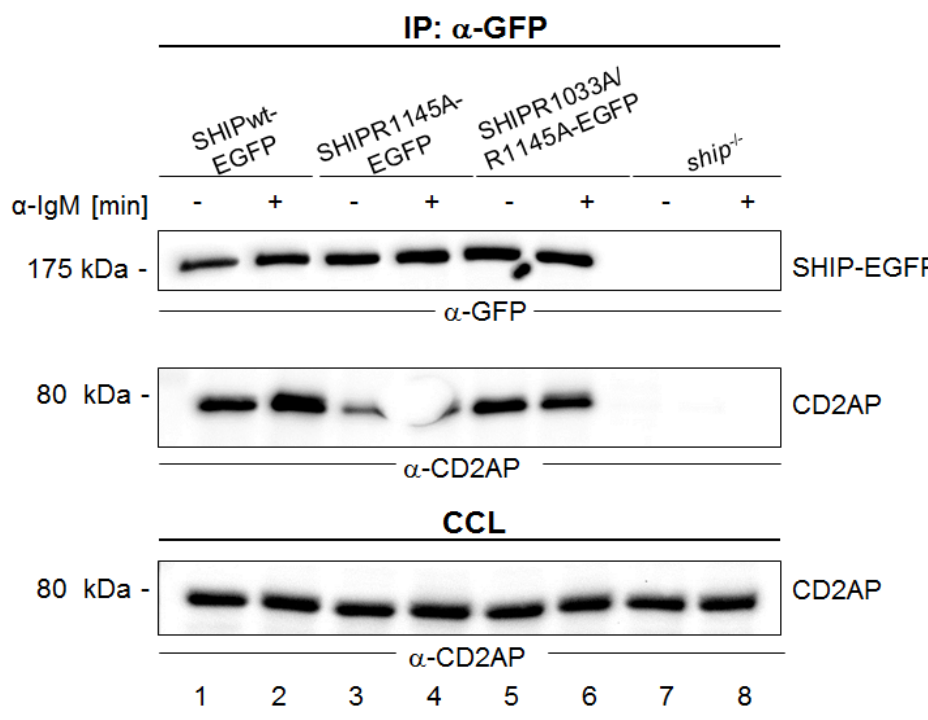

Figure 3.24: SHIP interacts with CIN85 and CD2AP in DT40 B cells. SHIP-deficient DT40 cells were transfected with plasmids encoding SHIPwt-EGFP (lanes 1, 2), SHIPR1145A-EGFP (lanes 3, 4) or SHIPR1033A/R1145A-EGFP (lanes 5, 6) or left untransfected (lanes 7, 8). Cells were left unstimulated or stimulated via their BCR for $3 \mathrm{~min}$. They were lysed and lysates (CCLs) were subjected to immunoprecipitation (IP) with an anti-GFP antibody. Immunoprecipitates were analyzed by immunoblotting with anti-GFP antibody to control pull-down efficiency (upper panels) and with either anti-CIN85 antibody (A, middle panel) or anti-CD2AP antibody (B, middle panel). CCLs were analyzed with antibodies against CIN85 or CD2AP (lower panels) to show the presence of the proteins in the cells.

A similar tendency was observed for SHIP recruitment. Here, a SHIP variant with mutations in both described binding motifs was more effectively recruited to the plasma 
membrane compared to SHIP carrying only the R1145A amino acid exchange (Figure 3.25).

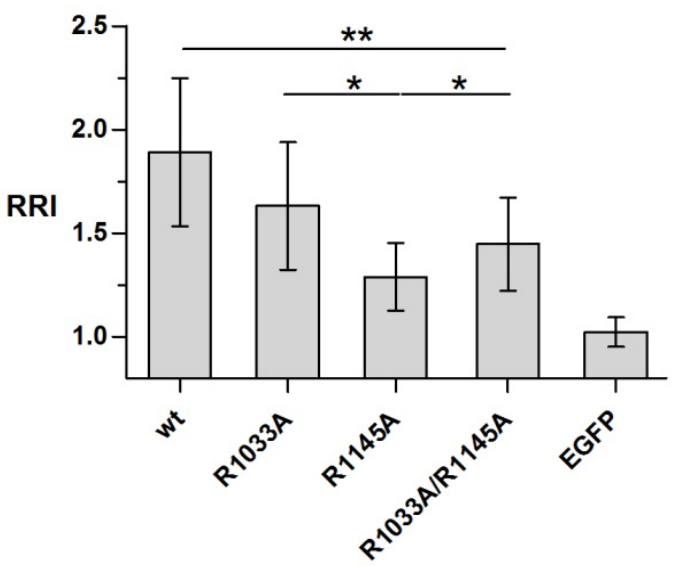

Figure 3.25: The recruitment of SHIP carrying mutations in described CIN85 binding motifs is reduced. SHIP-deficient DT40 cells were transfected with plasmids encoding EGFP-labeled SHIPwt, SHIPR1033A, SHIPR1145A, SHIPR1033A/R1145A or EGFP alone. SHIP localization was analyzed by confocal microscopy before and $3 \mathrm{~min}$ after BCR activation. The relative recruitment index (RRI) of SHIP in these cells was analyzed as described in figure legend 3.5. Bars represent means from $n=20$ cells (+/- SD). Student's t test: * $\mathrm{p}<0.05 ; * * \mathrm{p}<0.0001$.

These experiments show that SHIP interacts with CIN85 and CD2AP and that this requires the proline-rich region of SHIP encompassing R1145. Additional inactivation of the proline-rich region encompassing R1033 improved interaction of SHIPR1145A with CD2AP and CIN85.

\subsubsection{Nck2 binds to proline-rich regions of SHIP}

The interactome analysis identified Nck2 as an interaction partner of SHIP. Nck2 belongs to the noncatalytic region of tyrosine kinase (Nck) family, which has one other member, Nck1. They are involved in transducing activating signals to regulators of the actin cytoskeleton. Because Nck2 proteins possess three SH3 domains, interaction with SHIP is likely to be mediated by proline-rich regions of SHIP. Several proline-rich regions of SHIP were shown to be important for SHIP recruitment (see 3.2.3). Here, the binding of Nck2 to selected proline-rich regions of SHIP was analyzed. Immune purification experiments were in agreement with the mass spectrometry analysis and demonstrated that Nck2 interaction with SHIP is indeed mediated by SH3 domains binding to proline-rich regions (Figure 3.26). In particular, the proline-rich regions 
encompassing R1033 and R1145 were important for this interaction (Figure 3.26, lane 6). Whether lack of Nck2 expression affects SHIP recruitment was addressed in the context of a diploma thesis by J. Tucholski, who generated an Nck2-deficient DT40 cell line. However, he did not find impaired SHIP recruitment in the absence of Nck2 (Tucholski, 2010).

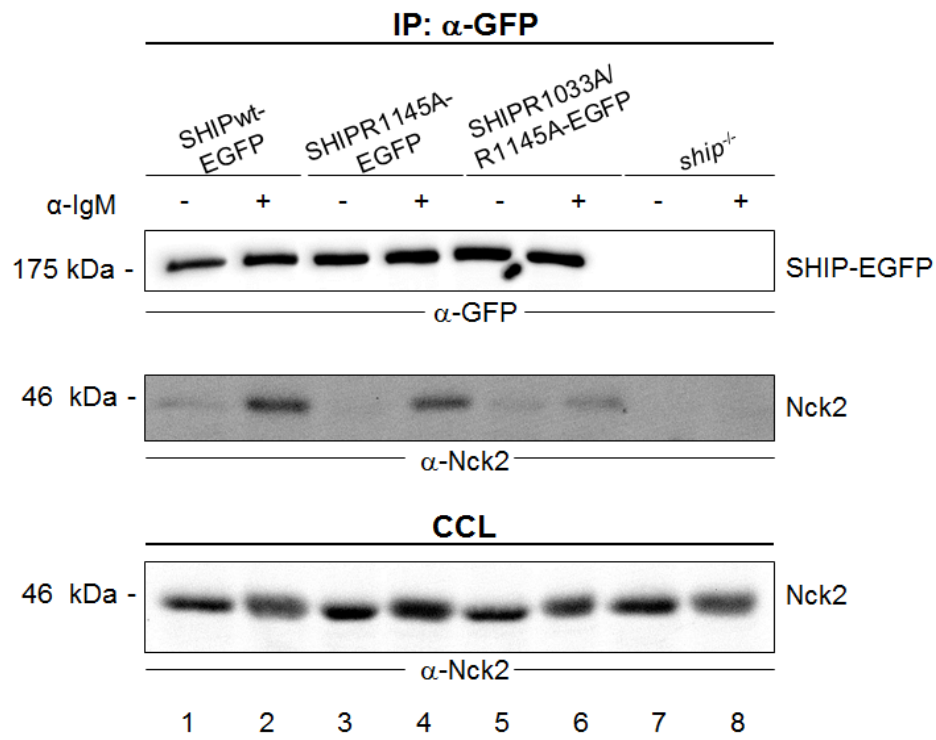

Figure 3.26: SHIP interacts with Nck2 in DT40 B cells. SHIP-deficient DT40 cells were transfected with plasmids encoding EGFP-labeled SHIPwt (lanes 1,2), SHIPR1145A (lanes 3, 4) or SHIPR1033A/R1145A (lanes 5, 6) or left untransfected (lanes 7, 8). Cells were left unstimulated or stimulated via their BCR for 3 min and lysed. Lysates (CCLs) were subjected to immunoprecipitation (IP) with an anti-GFP antibody. Immunoprecipitates were analyzed by immunoblotting with anti-GFP antibody to control pull-down efficiency (upper panels) and with anti-Nck2 antibody (middle panel). CCLs were analyzed with anti-Nck2 antibodies (lower panel) to show the presence of this protein in the cells. Results shown are representative for three experiments.

\subsubsection{HS1 binds to proline-rich regions of SHIP}

The hematopoietic cell-specific Lyn substrate 1 (HS1) is a protein that, albeit not identified by mass spectrometry with a sufficiently high score, could be considered a promising candidate to link SHIP to the actin cytoskeleton. Previous work from our group already showed an interaction of SHIP with HS1 (Hennemann, 2010). HS1 has a C-terminal SH3 domain, which could bind to one of the proline-rich regions of SHIP. To address this in more detail, the SH3 domain of HS1 (kindly provided by Dr. A. Hennemann) was used to precipitate SHIP carrying different mutations in selected proline-rich regions. Indeed, binding of SHIP to HS1 was strongly reduced when the 
very C-terminal proline-rich regions encompassing R1145 and K1151 were inactivated by amino acid exchanges (Figure 3.27, lanes 8, 9).

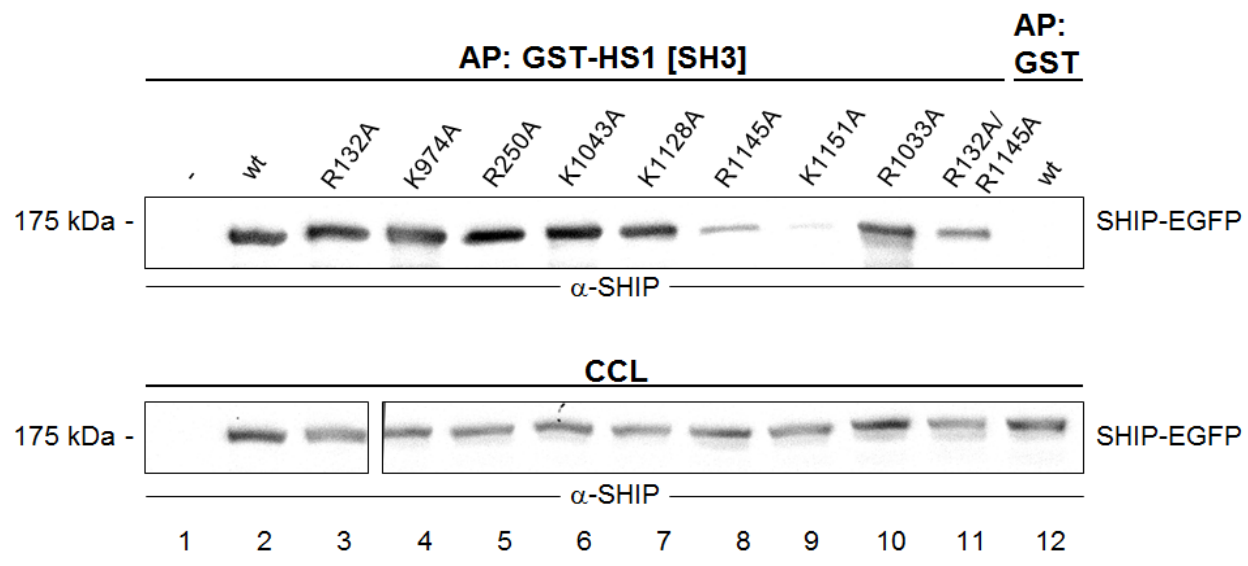

Figure 3.27: Binding of HS1 to SHIP is mediated by proline-rich regions encompassing R1145 and K1151. Cleared cellular lysates (CCLs) were prepared from SHIP-deficient DT40 transfectants expressing EGFP-labeled SHIP carrying the indicated mutations after retroviral gene transfer. CCLs were subjected to affinity purification (AP) with either GST-HS1[SH3] (lanes 1-11) or GST (lane 12). The precipitated proteins were analyzed by immunoblotting with anti-SHIP antibody (upper panel). Equivalent SHIP expression was shown by immunoblotting the CCLs with anti-SHIP antibody (lower panel). The indicated numbers refer to the position of amino acid exchanges that inactivated proline-rich regions. Protein sizes are indicated in $\mathrm{kDa}$.

Having identified a binding partner of proline-rich regions that is linked to the cytoskeleton (Gomez et al., 2006), it was interesting to find out whether HS1 is required for the plasma membrane recruitment of SHIP. An HS1-deficient DT40 cell line, which has recently been generated in our laboratory, was transfected with plasmids encoding EGFP-labeled SHIPwt. Confocal microscopy analyses revealed that the lack of HS1 resulted in decreased recruitment of SHIPwt (Figure 3.28). 


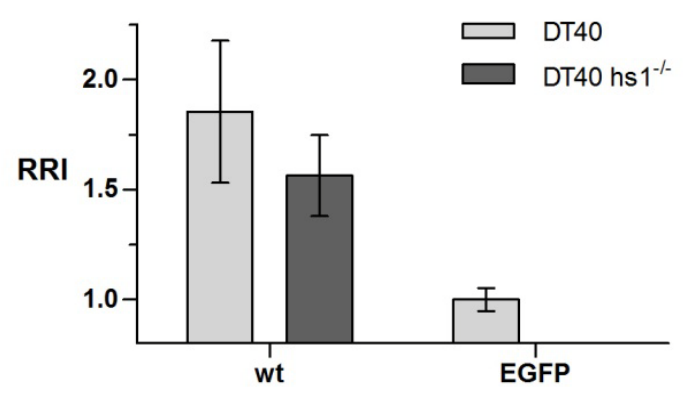

Figure 3.28: Lack of HS1 reduces SHIP plasma membrane recruitment. DT40 wt cells as well as HS1-deficient DT40 cells were transfected with plasmids encoding SHIPwt-EGFP. SHIP localization was analyzed by confocal microscopy before and 3 min after BCR activation. DT40 wt cells expressing EGFP were included for comparison. The relative recruitment index (RRI) of SHIP in these cells was analyzed as described in figure legend 3.5. Bars represent means from $n=20$ cells (+/- SD).

One noticeable observation was made during microscopy analyses of HS1-deficient cells. In most of the microscopy analyses performed in this study, SHIP was observed to a certain extent in a scattered manner at the plasma membrane of unstimulated cells (Figure 3.29 A and B). Efficient plasma membrane recruitment was still clearly visible. In HS1-deficient cells, however, this pre-recruitment was markedly reduced (Figure $3.29 \mathrm{C})$. The same was the case in cells lacking expression of the actin-binding protein 1 (Abp1, Figure 3.29 D), which is an adaptor that interacts with HS1 to control BCRproximal signaling events (Hennemann, 2010). Interestingly, pre-recruitment of SHIP to the plasma membrane was also absent when the proline-rich regions involved in HS1 binding were inactivated (Figure 3.29 E and F).

Taken together, CIN85, CD2AP and Nck2 do not play a major role in the BCRautonomous activation of SHIP, while HS1 has a small effect on plasma membrane recruitment. 

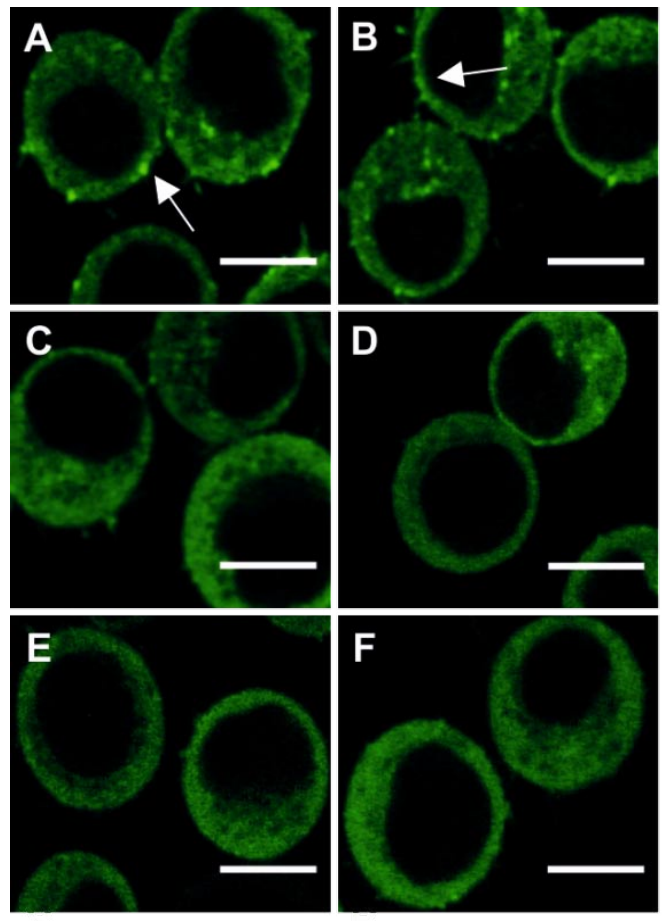

Figure 3.29: Pre-recruitment of SHIP to the plasma membrane of unstimulated cells is associated with expression of HS1 and Abp1 and presumably with their interaction with SHIP. Confocal microscopy images of SHIPwt-EGFP in unstimulated SHIP-deficient DT40 transfectants (A, B), unstimulated HS1-deficient (C) and Abp1-deficient DT40 transfectants (D) as well as of SHIPR1145AEGFP (E) and SHIPK1151A-EGFP (F) in unstimulated SHIP-deficient DT40 transfectants. Arrows mark scattered SHIP at the plasma membrane. Representative images were chosen from approximately 30 cells analyzed per setup. Scale bars $=5 \mu \mathrm{m}$.

\subsubsection{SHIP colocalizes with BCR microclusters}

This study clearly demonstrated the contribution of the SH2 domain to SHIP recruitment and function in positive signaling conditions (see 3.2.1). Following Fc $\gamma$ RIIB-BCR coactivation, the SH2 domain mediates SHIP recruitment by binding to the phosphorylated ITIM of the Fc $\gamma$ RIIB. A very central question that has not been answered yet concerns the identity of its binding partner in B cells in the absence of the Fc $\gamma$ RIIB. Binding of Lyn to the SH2 domain has been demonstrated in a monocytic leukemia cell line (Baran et al., 2003), but could not be confirmed for B cells in this study (data not shown). Another potential candidate was suggested by the analyzed interactome, which contained the Ig $\mu$ chain, i. e. part of the BCR. Previous experiments suggested that the interaction partner for the SH2 domain can be phosphorylated by the kinases Lyn as well as by Syk (see 3.3.2) since SHIP is recruited to some extend in the 
absence of either kinase. This is indeed the case for $\operatorname{Ig} \alpha$ and $\operatorname{Ig} \beta$ (Tamir \& Cambier, 1998; Rolli et al., 2002).

Based on the analysis of SHIP plasma membrane recruitment by confocal microscopy, it is not possible to draw conclusions about the exact localization of SHIP at the plasma membrane. Plasma membrane localization can therefore not be correlated with SHIP localization in the vicinity of $\operatorname{Ig} \alpha$ and $\operatorname{Ig} \beta$. Previous total internal reflection fluorescence microscopy (TIRFM) analysis by Dr. Facundo Batista, however, indicated that SHIPwt is recruited into microsignalosomes, which are signaling-competent antigen clusters. This implies a location very close to the BCR and probably a functional relevance of a potential interaction with the BCR. Therefore it was obvious to analyze the recruitment of SHIP into microsignalosomes in more detail. I performed the following experiments during a visit at Cancer Research UK, London, in collaboration with Dr. Facundo Batista and Tim Schnyder.

The aim of the TIRFM experiments was to analyze the colocalization of EGFP-labeled SHIPwt, SHIPR34G, SHIPYYFF, SHIPK1151A and SHIPR34G/YYFF/K1151A with BCR microclusters. The requirements of these structural motifs for SHIP function were shown in this study (see 3.2). TIRFM was performed on lipid bilayers containing fluorophore-labeled anti-BCR antibodies, which are used to indirectly detect the localization of the BCR. The measurements clearly showed a colocalization of SHIP with antigen-containing microclusters (Figure 3.30). Analysis of fluorescence intensity along a line showed clear overlapping of intensity peaks of SHIP and antigen-bound BCR. Image analysis revealed a colocalization of SHIPwt with microclusters of approximately $55 \%$. Moreover, TIRFM confirmed the important role of the SH2 domain as its inactivation resulted in a significantly reduced colocalization with antigen-containing BCR microclusters. This effect was more pronounced than that of inactivation of the NPXY motifs or the Grb2-binding site K1151. However, these results also showed that the $\mathrm{SH} 2$ domain is not the only motif mediating the colocalization because the inactivation of additional motifs in the triple mutant SHIPR34G/YYFF/K1151A-EGFP lead to an even more reduced colocalization. 
A
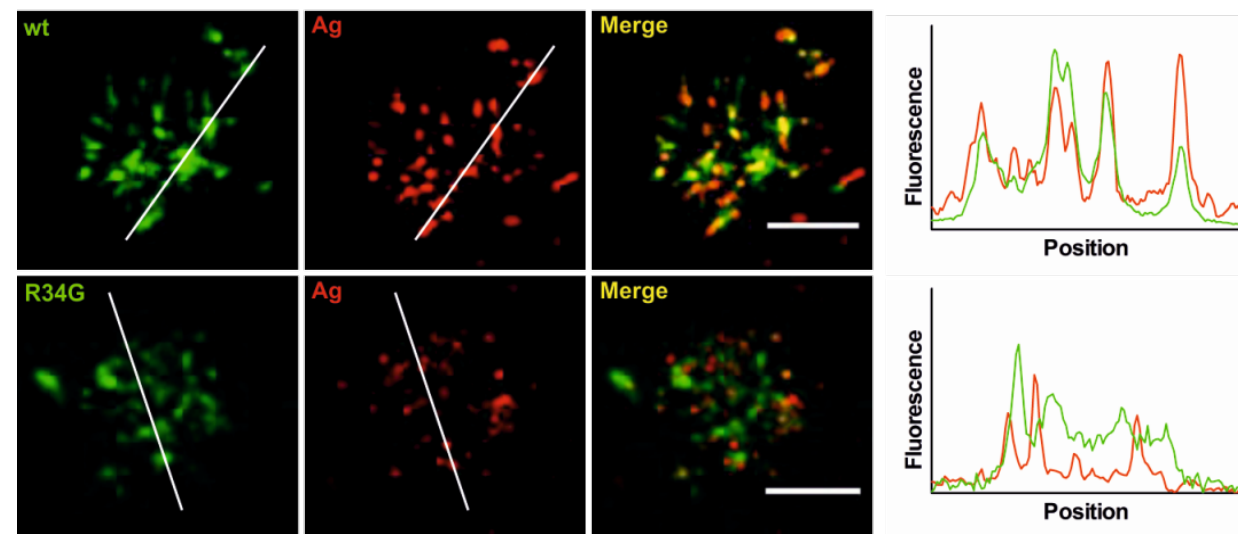

Merge
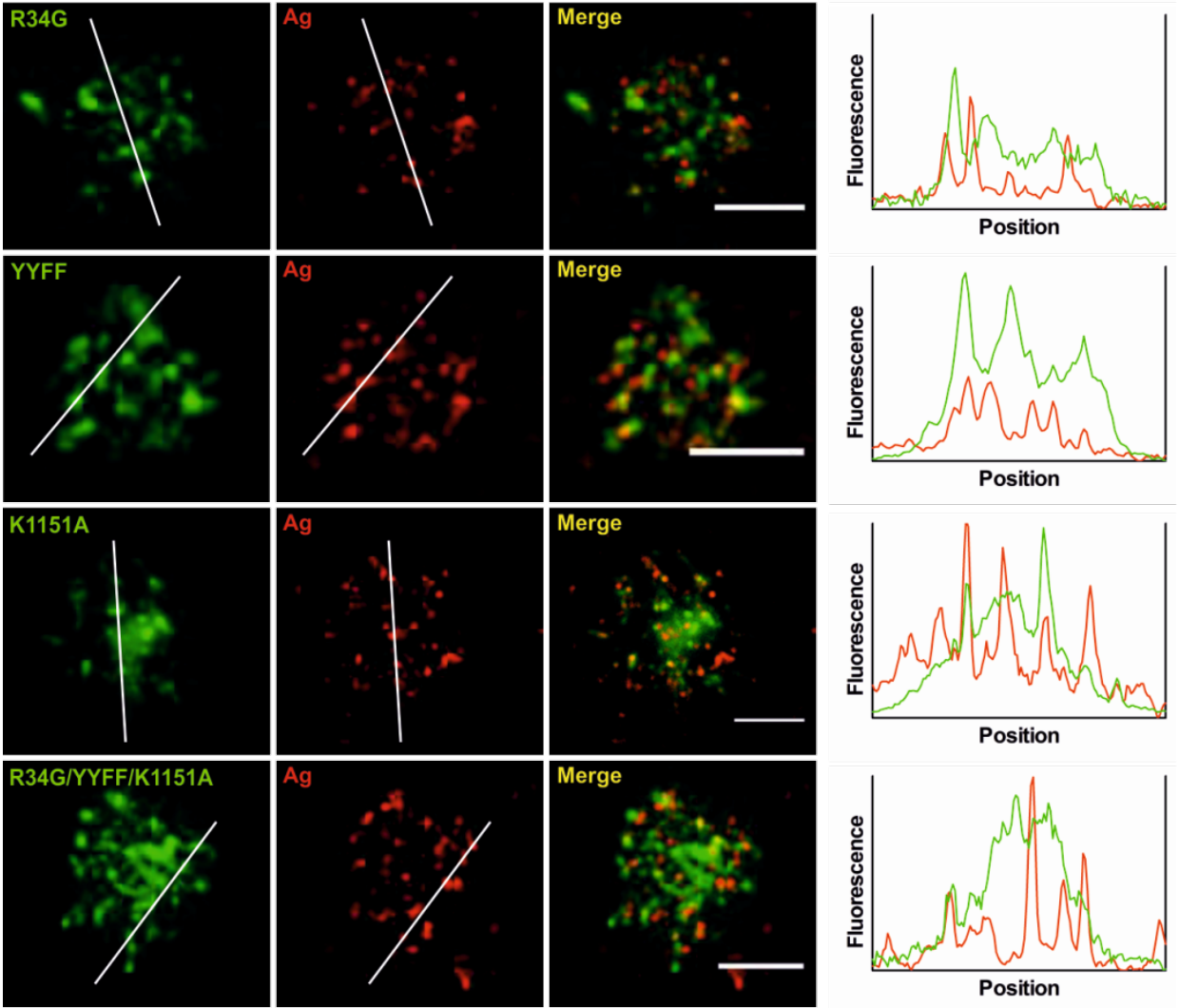

B

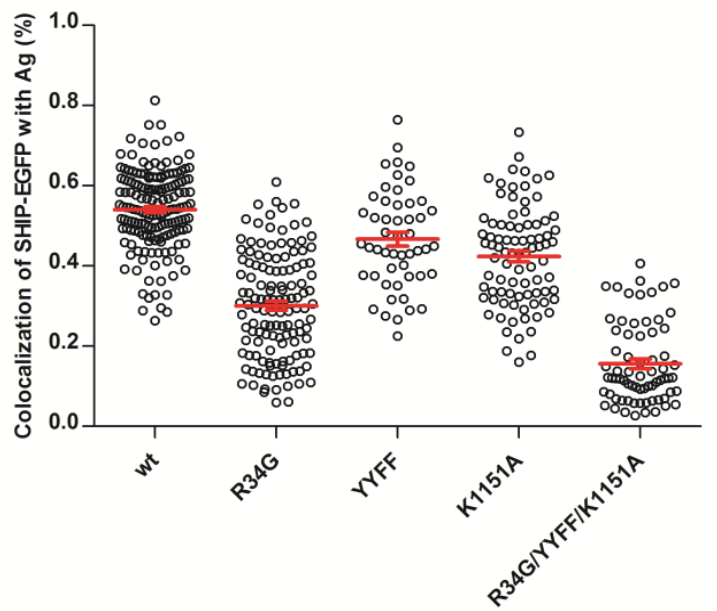

Figure 3.30: SHIP colocalizes with antigen-containing microclusters and this depends on the SH2 domain of SHIP. (A) SHIP-deficient DT40 cells expressing SHIPwt-EGFP, SHIPR34G-EGFP, SHIPYYFF-EGFP or SHIPR34G/YYFF/K1151A-EGFP after retroviral gene transfer were analyzed by TIRFM. (continued on next page) 
(legend to Figure 3.30 continued TIRFM was performed on lipid bilayers containing Alexa Fluo 633labeled anti-chicken IgM as surrogate antigen (Ag). Shown are representative TIRFM images and the relative fluorescence intensity (in arbitrary units) along a white line. (B) Images of cells described in (A) were analyzed by Imaris. Shown is the colocalization of EGFP intensity above a threshold with antigen (Ag). Each point is one cell, pooled from several independent experiments (mean and SEM in red).

Dok-3 and Shc are known interaction partners of the NPXY motifs, while Grb2 was identified to bind to K1151. Having analyzed the impact of these motifs on colocalization with microclusters, the next question was whether this impact could also be seen in DT40 cells lacking expression of the respective interaction partners. This was indeed the case. Lack of Dok-3 or Shc resulted in a colocalization of approximately $45 \%$, as did inactivation of the NPXY motifs (Figure 3.31). Likewise, consequences of a lack of Grb2 were comparable to the inactivation of the Grb2 binding site K1151, which resulted in a colocalization of $40 \%$.

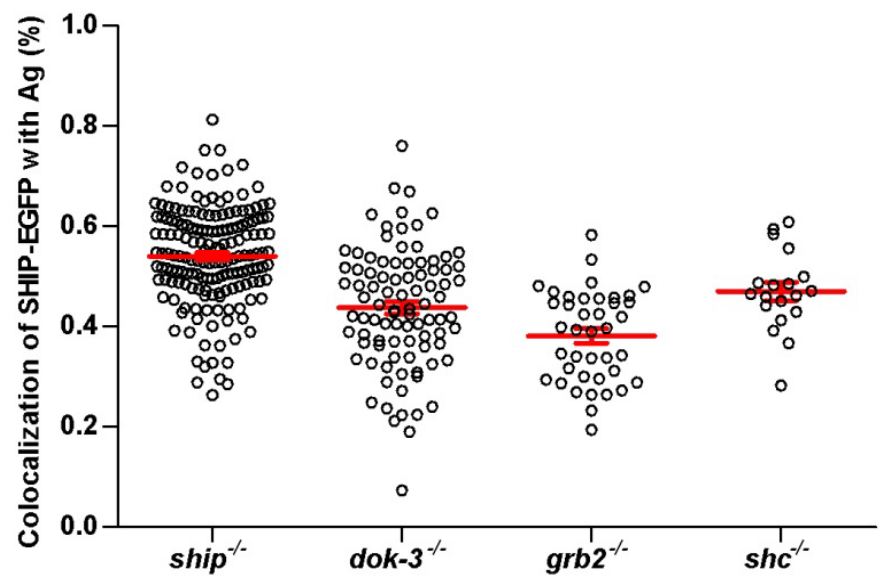

Figure 3.31: Dok-3, Grb2 and Shc contribute to SHIP colocalization with antigen-containing microclusters. DT40 cells lacking expression of SHIP, Dok-3, Grb2 or Shc were transfected with plasmids encoding SHIPwt-EGFP. Colocalization of SHIPwt-EGFP with antigen (Ag)-containing microclusters was analyzed by TIRFM on lipid bilayers containing Alexa Fluo 633-labeled anti-chicken IgM as surrogate antigen. Images were analyzed by Imaris. Shown is the colocalization of EGFP intensity above a threshold with antigen (Ag). Each point is one cell, pooled from several independent experiments (mean and SEM in red).

TIRFM experiments have thus confirmed the significance of the analyzed protein domains that has been demonstrated by confocal microscopy before. In addition, they show that SHIP is recruited into BCR-containing microclusters. 


\subsubsection{Ig $\alpha$ and Ig $\beta$ are potential membrane anchors of SHIP}

TIRFM analyses (see 3.3.5) and mass spectrometry analysis presented above (see 3.3.1) suggested the interaction of SHIP with $\operatorname{Ig} \alpha$ and $\operatorname{Ig} \beta$. To further investigate this hypothesis, a DT40 system had to be generated that allows studying the individual contribution of $\operatorname{Ig} \alpha$ as well as $\operatorname{Ig} \beta$. In the BCR, however, they naturally occur as dimers. By attaching the extracellular domain of CD8 to the intracellular domain of either Ig $\alpha$ or $\operatorname{Ig} \beta$ and by using these constructs to transfect DT40 cells, a system was generated that allowed stimulation of the cells with anti-CD8 antibodies. This way, activation would be transduced either exclusively via $\operatorname{Ig} \alpha$ or $\operatorname{Ig} \beta$. Confocal microscopy analysis was performed to investigate whether SHIP is recruited in this system and if differences between signaling via $\operatorname{Ig} \alpha$ or via $\operatorname{Ig} \beta$ exist. SHIP plasma membrane recruitment was observed following stimulation of CD8Ig $\alpha$ - and CD8Ig $\beta$-expressing cells with anti-CD8 antibody (Figure 3.32 A). The recruitment was clearly decreased, but still measurable, if the SH2 domain of SHIP was inactivated. The system also allowed the induction of $\mathrm{Ca}^{2+}$ mobilization by activation with anti-CD8 antibodies. Since it was based on a SHIP-deficient background, $\mathrm{Ca}^{2+}$ concentrations stayed high after stimulation of the parental cells (Figure 3.32 B, C). SHIP was functional in this system as reconstituting the cells with SHIPwt decreased $\mathrm{Ca}^{2+}$ levels. Reconstitution with SHIPR34G only weakly decreased BCR-induced $\mathrm{Ca}^{2+}$ concentrations. 
A

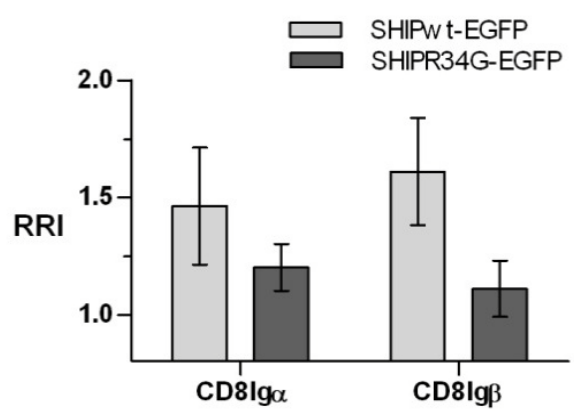

B

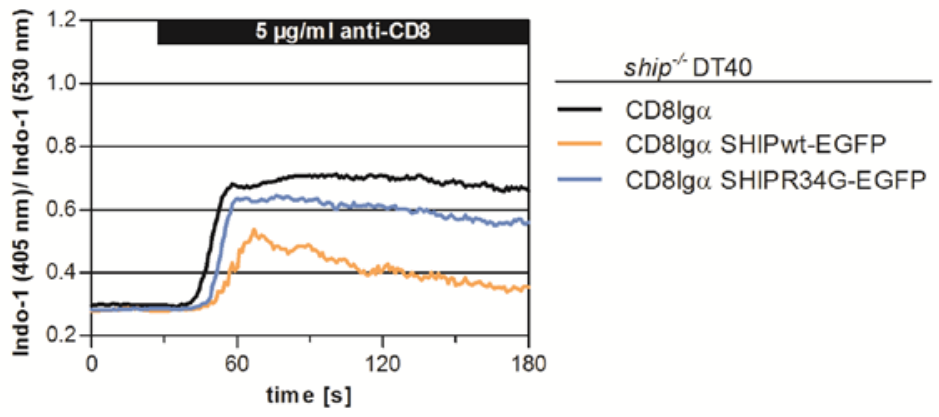

C

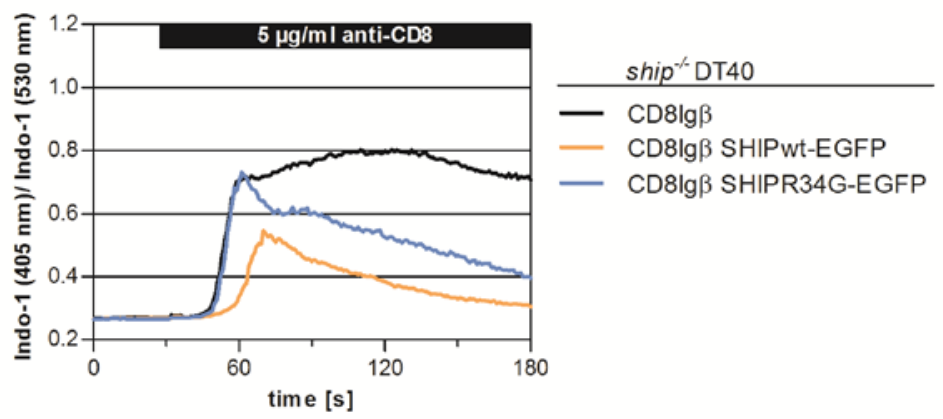

Figure 3.32: SHIP is recruited to the plasma membrane and is functional when signaling is only mediated via Iga or Ig $\boldsymbol{\beta}$. (A) SHIP-deficient DT40 cells were transfected with plasmids encoding CD8Ig $\alpha$ or CD8Ig $\beta$. Selected clones with comparable CD8 expression levels were then infected with retroviruses containing plasmids encoding SHIPwt-EGFP or SHIPR34G-EGFP. Cells were analyzed by confocal microscopy before and 3 min after stimulation with anti-CD8 antibodies. RRIs were calculated as described in figure legend 3.5. Bars represent means from $n=20$ cells (+/- SD). RRI, relative recruitment index. (B, C) Cells described in (A) were loaded with the $\mathrm{Ca}^{2+}$ indicator Indo-1 and antiCD8-induced $\mathrm{Ca}^{2+}$ fluxes were measured by flow cytometry. The result shown here is representative for 3 measurements.

To perform biochemical interaction studies with this setup, $C D 8 \operatorname{Ig} \alpha$ and $C D 8 \operatorname{Ig} \beta$ were fused to an HA-tag, which could easily be precipitated and detected with commercial anti-HA antibodies. Lysates of cells expressing either CD8Ig $\alpha-\mathrm{HA}$ or CD8Ig $\beta$-HA were subjected to affinity purification using the SH2 domain of SHIP. As a control, the known binding partner Fc $\gamma$ RIIB was included, in this case also HA-labeled. It was 
activated using pervanadate, which induces tyrosine phosphorylation by inhibiting phosphatases (Wienands et al., 1996). Following activation of the cells, the SH2 domain could indeed precipitate $\operatorname{Ig} \alpha, \operatorname{Ig} \beta$ as well as the Fc $\gamma$ RIIB (Figure 3.33, upper panel, lanes 2, 4, 8). Inactivation of the SH2 domain by a R34G amino acid exchange abrogated the ability of SHIP to bind Ig $\alpha, \operatorname{Ig} \beta$ and Fc $\gamma$ RIIB (Figure 3.33, middle panel, lanes 2, 4, 8).

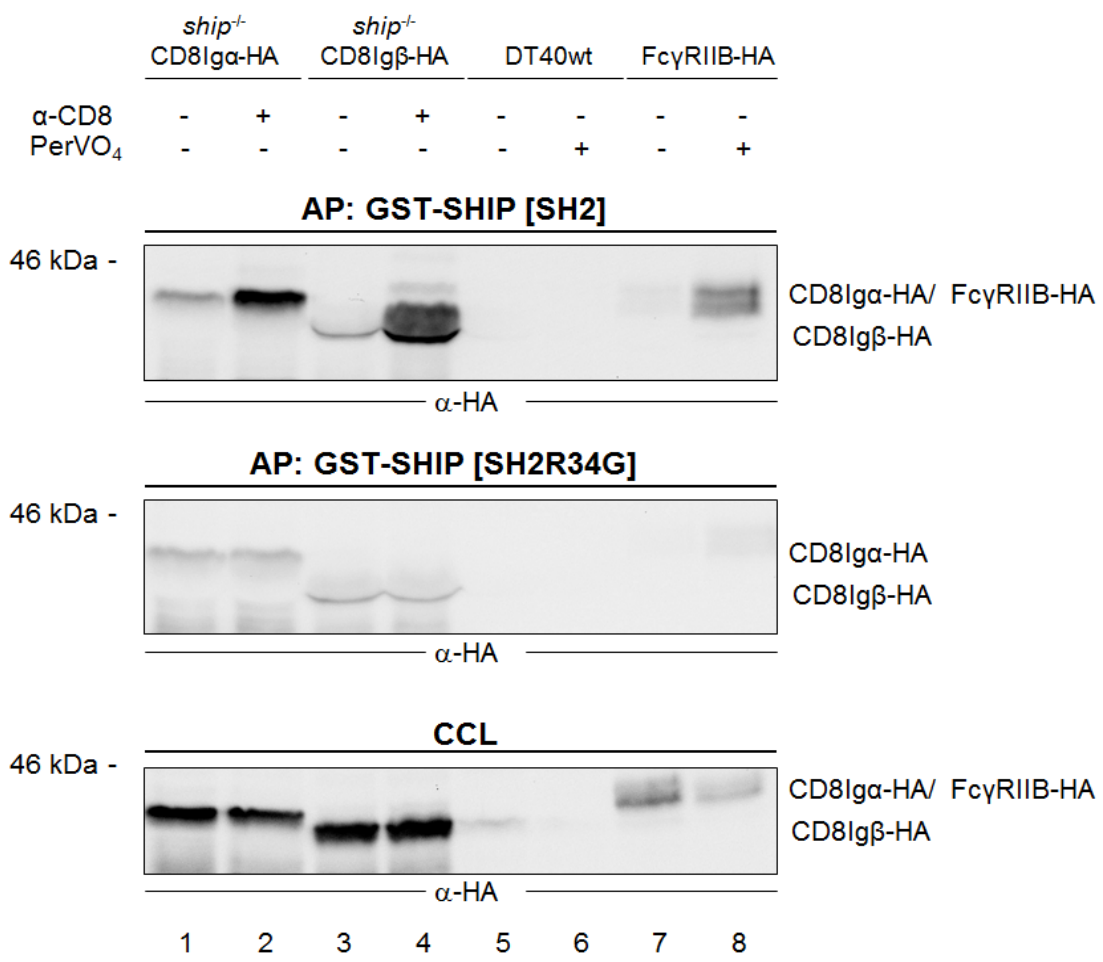

Figure 3.33: The intact SH2 domain of SHIP precipitates $\operatorname{Ig} \alpha$ and $\operatorname{Ig} \beta$. Cleared cellular lysates (CCLs) prepared from SHIP-deficient DT40 transfectants expressing CD8Ig $\alpha$-HA (lanes 1, 2) or CD8Ig $\beta$ HA (lanes 3, 4) as well as from DT40 wt cells (lanes 5, 6) and DT40 transfectants expressing Fc $\gamma$ RIIBHA (lanes 7, 8) were stimulated with $\alpha$-CD8 antibody for $1 \mathrm{~min}$ or with pervanadate $(\text { PerVO })_{4}$ for $10 \mathrm{~min}$. They were then subjected to affinity purification (AP) with either GST-SHIP[SH2] or GSTSHIP[SH2R34G]. Isolated proteins were analyzed by immunoblotting with anti-HA antibody. Expression of HA-labeled proteins was shown by immunoblotting the CCLs with anti-HA antibody (lower panel). Protein sizes are indicated in $\mathrm{kDa}$. Data represent the results of three independent experiments.

The affinity purification experiments further demonstrated that, to be functional, the isolated SH2 domain must encompass the amino acids 1-124. Initial experiments were carried out using a shorter version (1-101), which could not precipitate the $\operatorname{Ig} \alpha$ - and $\operatorname{Ig} \beta$ containing chimera, probably due to incomplete folding.

An interaction demonstrated by affinity purification might still be mediated by a third protein. To assess whether the observed binding was direct, far western blot analysis 
was carried out. Here, proteins blotted on a nitrocellulose membrane were first incubated with the GST-labeled SH2 domain of SHIP as well as with control SH2 domains. Subsequently, the binding of these protein domains was detected using an anti-GST antibody. The far western blot experiment made use of the cells expressing CD8Ig $\alpha$-HA or CD8Ig $\beta$-HA. An anti-HA IP was done first to enrich HA-expressing proteins. The tandem SH2 domains of Syk (kindly provided by Prof. J. Wienands) were used as a positive control because they are known binding partners of $\operatorname{Ig} \alpha$ and $\operatorname{Ig} \beta$. By far western blot analysis, it was in fact possible to demonstrate a direct binding of the SH2 domain of SHIP to Ig $\alpha$ and $\operatorname{Ig} \beta$ (Figure 3.34, upper panel, lanes 2, 4).

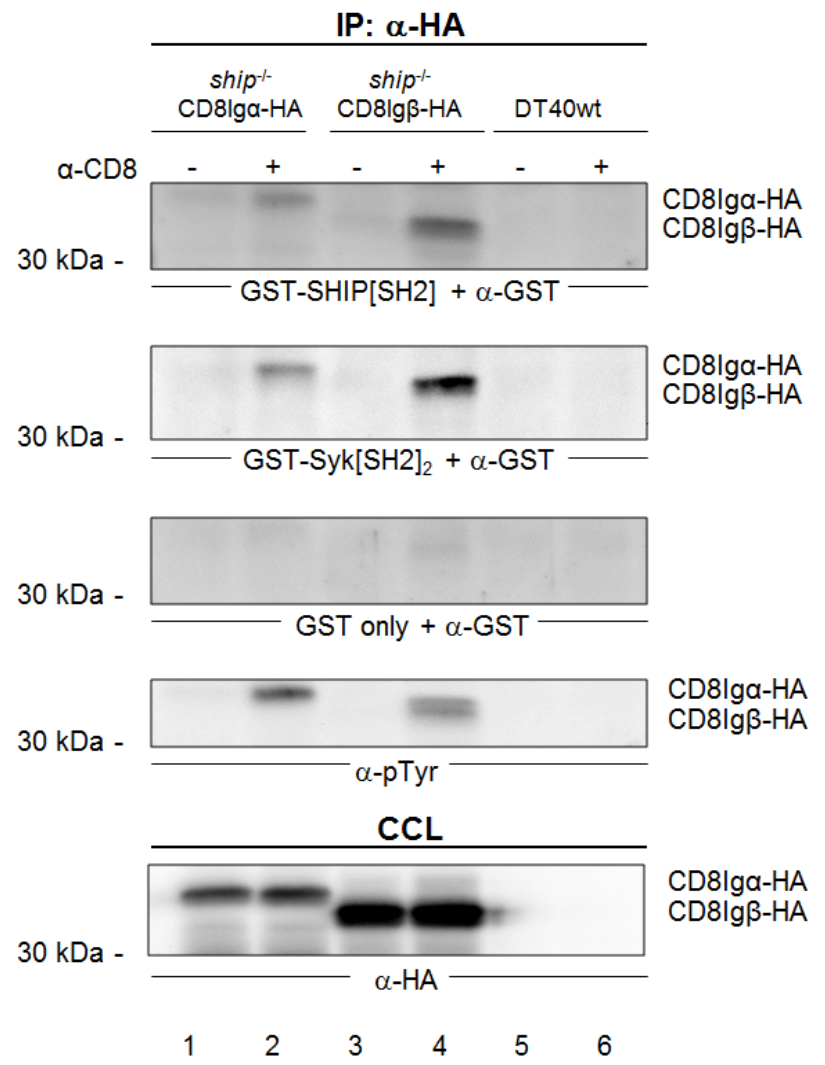

Figure 3.34: Direct interaction between the SH2 domain of SHIP and Iga and Igß. Cleared cellular lysates (CCLs) prepared from SHIP-deficient DT40 transfectants expressing CD8Ig $\alpha$-HA (lanes 1, 2) or CD8Ig $\beta$-HA (lanes 3,4 ) as well as from DT40 wt cells (lanes 5, 6) were stimulated with $\alpha$-CD8 antibody. They were then subjected to immunoprecipitation (IP) with anti-HA antibody. Immunoprecipitates were separated by SDS-PAGE and developed as a far western blot. Blots were incubated with GST-SHIP [SH2], GST-Syk [SH2] $]_{2}$ or GST only, followed by incubation with anti-GST antibody. The phosphorylation status was analyzed by immunoblotting with anti-phosphotyrosine antibody ( $\alpha$-pTyr). Expression of HA-labeled proteins was shown by immunoblotting the CCLs with anti-HA antibody (lower panel). Protein sizes are indicated in $\mathrm{kDa}$. Data represents the results of three independent experiments. 
One crucial binding partner of $\operatorname{Ig} \alpha$ and $\operatorname{Ig} \beta$ during BCR signaling is the kinase Syk. It preferentially binds with its tandem SH2 domains to the doubly phosphorylated ITAM, i. e. with both the N-terminal and the C-terminal tyrosine phosphorylated. To find out more about how the single SH2 domain of SHIP could compete with Syk, the identification of the interaction site within Ig $\alpha$ was necessary. To adress this, affinity purifications were carried out using biotinylated peptides that contained parts of the sequence of Ig $\alpha$ with differential phosphorylations of the N-terminal or C-terminal tyrosine of the ITAM or the non-ITAM Y204 (kindly provided by Dr. N. Engels). These peptides were used to precipitate SHIP from DT40 cells. Using this assay, it was possible to demonstrate the binding of SHIPwt-EGFP to Ig $\alpha$-peptides (Figure 3.35, upper panel). The binding was strongest when both ITAM peptides were phosphorylated (Figure 3.35, lane 4). Binding could also be detected if the C-terminal ITAM tyrosine or the non-ITAM Y204 were phosphorylated (Figure 3.35, lanes 3, 6, 7). An interaction with SHIPR34G-EGFP carrying an inactivated SH2 domain or with EGFP alone could not been shown. However, it should be noted, that the phosphorylation status of the peptides could not be unambiguously assessed. Nevertheless, analyzing the precipitates for binding of the known interaction partner Syk caused the expected results as Syk mainly bound to the doubly phosphorylated Ig $\alpha$ peptide (Figure 3.35, lower panel, lane 4). Weak binding was found if only the Nterminal tyrosine was phosphorylated. 


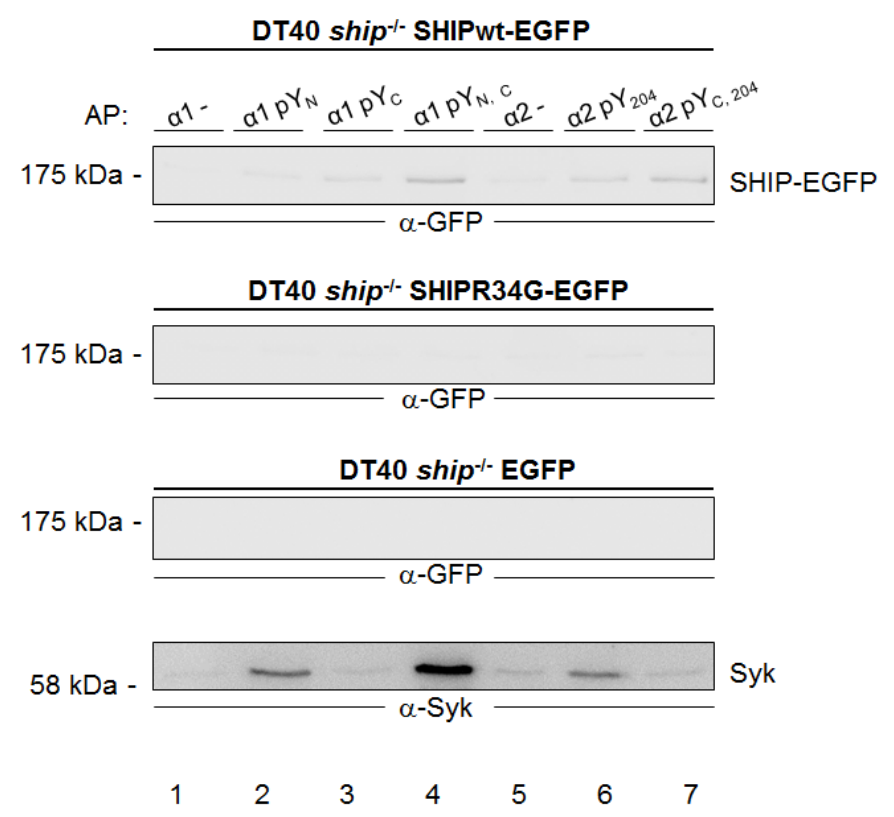

Figure 3.35: SHIP binds with its SH2 domain to phosphorylated Iga. Lysates of unstimulated SHIPdeficient DT40 transfectants expressing SHIPwt-EGFP (upper panel), SHIPR34G-EGFP (middle panel) or EGFP alone (lower two panels) were subjected to affinity purification (AP) with biotinylated peptides containing parts of the sequence of Ig $\alpha$. The sequence encompassed either the region around the ITAM ( $\alpha 1$ ) without phosphorylation (lane 1), with only the N-terminal (lane 2), only the C-terminal (lane 3) or both ITAM tyrosines phosphorylated (lane 4). AP was also done with peptides encompassing the Cterminal ITAM tyrosine and the non-ITAM tyrosine $204(\alpha 2)$. Here, this sequence was either unphosphorylated (lane 5), phosphorylated on tyrosine 204 (lane 6) or on the C-terminal tyrosine and on tyrosine 204 (lane 7). Precipitates were analyzed for the presence of EGFP using anti-GFP antibodies and for the presence of Syk using anti-Syk antibodies. Protein sizes are indicated in kDa. Peptides, except for $\alpha 1 \mathrm{pY}_{\mathrm{c}}$, were kindly provided by Dr. N. Engels. Data shown is representative for 2 experiments.

The above described experiments show that SHIP colocalizes with antigen-containing microclusters and that is is therefore in the direct vicinity of the BCR. Moreover, in vitro, direct binding of the SHIP SH2 domain to phosphorylated $\operatorname{Ig} \alpha$ and $\operatorname{Ig} \beta$ can be demonstrated. 


\section{Discussion}

The SH2 domain-containing 5' inositol phosphatase (SHIP) is a major inhibitor of B cell activation following coactivation of the BCR and the Fc $\gamma$ RIIB (Ono et al., 1997). Different studies indicated that SHIP is also activated in BCR-autonomous signaling (Bolland et al., 1998; Okada et al., 1998; Brauweiler et al., 2000). How it is activated in these conditions was, however, not known yet. The goal of this study was therefore to identify the underlying mechanism of SHIP activation under positive signaling conditions. In summary, this study verified the process of FcyRIIB-independent SHIP recruitment in primary B cells and DT40 B cells. It further demonstrated that SHIP activation following BCR activation alone is primarily mediated by binding of the SHIP SH2 domain to the signaling subunits of the BCR. Plasma membrane localization is supported and stabilized by participation in ternary complexes consisting of Shc, Dok-3 and Grb2 and binding to HS1.

\subsection{SHIP is activated independently of the FcyRIIB}

Following activation, cytosolic SHIP translocates to the plasma membrane and hydrolyzes phospholipids located at the inner leaflet of the plasma membrane. Earlier studies consequently suggested that SHIP recruitment to the plasma membrane is the most important step in SHIP activation (Aman et al., 2000; Phee et al., 2000). Indeed, membrane-targeted expression of SHIP is sufficient for its inhibitory potential (Ono et al., 1997).

In this study, translocation to the plasma membrane was therefore used as a major readout for SHIP activation. The confocal microscopy analysis of this process was more practical and precise than alternative methods such as isolation of membrane fractions and their analysis by western blot. Relocalization of SHIP to the plasma membrane was demonstrated in primary mouse B cells stimulated with $\mathrm{F}\left(\mathrm{ab}{ }^{\prime}\right)_{2}$ fragments of anti-BCR antibodies. This is a BCR-autonomous event because even though mouse B cells do express the low-affinity receptor for IgG, Fc $\gamma$ RIIB, stimulation with $F(a b \text { ' })_{2}$ fragments 
prevents its stimulation and therefore simulates positive signaling conditions. This is in agreement with studies showing BCR-induced SHIP enrichment in membrane fractions of the B cell line Ramos (Petrie et al., 2000). BCR-induced membrane translocation of SHIP was also clearly visible in DT40 B cells, which were used for further detailed analysis of the molecular mechanisms. Introducing SHIP-EGFP into SHIP-deficient DT40 cells resulted in efficient inhibition of BCR-induced $\mathrm{Ca}^{2+}$ mobilization compared to cells expressing only EGFP, demonstrating BCR-dependent SHIP activation. This correlates well with findings by Okada and colleagues, who compared SHIP-deficient with wild-type DT40 cells and observed a similar impact of SHIP on $\mathrm{Ca}^{2+}$ fluxes (Okada et al., 1998).

Moreover, SHIP phosphorylation in positive signaling conditions was clearly demonstrated in DT40 cells. It was further increased after BCR-Fc $\gamma$ RIIB coactivation. Phosphorylation of SHIP is a prerequisite for its interaction with the adaptor proteins Shc (Lioubin et al., 1996) and Dok-3 (Lemay et al., 2000). Some controversy exists as far as SHIP phosphorylation in the absence of the FcyRIIB is concerned. Although some studies find that SHIP is only phosphorylated following BCR-Fc $\gamma$ RIIB coactivation (Chacko et al., 1996; Tridandapani et al., 1997), my results are in line with observations by others (Saxton et al., 1994).

In summary, these results demonstrate BCR-induced SHIP activation. SHIP phosphorylation, but not its recruitment, is further enhanced by BCR-Fc $\gamma$ RIIB coactivation. SHIP activation thus occurs also in positive signaling conditions, without involvement of the FcyRIIB. Nevertheless, it should be noted that coactivation has consequences beyond SHIP recruitment, such as decreased CD19 phosphorylation, leading to reduced PI3K recruitment and less PtdIns(3,4,5) $\mathrm{P}_{3}$ production (Hippen et al., 1997). Moreover, SHIP recruitment to the FcyRIIB results in increased formation of SHIP-Grb2-Dok-3 complexes, enforcing inhibition by SHIP (Neumann et al., 2011). It should thus be emphasized that BCR-autonomous SHIP activation does not imply redundancy of the Fc $\gamma$ RIIB, but rather another level of control in cellular activation. 


\subsection{Molecular mechanism of FcyRIIB-independent SHIP activation}

\subsubsection{SHIP colocalizes with BCR microclusters}

Confocal microscopy analysis can only reveal whether SHIP theoretically has the possibility to hydrolyze PtdIns(3,4,5) $\mathrm{P}_{3}$ leading to depletion of membrane anchors for the $\mathrm{Ca}^{2+}$ initiation complex (Ono et al., 1996). It does not provide information about the exact localization of SHIP within the plasma membrane area due to limited resolution. However, the exact localization of a protein at the membrane is highly important (Dykstra et al., 2003). Submembraneous organization and the right localization with regard to substrates and interaction partners are appreciated to be essential for lymphocyte activation (reviewed in Pierce \& Liu, 2010; Treanor et al., 2010). State-ofthe-art TIRFM analyses carried out in cooperation with Dr. Facundo Batista and Tim Schnyder revealed that a significant proportion of SHIP colocalizes with BCR microclusters after BCR activation alone. BCR microclusters mediate the assembly of signaling-active microsignalosomes (Weber et al., 2008). This contradicts published observations that colocalization of SHIP and the BCR requires Fc $\gamma$ RIIB coactivation (Phee et al., 2001). However, these findings were based on fixed and stained samples analyzed by confocal microscopy and might have missed BCR-induced colocalization. A colocalization of approximately 55 \% cannot be explained by coincidence or simple diffusion as microsignalosomes specifically include some molecules while excluding others (Depoil et al., 2008; Weber et al., 2008). The fact that SHIP colocalizes with microclusters implies that the dampening effect of the phosphatase is important in this context. Colocalization with BCR microclusters further implies efficient hydrolysis of PtdIns $(3,4,5) \mathrm{P}_{3}$ at the site of their production by PI3K, which is part of the signalosome (reviewed in Harwood \& Batista, 2010).

Comparing TIRFM analyses, which were carried out on lipid bilayers mimicking membrane-bound antigen, and confocal microscopy analyses performed with soluble antigen showed comparable recruitment of SHIP variants. This is interesting regarding studies arguing that membrane-bound antigen is the predominant form of antigen encountered by B cells in vivo (Depoil et al., 2008). SHIP activation apparently does not depend on the mode of antigen encounter.

TIRFM analyses demonstrated that SHIP colocalization with BCR microclusters depends on the SH2 domain, which is consistent with its requirement for membrane 
recruitment and $\mathrm{Ca}^{2+}$ inhibition. The reduced recruitment to the plasma membrane is also in agreement with strongly reduced phosphorylation by Lyn, which associates with BCR microclusters (Sohn et al., 2008). This is supported by similar observations made in IL-3-stimulated DA-ER cells (Liu et al., 1997a).

\subsubsection{SHIP interacts with the signaling subunits of the BCR}

The predominant role of the SH2 domain underlined that the identification of its interaction partner is of prime importance for the elucidation of the mechanism of SHIP activation. Here, I demonstrate the in vitro interaction of the SH2 domain with Ig $\alpha$ and $\operatorname{Ig} \beta$, which is supported by the observed colocalization with BCR microclusters. In the affinity purification experiments, the SHIP SH2 domain precipitated the known interaction partner, Fc $\gamma$ RIIB, in lower amounts than $\operatorname{Ig} \alpha$ and $\operatorname{Ig} \beta$. However, the Fc $\gamma$ RIIB was also expressed at lower levels and was phosphorylated as a result of pervanadate treatment, while $\operatorname{Ig} \alpha$ and $\operatorname{Ig} \beta$, expressed as fusion proteins with $\mathrm{CD} 8$, were phosphorylated in consequence of anti-CD8 stimulation. These different stimulation conditions hindered direct comparison. In all three cases, interaction was lost after inactivation of the SHIP SH2 domain, proving the specificity of the SH2 domain. The direct mode of this interaction was shown by far western experiments. Here, the ITAMbinding tandem SH2 domains of Syk were used as a control. They bound stronger to $\operatorname{Ig} \beta$ than to Ig $\alpha$, which is explained by slightly higher expression levels of $\operatorname{Ig} \beta$ as well as by the fact that Syk prefers the Ig $\beta$ ITAM (Wienands et al., 1995).

In the literature, Shc and Lyn were suggested to be binding partners of the SH2 domain (Liu et al., 1997b; Baran et al., 2003). However, studies by Lamkin and colleagues argued against an interaction of Shc and the SH2 domain (Lamkin et al., 1997). Because Lyn is required for microsignalosome assembly (Weber et al., 2008), it is conceivable that SHIP colocalization with microclusters depends on interaction with Lyn. However, binding to Lyn apart from the substrate-enzyme interaction could not be demonstrated in this study (data not shown). Moreover, SHIP was still recruited, albeit to a lesser extent and in a delayed manner, in Lyn-deficient cells. This implied binding of the SH2 domain to a protein that is not only phosphorylated by Lyn but also by other kinases. Indeed, the signaling units of the BCR, $\operatorname{Ig} \alpha$ and $\operatorname{Ig} \beta$, are phosphorylated by Lyn and Syk. This is described in the literature (Rolli et al., 2002) and can be concluded from observations that Lyn-deficient cells are able to mobilize $\mathrm{Ca}^{2+}$ following $\mathrm{BCR}$ 
activation. The delayed recruitment of SHIP in Lyn-deficient cells might stem from Syk being less effective in phosphorylating the $\operatorname{Ig} \alpha-\operatorname{Ig} \beta$ heterodimer and is in agreement with the commonly observed delayed onset of BCR-induced $\mathrm{Ca}^{2+}$ mobilization in Lyndeficient cells (Takata et al., 1994). Considering the reduced SHIP recruitment in Lyndeficient cells and the fact that Lyn phosphorylates SHIP, one might reason that the reduced recruitment is solely due to missing SHIP phosphorylation and consequently absence of protein interactions contributing to recruitment. However, SHIPwt recruitment in Lyn-deficient cells was more impaired than SHIPYYFF recruitment in wild-type cells. Hence it is obvious that Lyn has functions exceeding SHIP phosphorylation. Considering its broad range of substrates (Scapini et al., 2009), it is in fact likely that Lyn additionally phosphorylates interaction partners of SHIP. One such interaction partner phosphorylated by Lyn is Dok-3 (Stork et al., 2007). However, as unphosphorylated Dok-3 cannot efficiently participate in the ternary complex SHIPGrb2-Shc, this consequence of reduced SHIP-Dok-3 interaction is already contained within the SHIPYYFF phenotype and does thus not explain the observed difference.

SHIP binding to ITAMs is in fact plausible considering published interactions of SHIP. Previous studies reported that SHIP not only binds to ITIMs having the consensus sequence $(\mathrm{I} / \mathrm{V} / \mathrm{L} / \mathrm{S}) \mathrm{XYXX}(\mathrm{I} / \mathrm{V} / \mathrm{L} / \mathrm{S})$, where $\mathrm{X}$ denotes any amino acid, but also to ITAMs, which have the consensus sequence $\mathrm{YXX}(\mathrm{I} / \mathrm{L}) \mathrm{X}_{6-8} \mathrm{YXX}(\mathrm{I} / \mathrm{L})$. Osborne and colleagues used a yeast tribrid system to identify the SH2 domain of SHIP as a downstream effector of the phosphorylated ITAM-containing high-affinity IgE receptor FceRI $\gamma$ chain on mast cells (Osborne et al., 1996). More precisely, they did mutational analysis to show that SHIP binding requires the C-terminal tyrosine and leucine residues of the ITAM but not the respective residues in the $\mathrm{N}$-terminal part. In addition, they demonstrated that the isolated SH2 domain of SHIP interacts with phosphorylated ITAM-containing CD3 $\gamma, \delta$, and $\varepsilon$ chains as well as with the T-cell receptor-associated $\zeta$ chains. Inhibition by ITAM-containing molecules has also been discussed by Barrow and Trowsdale (Barrow \& Trowsdale, 2006). One interesting example is IgA-mediated signaling in peripheral blood mononuclear cells, which can have pro- as well as antiinflammatory effects (Pasquier et al., 2005). IgA binds to the IgA Fc receptor Fc $\alpha$ RI, which can be physically associated with the ITAM-containing FcR $\gamma$. Monomeric IgA leads to incomplete phosphorylation of the ITAM in FcR $\gamma$ and consequently inhibition of cellular activation, while binding of multimeric IgA complexes results in strong phosphorylation of the ITAM and cellular activation. Pasquier and colleagues explained 
these observed differences by differential recruitment of downstream effectors to FcaRI (Pasquier et al., 2005). While weak ITAM phosphorylation results in strong recruitment of the inhibitory SHP1, complete ITAM phosphorylation clearly favors Syk recruitment and consequently cellular activation. A similar correlation in B cells was recently shown by a study demonstrating that ITAM monophosphorylation in anergic B cells is associated with inhibitory signaling via SHIP (O'Neill et al., 2011).

Affinity purification with differentially phosphorylated Ig $\alpha$ peptides further suggested that SHIP binding to ITAMs could be narrowed down to the C-terminal tyrosine. Even though the phosphorylation status of the peptides could not be determined precisely, control experiments with the tandem SH2 domains of Syk produced the expected results as they bound strongest to doubly phosphorylated ITAMs and showed some binding to N-terminally phosphorylated ITAMs. Binding of Syk to monophosphorylated ITAMs might be possible considering that binding of Syk to so-called hemITAMs of C-type lectin-like receptor 2 occurs. These hemITAMs have a single YXXL sequence and can signal via Syk (Severin et al., 2011). Indeed, the N-terminal ITAM tyrosine of mouse $\operatorname{Ig} \alpha$ and $\operatorname{Ig} \beta$, which was used for generation of the fusion proteins, is found in the context of a hemITAM. Assuming that the phosphorylation status of the Ig $\alpha$ peptides is secure, the experiments suggest preferred SHIP binding to those peptides carrying phosphorylations on the C-terminal ITAM tyrosine.

SHIP binding to Ig $\alpha$ and $\operatorname{Ig} \beta$ implies competition with Syk. The tandem SH2 domains of Syk have a higher avidity to ITAMs compared to single SH2 domains (Ottinger et al., 1998). Even though one of the SH2 domains may dissociate and reassociate, binding is maintained by the second SH2 domain. This is not the case for SHIP having only one SH2 domain. It is likely that competition between SHIP and Syk is relevant in situations of weak or asymmetrical ITAM phosphorylation. Pao and colleagues found that phosphorylation of Ig $\alpha$ and $\operatorname{Ig} \beta$ ITAMs is asymmetrical. However, they observed preferential phosphorylation of the N-terminal tyrosine (Pao et al., 1998), which is in accordance with findings that Lyn preferentially phosphorylates the N-terminal tyrosine of Ig $\alpha$ (Flaswinkel \& Reth, 1994; Schmitz et al., 1996). Accordingly, other experiments also argued for strong phosphorylation of the membrane-proximal ITAM tyrosine and the non-ITAM Y204 of Ig $\alpha$ but not of the C-terminal ITAM tyrosine (Kabak et al., 2002), maybe due to an inhibitory effect of serine and threonine residues around the Cterminal tyrosine (Muller et al., 2000; Patterson et al., 2011). One very recent study on SHIP-mediated inhibitory signaling in anergic cells also detected SHIP phosphorylation 
only in the presence of the N-terminal tyrosine of $\operatorname{Ig} \alpha$ and $\operatorname{Ig} \beta$ (O'Neill et al., 2011). Therefore, further experiments need to be done to unequivocally identify the ITAM tyrosine residue binding to SHIP. It should be noted that the action of tyrosine kinases is counterbalanced by tyrosine phosphatases. SHP1 dephosphorylates Ig $\alpha$ (Rolli et al., 2002) and it cannot be excluded that this dephosphorylation process transiently yields C-terminally monophosphorylated ITAMs.

Weak binding of the SH2 domain to the non-ITAM Y204 of Ig $\alpha$ was observed in affinity purification experiments. Y204 binds to SLP-65 and is therefore involved in recruitment of the $\mathrm{Ca}^{2+}$ initiation complex (Engels et al., 2001). Its presence in Ig $\alpha$ is one obvious difference between $\operatorname{Ig} \alpha$ and $\operatorname{Ig} \beta$ (reviewed in Wienands \& Engels, 2001). However, biochemical experiments described before did not point to differential SHIP binding to $\operatorname{Ig} \alpha$ and $\operatorname{Ig} \beta$, rendering binding to Y204 unlikely. In addition, functional assays investigating SHIP recruitment and inhibition of $\mathrm{Ca}^{2+}$ mobilization after signaling exclusively via $\operatorname{Ig} \alpha$ or $\operatorname{Ig} \beta$ did not suggest such a difference either. Although differences between $\operatorname{Ig} \alpha$ and $\operatorname{Ig} \beta$ with regard to SHIP activation have not been observed in this thesis, in vivo situations of partial phosphorylation might favor SHIP binding to Ig $\alpha$ only. Barrow and Trowsdale addressed the fact that some ITAMs contain within their sequence a consensus ITIM, which they named "closet ITIM" (Barrow \& Trowsdale, 2006). Partial phosphorylation of only the ITIM tyrosine residue might promote recruitment of ITIM-binding proteins as opposed to complete ITAM phosphorylation. In fact, the C-terminal ITAM tyrosine of mouse Ig $\alpha$ and its neighboring residues display such a closet ITIM.

\subsubsection{Stabilization of SHIP plasma membrane localization by ternary complexes}

As outlined above, the SH2 domain is important for colocalization of SHIP with microclusters as well as for binding to $\operatorname{Ig} \alpha$ and $\operatorname{Ig} \beta$ and inhibition of $\mathrm{Ca}^{2+}$ mobilization. However, other domains also contribute to SHIP function as even in the absence of a functional SH2 domain, inhibition of $\mathrm{Ca}^{2+}$ mobilization was not completely abrogated. Moreover, inactivation of other domains apart from the SH2 domain had implications for SHIP recruitment and function. Especially the NPXY1020 motif and the proline-rich regions encompassing R1145 and K1151 were required for optimal recruitment, while $\mathrm{Ca}^{2+}$ inhibition depended on Y1020 and proline-rich regions encompassing K1151 and 
R132. This is in agreement with findings by Aman and colleagues, who observed that a truncated version of SHIP lacking both NPXY motifs and the C-terminal proline-rich regions inhibited $\mathrm{Ca}^{2+}$ mobilization after BCR-Fc $\gamma$ RIIB coactivation less efficiently than SHIPwt (Aman et al., 2000). They could restore these defects by membrane targeted expression of the truncated SHIP variant, implying that the C-terminal region might either be needed to direct SHIP to the plasma membrane or to stabilize it there.

This is in line with the observation that participation of SHIP in the ternary complexes SHIP-Grb2-Shc and SHIP-Grb2-Dok-3 stabilizes its plasma membrane localization. Shc may contribute to SHIP recruitment as it translocates to the plasma membrane following BCR activation (Saxton et al., 1994). This might be mediated by binding to Ig $\alpha$ via its SH2 domain (Baumann et al., 1994; D'Ambrosio et al., 1996) or the Grb2-associated binding protein 1 (Ingham et al., 1998). Dok-3, on the other hand, localizes constitutively to the plasma membrane of DT40 B cells (Stork et al., 2007) and can thereby stabilize SHIP membrane localization.

In this study, I identified the proline-rich region encompassing K1151 as the Grb2binding site in SHIP. This is in agreement with reported observations that the binding site is a proline-rich region in the C-terminal part of SHIP (Damen et al., 1996). Inactivation of this binding site disrupted SHIP-Shc interaction, which proofs that Grb2 binding to SHIP is required for stable SHIP-Shc interaction. Until now, this assumption depended on the fact that a peptide with the Grb2-binding, proline-rich sequence of Son of Sevenless (Sos) can disrupt the SHIP-Shc interaction (Harmer \& DeFranco, 1999). Grb2 is required for stable interaction of SHIP with Shc and Dok-3. Nevertheless, lack of Grb2 did not combine the recruitment defects observed in Shc- and Dok-3-deficient cells, indicating that the contribution of both ternary complexes to SHIP recruitment is rather small in comparison to the contribution of the SH2 domain of SHIP. This was reflected by TIRFM analyses showing that the SH2 domain is more important for recruitment than the other domains analyzed and that lack of Shc, Dok-3 or Grb2 leads only to a small reduction in colocalization with BCR-containing microclusters. Grb2binding-deficient SHIP, SHIPK1151, also colocalizes with BCR microclusters. Even though its general plasma membrane recruitment is significantly reduced, the proportion that is recruited is mainly recruited into areas of microclusters, where it can efficiently inhibit $\mathrm{Ca}^{2+}$ mobilization. This is consistent with the minor impact of this amino acid exchange on the inhibition of $\mathrm{Ca}^{2+}$ mobilization. 
Experiments presented in this study demonstrated that the tyrosine residue Y917 does not influence SHIP recruitment or activity, even though early studies on SHIP as an Shc interaction partner pointed at a more important role of Y917. In these studies, a yeast two-hybrid screen with the Shc PTB domain as a bait was done and identified some clones having only the Y917 phosphotyrosine motif and several with both phosphotyrosine motifs (Lioubin et al., 1996). Here, I showed that phenylalanine substitutions of Y917 or Y1020 abrogated interaction with Shc. It is not clear why interaction with Shc having only one PTB domain requires both phosphotyrosines. Lamkin and colleagues have used COS cells expressing SHIP to show that single phenylalanine substitutions significantly reduced SHIP co-immunoprecipitation with the Shc PTB domain. Inactivation of both phosphotyrosines abrogated SHIP binding in their assay as well (Lamkin et al., 1997). It might be possible that Shc favors binding to Y1020, but is inferior to Dok-3, which only binds to Y1020. This would result in the apparent requirement of both phosphotyrosines. Co-immunoprecipitation of SHIP and Shc was only possible from stimulated cells, which is in line with findings by others (Liu et al., 1994). Conflicting reports about a constitutive interaction of those two proteins might be due to the cellular system used in the respective study (Osborne et al., 1996). I showed that formation of the ternary complex SHIP-Grb2-Shc is necessary for the interaction between SHIP and Shc. Formation of this complex was not possible in the assay by Lamkin and colleagues described above as they only used the PTB domain of Shc for Co-IP (Lamkin et al., 1997). Nevertheless, they successfully coimmunoprecipitated SHIP, probably due to the excessive addition of the PTB domain allowing observation also of instable interactions.

Although I found that the lack of Shc reduced SHIP recruitment to the plasma membrane, it was shown that Shc does not contribute to inhibition of $\mathrm{Ca}^{2+}$ mobilization following BCR-Fc $\gamma$ RIIB coactivation (Aman et al., 2000). Possibly the interaction between SHIP and Shc is functionally more relevant for Shc than for SHIP. In fact, Shc must interact with SHIP to become phosphorylated or to maintain phosphorylation (Ingham et al., 1999) and can only then form a complex with Grb2 and the Ras guanine nucleotide exchange factor Sos (Harmer \& DeFranco, 1997), leading to activation of the Ras/MAPK pathway. It is therefore likely that Shc has only a minor impact on SHIP recruitment and that the importance of this interaction is rather to allow efficient Shc phosphorylation and to replace Shc-Grb-Sos complexes by Shc-Grb2-SHIP complexes. Shc is phosphorylated by Syk (Nagai et al., 1995), which is a prerequisite for its 
interaction with SHIP. Reduced SHIP recruitment observed in Syk-deficient cells might therefore be due to the fact that Shc cannot be phosphorylated and can consequently not bind to SHIP and contribute to its recruitment.

Comparable to Shc, Dok-3 binding to SHIP also has a minor stabilizing role in SHIP recruitment. Confocal microscopy analyses performed in this study showed that it contributed to SHIP recruitment to a similar extent as Shc. The BCR-induced interaction of Dok-3 and SHIP in Grb2-expressing cells was clearly demonstrated in this study. Dok-3 is a negative regulator of BCR-induced $\mathrm{Ca}^{2+}$ signaling as it recruits Grb2, which then inhibits Btk-dependent activation of PLC- $\gamma 2$ in a process that does not require SHIP (Stork et al., 2007). A role of the SHIP-Dok-3 complex in inhibition of the JUN N-terminal kinase was not analyzed here, but should be noted to underline the importance of this complex for processes other than $\mathrm{Ca}^{2+}$ mobilization (Robson et al., 2004).

Although both complexes have only minor stabilizing roles in SHIP recruitment, abrogation of these interactions by inactivation of the phosphotyrosine motifs has functional consequences. The diminished recruitment of SHIPYYFF translated into impaired inhibition of $\mathrm{Ca}^{2+}$ mobilization, which was in fact more impaired than after inactivation of the Grb2-binding site. A reason might be that Dok-3 is found in microsignalosomes (Schnyder et al., 2011) and that SHIP binding to Dok-3 supports SHIP translocation into membrane areas where efficient PtdIns $(3,4,5) \mathrm{P}_{3}$ hydrolysis can take place. However, Grb2 is also located in microsignalosomes (Schnyder et al., 2011) implying that inactivation of the Grb2-binding site should impair inhibition of $\mathrm{Ca}^{2+}$ mobilization as much as inactivation of the NPXY motifs. Here it should be noted that transient interactions of SHIP with one of the other components of the ternary complexes are probably possible despite the lack of the third component. Transient interaction, presumably not equally to all interaction partners, but with hierarchical preferences, might be too weak for biochemical detection, but sufficient to support recruitment.

\subsubsection{SHIP-HS1 interaction contributes to membrane recruitment}

SHIP plasma membrane localization is furthermore supported by interaction with HS1. This interaction is mediated by the proline-rich regions encompassing R1145 or K1151. As they are located adjacent to each other, inactivation of one domain possibly disturbs 
binding of HS1, which has only SH3 domain, to the other domain. HS1 translocates Syk-dependently into lipid rafts (Hao et al., 2004). This offers another possible explanation for the observed reduction in SHIP recruitment in Syk-deficient cells, apart from the role of Shc mentioned above. Furthermore, HS1 promotes actin assembly and branching (Uruno et al., 2003) and might link SHIP recruitment to cytoskeletal rearrangements. Such a link was suggested by the observation that SHIP recruitment is impaired after chemical disturbance of actin polymerization (Tucholski, 2010). Consistent with this, a slight reduction in SHIP recruitment was detected in the absence of HS1. Another observation might be associated with SHIP-HS1 interaction. This concerns the corresponding pre-recruitment pattern in HS1- or Abp1-deficient cells or after alanine substitutions of K1151 or R1145, which were identified as potential binding sites for HS1. Determining the biological significance of pre-recruitment will require further investigations.

A contribution of CD2AP, CIN85 and Nck2, which are also associated with the cytoskeleton, to SHIP activation was not observed. Interaction of SHIP with these proteins was shown by mass spectrometry and biochemical analyses. Their contribution to SHIP activation was indirectly assessed by analyzing the influence of inactivating the identified binding motifs. All three proteins bind via SH3 domains to the proline-rich region encompassing R1145 in SHIP. SHIPR1145A is less efficiently recruited to the plasma membrane and, apart from HS1, no potential interaction partner of this motif is known. CIN85 binding to SHIPR1033A/R1145A was described to be reduced in HEK293T cells (Kowanetz et al., 2004). In this thesis, binding of CIN85 and CD2AP was only reduced to SHIPR1145A, but not to SHIPR1033A/R1145A. The reason for this observation is unclear. They might have another potential interaction site that was missed in the affinity purification experiment. Interestingly, the interaction of SHIP and Nck2 was only observed in stimulated cells even though binding is likely to occur via proline-rich regions and should therefore not depend on phosphorylation events. Inducible SH3 domain-mediated interaction was found for other proteins (Chen et al., 2006) and explained by an activation-induced conformational change that exposes the interaction site. However, since Nck2 interaction was found to depend on R1145, the same site that mediates constitutive interaction with CIN85 and CD2AP, this possibility is less likely. Efficient inhibition of $\mathrm{Ca}^{2+}$ mobilization by SHIPR1145A makes contribution of CD2AP, CIN85 and Nck2 to SHIP activation unlikely, even though they might support recruitment to some extent. Interaction with CIN85 and Nck2 might even 
contribute to colocalization of SHIP with microclusters because CIN85 colocalizes with microclusters (Oellerich et al., 2011) and, even though the exact localization of Nck2 at the plasma membrane of B cells is still unclear, studies in T cells showed its recruitment to the TCR (Gil et al., 2002).

Substrate binding of the catalytic domain, which is essential for inhibition of $\mathrm{Ca}^{2+}$ fluxes (Ono et al., 1997), does not contribute to recruitment. Inactivation of this domain by a D676G amino acid exchange even resulted in a small increase in SHIP recruitment. This might indicate the existence of an inhibitory feedback mechanism that becomes operative as soon as a certain amount of PtdIns $(3,4,5) \mathrm{P}_{3}$ is hydrolyzed. In the absence of catalytic activity, this feedback inhibition would not be switched on. Concerning $\mathrm{Ca}^{2+}$ fluxes, inhibition by SHIPD676G-EGFP was more effective than by EGFP alone, suggesting that SHIP has inhibitory functions beyond its phosphatase activity.

The main findings of this thesis are summarized in a model of Fc $\gamma$ RIIB-independent SHIP activation, which includes binding of the SH2 domain to ITAMs of $\operatorname{Ig} \alpha$ and $\operatorname{Ig} \beta$ and stabilization of membrane localization by complexes consisting of SHIP-Grb2-Shc and SHIP-Grb2-Dok-3 as well as binding to HS1 (Figure 4.1). SHIP binding to ITAMs brings SHIP into the vicinity of Lyn, which phosphorylates SHIP and allows for efficient formation of the ternary complexes. Stabilization of plasma membrane localization by participating in these complexes is necessary for full SHIP function. Finally, these results demonstrate that SHIP not only mediates signal inhibition in response to immune complexes in conjunction with the Fc $\gamma$ RIIB, but is also functional under positive signaling conditions, probably by setting thresholds for activation. Even resting cells are permanently on the verge of activation (Pierce \& Liu, 2010) and it is tempting to speculate about SHIP preventing inappropriate activation. The experiments further suggest that signaling cannot be regarded as a linear process with interactions and events happening in a strict order. It is possible that weak phosphorylation is enough to mediate an interaction that has marked consequences and that SHIP can switch from one mode of interaction to another. The proposed model of SHIP activation therefore rather reflects the paradigm of signaling as a coordinated recruitment of signaling proteins into protein complexes, where different transient interactions are possible. This view is shared by several authors regarding signaling in general (Reth \& Brummer, 2004; Fruman \& Bismuth, 2009; Kim et al., 2010). 


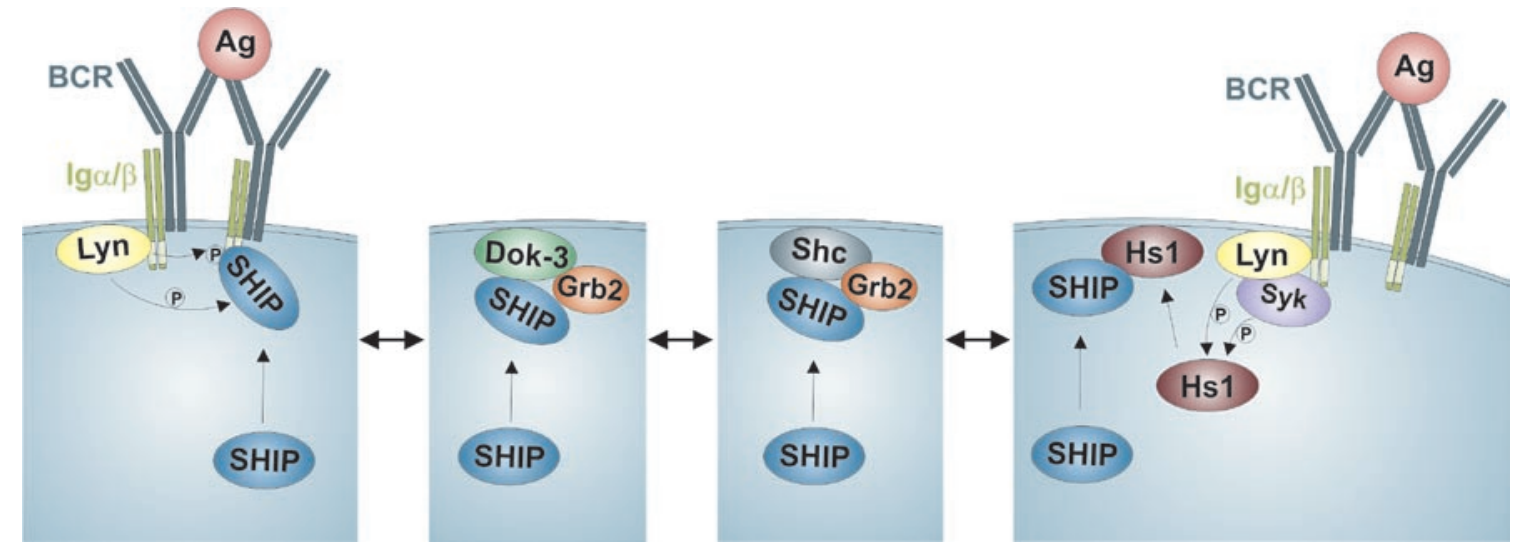

Figure 4.1: Proposed model of FcyRIIB-independent SHIP activation. After BCR activation by antigen (Ag) binding, cytosolic SHIP is recruited to the plasma membrane by binding to monophosphorylated ITAMs of $\operatorname{Ig} \alpha$ and $\operatorname{Ig} \beta$. This facilitates its phosphorylation by Lyn. Binding to Dok-3, Shc and Grb2 in the context of ternary complexes supports recruitment. The majority of SHIP is recruited into microsignalosomes. Binding to HS1, which is phosphorylated by Lyn and Syk, also contributes to recruitment. SHIP can presumably switch from one mode of interaction to the other. Plasma membrane localization of SHIP is sufficient for activation. 


\section{Summary and Conclusions}

Activation of the $\mathrm{B}$ cell antigen receptor (BCR) initiates a signaling pathway with pivotal consequences for the cellular response. The need for regulation of BCR signaling is therefore obvious and clearly demonstrated by the fatal effects caused by defects in this signaling cascade, which can be as severe as autoimmunity, immunodeficiency or cancer (Niiro \& Clark, 2002). One essential negative regulator of B cell activation is the inositol phosphatase SHIP, which hydrolyzes the membrane phospholipid phosphatidylinositol-3, 4, 5-trisphosphate and thereby depletes membrane anchors for activating enzymes of the BCR signaling cascade. Two ways of SHIP activation exist. On the one hand, it is activated in consequence of BCR-Fc $\gamma$ RIIB coactivation by immune complexes. In such inhibitory signaling conditions, SHIP is directly recruited to the ITIM of the FcyRIIB, thereby translocating the protein to the plasma membrane into the vicinity of its phospholipid substrate. The cooperation of SHIP and the Fc $\gamma$ RIIB provides a feedback control to prevent excessive antigen-specific antibody production. On the other hand, a role of SHIP in BCR- autonomous signaling was indicated by studies showing FcrRIIB-independent SHIP activation. However, despite the fundamental inhibitory role of SHIP, it was unknown how it is activated in the absence of the FcyRIIB. The elucidation of the underlying mechanism of BCRautonomous SHIP activation was the goal of this thesis. As membrane translocation is essential for SHIP activation, the structural requirements for this process were assessed by confocal microscopy analysis of EGFP-labeled SHIP variants. This clearly demonstrated FcyRIIB-independent recruitment of SHIP and showed that the SH2 domain, the phosphotyrosine motif at Y1020 and proline-rich regions at the C-terminus contribute to efficient plasma membrane recruitment of SHIP, with the SH2 domain having the largest impact. A more precise analysis of SHIP membrane localization by TIRF microscopy revealed SH2 domain-dependent colocalization of SHIP with BCR microclusters. Recruitment into microcluster-derived microsignalosomes allows efficient signal inhibition by SHIP. I further showed binding of the SH2 domain to the signaling subunits of the BCR, $\operatorname{Ig} \alpha$ and $\operatorname{Ig} \beta$. This facilitates phosphorylation of SHIP by 
BCR-associated Lyn, which was shown to be the only kinase mediating BCR-induced SHIP phosphorylation in DT40 cells. According to my data, the SH2 domain is crucial for SHIP activation, while the C-terminus of SHIP stabilizes membrane localization. Indeed, phosphorylated SHIP can efficiently participate in the ternary complexes SHIPGrb2-Shc and SHIP-Grb2-Dok-3. Besides the phosphotyrosine motifs, this requires the Grb2-binding site, which was identified to be the proline-rich region around K1151. Membrane recruitment is further supported by the interaction of SHIP with actin cytoskeleton-associated HS1, which is mediated by C-terminal proline-rich regions of SHIP. According to these results, the processes described are not organized in a strict hierarchical order, but are rather in a dynamic equilibrium.

In this thesis I showed that signal inhibition by SHIP is also operative under positive signaling conditions. BCR-autonomous SHIP activation demonstrates that inhibition by SHIP is a significant component of the intricate regulatory network that controls B cell activation. Increased SHIP phosphorylation and increased formation of SHIP-Grb2Dok-3 complexes, on the other hand, are two consequences of BCR-Fc $\gamma$ RIIB coactivation demonstrating the non-redundant function of the FcyRIIB. The colocalization of SHIP with BCR microclusters that results in effective signal inhibition is in line with the spatially organized processes within the plasma membrane that are today's accepted paradigm of signaling. Instead of homogenous distribution of signaling molecules, spatial segregation provides specific microenvironments for regulation of cellular activation. Their analysis requires state-of-the-art high-resolution microscopy analysis as used in this study. Due to its regulatory role in the PI3K pathway, the recently discovered suppressive effect on B cell lymphomas (Miletic et al., 2010) and its significant regulatory Fc $\gamma$ RIIB-independent impact on BCR signaling, SHIP is a highpotential therapeutic target and SHIP activators can be envisaged for the treatment of hematopoietic and immune disorders. Data on the molecular mechanism of SHIP activation presented here may contribute to the development of therapies targeting SHIP. 


\section{Bibliography}

Abudula A, Grabbe A, Brechmann M, Polaschegg C, Herrmann N, Goldbeck I, Dittmann K, Wienands J (2007) SLP-65 signal transduction requires Src homology 2 domain-mediated membrane anchoring and a kinase-independent adaptor function of Syk. $J$ Biol Chem 282: 29059-29066

Adachi T, Wienands J, Wakabayashi C, Yakura H, Reth M, Tsubata T (2001) SHP-1 requires inhibitory co-receptors to down-modulate $\mathrm{B}$ cell antigen receptor-mediated phosphorylation of cellular substrates. J Biol Chem 276: 26648-26655

Aman MJ, Walk SF, March ME, Su HP, Carver DJ, Ravichandran KS (2000) Essential role for the C-terminal noncatalytic region of SHIP in FcgammaRIIB1-mediated inhibitory signaling. Mol Cell Biol 20: 3576-3589

Antony P, Petro JB, Carlesso G, Shinners NP, Lowe J, Khan WN (2004) B-cell antigen receptor activates transcription factors NFAT (nuclear factor of activated T-cells) and NF-kappaB (nuclear factor kappaB) via a mechanism that involves diacylglycerol. Biochem Soc Trans 32: 113-115

Baba TW, Humphries EH (1984) Differential response to avian leukosis virus infection exhibited by two chicken lines. Virology 135: 181-188

Baran CP, Tridandapani S, Helgason CD, Humphries RK, Krystal G, Marsh CB (2003) The inositol 5'-phosphatase SHIP-1 and the Src kinase Lyn negatively regulate macrophage colonystimulating factor-induced Akt activity. J Biol Chem 278: 38628-38636

Barrow AD, Trowsdale J (2006) You say ITAM and I say ITIM, let's call the whole thing off: the ambiguity of immunoreceptor signalling. Eur J Immunol 36: 1646-1653

Batista FD, Iber D, Neuberger MS (2001) B cells acquire antigen from target cells after synapse formation. Nature 411: 489-494

Baumann G, Maier D, Freuler F, Tschopp C, Baudisch K, Wienands J (1994) In vitro characterization of major ligands for Src homology 2 domains derived from protein tyrosine kinases, from the adaptor protein SHC and from GTPase-activating protein in Ramos B cells. Eur J Immunol 24: 1799-1807

Bolland S, Pearse RN, Kurosaki T, Ravetch JV (1998) SHIP modulates immune receptor responses by regulating membrane association of Btk. Immunity 8: 509-516 
Brauweiler A, Tamir I, Dal Porto J, Benschop RJ, Helgason CD, Humphries RK, Freed JH, Cambier JC (2000) Differential regulation of B cell development, activation, and death by the src homology 2 domain-containing 5' inositol phosphatase (SHIP). J Exp Med 191: 1545-1554

Burnet FM (1959) The Clonal Selection Theory of Acquired Immunity. The University Press, Cambridge

Cardone MH, Roy N, Stennicke HR, Salvesen GS, Franke TF, Stanbridge E, Frisch S, Reed JC (1998) Regulation of cell death protease caspase-9 by phosphorylation. Science 282: 1318-1321

Carpten JD, Faber AL, Horn C, Donoho GP, Briggs SL, Robbins CM, Hostetter G, Boguslawski S, Moses TY, Savage S, Uhlik M, Lin A, Du J, Qian YW, Zeckner DJ, Tucker-Kellogg G, Touchman J, Patel K, Mousses S, Bittner M, Schevitz R, Lai MH, Blanchard KL, Thomas JE (2007) A transforming mutation in the pleckstrin homology domain of AKT1 in cancer. Nature 448: $439-444$

Carrasco YR, Fleire SJ, Cameron T, Dustin ML, Batista FD (2004) LFA-1/ICAM-1 interaction lowers the threshold of B cell activation by facilitating B cell adhesion and synapse formation. Immunity 20: 589-599

Chacko GW, Tridandapani S, Damen JE, Liu L, Krystal G, Coggeshall KM (1996) Negative signaling in B lymphocytes induces tyrosine phosphorylation of the 145-kDa inositol polyphosphate 5-phosphatase, SHIP. J Immunol 157: 2234-2238

Chen CL, Lehmeyer JE, Cooper MD (1982) Evidence for an IgD homologue on chicken lymphocytes. J Immunol 129: 2580-2585

Chen R, Latour S, Shi X, Veillette A (2006) Association between SAP and FynT: Inducible SH3 domain-mediated interaction controlled by engagement of the SLAM receptor. Mol Cell Biol 26: 5559-5568

Chung JH, Ginn-Pease ME, Eng C (2005) Phosphatase and tensin homologue deleted on chromosome 10 (PTEN) has nuclear localization signal-like sequences for nuclear import mediated by major vault protein. Cancer Res 65: 4108-4116

Clement S, Krause U, Desmedt F, Tanti JF, Behrends J, Pesesse X, Sasaki T, Penninger J, Doherty M, Malaisse W, Dumont JE, Le Marchand-Brustel Y, Erneux C, Hue L, Schurmans S (2001) The lipid phosphatase SHIP2 controls insulin sensitivity. Nature 409: 92-97

Corpet F (1988) Multiple sequence alignment with hierarchical clustering. Nucleic Acids Res 16: $10881-10890$

Cox D, Dale BM, Kashiwada M, Helgason CD, Greenberg S (2001) A regulatory role for Src homology 2 domain-containing inositol 5'-phosphatase (SHIP) in phagocytosis mediated by Fc gamma receptors and complement receptor 3 (alpha(M)beta(2); CD11b/CD18). J Exp Med 193: $61-71$ 
Cui J, Matkovich SJ, deSouza N, Li S, Rosemblit N, Marks AR (2004) Regulation of the type 1 inositol 1,4,5-trisphosphate receptor by phosphorylation at tyrosine 353. J Biol Chem 279: 16311-16316

D'Ambrosio D, Hippen KL, Cambier JC (1996) Distinct mechanisms mediate SHC association with the activated and resting B cell antigen receptor. Eur J Immunol 26: 1960-1965

Daeron M, Latour S, Malbec O, Espinosa E, Pina P, Pasmans S, Fridman WH (1995) The same tyrosine-based inhibition motif, in the intracytoplasmic domain of Fc gamma RIIB, regulates negatively BCR-, TCR-, and FcR-dependent cell activation. Immunity 3: 635-646

Damen JE, Liu L, Rosten P, Humphries RK, Jefferson AB, Majerus PW, Krystal G (1996) The $145-\mathrm{kDa}$ protein induced to associate with Shc by multiple cytokines is an inositol tetraphosphate and phosphatidylinositol 3,4,5-triphosphate 5-phosphatase. Proc Natl Acad Sci U S A 93: 1689-1693

Damen JE, Ware MD, Kalesnikoff J, Hughes MR, Krystal G (2001) SHIP's C-terminus is essential for its hydrolysis of PIP3 and inhibition of mast cell degranulation. Blood 97: 13431351

Datta SR, Dudek H, Tao X, Masters S, Fu H, Gotoh Y, Greenberg ME (1997) Akt phosphorylation of BAD couples survival signals to the cell-intrinsic death machinery. Cell 91: 231-241

Davis RS, Ehrhardt GR, Leu CM, Hirano M, Cooper MD (2005) An extended family of Fc receptor relatives. Eur J Immunol 35: 674-680

Depoil D, Fleire S, Treanor BL, Weber M, Harwood NE, Marchbank KL, Tybulewicz VL, Batista FD (2008) CD19 is essential for B cell activation by promoting B cell receptor-antigen microcluster formation in response to membrane-bound ligand. Nat Immunol 9: 63-72

Di Paolo G, De Camilli P (2006) Phosphoinositides in cell regulation and membrane dynamics. Nature 443: 651-657

Dolmetsch RE, Lewis RS, Goodnow CC, Healy JI (1997) Differential activation of transcription factors induced by Ca2+ response amplitude and duration. Nature 386: 855-858

Doody GM, Justement LB, Delibrias CC, Matthews RJ, Lin J, Thomas ML, Fearon DT (1995) A role in B cell activation for CD22 and the protein tyrosine phosphatase SHP. Science 269: 242-244

Dykstra M, Cherukuri A, Sohn HW, Tzeng SJ, Pierce SK (2003) Location is everything: lipid rafts and immune cell signaling. Annu Rev Immunol 21: 457-481 
Edmondson DG, Dent SY (2001) Identification of protein interactions by far western analysis. Curr Protoc Protein Sci Chapter 19: Unit 1917

Engels N, Engelke M, Wienands J (2008) Conformational plasticity and navigation of signaling proteins in antigen-activated B lymphocytes. Adv Immunol 97: 251-281

Engels N, Wollscheid B, Wienands J (2001) Association of SLP-65/BLNK with the B cell antigen receptor through a non-ITAM tyrosine of Ig-alpha. Eur J Immunol 31: 2126-2134

Falasca M, Logan SK, Lehto VP, Baccante G, Lemmon MA, Schlessinger J (1998) Activation of phospholipase $\mathrm{C}$ gamma by PI 3-kinase-induced $\mathrm{PH}$ domain-mediated membrane targeting. Embo J 17: 414-422

Ferraro E, Peluso D, Via A, Ausiello G, Helmer-Citterich M (2007) SH3-Hunter: discovery of SH3 domain interaction sites in proteins. Nucleic Acids Res 35: W451-454

Field KA, Holowka D, Baird B (1997) Compartmentalized activation of the high affinity immunoglobulin E receptor within membrane domains. J Biol Chem 272: 4276-4280

Flaswinkel H, Reth M (1994) Dual role of the tyrosine activation motif of the Ig-alpha protein during signal transduction via the B cell antigen receptor. Embo J 13: 83-89

Fleire SJ, Goldman JP, Carrasco YR, Weber M, Bray D, Batista FD (2006) B cell ligand discrimination through a spreading and contraction response. Science 312: 738-741

Franke TF (2008) Intracellular signaling by Akt: bound to be specific. Sci Signal 1: pe29

Fruman DA, Bismuth G (2009) Fine tuning the immune response with PI3K. Immunol Rev 228: 253-272

Fu C, Turck CW, Kurosaki T, Chan AC (1998) BLNK: a central linker protein in B cell activation. Immunity 9: 93-103

Gaidos G, Soni S, Oswald DJ, Toselli PA, Kirsch KH (2007) Structure and function analysis of the CMS/CIN85 protein family identifies actin-bundling properties and heterotypic-complex formation. J Cell Sci 120: 2366-2377

Gil D, Schamel WW, Montoya M, Sanchez-Madrid F, Alarcon B (2002) Recruitment of Nck by $\mathrm{CD} 3$ epsilon reveals a ligand-induced conformational change essential for $\mathrm{T}$ cell receptor signaling and synapse formation. Cell 109: 901-912

Giuriato S, Payrastre B, Drayer AL, Plantavid M, Woscholski R, Parker P, Erneux C, Chap H (1997) Tyrosine phosphorylation and relocation of SHIP are integrin-mediated in thrombinstimulated human blood platelets. J Biol Chem 272: 26857-26863 
Goitsuka R, Fujimura Y, Mamada H, Umeda A, Morimura T, Uetsuka K, Doi K, Tsuji S, Kitamura D (1998) BASH, a novel signaling molecule preferentially expressed in B cells of the bursa of Fabricius. J Immunol 161: 5804-5808

Gold MR, Aebersold R (1994) Both phosphatidylinositol 3-kinase and phosphatidylinositol 4kinase products are increased by antigen receptor signaling in B cells. J Immunol 152: $42-50$

Gold MR, Matsuuchi L, Kelly RB, DeFranco AL (1991) Tyrosine phosphorylation of components of the B-cell antigen receptors following receptor crosslinking. Proc Natl Acad Sci U S A 88: $3436-3440$

Gomez TS, McCarney SD, Carrizosa E, Labno CM, Comiskey EO, Nolz JC, Zhu P, Freedman BD, Clark MR, Rawlings DJ, Billadeau DD, Burkhardt JK (2006) HS1 functions as an essential actin-regulatory adaptor protein at the immune synapse. Immunity 24: 741-752

Greenman J, Tutt AL, George AJ, Pulford KA, Stevenson GT, Glennie MJ (1991) Characterization of a new monoclonal anti-Fc gamma RII antibody, AT10, and its incorporation into a bispecific $\mathrm{F}\left(\mathrm{ab}^{\prime}\right) 2$ derivative for recruitment of cytotoxic effectors. Mol Immunol 28: $1243-1254$

Grynkiewicz G, Poenie M, Tsien RY (1985) A new generation of Ca2+ indicators with greatly improved fluorescence properties. J Biol Chem 260: 3440-3450

Gupta N, Wollscheid B, Watts JD, Scheer B, Aebersold R, DeFranco AL (2006) Quantitative proteomic analysis of B cell lipid rafts reveals that ezrin regulates antigen receptor-mediated lipid raft dynamics. Nat Immunol 7: 625-633

Hao JJ, Carey GB, Zhan X (2004) Syk-mediated tyrosine phosphorylation is required for the association of hematopoietic lineage cell-specific protein 1 with lipid rafts and B cell antigen receptor signalosome complex. J Biol Chem 279: 33413-33420

Harmer SL, DeFranco AL (1997) Shc contains two Grb2 binding sites needed for efficient formation of complexes with SOS in B lymphocytes. Mol Cell Biol 17: 4087-4095

Harmer SL, DeFranco AL (1999) The src homology domain 2-containing inositol phosphatase SHIP forms a ternary complex with Shc and Grb2 in antigen receptor-stimulated B lymphocytes. J Biol Chem 274: 12183-12191

Harwood NE, Batista FD (2008) New insights into the early molecular events underlying B cell activation. Immunity 28: 609-619

Harwood NE, Batista FD (2010) Early events in B cell activation. Annu Rev Immunol 28: 185210 
Hashimoto A, Okada H, Jiang A, Kurosaki M, Greenberg S, Clark EA, Kurosaki T (1998) Involvement of guanosine triphosphatases and phospholipase C-gamma2 in extracellular signalregulated kinase, c-Jun NH2-terminal kinase, and p38 mitogen-activated protein kinase activation by the B cell antigen receptor. J Exp Med 188: 1287-1295

Hashimoto A, Takeda K, Inaba M, Sekimata M, Kaisho T, Ikehara S, Homma Y, Akira S, Kurosaki T (2000) Cutting edge: essential role of phospholipase C-gamma 2 in B cell development and function. $J$ Immunol 165: 1738-1742

Hayden MS, Ghosh S (2008) Shared principles in NF-kappaB signaling. Cell 132: 344-362

Helgason CD, Damen JE, Rosten P, Grewal R, Sorensen P, Chappel SM, Borowski A, Jirik F, Krystal G, Humphries RK (1998) Targeted disruption of SHIP leads to hemopoietic perturbations, lung pathology, and a shortened life span. Genes Dev 12: 1610-1620

Helgason CD, Kalberer CP, Damen JE, Chappel SM, Pineault N, Krystal G, Humphries RK (2000) A dual role for Src homology 2 domain-containing inositol-5-phosphatase (SHIP) in immunity: aberrant development and enhanced function of b lymphocytes in ship -/- mice. $J$ Exp Med 191: 781-794

Hennemann A (2010) Integration der Adapterproteine mAbp1 und HS1 in signalleitende Prozesse von B-Lymphozyten und dendritischen Zellen. Faculty of Chemistry, University of Bielefeld, Bielefeld

Hippen KL, Buhl AM, D'Ambrosio D, Nakamura K, Persin C, Cambier JC (1997) Fc gammaRIIB1 inhibition of BCR-mediated phosphoinositide hydrolysis and Ca2+ mobilization is integrated by CD19 dephosphorylation. Immunity 7: 49-58

Hogan PG, Chen L, Nardone J, Rao A (2003) Transcriptional regulation by calcium, calcineurin, and NFAT. Genes Dev 17: 2205-2232

Hombach J, Leclercq L, Radbruch A, Rajewsky K, Reth M (1988) A novel 34-kd protein coisolated with the IgM molecule in surface IgM-expressing cells. Embo J 7: 3451-3456

Humphrey MB, Lanier LL, Nakamura MC (2005) Role of ITAM-containing adapter proteins and their receptors in the immune system and bone. Immunol Rev 208: 50-65

Ingham RJ, Holgado-Madruga M, Siu C, Wong AJ, Gold MR (1998) The Gab1 protein is a docking site for multiple proteins involved in signaling by the B cell antigen receptor. $J$ Biol Chem 273: 30630-30637

Ingham RJ, Okada H, Dang-Lawson M, Dinglasan J, van Der Geer P, Kurosaki T, Gold MR (1999) Tyrosine phosphorylation of shc in response to B cell antigen receptor engagement depends on the SHIP inositol phosphatase. J Immunol 163: 5891-5895 
Iwasaki A, Medzhitov R (2004) Toll-like receptor control of the adaptive immune responses. Nat Immunol 5: 987-995

Jacob A, Cooney D, Tridandapani S, Kelley T, Coggeshall KM (1999) FcgammaRIIb modulation of surface immunoglobulin-induced Akt activation in murine B cells. J Biol Chem 274: $13704-13710$

Kabak S, Skaggs BJ, Gold MR, Affolter M, West KL, Foster MS, Siemasko K, Chan AC, Aebersold R, Clark MR (2002) The direct recruitment of BLNK to immunoglobulin alpha couples the B-cell antigen receptor to distal signaling pathways. Mol Cell Biol 22: 2524-2535

Kane LP, Shapiro VS, Stokoe D, Weiss A (1999) Induction of NF-kappaB by the Akt/PKB kinase. Curr Biol 9: 601-604

Kim KA, Spencer SL, Albeck JG, Burke JM, Sorger PK, Gaudet S, Kim do H (2010) Systematic calibration of a cell signaling network model. BMC Bioinformatics 11: 202

Kirsch KH, Georgescu MM, Ishimaru S, Hanafusa H (1999) CMS: an adapter molecule involved in cytoskeletal rearrangements. Proc Natl Acad Sci U S A 96: 6211-6216

Kohler F, Storch B, Kulathu Y, Herzog S, Kuppig S, Reth M, Jumaa H (2005) A leucine zipper in the $\mathrm{N}$ terminus confers membrane association to SLP-65. Nat Immunol 6: 204-210

Kowanetz K, Husnjak K, Holler D, Kowanetz M, Soubeyran P, Hirsch D, Schmidt MH, Pavelic K, De Camilli P, Randazzo PA, Dikic I (2004) CIN85 associates with multiple effectors controlling intracellular trafficking of epidermal growth factor receptors. Mol Biol Cell 15: 3155-3166

Kurosaki T, Kurosaki M (1997) Transphosphorylation of Bruton's tyrosine kinase on tyrosine 551 is critical for B cell antigen receptor function. J Biol Chem 272: 15595-15598

Kusumi A, Nakada C, Ritchie K, Murase K, Suzuki K, Murakoshi H, Kasai RS, Kondo J, Fujiwara T (2005) Paradigm shift of the plasma membrane concept from the two-dimensional continuum fluid to the partitioned fluid: high-speed single-molecule tracking of membrane molecules. Annu Rev Biophys Biomol Struct 34: 351-378

Laemmli UK (1970) Cleavage of structural proteins during the assembly of the head of bacteriophage T4. Nature 227: 680-685

Lam KP, Kuhn R, Rajewsky K (1997) In vivo ablation of surface immunoglobulin on mature B cells by inducible gene targeting results in rapid cell death. Cell 90: 1073-1083

Lamkin TD, Walk SF, Liu L, Damen JE, Krystal G, Ravichandran KS (1997) Shc interaction with Src homology 2 domain containing inositol phosphatase (SHIP) in vivo requires the Shcphosphotyrosine binding domain and two specific phosphotyrosines on SHIP. J Biol Chem 272: 10396-10401 
Lemay S, Davidson D, Latour S, Veillette A (2000) Dok-3, a novel adapter molecule involved in the negative regulation of immunoreceptor signaling. Mol Cell Biol 20: 2743-2754

Li X (2008) Analyse der B-Zell-Antigen-Rezeptor induzierten Aktivierung der Src

homology 2-containing Inositol 5'-Phosphatase SHIP. Dept. of Cellular and Molecular Immunology, Göttingen, Georg-August University, Göttingen

Lindvall JM, Blomberg KE, Valiaho J, Vargas L, Heinonen JE, Berglof A, Mohamed AJ, Nore BF, Vihinen M, Smith CI (2005) Bruton's tyrosine kinase: cell biology, sequence conservation, mutation spectrum, siRNA modifications, and expression profiling. Immunol Rev 203: 200-215

Lioubin MN, Algate PA, Tsai S, Carlberg K, Aebersold A, Rohrschneider LR (1996) p150Ship, a signal transduction molecule with inositol polyphosphate-5-phosphatase activity. Genes Dev 10: $1084-1095$

Liu L, Damen JE, Cutler RL, Krystal G (1994) Multiple cytokines stimulate the binding of a common 145-kilodalton protein to Shc at the Grb2 recognition site of Shc. Mol Cell Biol 14: 6926-6935

Liu L, Damen JE, Hughes MR, Babic I, Jirik FR, Krystal G (1997a) The Src homology 2 (SH2) domain of SH2-containing inositol phosphatase (SHIP) is essential for tyrosine phosphorylation of SHIP, its association with Shc, and its induction of apoptosis. J Biol Chem 272: 8983-8988

Liu L, Damen JE, Ware MD, Krystal G (1997b) Interleukin-3 induces the association of the inositol 5-phosphatase SHIP with SHP2. J Biol Chem 272: 10998-11001

Liu Q, Sasaki T, Kozieradzki I, Wakeham A, Itie A, Dumont DJ, Penninger JM (1999) SHIP is a negative regulator of growth factor receptor-mediated PKB/Akt activation and myeloid cell survival. Genes Dev 13: 786-791

Liu Q, Shalaby F, Jones J, Bouchard D, Dumont DJ (1998) The SH2-containing inositol polyphosphate 5-phosphatase, ship, is expressed during hematopoiesis and spermatogenesis. Blood 91: 2753-2759

Lösing M (2007) Funktionelle Untersuchung des cytosolischen Adaptorproteins downstream of kinase-3 in B-Zellen. Dept. of Cellular and Molecular Immunology, Georg-August-University, Göttingen

Maeda A, Kurosaki M, Ono M, Takai T, Kurosaki T (1998) Requirement of SH2-containing protein tyrosine phosphatases SHP-1 and SHP-2 for paired immunoglobulin-like receptor B (PIR-B)-mediated inhibitory signal. J Exp Med 187: 1355-1360

Maeda A, Scharenberg AM, Tsukada S, Bolen JB, Kinet JP, Kurosaki T (1999) Paired immunoglobulin-like receptor B (PIR-B) inhibits BCR-induced activation of Syk and Btk by SHP-1. Oncogene 18: 2291-2297 
Maehama T, Dixon JE (1998) The tumor suppressor, PTEN/MMAC1, dephosphorylates the lipid second messenger, phosphatidylinositol 3,4,5-trisphosphate. J Biol Chem 273: 1337513378

Manders E, Verbeek F, Aten J (1993) Measurement of co-localization of objects in dual-colour confocal images. Journal of Microscopy 169: 375-338

Marshall AJ, Niiro H, Yun TJ, Clark EA (2000) Regulation of B-cell activation and differentiation by the phosphatidylinositol 3-kinase and phospholipase Cgamma pathway. Immunol Rev 176: 30-46

Masuda A, Nakamura A, Maeda T, Sakamoto Y, Takai T (2007) Cis binding between inhibitory receptors and MHC class I can regulate mast cell activation. J Exp Med 204: 907-920

Mayer BJ, Eck MJ (1995) SH3 domains. Minding your p's and q's. Curr Biol 5: 364-367

Miletic AV, Anzelon-Mills AN, Mills DM, Omori SA, Pedersen IM, Shin DM, Ravetch JV, Bolland S, Morse HC, 3rd, Rickert RC (2010) Coordinate suppression of B cell lymphoma by PTEN and SHIP phosphatases. J Exp Med 207: 2407-2420

Muller R, Wienands J, Reth M (2000) The serine and threonine residues in the Ig-alpha cytoplasmic tail negatively regulate immunoreceptor tyrosine-based activation motif-mediated signal transduction. Proc Natl Acad Sci U S A 97: 8451-8454

Nagai K, Takata M, Yamamura H, Kurosaki T (1995) Tyrosine phosphorylation of Shc is mediated through Lyn and Syk in B cell receptor signaling. J Biol Chem 270: 6824-6829

Nakamura K, Brauweiler A, Cambier JC (2000) Effects of Src homology domain 2 (SH2)containing inositol phosphatase (SHIP), SH2-containing phosphotyrosine phosphatase (SHP)-1, and SHP-2 SH2 decoy proteins on Fc gamma RIIB1-effector interactions and inhibitory functions. J Immunol 164: 631-638

Neumann K (2008) On adaptor proteins shaping Ca2+ signals in activated B lymphocytes. Faculaty of Chemistry, University of Bielefeld, Bielefeld

Neumann K, Oellerich T, Heine I, Urlaub H, Engelke M (2011) Fc gamma receptor IIb modulates the molecular Grb2 interaction network in activated B cells. Cell Signal 23: 893-900

Niiro H, Clark EA (2002) Regulation of B-cell fate by antigen-receptor signals. Nat Rev Immunol 2: 945-956

Nimmerjahn F, Ravetch JV (2008) Fcgamma receptors as regulators of immune responses. Nat Rev Immunol 8: 34-47 
O'Neill SK, Getahun A, Gauld SB, Merrell KT, Tamir I, Smith MJ, Dal Porto JM, Li QZ, Cambier JC (2011) Monophosphorylation of CD79a and CD79b ITAM Motifs Initiates a SHIP1 Phosphatase-Mediated Inhibitory Signaling Cascade Required for B Cell Anergy. Immunity

Oellerich T, Bremes V, Neumann K, Bohnenberger H, Dittmann K, Hsiao HH, Engelke M, Schnyder T, Batista FD, Urlaub H, Wienands J (2011) The B-cell antigen receptor signals through a preformed transducer module of SLP65 and CIN85. Embo J 30: 3620-3634

Oellerich T, Gronborg M, Neumann K, Hsiao HH, Urlaub H, Wienands J (2009) SLP-65 phosphorylation dynamics reveals a functional basis for signal integration by receptor-proximal adaptor proteins. Mol Cell Proteomics 8: 1738-1750

Oikawa T, Yamaguchi H, Itoh T, Kato M, Ijuin T, Yamazaki D, Suetsugu S, Takenawa T (2004) PtdIns(3,4,5)P3 binding is necessary for WAVE2-induced formation of lamellipodia. Nat Cell Biol 6: 420-426

Okada H, Bolland S, Hashimoto A, Kurosaki M, Kabuyama Y, Iino M, Ravetch JV, Kurosaki T (1998) Role of the inositol phosphatase SHIP in B cell receptor-induced Ca2+ oscillatory response. J Immunol 161: 5129-5132

Okada T, Maeda A, Iwamatsu A, Gotoh K, Kurosaki T (2000) BCAP: the tyrosine kinase substrate that connects B cell receptor to phosphoinositide 3-kinase activation. Immunity 13: 817-827

Ong CJ, Ming-Lum A, Nodwell M, Ghanipour A, Yang L, Williams DE, Kim J, Demirjian L, Qasimi P, Ruschmann J, Cao LP, Ma K, Chung SW, Duronio V, Andersen RJ, Krystal G, Mui AL (2007) Small-molecule agonists of SHIP1 inhibit the phosphoinositide 3-kinase pathway in hematopoietic cells. Blood 110: 1942-1949

Ong SE, Blagoev B, Kratchmarova I, Kristensen DB, Steen H, Pandey A, Mann M (2002) Stable isotope labeling by amino acids in cell culture, SILAC, as a simple and accurate approach to expression proteomics. Mol Cell Proteomics 1: 376-386

Ono M, Bolland S, Tempst P, Ravetch JV (1996) Role of the inositol phosphatase SHIP in negative regulation of the immune system by the receptor Fc(gamma)RIIB. Nature 383: 263266

Ono M, Okada H, Bolland S, Yanagi S, Kurosaki T, Ravetch JV (1997) Deletion of SHIP or SHP-1 reveals two distinct pathways for inhibitory signaling. Cell 90: 293-301

Osborne MA, Zenner G, Lubinus M, Zhang X, Songyang Z, Cantley LC, Majerus P, Burn P, Kochan JP (1996) The inositol 5'-phosphatase SHIP binds to immunoreceptor signaling motifs and responds to high affinity IgE receptor aggregation. J Biol Chem 271: 29271-29278

Ottinger EA, Botfield MC, Shoelson SE (1998) Tandem SH2 domains confer high specificity in tyrosine kinase signaling. J Biol Chem 273: 729-735 
Pao LI, Famiglietti SJ, Cambier JC (1998) Asymmetrical phosphorylation and function of immunoreceptor tyrosine-based activation motif tyrosines in B cell antigen receptor signal transduction. J Immunol 160: 3305-3314

Pasquier B, Launay P, Kanamaru Y, Moura IC, Pfirsch S, Ruffie C, Henin D, Benhamou M, Pretolani M, Blank U, Monteiro RC (2005) Identification of FcalphaRI as an inhibitory receptor that controls inflammation: dual role of FcRgamma ITAM. Immunity 22: 31-42

Patterson HC, Kraus M, Wang D, Shahsafaei A, Henderson JM, Seagal J, Otipoby KL, Thai TH, Rajewsky K (2011) Cytoplasmic Ig alpha serine/threonines fine-tune Ig alpha tyrosine phosphorylation and limit bone marrow plasma cell formation. J Immunol 187: 2853-2858

Pearse RN, Kawabe T, Bolland S, Guinamard R, Kurosaki T, Ravetch JV (1999) SHIP recruitment attenuates FC gamma RIIB-induced B cell apoptosis. Immunity 10: 753-760

Pesesse X, Deleu S, De Smedt F, Drayer L, Erneux C (1997) Identification of a second SH2domain-containing protein closely related to the phosphatidylinositol polyphosphate 5phosphatase SHIP. Biochem Biophys Res Commun 239: 697-700

Petrie RJ, Schnetkamp PP, Patel KD, Awasthi-Kalia M, Deans JP (2000) Transient translocation of the B cell receptor and Src homology 2 domain-containing inositol phosphatase to lipid rafts: evidence toward a role in calcium regulation. J Immunol 165: 1220-1227

Phee H, Jacob A, Coggeshall KM (2000) Enzymatic activity of the Src homology 2 domaincontaining inositol phosphatase is regulated by a plasma membrane location. $J$ Biol Chem 275: 19090-19097

Phee H, Rodgers W, Coggeshall KM (2001) Visualization of negative signaling in B cells by quantitative confocal microscopy. Mol Cell Biol 21: 8615-8625

Pierce SK, Liu W (2010) The tipping points in the initiation of B cell signalling: how small changes make big differences. Nat Rev Immunol 10: 767-777

Rameh LE, Chen CS, Cantley LC (1995) Phosphatidylinositol $(3,4,5) \mathrm{P} 3$ interacts with SH2 domains and modulates PI 3-kinase association with tyrosine-phosphorylated proteins. Cell 83: 821-830

Reth M, Brummer T (2004) Feedback regulation of lymphocyte signalling. Nat Rev Immunol 4: 269-277

Robson JD, Davidson D, Veillette A (2004) Inhibition of the Jun N-terminal protein kinase pathway by SHIP-1, a lipid phosphatase that interacts with the adaptor molecule Dok-3. Mol Cell Biol 24: 2332-2343 
Rolli V, Gallwitz M, Wossning T, Flemming A, Schamel WW, Zurn C, Reth M (2002) Amplification of B cell antigen receptor signaling by a Syk/ITAM positive feedback loop. Mol Cell 10: 1057-1069

Saiki RK, Scharf S, Faloona F, Mullis KB, Horn GT, Erlich HA, Arnheim N (1985) Enzymatic amplification of beta-globin genomic sequences and restriction site analysis for diagnosis of sickle cell anemia. Science 230: 1350-1354

Salim K, Bottomley MJ, Querfurth E, Zvelebil MJ, Gout I, Scaife R, Margolis RL, Gigg R, Smith CI, Driscoll PC, Waterfield MD, Panayotou G (1996) Distinct specificity in the recognition of phosphoinositides by the pleckstrin homology domains of dynamin and Bruton's tyrosine kinase. Embo J 15: 6241-6250

Sambrook J, Russell DW (2000) Molecular Cloning: A Laboratory Manual, 3. Vol., Vol. 3: Cold Spring Harbor Laboratory.

Sanchez M, Misulovin Z, Burkhardt AL, Mahajan S, Costa T, Franke R, Bolen JB, Nussenzweig M (1993) Signal transduction by immunoglobulin is mediated through Ig alpha and Ig beta. J Exp Med 178: 1049-1055

Sattler M, Verma S, Byrne CH, Shrikhande G, Winkler T, Algate PA, Rohrschneider LR, Griffin JD (1999) BCR/ABL directly inhibits expression of SHIP, an SH2-containing polyinositol-5-phosphatase involved in the regulation of hematopoiesis. Mol Cell Biol 19: 74737480

Saxton TM, van Oostveen I, Bowtell D, Aebersold R, Gold MR (1994) B cell antigen receptor cross-linking induces phosphorylation of the p21ras oncoprotein activators SHC and mSOS1 as well as assembly of complexes containing SHC, GRB-2, mSOS1, and a 145-kDa tyrosinephosphorylated protein. J Immunol 153: 623-636

Scapini P, Pereira S, Zhang H, Lowell CA (2009) Multiple roles of Lyn kinase in myeloid cell signaling and function. Immunol Rev 228: 23-40

Schamel WW, Reth M (2000) Monomeric and oligomeric complexes of the B cell antigen receptor. Immunity 13: 5-14

Scharenberg AM, Humphries LA, Rawlings DJ (2007) Calcium signalling and cell-fate choice in B cells. Nat Rev Immunol 7: 778-789

Schmitz R, Baumann G, Gram H (1996) Catalytic specificity of phosphotyrosine kinases Blk, Lyn, c-Src and Syk as assessed by phage display. J Mol Biol 260: 664-677

Schneckenburger H (2005) Total internal reflection fluorescence microscopy: technical innovations and novel applications. Curr Opin Biotechnol 16: 13-18 
Schnyder T, Castello A, Feest C, Harwood NE, Oellerich T, Urlaub H, Engelke M, Wienands J, Bruckbauer A, Batista FD (2011) B cell receptor-mediated antigen gathering requires ubiquitin ligase $\mathrm{Cbl}$ and adaptors Grb2 and Dok-3 to recruit dynein to the signaling microcluster. Immunity 34: 905-918

Severin S, Pollitt AY, Navarro-Nunez L, Nash CA, Mourao-Sa D, Eble JA, Senis YA, Watson SP (2011) Syk-dependent phosphorylation of CLEC-2: a novel mechanism of hemimmunoreceptor tyrosine-based activation motif signaling. J Biol Chem 286: 4107-4116

Sgroi D, Varki A, Braesch-Andersen S, Stamenkovic I (1993) CD22, a B cell-specific immunoglobulin superfamily member, is a sialic acid-binding lectin. $J$ Biol Chem 268: 70117018

Simons K, Toomre D (2000) Lipid rafts and signal transduction. Nat Rev Mol Cell Biol 1: 31-39

Sinclair NR (2000) Immunoreceptor tyrosine-based inhibitory motifs on activating molecules. Crit Rev Immunol 20: 89-102

Sohn HW, Tolar P, Jin T, Pierce SK (2006) Fluorescence resonance energy transfer in living cells reveals dynamic membrane changes in the initiation of B cell signaling. Proc Natl Acad Sci U S A 103: 8143-8148

Sohn HW, Tolar P, Pierce SK (2008) Membrane heterogeneities in the formation of B cell receptor-Lyn kinase microclusters and the immune synapse. J Cell Biol 182: 367-379

Stork B, Engelke M, Frey J, Horejsi V, Hamm-Baarke A, Schraven B, Kurosaki T, Wienands J (2004) Grb2 and the non-T cell activation linker NTAL constitute a $\mathrm{Ca}(2+)$-regulating signal circuit in B lymphocytes. Immunity 21: 681-691

Stork B, Neumann K, Goldbeck I, Alers S, Kahne T, Naumann M, Engelke M, Wienands J (2007) Subcellular localization of Grb2 by the adaptor protein Dok-3 restricts the intensity of Ca2+ signaling in B cells. Embo J 26: 1140-1149

Takata M, Kurosaki T (1996) A role for Bruton's tyrosine kinase in B cell antigen receptormediated activation of phospholipase C-gamma 2. J Exp Med 184: 31-40

Takata M, Sabe H, Hata A, Inazu T, Homma Y, Nukada T, Yamamura H, Kurosaki T (1994) Tyrosine kinases Lyn and Syk regulate B cell receptor-coupled Ca2+ mobilization through distinct pathways. Embo J 13: 1341-1349

Talmage DW (1959) Clonal selection theory. Science 129: 1643-1648

Tamir I, Cambier JC (1998) Antigen receptor signaling: integration of protein tyrosine kinase functions. Oncogene 17: 1353-1364 
Tamir I, Stolpa JC, Helgason CD, Nakamura K, Bruhns P, Daeron M, Cambier JC (2000) The RasGAP-binding protein p62dok is a mediator of inhibitory FcgammaRIIB signals in B cells. Immunity 12: 347-358

Towbin H, Staehelin T, Gordon J (1989) Immunoblotting in the clinical laboratory. J Clin Chem Clin Biochem 27: 495-501

Treanor B, Depoil D, Gonzalez-Granja A, Barral P, Weber M, Dushek O, Bruckbauer A, Batista FD (2010) The membrane skeleton controls diffusion dynamics and signaling through the B cell receptor. Immunity 32: 187-199

Tridandapani S, Kelley T, Pradhan M, Cooney D, Justement LB, Coggeshall KM (1997) Recruitment and phosphorylation of SH2-containing inositol phosphatase and Shc to the B-cell Fc gamma immunoreceptor tyrosine-based inhibition motif peptide motif. Mol Cell Biol 17: 4305-4311

Tucholski J (2010) Die Inositolphosphatase-unabhängige Funktion der Src homology 2containing Inositol 5'-Phosphatase SHIP. Dept. of Cellular and Molecular Immunology, GeorgAugust-University Göttingen, Göttingen

Tuveson DA, Carter RH, Soltoff SP, Fearon DT (1993) CD19 of B cells as a surrogate kinase insert region to bind phosphatidylinositol 3-kinase. Science 260: 986-989

Uruno T, Zhang P, Liu J, Hao JJ, Zhan X (2003) Haematopoietic lineage cell-specific protein 1 (HS1) promotes actin-related protein (Arp) 2/3 complex-mediated actin polymerization. Biochem J 371: 485-493

Venkitaraman AR, Williams GT, Dariavach P, Neuberger MS (1991) The B-cell antigen receptor of the five immunoglobulin classes. Nature 352: 777-781

Weber K, Osborn M (1969) The reliability of molecular weight determinations by dodecyl sulfate-polyacrylamide gel electrophoresis. J Biol Chem 244: 4406-4412

Weber M, Treanor B, Depoil D, Shinohara H, Harwood NE, Hikida M, Kurosaki T, Batista FD (2008) Phospholipase C-gamma2 and Vav cooperate within signaling microclusters to propagate B cell spreading in response to membrane-bound antigen. $J$ Exp Med 205: 853-868

Wienands J, Engels N (2001) Multitasking of Ig-alpha and Ig-beta to regulate B cell antigen receptor function. Int Rev Immunol 20: 679-696

Wienands J, Freuler F, Baumann G (1995) Tyrosine-phosphorylated forms of Ig beta, CD22, TCR zeta and HOSS are major ligands for tandem SH2 domains of Syk. Int Immunol 7: 17011708

Wienands J, Larbolette O, Reth M (1996) Evidence for a preformed transducer complex organized by the B cell antigen receptor. Proc Natl Acad Sci U S A 93: 7865-7870 
Wienands J, Schweikert J, Wollscheid B, Jumaa H, Nielsen PJ, Reth M (1998) SLP-65: a new signaling component in B lymphocytes which requires expression of the antigen receptor for phosphorylation. J Exp Med 188: 791-795

Zhang W, Liu HT (2002) MAPK signal pathways in the regulation of cell proliferation in mammalian cells. Cell Res 12: 9-18

Zhang Y, Wienands J, Zurn C, Reth M (1998) Induction of the antigen receptor expression on B lymphocytes results in rapid competence for signaling of SLP-65 and Syk. Embo J 17: 73047310

Zubay G (1973) In vitro synthesis of protein in microbial systems. Annu Rev Genet 7: 267-287 


\section{Curriculum vitae}

\section{Personal information}

\section{Birgit Manno}

Date of birth

March 12, 1982

Place of birth

Schwäbisch Hall

Nationality

German

\section{Education}

$2008-2011$

Georg-August University Göttingen, Germany

$\mathrm{PhD}$ thesis in the Dept. of Cellular and Molecular Immunology

Title: "Molecular mechanism of B cell antigen receptor-induced

SHIP activation”

2007 - $2008 \quad$ Karolinska Institutet Stockholm, Sweden

MSc thesis in the Dept. of Microbiology, Tumor and Cell Biology

Title: "Characterization of TRAPC, a novel triggering receptor expressed on antigen-presenting cells"

2006 - 2011 International Max Planck Research School Göttingen, Germany Molecular Biology MSc/PhD Program

2006

Georg-August University Göttingen, Germany

BSc thesis in the Dept. of Cardiology and Pneumology,

Heart Research Center

Title: "In vitro differentiation of mouse spermatogonial stem cells into pancreatic cells"

2003 - 2006 Georg-August University Göttingen, Germany

Molecular Medicine BSc Program

2003

Liverpool John Moores University, Liverpool, UK

Molecular Biology, Erasmus semester

2001 - $2003 \quad$ University of Applied Sciences Flensburg, Germany

Biotechnology and Process Engineering (intermediate diploma)

2001

Fördegymnasium Flensburg, Germany

University entrance qualification (Abitur) 


\section{Teaching}

2008 - $2011 \quad$ Supervision of lab rotation students from different master programs

\section{Fellowships}

06/2011 - 07/2011 EMBO Short-Term Fellowship

10/2007 - 03/2008 Bayer Fellowship (Bayer Science \& Education Foundation)

09/2006 - 08/2007 International Max Planck Research School Stipend

01/2003 - 05/2003 Erasmus Stipend (EU-program)

\section{Conferences}

$2011 \quad$ Keystone Symposium B cells: "New insights into normal versus dysregulated function”, Whistler, Canada (poster)

2011 Study group Biology of B Lymphocytes, “9 9 th $B$ cell forum”, Bad Sooden-Allendorf, Germany (poster)

\section{Extracurricular activities}

$2008-2010$

Co-Organizer of the $6^{\text {th }}$ and $7^{\text {th }}$ International $\mathrm{PhD}$ Student Symposium "Horizons in Molecular Biology" and the $3^{\text {rd }}$ and $4^{\text {th }}$ Horizons Career Fair, Göttingen, Germany (involving public relation, organization of workshops, moderation of podium discussion, event management) 